\title{
Structure, variability, and dynamics of the West Greenland Boundary Current System
}

\author{
by \\ Astrid Pacini \\ B.S., Yale University (2016) \\ Submitted to the Department of Earth, Atmospheric and Planetary Sciences \\ in partial fulfillment of the requirements for the degree of \\ Doctor of Philosophy \\ at the \\ MASSACHUSETTS INSTITUTE OF TECHNOLOGY \\ and the \\ WOODS HOLE OCEANOGRAPHIC INSTITUTION
}

February 2022

(C)2022 Astrid Pacini. All rights reserved.

The author hereby grants to MIT and WHOI permission to reproduce and to distribute publicly paper and electronic copies of this thesis document in whole or in part in any medium now known or hereafter created.

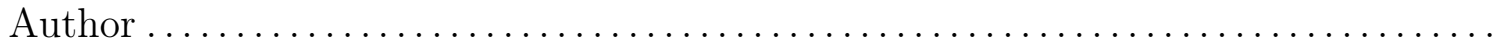

Joint Program in Oceanography/Applied Ocean Science and Engineering Massachusetts Institute of Technology \& Woods Hole Oceanographic Institution

December 22, 2021

Certified by

Robert S. Pickart

Senior Scientist

Woods Hole Oceanographic Institution

Thesis Supervisor

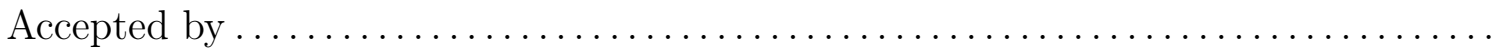

Glenn Flierl

Chair, Joint Committee for Physical Oceanography Massachusetts Institute of Technology \& Woods Hole Oceanographic Institution 


\title{
Structure, variability, and dynamics of the West Greenland Boundary Current System
}

\author{
by \\ Astrid Pacini \\ Submitted to the Department of Earth, Atmospheric and Planetary Sciences \\ Massachusetts Institute of Technology \& Woods Hole Oceanographic Institution \\ on December 22, 2021, in partial fulfillment of the \\ requirements for the degree of \\ Doctor of Philosophy
}

\begin{abstract}
The ventilation of intermediate waters in the Labrador Sea has important implications for the strength of the Atlantic Meridional Overturning Circulation. Boundary current-interior interactions regulate the exchange of properties between the slope and the basin, which in turn regulates the magnitude of interior convection and the export of ventilated waters from the subpolar gyre. This thesis characterizes the West Greenland Boundary Current System near Cape Farewell across a range of spatio-temporal scales. The boundary current system is composed of three velocity cores: (1) the West Greenland Coastal Current (WGCC), transporting Greenland and Arctic meltwaters on the shelf; (2) the West Greenland Current (WGC), which advects warm, saline Atlantic-origin water at depth, meltwaters at the surface, and newly-ventilated Labrador Sea Water (LSW); and (3) the Deep Western Boundary Current, which carries dense overflow waters ventilated in the Nordic Seas. The seasonal presence of the LSW and Atlantic-origin water are dictated by air-sea buoyancy forcing, while the seasonality of the WGCC is governed by remote wind forcing and the propagation of coastally trapped waves from East Greenland. Using mooring data and hydrographic surveys, we demonstrate mid-depth intensified cyclones generated at Denmark Strait are found offshore of the WGC and enhance the overflow water transport at synoptic timescales. Using mooring, hydrographic, and satellite data, we demonstrate that the WGC undergoes extensive meandering due to baroclinic instability that is enhanced in winter due to LSW formation adjacent to the current. This leads to the production of small-scale, anticyclonic eddies that can account for the entirety of wintertime heat loss within the Labrador Sea. The meanders are shown to trigger the formation of Irminger Rings downstream. Using mooring, hydrographic, atmospheric, and Lagrangian data, and a mixing model, we find that strong atmospheric storms known as forward tip jets cause upwelling at the shelfbreak that triggers offshore export of freshwater. This freshwater flux can explain the observed lack of ventilation in the eastern Labrador Sea. Together, this thesis documents previously unobserved interannual, seasonal, and synoptic-scale variability and dynamics within the West Greenland boundary current system that must be accounted for in future modeling.
\end{abstract}

Thesis Supervisor: Robert S. Pickart

Title: Senior Scientist

Woods Hole Oceanographic Institution 


\section{Acknowledgments}

There are so many individuals who have had an impact on this thesis, and I will forever be grateful for the support, encouragement, and kindness I have received throughout my time in the Joint Program. It is impossible to thank everyone, but I hope you know, if you are reading this, that I am thankful.

Bob has been generous with his time, his ideas, and his passion for science. He has made this work possible through his brilliant research and exceptional mentorship. Bob has taught me about the kind of scientist, and person, I would like to become.

I thank my committee - Amy, Glen, and Mick - for the invigorating scientific discussions, the ideas, and the encouragement. I am grateful to Mick for always reminding me to think about the bigger picture, and why the work is important. I am grateful to Glen for imbuing positivity into every meeting, and for being such a caring advisor during my time as co-chief scientist on the RV Neil Armstrong. I am grateful to Amy for being a role model for me in science and in leadership.

I am thankful for the support from the WHOI Academic Programs Office, the EAPS administration, and the PO front office. Special thanks to Meg Tivey, Jim Yoder, Kris Kipp, Lea Fraser, Julia Westwater, Christine Charette, Delia Oppo, Kama Thieler, Susan Sholi, Molly Kelleher, Annie Doucette, Trish Brown, Sarah Xander, Julie Hildebrandt, Hazel Salazar, Brandon Milardo, Megan Jordan, Daisy Caban, Christine Maglio.

To my lab-mates past and present: thank you for the scientific discussions, laughter, and support. Whether we were on land or at sea, I knew I could turn to you no matter what, and for that I will always be thankful. This includes Ben Harden, Bridget Ovall, Bryce Corlett, Carolina Nobre, Fei Tian, Isabela Le Bras, Jianqiang Li, Kjetil Våge, Lola Pérez-Hernández, Maria Pisareva, and Min Li. I would like to give special thanks to Jie Huang, Nick Foukal, Leah McRaven, Stefanie Semper, and Peigen Lin for being there at every step of the way, and more importantly, for being my friends.

While at sea, I learned from the insightful and caring instruction of Frank Bahr, Dan Torres, John Kemp, and Jim Ryder. Thank you for sharing your wisdom with

me. I would like to thank the captains and crews of the USCGC Healy (4 cruises), the Bjarni Sæmundsson (1 crusie), the NRV Alliance (1 cruise), and, nearest and dearest to me, the RV Neil Armstrong ( 5 cruises) for hosting me in stormy and icy seas. These crews always made me feel safe and at home.

To my friends and classmates in the Joint Program and within EAPS: you have made me smile every day, and I'm so thankful this program brought us together. There are too many people to list, but I would like to say a special thank you to Mara Freilich, Joleen Heidrich, Suzi Clark, Rachel Housego, Jen Karolewski, Bryan Kaiser, Seb Essink, Jake Forsyth, James Kuo, Justin Suca, Jing He, Jule Middleton, and Mallory Ringham.

To the friends who have become family: thank you for always being there. This includes my Clary family: Julia Wilcots, Tristan Abbott, Raphaël Rousseau-Rizzi, Florence Bergeron, Henri Drake, Lyssa Freese, Santiago Benavides, Evgenia Prikhodko; my Ni family: Cynthia Ni, Neil Dalvie, Juliet Barker, Mickey Stone, Nika Stone; my 
Boise family: Madeleine Faucher, Gaelen Guzman, Ian Faucher, Megan Faucher, Paul Faucher; and my before family: Colleen Hanlon, Mieke Scherpbier, Catherine Shaw, Hannah Carrese, Izzy O'Connell, and Ali Mitchell. Thank you for the hugs and the laughter and the love.

To my grandparents Nana, Nonna, and Nonno: grazie. They have loved me and supported me unconditionally, and they taught me I could be whatever I set my mind to. I am so thankful to share this thesis with them.

To Sam: you are the best gift that grad school has given me. I am thankful for you every day.

To my Mom, Dad, and brother: you made this possible. They remind me every day what it means to love and support unconditionally. This thesis is theirs as much as it is mine. Thank you.

The work in this dissertation was funded by the National Science Foundation grants OCE-1259618 and OCE-1756361. 


\section{Contents}

1 Introduction 13

1.1 The Atlantic Meridional Overturning Circulation _. . . . . . . 13

1.2 Convective processes . . . . . . . . . . . . . . 15

1.3 The AMOC in a changing climate . . . . . . . . . . . 17

1.4 Thesis outline . . . . . . . . . . . . . . . . . . . . . . . . . . . . . . 19

2 Mean conditions and seasonality of the West Greenland boundary current system near Cape Farewell 23

2.1 Introduction . . . . . . . . . . . . . . . . . . . . 24

2.2 Data and methods . . . . . . . . . . . . . . . . . . . 29

2.2 .1 West Greenland mooring array . . . . . . . . . . . . . 29

2.2 .2 Additional datasets . . . . . . . . . . . . . . . . . . 34

2.3 Results and discussion . . . . . . . . . . . . . . . . . 35

2.3 .1 Mean conditions . . . . . . . . . . . . . . 35

2.3 .2 Water masses . . . . . . . . . . . . . . . . . . . . 38

2.3 .3 Volume transport . . . . . . . . . . . . . . . . . 43

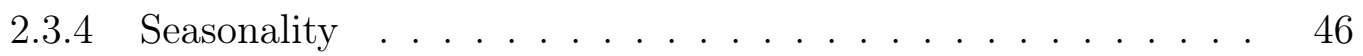

2.4 Summary and conclusions . . . . . . . . . . . . . . . . . . 59

2.5 Data availability . . . . . . . . . . . . . . . . . 61

2.6 Acknowledgements . . . . . . . . . . . . . . . . . . 62

3 Cyclones in the West Greenland Boundary Current System 63

3.1 Introduction . . . . . . . . . . . . . . . . . . . . . . 64

3.2 Data and methods . . . . . . . . . . . . . . . . . 69

3.2 .1 Mooring and shipboard data . . . . . . . . . . . 69

3.2.2 Eddy identification graphical user interface . . . . . . . . . . 72

3.3 Results . . . . . . . . . . . . . . . . . . . . . . . . 73

3.3 .1 Statistics . . . . . . . . . . . . . . . . 73

3.3.2 Cyclone characteristics . . . . . . . . . . . . . . 75

3.3 .3 Influence on transport . . . . . . . . . . . . . . . 84

3.3.4 Synoptic realization of cyclones from shipboard data . . . . 88

3.4 Discussion and conclusions . . . . . . . . . . . . . . . . . . . . 91

3.5 Data availability . . . . . . . . . . . . . . . . . . . . 92

3.6 Acknowledgements . . . . . . . . . . . . . . . . . . . . . . . . 92 
4 Meanders of the West Greenland Current near Cape Farewell 95

4.1 Introduction . . . . . . . . . . . . . . . . . . 96

4.2 Data and methods . . . . . . . . . . . . . . . 101

4.2 .1 Mooring data . . . . . . . . . . . . . . . . . . 101

4.2 .2 Satellite data . . . . . . . . . . . . . . . . . . . 103

4.2.3 Feature detection method . . . . . . . . . . . . . 103

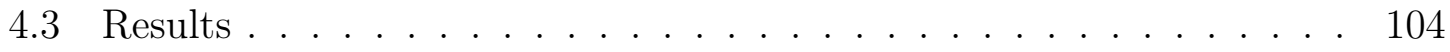

4.3.1 Statistics and structure of anticyclonic features and dipole pairs 104

4.3.2 Meanders or coherent features? . . . . . . . . . . . . . . 108

4.3.3 Formation mechanism . . . . . . . . . . . . . . . 115

4.3.4 Implications for the interior Labrador Sea . . . . . . . . . . . 123

4.3.5 Trends . . . . . . . . . . . . . . . . . . 124

4.3.6 Downstream consequences . . . . . . . . . . . . . 126

4.4 Conclusions and discussion . . . . . . . . . . . . . . . . . . . . . . 129

4.5 Data availability . . . . . . . . . . . . . . . . . . 131

4.6 Acknowledgements . . . . . . . . . . . . . . . . . 132

5 Wind-forced upwelling along the West Greenland shelfbreak: The role of tip jets and implications for Labrador Sea Water formation 133

5.1 Introduction . . . . . . . . . . . . . . . . . . . . 134

5.2 Data and methods . . . . . . . . . . . . . . . . . . 139

5.2.1 Mooring data . . . . . . . . . . . . . . 139

5.2 .2 Atmospheric data . . . . . . . . . . . . . . . . . . 141

5.2 .3 Shipboard data . . . . . . . . . . . . . . . . . . . . . . . . . . . . . . . . . . 141

5.2 .4 Interior Labrador Sea data . . . . . . . . . . . . . . . . . . 143

5.2.5 One-dimensional mixed layer model . . . . . . . . . . . . . . 143

5.3 Results . . . . . . . . . . . . . . . . . . . . . . . . . . . . . . . . . . . . 145

5.3.1 Diagnosing upwelling events . . . . . . . . . . . . . 145

5.3.2 General characteristics of upwelling events . . . . . . . . . . . 148

5.3.3 Hydrographic response to upwelling-favorable winds . . . . . . 151

5.3.4 Nature of the wind forcing . . . . . . . . . . . . . . . . 153

5.3.5 Case studies of two September storms . . . . . . . . . . . . . 156

5.3.6 Cross-stream property fluxes . . . . . . . . . . . . . . . 162

5.3.7 Impact on stratification in the basin . . . . . . . . . . . 166

5.4 Conclusions . . . . . . . . . . . . . . . . . 170

5.5 Data availability . . . . . . . . . . . . . . . . . . . 171

5.6 Acknowledgements . . . . . . . . . . . . . . . 171

6 Conclusions 173

6.1 Summary . . . . . . . . . . . . . . . . . . . . . . 174

6.2 Questions raised by this work . . . . . . . . . . . 176 


\section{List of Figures}

1-1 AMOC Schematic . . . . . . . . . . . . . . . . . . . . . 14

$1-2 \quad$ OSNAP Schematic . . . . . . . . . . . . . . . . . 18

2-1 Schematic circulation of Irminger and Labrador Seas . . . . . . . 26

2-2 Array configuration . . . . . . . . . . . . . . . . . . . 30

$2-3$ Mean flow vectors . . . . . . . . . . . . . . . . . . 33

$2-4$ Mean vertical sections $\ldots \ldots \ldots \ldots \ldots \ldots \ldots$

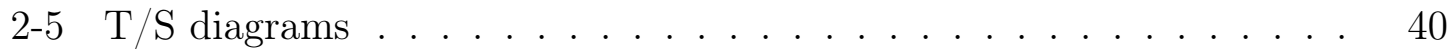

$2-6$ Watermass diagrams . . . . . . . . . . . . . . . . . 42

2-7 Transport timeseries . . . . . . . . . . . . . . . . . . . 45

2-8 Labrador Sea Water seasonality . . . . . . . . . . . . . . . 47

2-9 Labrador Sea Water cores . . . . . . . . . . . . . . . . . . 48

2-10 Irminger Water seasonality . . . . . . . . . . . . . . . . 50

2-11 Iriminger Water pathway . . . . . . . . . . . . . . . 51

2-12 Winter evolution of Irminger Water properties . . . . . . . . . . 52

2-13 Transport of Labrador Sea Water and Irminger Water . . . . . . . . . 53

2-14 Upper Polar Water seasonality . . . . . . . . . . . . . . . . . 55

2-15 Upper Polar Water correlation maps . . . . . . . . . . . . . 56

3-1 Schematic circulation of Irminger and Labrador Seas . . . . . . . 66

$3-2$ Array configuration . . . . . . . . . . . . . . . . . 70

3-3 Graphical User Interface . . . . . . . . . . . . . . . . . 74

$3-4$ Cyclone statistics . . . . . . . . . . . . . . . . 75

3-5 Model cyclone . . . . . . . . . . . . . . . . . . . . . . . 77

3-6 Composite cyclone . . . . . . . . . . . . . . . . . . . . . 79

3-7 Lateral cyclone velocities . . . . . . . . . . . . . . . . . . . . 82

3-8 Vertical cyclone velocities . . . . . . . . . . . . . . 85

3-9 Cyclone presence in first 3 months of deployment . . . . . . . . 87

$3-10$ Synoptic survey . . . . . . . . . . . . . . . . . . . . 89

4-1 Schematic and eddying circulation of Labrador Sea . . . . . . . . 99

$4-2$ Array configuration . . . . . . . . . . . . . . . . . . . 102

4-3 Meander statistics . . . . . . . . . . . . . . . . . . . 105

$4-4 \quad$ Mooring EKE . . . . . . . . . . . . . . . . . . . . 106

$4-5 \quad$ LS5 Composite . . . . . . . . . . . . . . . . . . . 107

$4-6 \quad$ LS6 Composite . . . . . . . . . . . . . . . . . . . . 108 
4-7 Relative vorticity . . . . . . . . . . . . . . . . . . . . 110

$4-8$ Satellite SST . . . . . . . . . . . . . . . . . . . . . . 112

4-9 Schematic meander . . . . . . . . . . . . . . . . . . . . . . 113

4-10 Energetics components . . . . . . . . . . . . . . . . . . 118

4-11 Meander index timeseries correlations . . . . . . . . . . . . . . . . 120

4-12 Trends . . . . . . . . . . . . . . . . . . . . . . 125

4-13 Satellite EKE . . . . . . . . . . . . . . . . . . . . 127

4-14 Lagged EKE correlations . . . . . . . . . . . . . . . . . . . 129

5-1 Schematic circulation with low pressure . . . . . . . . . . 136

$5-2$ Array configuration . . . . . . . . . . . . . . . . . . 140

5-3 Atmospheric data . . . . . . . . . . . . . . . . . . . . . . . . . . . . . . . . . . . . . . . . . 142

$5-4$ Argo data . . . . . . . . . . . . . . . . . . 144

$5-5$ Upwelling events . . . . . . . . . . . . . . . . 147

$5-6$ Cumulative Ekman transport . . . . . . . . . . . . . . . . 150

$5-7$ Composite upwelling . . . . . . . . . . . . . . . . . . 151

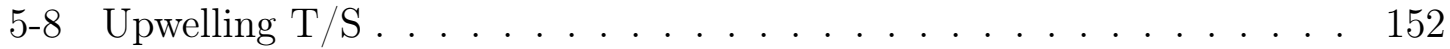

$5-9$ Peak event atmospheric conditions . . . . . . . . . . . . . 154

5-10 Atmospheric composites . . . . . . . . . . . . . . . . . 155

5-11 September 2014 storm timeseries . . . . . . . . . . . . . . . 157

5-12 September 2014 storm composites . . . . . . . . . . . . . . . 158

5-13 September 2018 hydrographic sections . . . . . . . . . . . . . . . 161

$5-14$ Property fluxes . . . . . . . . . . . . . . . . . . 163

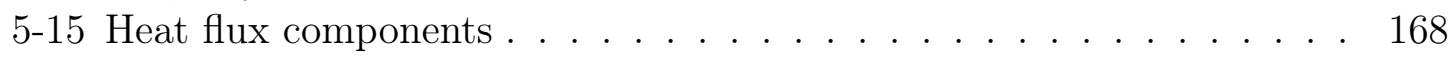

5-16 Mixed layer development . . . . . . . . . . . . . . . . . 169 


\section{List of Tables}

2.1 Water mass definitions . . . . . . . . . . . . . . . . . . . . . 39

2.2 Water mass transports . . . . . . . . . . . . . . . . 44

3.1 Cyclone properties . . . . . . . . . . . . . . . 83

3.2 Cyclone transport . . . . . . . . . . . . . . . . . 86

5.1 Storm fluxes . . . . . . . . . . . . . . . . . . . . . . . 164 


\section{Chapter 1}

\section{Introduction}

\subsection{The Atlantic Meridional Overturning Circulation}

The meridional overturning circulation (MOC) of the global ocean represents a primary pathway for heat transport within the climate system (IPCC, 2013; Rahmstorf et al., 2015; Buckley and Marshall, 2016). Warm, light waters are transported poleward by surface currents; cold, dense waters are transported equatorward at depth (e.g. Rahmstorf, 2006). In the Atlantic Ocean, this redistribution of heat and freshwater is referred to as the Atlantic Meridional Overturning Circulation (AMOC). There are four components of the AMOC: (1) convection at high latitudes that triggers local sinking and the production of ventilated waters; (2) the equatorward transport of this convected water at depth; (3) upwelling of deep waters to the surface layer in the interior basins; and (4) the poleward transport of warm, light waters near the surface (Figure 1-1; e.g., Kuhlbrodt et al. 2007; Johnson et al. 2019).

In the Atlantic Ocean, two cells together form the AMOC: an abyssal cell consisting of Antarctic Bottom Water (AABW), and a deep cell concentrated in the North Atlantic, which consists of waters ventilated in the Nordic Seas and subpolar gyre (Kuhlbrodt et al., 2007). The AMOC has been shown to influence Northern Hemisphere climate (Sutton and Hodson, 2005; Knight et al., 2006; Zhang and Del- 


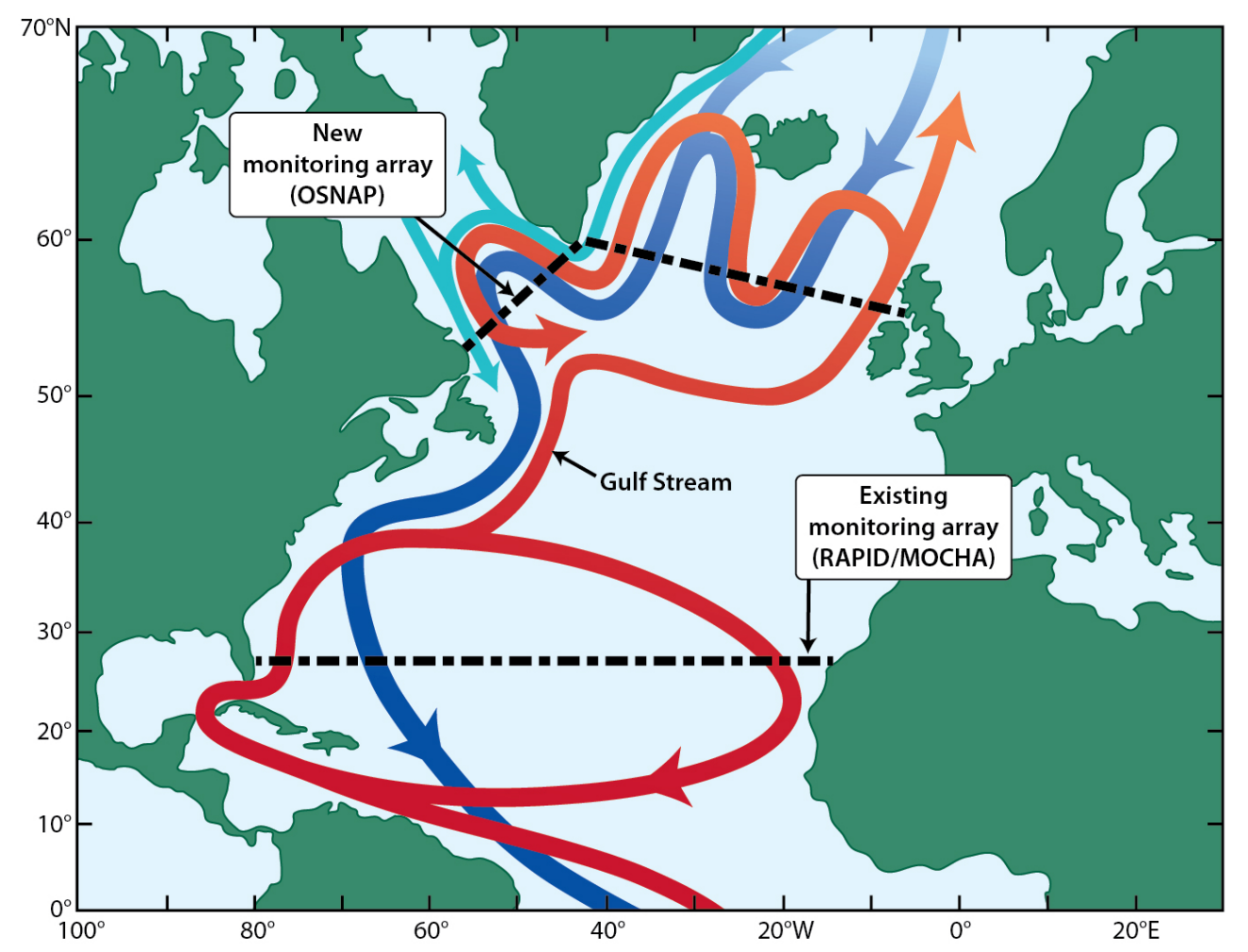

Figure 1-1: Schematic circulation of the Atlantic Meridional Overturning Circulation (AMOC), where warm, light waters are advected northwards at the surface, and cold, dense waters are advected southward at depth. Image Credit: WHOI.

worth, 2006; Rhines et al., 2008; Smith et al., 2010), sea surface temperatures in the North Atlantic (Knight et al., 2005; Delworth et al., 2007; Robson et al., 2012; Yeager et al., 2012), Greenland and Arctic ice melt (Rignot and Kanagaratnam, 2006; Serreze et al., 2007; Holland et al., 2008; Straneo et al., 2010), carbon uptake and transport (Rosón et al., 2003; Sabine et al., 2004; Takahashi et al., 2009; Steinfeldt et al., 2009; Khatiwala et al., 2013; Pérez et al., 2013; Halloran et al., 2014; Li et al., 2016), and nutrient distribution and primary productivity (Palter and Lozier, 2008). As such, it is critical to understand how the AMOC works in order to predict how it might change in the future. 


\subsection{Convective processes}

Air-sea buoyancy exchange in the North Atlantic subpolar gyre and Nordic Seas triggers dense water formation (e.g. Buckley and Marshall, 2016; Johnson et al., 2019). The locus of these ventilated waters, generally referred to as North Atlantic Deep Water (NADW), resides between 1000-3000 m depth and constitutes the lower limb of the AMOC in the northern hemisphere (Johnson et al., 2019).

The subpolar gyre is generally defined as the cyclonic circulation between $50^{\circ} \mathrm{N}$ and $65^{\circ} \mathrm{N}$ and consists of a series of strong boundary currents (e.g. Talley and McCartney, 1982) and interior recirculations (Bower et al., 2009). Positive wind stress curl in the subpolar North Atlantic leads to Ekman divergence at the surface and a depressed sea surface height (SSH) in the interior. This SSH pattern is associated with geostrophic cyclonic flow observed around the periphery of the gyre (e.g. Foukal and Lozier, 2017) and corresponds to isopycnal doming in the interior which isolates waters within the interior (Send and Marshall, 1995). These weakly-stratified, isolated waters in the interior basins are then exposed to strong buoyancy forcing at the surface which results in the production of ventilated waters via convection in specific regions (Send and Marshall, 1995).

Convection in the Nordic Seas produces waters comprising the deepest, densest limb of the Northern Hemisphere AMOC (e.g. Chafik and Rossby, 2019; Lozier et al., 2019; Huang et al., 2020). These waters are exported across the Greenland-Scotland ridge and flow equatorward in the Deep Western Boundary Current (Dickson and Brown, 1994). Convection in the Labrador and Irminger Seas produces the intermediate ventilated water mass known as Labrador Sea Water (LSW; e.g. Clarke and Gascard 1983; Lab Sea Group 1998). Specifically, LSW is formed in the western Labrador basin (e.g. Pickart et al., 2002), western Irminger basin (Pickart et al., 2003a,b; Våge et al., 2008; de Jong and de Steur, 2016), within a small recirculation gyre south of Greenland (Pickart and Spall, 2007; Piron et al., 2017; Zunino et al., 2020), and within the boundary currents adjacent to Greenland and the Labrador coast (Pickart et al., 2002; Le Bras et al., 2020). The formation and subsequent 
spreading of these ventilated waters via boundary currents (Pickart, 1992; Dickson and Brown, 1994; Fischer et al., 2010) and interior pathways (Lavender et al., 2000; Bower et al., 2009) has important implications for the dynamics of the AMOC.

The production of LSW is a function both of buoyancy exchange at the surface and preconditioning of the water column prior to onset of convection (e.g. Lilly et al., 1999). The boundary currents circumnavigating the subpolar gyre, and especially the Labrador Sea, are hypothesized to play an important role in exchange of properties between the slope and the basin (e.g. Lilly et al., 1999; Spall, 2004), which modulates the water mass transformation in the interior. Observations and models also indicate that overturning in depth and density space within the Labrador Sea are not collocated, but are both influenced by boundary current composition and processes (Spall and Pickart, 2001; Pickart et al., 2002; Spall, 2004; Pickart and Spall, 2007).

Recent observational evidence highlights the dominant role of the eastern North Atlantic in regulating the strength of the AMOC (Lozier et al., 2019), challenging the historical notion that the AMOC is primarily regulated in the Labrador Sea (Hodson and Sutton, 2012; Robson et al., 2014; Jackson et al., 2016; Danabasoglu et al., 2016; Thornalley et al., 2018). Using the same observational record as Lozier et al. (2019), Zou et al. (2020) present evidence of strong density compensation in the Labrador Sea, as was initially hypothesized by Pickart and Spall (2007). Models often fail to reproduce LSW production rates, and often overestimate ventilation in the Labrador Sea and its impact on AMOC, as they struggle to resolve mesoscale and submesoscale processes within the boundary currents (Li et al., 2019), and thus are unable to reproduce heat and freshwater fluxes to the interior. Additionally, recent observations indicate the need to look beyond density changes in the lower limb of the $\mathrm{AMOC}$ as a way to predict its strength, and instead highlight the need to integrate the pathways and small-scale processes involved in overturning to quantify its magnitude (Li et al., 2021). As such, it is critical to understand the water mass composition and variability of the boundary current systems, as well as the processes contributing to boundary current-interior interaction, in order to understand the ramifications for the interior basins. 


\subsection{The AMOC in a changing climate}

Given the importance of the AMOC in regulating climate variability, it is critical to understand how the AMOC has changed on decadal and millennial timescales, and to forecast how it might change in the future. Paleoreconstructions of AMOC proxies such as sea surface temperature and primary productivity timeseries are used to shed light on the strength of the AMOC in past centuries and to compare it to the presentday AMOC. From this paleoclimate perspective, many studies argue that the AMOC is slowing (e.g. Rahmstorf, 2002; Caesar et al., 2018, 2021; Boers, 2021).

The modern-day observational record is not long enough to adjudicate on AMOC trends. The U.K.-U.S. Rapid Climate Change-Meridional Overturning Circulation and Heatflux Array (RAPID-MOCHA), deployed at $26.5^{\circ} \mathrm{N}$, has monitored the AMOC in the subtropical gyre since 2004 and revealed large interannual (Cunningham et al., 2007; Kanzow et al., 2007; McCarthy et al., 2015; Srokosz and Bryden, 2015) and high-frequency variability (Srokosz and Bryden, 2015). More recently, the Overturning in the Subpolar North Atlantic Program (OSNAP) has monitored the overturning circulation within the subpolar gyre using a composite set of moorings deployed near $60^{\circ} \mathrm{N}$ between Canada and Scotland (Figure 1-2; Lozier et al. 2017, 2019). The RAPID-MOCHA and OSNAP timeseries are not long enough to provide a definitive answer as to the proposed AMOC slowdown, but continuing to collect these data will be imperative to future understanding of both short-term and long-term trends.

Highlighting this uncertainty in AMOC strength, the most recent Intergovernmental Panel on Climate Change (IPCC, 2021) report describes only medium confidence that the AMOC has weakened relative to 1850-1900. However, the IPCC (2013) report deems AMOC weakening in the 21st century as very likely. They present a range of forecasts for the AMOC strength as a function of global temperature change, and evaluate the ramifications that variations in AMOC strength could have on physical, biological, and human systems. The projected consequences include increased storminess and sea level rise in the North Atlantic, to increased droughts in Asia and decreased sea ice and snow in Antarctica (IPCC, 2021). 


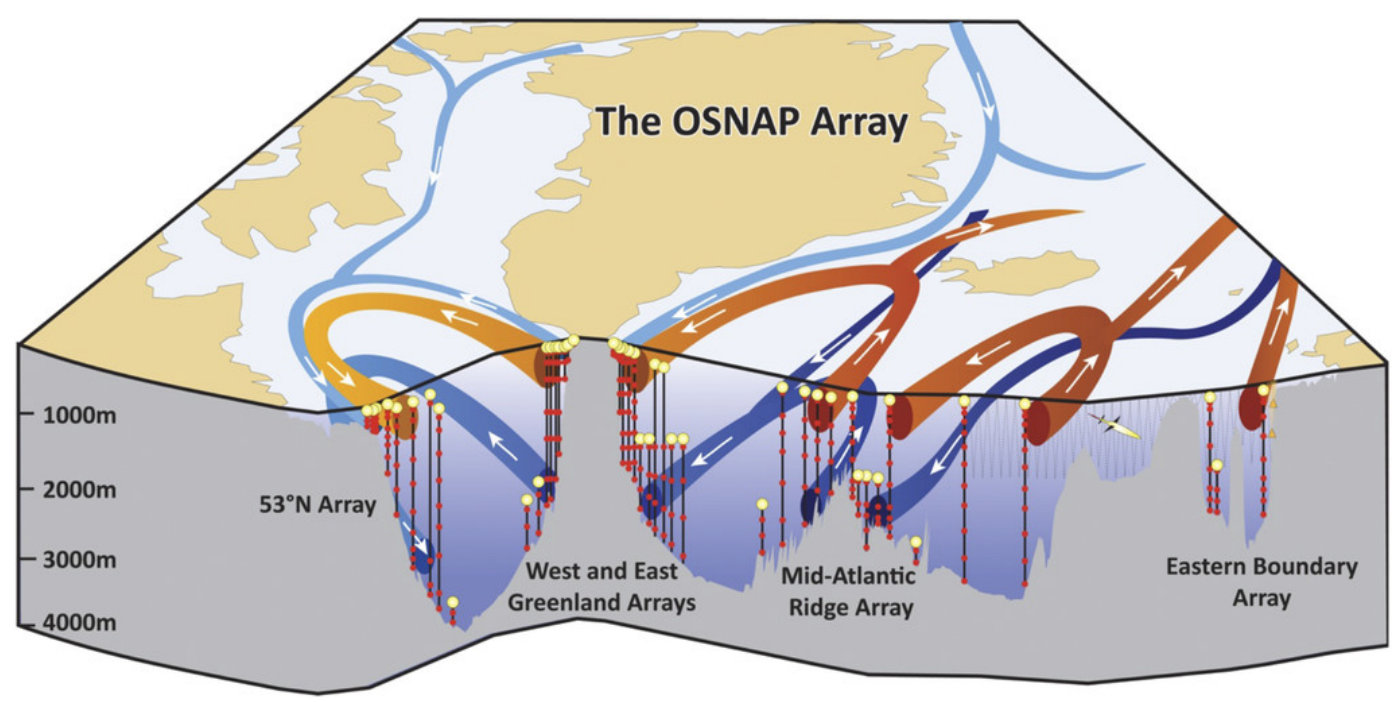

Figure 1-2: The OSNAP observational array, with the schematic circulation overlaid. From Lozier et al. (2017).

Greenhouse gas emissions over the last century have led to an increase in global temperatures that are reshaping the way the climate system works (IPCC, 2021). One clear consequence of these warming trends is the observed and projected melt of Arctic sea ice, Arctic permafrost, and the Greenland ice sheet (Bamber et al., 2012; Stroeve and Notz, 2018; IMBIE, 2020). Many studies have shown a direct link between the amount and distribution of freshwater in the North Atlantic and the strength of the AMOC (Stommel, 1961; Rooth, 1982; Manabe and Stouffer, 1988; Maier-Reimer and Mikolajewicz, 1989; Rahmstorf, 1995; Malmberg and Jónsson, 1997; Stouffer et al., 2006; Jahn and Holland, 2013; Weijer et al., 2019). For instance, historical data reveal the shutdown of convective processes in the interior Labrador Sea due to the presence of a large freshwater signal emanating from the Arctic, known as the Great Salinity Anomaly (e.g. Lazier, 1980; Dickson et al., 1988; Gelderloos et al., 2012). Models have investigated the relationship between increases in freshwater in the interior basins of the subpolar gyre and the strength of the AMOC by performing "hosing" experiments, whereby a large freshwater signal is introduced within the subpolar gyre and the implications for the strength of the AMOC are assessed (Huybrechts et al., 2002; Fichefet et al., 2003; Ridley et al., 2005; Jungclaus et al., 2006; Gerdes et al., 2006; Stouffer et al., 2006; Swingedouw et al., 2006; Vizcaíno et al., 2008; Hu et al., 2011; 
Swingedouw et al., 2015). However, the precise processes and pathways by which this freshwater enters the interior basins, as well as the magnitude of the flux, remains uncertain in both models and observations.

Increased global temperatures are also leading to the "Atlantification" of the Arctic. This refers to recent warming trends and reduction in sea ice cover on the Atlantic side of the Arctic Ocean, triggered by changes in the properties of Atlantic-origin waters entering the Arctic (Sandø et al., 2010; Årthun et al., 2012; Asbjørnsen et al., 2020). This same Atlantic-origin water also travels cyclonically around the subpolar gyre and is the primary source of heat to the interior Labrador Sea (e.g. Cuny et al., 2002; Lazier et al., 2002). In the Labrador Sea, this warm, saline water is referred to as Irminger Water (IW; Cuny et al. 2002; Lazier et al. 2002), and, when fluxed offshore, acts to restratify the convective patch after wintertime ventilation. As with freshwater, this offshore flux of heat is governed by mesoscale to submesoscale processes that require further study, particularly if these waters are warming.

\subsection{Thesis outline}

This thesis seeks to improve our understanding of one of the boundary current systems in the subpolar North Atlantic that influences the formation and spreading of newly ventilated waters and thus impacts the AMOC. While there have been extensive mooring measurements along the western boundaries of both the Labrador and Irminger Seas (e.g. Dickson and Brown, 1994; Fischer et al., 2004; Daniault et al., 2011; Zantopp et al., 2017), to date there have been virtually no timeseries measurements of the West Greenland boundary current system. As part of the OSNAP monitoring system, a high-resolution mooring array was deployed for the first time across the west Greenland shelf and slope. In this thesis, four years of data (2014-18) from the OSNAP West Greenland array are used to investigate the structure and variability of the boundary current system over a range of spatio-temporal scales, estimate slope-basin exchange of properties, and assess the associated impacts on interior convection in the Labrador Sea. The thesis consists of four chapters, three of 
which are published. The fourth chapter will be submitted in the near future.

In chapter 2 , the mean conditions and seasonal variability of the West Greenland boundary current system are diagnosed. The current system is comprised of three parts: (1) the West Greenland Coastal Current, which advects cold and fresh waters of Artic and Greenland origin; (2) the West Greenland Current, which advects cold waters at the surface and warm, saline, Atlantic-origin waters at depth; and (3) the Deep Western Boundary Current, which advects waters ventilated in the Nordic Seas. LSW is present at the seaward end of the array in an offshore recirculation gyre, as well as at the base of the West Greenland Current. We find that the overall transport of the boundary current system does not vary on seasonal timescales, but the transport of LSW is anti-correlated with that of the Atlantic-origin water. This is due to modification of the Atlantic-origin water during wintertime. The seasonality in transport of the cold, fresh waters in the coastal current can be explained by remote wind forcing and subsequent adjustment via coastal trapped waves. These results represent the first year-round view of the boundary current system and improve our understanding of wintertime dynamics in the region. This chapter was published in Journal of Physical Oceanography in 2020.

In chapter 3, the first observations are presented of Denmark Strait Overflow Water cyclones which have rounded Cape Farewell and progressed into the Labrador Sea. These cyclonic features are formed as dense water cascades over the Denmark Strait sill and spins up cyclonic vorticity as the water column stretches. While previously believed to spin down or retroflect along the southeast coast of Greenland, this study demonstrates that another possible fate for these features is to enter the Labrador Sea at the offshore edge of the West Greenland Current. Using data from the OSNAP East Greenland array it is shown that roughly half the cyclones reaching Cape Farewell follow this route, passing by the West Greenland array about once per week. They act to enhance the transport of overflow waters in the boundary current system. This chapter was published in Journal of Physical Oceanography in 2021.

In chapter 4 , it is shown that the West Greenland Current meanders due to baroclinic instability. The meanders are most energetic during winter when the isopycnal 
slope of the boundary current is enhanced due to offshore convection. The data indicate that this process produces small-scale, surface-intensified eddies. According to models, such eddies are an important source of heat and freshwater to the interior basin, but have not been observed until now. The interannual variability of the meandering is also investigated, and it is demonstrated that the meanders act to trigger the formation of the well-known Irminger Rings downstream. This chapter is accepted for publication in Deep Sea Research $I$.

In chapter 5, the role of wind-forcing on the dynamics of the West Greenland Current is investigated. In particular, upwelling events along the West Greenland shelfbreak are shown to be an early consequence of the formation of forward tip jets. These are strong atmospheric storms that develop when low pressure systems from the North Atlantic storm track impinge on the high topography of southern Greenland and trigger a narrow jet in the lee. The cross-shelf flux of properties due to these upwelling events is quantified. It is then demonstrated that, over the course of a winter, such an intermittent source of freshwater severely limits the development of the mixed layer. This explains why LSW production is not observed in the eastern Labrador Sea.

In sum, this thesis advances our understanding of the West Greenland boundary current system at synoptic to interannual timescales and investigates both internallyforced and externally-forced modes of variability. Understanding the composition and variability of the boundary current system is critical towards understanding its influence on the dynamics of the subpolar gyre. These advancements must be taken into account in the most recent generation of models, in order to accurately reproduce the stratification, water mass ventilation, and overturning within the Labrador Sea. 


\title{
Chapter 2
}

\section{Mean conditions and seasonality of the West Greenland boundary current system near Cape Farewell}

\begin{abstract}
The structure, transport, and seasonal variability of the West Greenland boundary current system near Cape Farewell are investigated using a high-resolution mooring array deployed from 2014 to 2018. The boundary current system is comprised of three components: the West Greenland Coastal Current, which advects cold and fresh Upper Polar Water (UPW); the West Greenland Current, which transports warm and salty Irminger Water (IW) along the upper slope and UPW at the surface; and the Deep Western Boundary Current, which advects dense overflow waters. Labrador Sea Water (LSW) is prevalent at the seaward side of the array within an offshore recirculation gyre and at the base of the West Greenland Current. The 4-yr mean transport of the full boundary current system is $31.1 \pm 7.4 \mathrm{~Sv}\left(1 \mathrm{~Sv} \equiv 10^{6} \mathrm{~m}^{3} / \mathrm{s}\right)$, with no clear seasonal signal. However, the individual water mass components exhibit seasonal cycles in hydrographic properties and transport. LSW penetrates the boundary current locally, through entrainment/mixing from the adjacent recirculation gyre, and also enters the current upstream in the Irminger Sea. IW is modified through air-sea interaction during winter along the length of its trajectory around the Irminger Sea, which converts some of the water to LSW. This, together with the seasonal increase in LSW entering the current, results in an anticorrelation in transport between these two water masses. The seasonality in UPW transport can be explained by remote wind forcing and subsequent adjustment via coastal trapped waves. Our results provide the first quantitatively robust observational description of the boundary current in the eastern Labrador Sea.
\end{abstract}

This chapter is published as Pacini et al. (2020). Mean Conditions and Seasonality of the West Greenland Current System near Cape Farewell. Journal of Physical Oceanography, 50(10):28492871. (C) American Meteorological Society. Used with permission. 


\section{$2.1 \quad$ Introduction}

Convection at high latitudes in the North Atlantic produces intermediate and overflow waters (Dickson and Brown, 1994; Lazier et al., 2002) and is responsible for the downwelling branch of the global overturning circulation (e.g. Killworth, 1983; Våge et al., 2008). The resulting meridional flux of heat helps regulate Northern Hemisphere climate. Furthermore, the convection is an important mechanism for carbon sequestration from the atmosphere to the deep ocean (Takahashi et al., 2009; Khatiwala et al., 2013). Due in part to the small Rossby radius of deformation at high latitudes, more extensive observations are needed to quantify the extent to which the regional current systems contribute to these processes.

There are two locations where open-ocean convection forms the intermediate water mass known as Labrador Sea Water (LSW): the western Labrador Sea (Clarke and Gascard, 1983; Lab Sea Group, 1998; Pickart et al., 2002) and the southwestern Irminger Sea (Pickart et al., 2003a,b). The strength of convection, due to large heat fluxes and wind stress curl, varies greatly from year to year and is intimately connected with the North Atlantic Oscillation and the associated westerly winds (Hurrell, 1995; Våge et al., 2009a). The mechanisms that govern convection in the two basins differ. Convection in the Labrador Sea is predominantly driven by passing low pressure systems that draw cold air off of the Labrador landmass and increase the surface heat loss from the ocean in conjunction with changes in ice cover (Våge et al., 2009a). Convection in the Irminger Sea is more tightly coupled to the presence of the forward Greenland tip jet, a localized, narrow atmospheric jet that results from the interaction of passing atmospheric cyclones with the high topography of southern Greenland. These features act to enhance surface buoyancy loss and produce LSW (e.g. Pickart et al., 2003a; Våge et al., 2008)

The newly ventilated intermediate waters are exported from the subpolar gyre by way of the boundary current system of the Irminger and Labrador Seas (Pickart, 1992; Dickson and Brown, 1994; Fischer et al., 2010) and also via interior pathways (Lavender et al., 2000; Bower et al., 2009). In the Irminger Sea, the boundary 
current system consists of the following components, progressing from onshore to offshore: the East Greenland Coastal Current (EGCC) (Bacon, 2002; Sutherland and Pickart, 2008); the East Greenland/Irminger Current (EGC/IC) in the vicinity of the shelfbreak (Sutherland and Pickart, 2008); the East Greenland Spill Jet on the upper continental slope (e.g. von Appen et al., 2014a); and finally the Deep Western Boundary Current (DWBC) at the base of the slope (Dickson and Brown, 1994) (Figure 2-1). The EGCC transports Arctic-origin water and glacial runoff from Greenland between the surface and $200 \mathrm{~m}$ (Bacon, 2002; Sutherland and Pickart, 2008). The EGC/IC advects a combination of Arctic waters exported through Denmark Strait and Atlantic-origin waters from the Irminger Sea (Cuny et al., 2002; Pickart et al., 2005; Fratantoni and Pickart, 2007). The East Greenland Spill Jet is believed to combine with the EGC/IC as the two currents flow southward toward Cape Farewell (Brearley et al., 2012; von Appen et al., 2014a). The DWBC advects overflow waters that are ventilated in the Nordic Seas (Dickson and Brown, 1994).

The EGCC, EGC/IC, and DWBC from the eastern side of Greenland persist around the southern tip of Greenland, known as Cape Farewell, to form the West Greenland boundary current system (see Figure 2-1b). Northwest of Cape Farewell, the EGCC becomes the West Greenland Coastal Current (WGCC), and the EGC/IC becomes the West Greenland Current (WGC). While previous studies have considered the WGCC and WGC as a single flow (e.g., Rykova et al. 2015), here we distinguish the two components based on their water mass characteristics. It has recently been shown that, as the coastal current rounds Cape Farewell, it gets diverted close to the shelfbreak due to the local bathymetry. This allows some of the freshwater advected by the current to be fluxed seaward into the basin via baroclinic instability (Lin et al., 2018). Additionally, Holliday et al. (2007, 2009) argue that approximately one-third of both the EGC/IC transport and DWBC transport recirculate into the Irminger Sea at Eirik Ridge, the seaward protrusion of the 2000-3500-m bathymetric contours south of Cape Farewell.

Progressing northward, some portion of the WGCC and WGC flows through Davis Strait into Baffin Bay (Cuny et al., 2005; Curry et al., 2011, 2014), while the remain- 

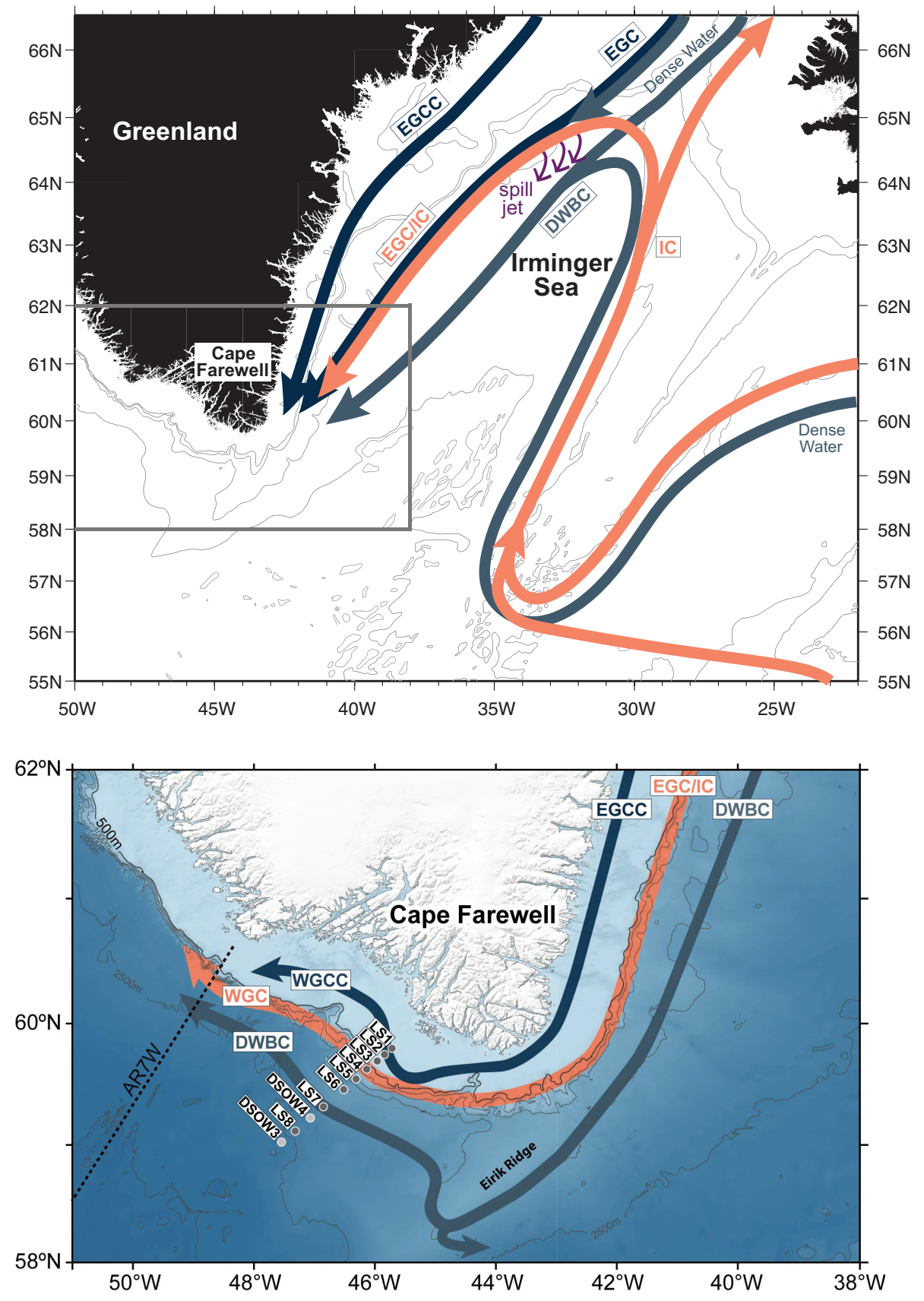

Figure 2-1: (a) Schematic circulation around the Irminger Sea and in the East Greenland boundary current system. See (b) for enlarged view within the gray box. (b) Schematic circulation around the southern tip of Greenland, with the OSNAP West Greenland moorings marked by the gray circles. Dark gray indicates full-depth moorings, and light gray indicates bottom-instrumented moorings. The black dashed line indicates the AR7W hydrographic line. 
der circulates around the northern edge of the Labrador Sea and turns southward along the Labrador and Newfoundland coasts. In addition to advecting water masses equatorward via the mean flow, strong mesoscale variability (e.g. Lilly et al., 1999) and Ekman transport play important roles in the exchange of waters between the boundary current and the interior Labrador Sea (Luo et al., 2016; Schulze Chretien and Frajka-Williams, 2018). This is vital for modulating the convective overturning during winter, restratifying the interior during spring (e.g. Straneo, 2006), and fluxing the newly ventilated LSW to lower latitudes (e.g Le Bras et al., 2017).

Unlike the western Irminger Sea and the western Labrador Sea, the boundary current system in the eastern Labrador Sea has not been well studied. The observations to date have consisted of limited shipboard sections, taken mostly during the warm months of the year. Repeat occupations of the AR7W line, extending from the Newfoundland shelf to the West Greenland shelf, have been performed annually since 1990 (see Figure 2-1b; note that the western end of this line was omitted in some years; see Lazier et al. 2002). In addition, a set of boundary current sections across the West Greenland shelf/slope is carried out each year (Ribergaard, 2014). Several studies have used these data, plus a smaller amount of wintertime shipboard sections, to investigate the mean, seasonal, and interannual variability of the WGCC and WGC. Rykova et al. (2015), using 18 occupations of the AR7W line (5 in wintertime) and altimeter-derived surface velocity, concluded that the WGCC exhibits a maximum in transport in the summer months (May-July), while the Atlantic-origin water in the WGC exhibits a maximum in temperature, salinity, and transport in the winter months (October-February). Using a diagnostic model for barotropic velocities together with the West Greenland sections, Myers et al. (2007) showed that the Atlantic-origin water is highly variable on interannual time scales in volume transport, lateral position, and salinity signature, with maxima in temperature, salinity, and transport in the 1960s. Using a similar approach, Myers et al. (2009) investigated the interannual variability of the presence of low-salinity waters on the shelf.

A region of high eddy kinetic energy on the West Greenland slope has been observed from satellite data and Lagrangian profilers (e.g. Prater, 2002; Lilly et al., 
2003). Anticyclonic features called Irminger Rings, with a core of warm, saline Atlantic-origin water, are spawned from this location and travel southwestward across the Labrador Sea, before spinning down in the interior of the basin (Lilly et al., 1999; Prater, 2002; Rykova et al., 2009; de Jong et al., 2014). Modeling studies have addressed the role of the boundary current, and this hot spot in particular, in fluxing properties into the interior Labrador Sea. It has been determined that the Irminger Rings, together with convective eddies (spawned by convection within the Labrador Sea) and boundary current eddies (spawned by instabilities all along the WGC), help balance the wintertime heat loss in the interior Labrador Sea (Gelderloos et al., 2011).

While the studies to date have advanced our understanding of the boundary current system west of Greenland, the observational description is largely incomplete. This is in part due to the lack of mooring time series, which provide information throughout the seasonal cycle. Here we present results from the first high-resolution mooring array deployed across the West Greenland boundary current system. The array is maintained as part of the Overturning in the Subpolar North Atlantic Program (OSNAP) (Lozier et al., 2017). We report on the first four years of data, 2014-18, and quantify the mean conditions and seasonality of the component water masses and velocity cores comprising the boundary current system. We further explain the nature of the seasonal signals and their connection to upstream conditions. The structure of the paper is as follows. In section 2.2 the data and processing are reported; the mean conditions are described in subsection 2.3.1; the water masses are identified in subsection 2.3.2; the transports are quantified in subsection 2.3.3; the seasonality is diagnosed in 2.3.4; and a summary and conclusions are presented in section 2.4. 


\subsection{Data and methods}

\subsubsection{West Greenland mooring array}

\section{Mooring configuration}

The data analyzed in this study come from 10 moorings, referred to as LS1-LS8, DSOW3, and DSOW4 (Figure 2-1b), deployed as part of OSNAP. This is a six-nation observational program that seeks to measure the time-varying meridional overturning circulation, heat flux, and freshwater flux in the northern North Atlantic, at approximately $60^{\circ} \mathrm{N}$. It consists of a suite of platforms, including moorings, gliders, floats, and hydrographic surveys (Lozier et al., 2017, 2019). The West Greenland mooring array presented here is referred to as the OSNAP WG array.

The configuration of the OSNAP WG array in the vertical is shown in Figure 2-2. Moorings LS1-LS3 on the West Greenland shelf are tripods that sit on the seafloor and contain an upward-facing acoustic Doppler current profiler (ADCP) and a MicroCAT measuring temperature, conductivity, and pressure. A second MicroCAT was situated on a buoyant tether at $50 \mathrm{~m}$ and connected to the tripod with a weak link. The link was designed to break free in case of an encounter with an iceberg. Moorings LS4-LS8 are tall moorings with top floats situated at $100 \mathrm{~m}$ containing an ADCP and MicroCAT. Beneath this were pairs of MicroCATs and Aquadopps spaced every 250-500 m. The Aquadopps provide point measurements of velocity. Each of the tall moorings contained a weak-link tether $50 \mathrm{~m}$ above the top float with a MicroCAT. The final two moorings, DSOW3 and DSOW4, are short bottom moorings with Aquadopp-MicroCAT pairs extending to $500 \mathrm{~m}$ above the bottom. The total instrumentation consisted of 49 MicroCATs, 33 Aquadopps, and 8 ADCPs (the ADCPs recorded temperature as well).

The overall data return over the 4 -yr period was $86 \%$. Separated by instrument type, it was $80.7 \%$ for MicroCAT temperature, $80.8 \%$ for MicroCAT salinity, $99.8 \%$ for the Aquadopps, and $99.6 \%$ for the ADCPs. The largest data loss was associated with the tethered MicroCATs. A significant number of these were torn off (presum- 


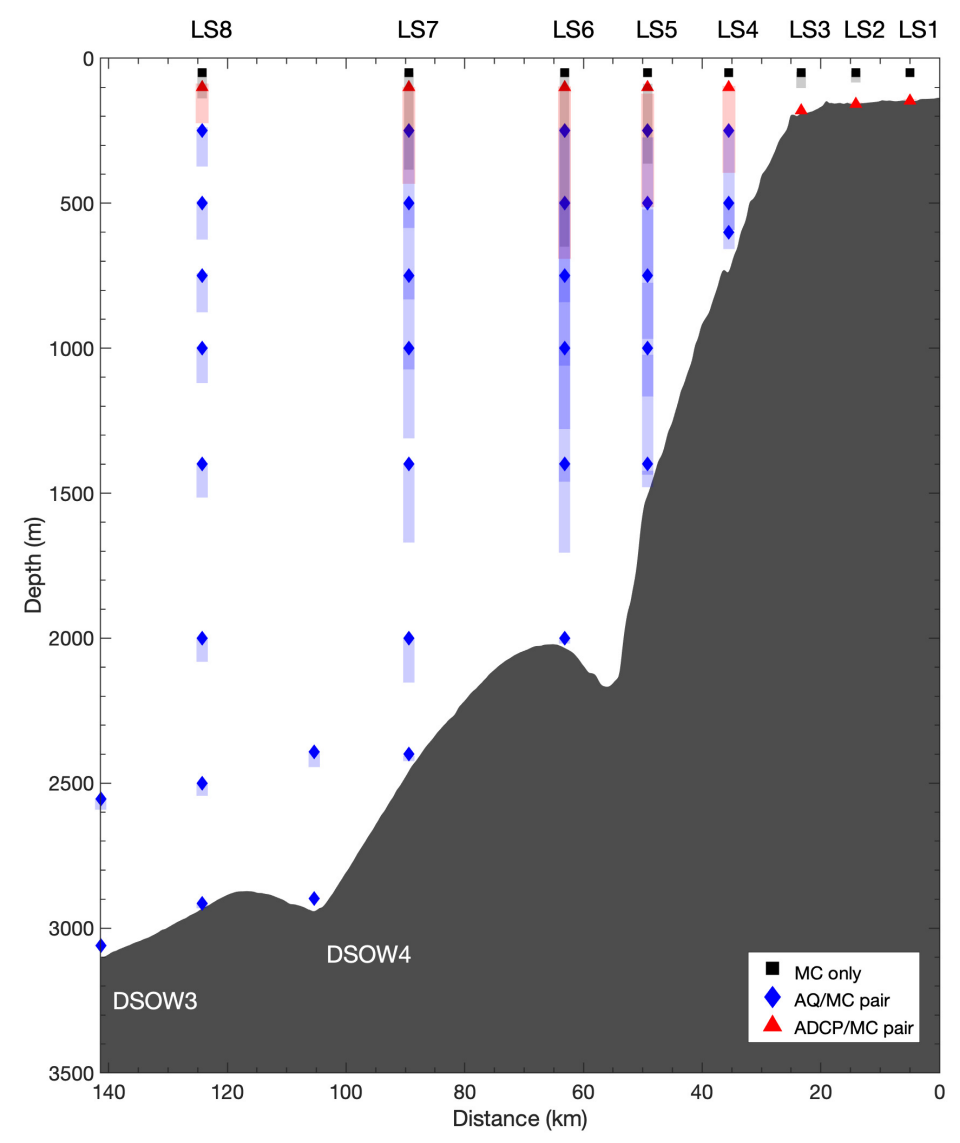

Figure 2-2: OSNAP WG instrument configuration (see the legend). The eight LS moorings were deployed by the Woods Hole Oceanographic Institution, and the two DSOW moorings were deployed by GEOMAR, Helmholtz Centre for Ocean Research, Kiel. Shading indicates the maximum vertical displacement of the instrumentation due to mooring blowdowns.

ably by icebergs), although in some cases the MicroCAT flotation was destroyed and the instrument settled at a deeper depth. Excluding the tethered MicroCATs, the overall data return was $91.9 \%$. The 2014-16 hydrographic time series from the 50-m MicroCAT at LS6 and the bottom MicroCAT at LS4 were removed because of the presence of sharp salinity jumps, possibly due to biofouling. Moorings LS4-LS7 experienced regular blowdowns due to unexpectedly strong currents (Figure 2-2). This was most pronounced at LS6, where, on occasion, some of the instruments were drawn down as much as $600 \mathrm{~m}$ in the vertical. Note that this is not generally a data loss, just a redistribution of the vertical coverage during energetic events. The details of 
this are described in section 2.2.1. All of the data were subsampled to hourly resolution, in order to match the sampling frequency of the ADCPs (the lowest common denominator for sampling frequency).

\section{Data Processing}

MicroCATs: Temperature, conductivity, and pressure were measured every $15 \mathrm{~min}$ using SBE37 MicroCATs. The initial MicroCAT precision is $\pm 0.002^{\circ} \mathrm{C}$ and \pm 0.0003 $\mathrm{S} / \mathrm{m}$ for temperature and conductivity, respectively. This means the instruments provide a precision of $\pm 0.0001-0.005$ in salinity given a temperature range of $0^{\circ} \mathrm{C}-8^{\circ} \mathrm{C}$. The conductivity measurements tend to drift over the course of a deployment. Shipboard conductivity-temperature-depth (CTD) casts were used to calibrate the instruments, following the methods outlined by Kanzow et al. (2006). The MicroCATs were attached to the CTD rosette and lowered to predetermined depths, then held at these positions for $10 \mathrm{~min}$. This was done both before the instruments were deployed and then immediately upon recovery.

These pre- and postdeployment calibration casts were then used to remove the drift (assumed to be linear) associated with the instrument during the 2-yr deployment.

Aquaadopps: Postdeployment processing of the Aquadopp data included a velocity rotation to correct for the local magnetic declination. The manufacturer's quality flag, based on an instrument tilt threshold, was triggered in cases of significant mooring blowdown due to the anomalously strong velocities. However, when inspecting the full Aquadopp measurement suite, including horizontal and vertical velocity components as well as roll and pitch across neighboring instruments, it was evident that this automatic editing was too restrictive. Furthermore, during the strongest blowdown events, the recorded roll/pitch could actually decrease in an apparent rollover effect of the tilt sensors; in extreme cases this went below the threshold value. In response, we edited the data based on visual inspection, particularly during the blowdown events, to identify poor returns. This included assessment of excessive $\mathrm{roll} / \mathrm{pitch}$ and vertical velocity, as well as consideration of outlier horizontal velocities relative to nearby instruments. 
ADCPs: Each OSNAP mooring used either a 75-kHz Teledyne RD Instruments Long Ranger (LR) or a 300-kHz Workhorse (WH) ADCP. Both were processed using MATLAB software routines developed at the Woods Hole Oceanographic Institution. Each hourly ensemble used a sequence of pings (39 pings/ensemble for LR; 60 pings/ensemble for $\mathrm{WH}$ ) that were internally averaged by the instrument. Instrumentderived percent good and error velocity criteria were used to flag bad data. Since all of the ADCPs were upward facing within range of the surface, a side-lobe interference criterion was applied to each record to eliminate bad data near the surface. The top $6 \%$ of the ADCP distance to surface was removed by the side-lobe interference flag. In cases where a MicroCAT was deployed on a tether above the ADCP, the bin where the flotation buoy was located was also corrupted and removed from the final data. A MicroCAT was deployed in combination with each ADCP. The MicroCAT data were interpolated onto the same time grid as the ADCP data and used for depth and speed of sound correction. The depths of each bin were subsequently remapped using the corrected MicroCAT-derived depths. Error criteria thresholds were designed to maximize the amount of good data. Finally, all data were visually inspected and manually corrected for remaining spurious errors not caught by the automated error detection criteria.

\section{Detiding and rotating velocities}

Tidal constituents were computed for the velocity time series using the harmonic

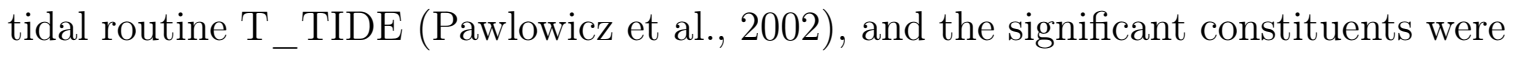
removed. The signal-to-noise ratio (which indicates significance when less than one) is computed by squaring the amplitude divided by its error (computed via bootstrapping). The data were also low-passed with a 36-h Butterworth filter, and the spectral properties of the detided and low-pass-filtered products were compared. They were found to be consistent, which verified successful removal of the semidiurnal (largest constituents: M2, S2) and diurnal (largest constituents: K1, S1, P1) tides. The data used in the remainder of this study are the detided time series.

The detided velocities were subsequently rotated into along-stream and cross- 


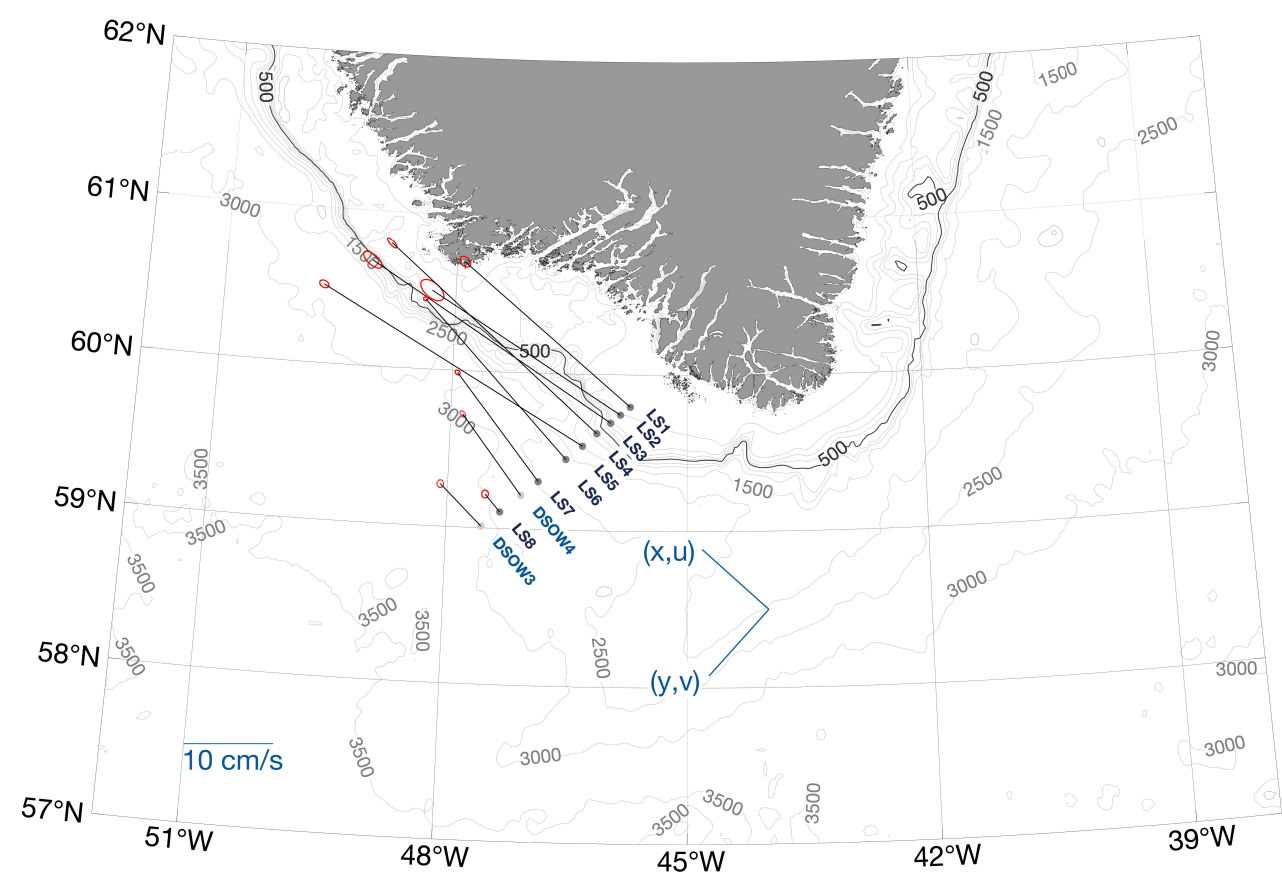

Figure 2-3: Depth-mean 2014-18 velocity vectors, with standard error ellipses in red. The orientation of the rotated coordinate system is indicated.

stream components as follows. Using the direction of the mean vectors as an initial choice, the rotation angle was varied at $0.01^{\circ}$ intervals and the mean cross-stream velocity was summed across the array at each value. The angle that minimized this sum (i.e., the cross-stream transport per unit length) was selected as the final rotation angle, which was $318.1^{\circ} \mathrm{T}$ (degrees true) (Figure 2-3). This angle is within $5^{\circ}$ of the mean flow of the individual moorings and the isobath orientation. All further velocities are presented in this rotated reference frame, with positive alongstream velocity $u$ directed toward the northwest and positive cross-stream velocity $y$ directed offshore toward the southwest.

\section{Gridding of vertical sections}

Hourly vertical sections were constructed for potential temperature referenced to the sea surface (hereafter referred to as temperature), practical salinity, potential density referenced to the sea surface (hereafter referred to as density), and along- and cross- 
stream velocity. The data were gridded using a Laplacian-spline interpolator at each time step (Smith and Wessel, 1990). The final gridding has a resolution of $5 \mathrm{~km}$ in the horizontal and $100 \mathrm{~m}$ in the vertical. This was obtained by first gridding the offshore data (LS5-DSOW3) at $15 \mathrm{~km}$ in the horizontal, $200 \mathrm{~m}$ in the vertical in order to account for the larger distances between these offshore moorings, then subsequently gridding the onshore moorings along with the coarsely gridded offshore product at the higher resolution. A bound was applied over the domain to account for only the data available at each time step, including a small amount of extrapolation. For example, if the instrumentation experienced blowdown, the upper portion of the water column that was no longer sampled at that time step was not gridded, in order to avoid extrapolating into areas with no available data. The bound applied to the hydrographic data is slightly different than that applied to the velocity data, as the 100-m ADCPs on the offshore moorings (mounted on the subsurface flotation) returned profiles of the upper water column, even when displaced vertically.

\subsubsection{Additional datasets}

The bathymetric data used in the vertical sections came from a shipboard survey during the initial mooring deployment in 2014, using the 12-kHz Knudsen echosounder on board the $\mathrm{R} / \mathrm{V}$ Knorr. The raw bottom data were regressed and visually selected and smoothed to produce the final bottom topography utilized in this study. The bathymetric data in all base maps are ETOPO2v2 (NGDC, 2006).

Additionally, the European Centre for Medium Range Weather Forecasting (ECMWF) ERA5 atmospheric reanalysis product is used to investigate the effects of atmospheric forcing - both large scale and regional features (Hersbach and Dee, 2016). This new product, which uses the Integrated Forecast System (IFS), has 3-hourly resolution, with $0.25^{\circ}$ grid spacing in latitude and longitude. Earlier studies have demonstrated that IFS-based reanalysis products compare favorably with observations at these latitudes (Renfrew et al., 2002, 2009).

Data from four other mooring arrays, three deployed as part of the OSNAP project and one deployed as part of an earlier field program investigating the EGC/IC south of 
Demark Strait (von Appen et al., 2014b) are used to investigate upstream connections with regard to the seasonality of the water masses in the boundary current. Processing details for the OSNAP data can be found in Lozier et al. (2019) while processing details for the northern EGC/IC array are documented in von Appen et al. (2014b).

\subsection{Results and discussion}

\subsubsection{Mean conditions}

The 4-yr mean, depth-averaged velocity vectors reveal that the predominant flow is toward the northwest, following the isobaths Figure 2-3. The flow is remarkably consistent, as seen by the small standard error ellipses marked in red (decorrelation time scales of 1-3 days, depending on the mooring). Moorings LS2 and LS8 indicate slightly higher variability in flow direction and speed; these signals will be discussed in section 2.3.4 and section 2.3.4, respectively. It is evident that the array bracketed the strongest part of the boundary current, as is shown by the weak mean flow at the offshore-most full-depth mooring (LS8) in Figure 2-3. Keep in mind that moorings DSOW3 and DSOW4 (shaded in light gray in Figure 2-3) occupy only the bottom 500 $\mathrm{m}$ of the water column, and therefore only measure the DWBC. The mean vertical sections presented below indicate that the array also captured the strongest flow in this deep layer.

The 2014-18 mean temperature, salinity, and along-stream and cross-stream velocity vertical sections are presented in Figure 2-4. This is the first year-long rendering of the full boundary current system in the eastern Labrador Sea. The temperature and salinity sections highlight the strong gradient from warm and salty conditions offshore near the surface to cool and fresh waters on the shelf. Off the shelf, the temperature dictates the stratification, with isotherms (and therefore isopycnals) sloping downward progressing onshore as deep as $1500 \mathrm{~m}$. There are two cores of high salinity, one centered near 400-m depth, and a deeper core that slopes upward progressing onshore. The shallow core is associated with the Atlantic-origin water, while the 
deeper core is part of the dense overflow water from the Faroe Bank Channel and Iceland-Faroe Ridge.

The mean along-stream velocity section reveals the bottom-intensified DWBC, centered at LS7 at $2400 \mathrm{~m}$ with velocities exceeding $25 \mathrm{~cm} / \mathrm{s}$. This deep core advects overflow waters with densities greater than $27.8 \mathrm{~kg} / \mathrm{m}^{3}$. Inshore and above the DWBC, the surface-intensified WGC advects the Atlantic-origin water centered at LS4 and LS5, with velocities up to $80 \mathrm{~cm} / \mathrm{s}$. This core of warm, salty water is offset vertically from the maximum WGC velocity and detached from the topography. The WGC can be seen in Figure 2-3 as the two strongest velocity vectors at LS4 and LS5. The WGC also exhibits a slight tendency toward positive cross-stream velocities, meaning that the current is angled slightly toward the interior of the Labrador Sea compared to the rest of the flow. The vertical sections in Rykova et al. (2015) showed the Atlantic-origin water banked against the topography, in contrast to Figure 2-4b where the maximum salinity is separated from the topography by a wedge of lower-salinity water. However, the station spacing of their data was as large as 30 $\mathrm{km}$ in the boundary current. The detached core measured here is consistent with the high-resolution shipboard hydrographic data presented by Lin et al. (2018). It is also consistent with the slightly offshore orientation of the WGC, which would move this water mass away from the topography as it progresses northward. Furthermore, the majority of the data used by Rykova et al. (2015) were collected in summer. It is shown below in section 2.3.4 that the banking of the IW at the OSNAP WG array against the topography is a seasonal feature, present mainly in summer. It is also possible that the position of the water mass evolves as it moves downstream. Myers et al. (2009), only using summer data, do not show high salinity waters banked against the topography at Cape Farewell, but they do observe this feature farther downstream. 

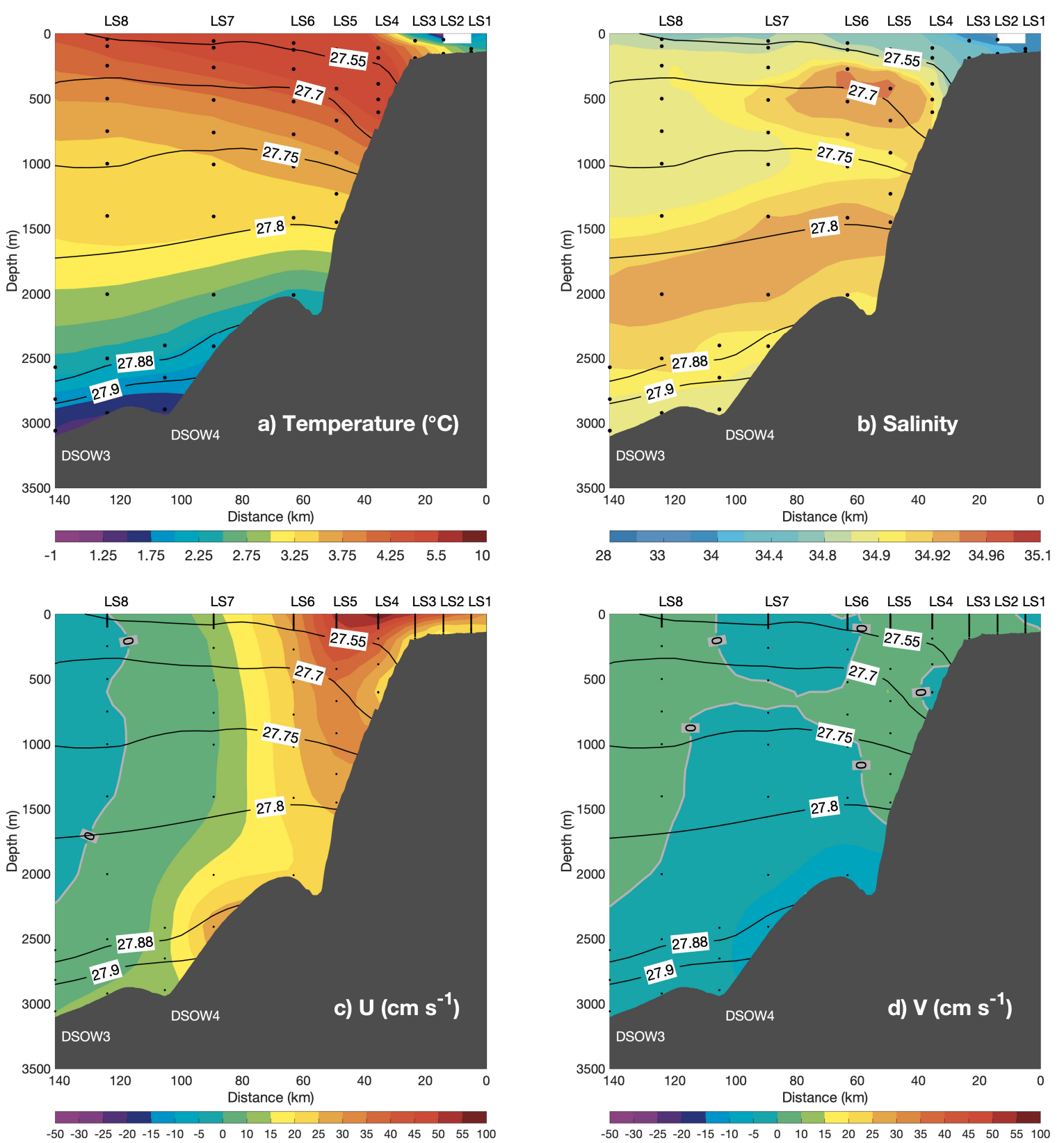

Figure 2-4: 2014-18 mean vertical sections of (a) temperature, (b) salinity, (c) along-stream velocity, and (d) cross-stream velocity, with isopycnals overlaid (black contours; $\mathrm{kg} / \mathrm{m}^{3}$ ). The nominal instrument positions are indicated by the black dots. The $0 \mathrm{~cm} / \mathrm{s}$ velocity contour (thick gray) is indicated in (c) and (d). 
The WGCC is a surface-intensified flow of cold, fresh water that is captured by LS1 and LS2, flowing at $20-30 \mathrm{~cm} / \mathrm{s}$. In the mean the WGCC is merged with the WGC, although instantaneously it often appears as a separate core. Unfortunately, the OSNAP WG array did not extend far enough onto the shelf to bracket the coastal current. This motivated the deployment of two additional tripods inshore of LS1 when the array was serviced in 2018 (data not yet recovered).

\subsubsection{Water masses}

The West Greenland boundary current system advects six different water masses, which are present in varying quantities throughout the year. The water masses are as follows, progressing from shallow to deep: 1) cold and fresh Upper Polar Water (UPW), which is a mixture of buoyant outflow from the Arctic and Greenland runoff (Rudels et al., 2002; Sutherland et al., 2009)-this occupies a wedge that extends from the shelf to roughly mooring LS5; 2) seaward of LS5, Upper Ambient Water (UAW) is found in the top $200 \mathrm{~m}$, which is a mixture of interior water and UPW that has penetrated offshore; 3) warm and salty Irminger Water (IW), which is the Atlantic-origin water that has circulated cyclonically in the subpolar gyre (Lazier et al., 2002; Cuny et al., 2002; Pickart et al., 2005; Myers et al., 2007); 4) weakly stratified Labrador Sea Water (LSW), which is formed by convection in the Labrador and Irminger Seas and exhibits low potential vorticity (e.g Lazier et al., 2002); 5) cold and salty Northeast Atlantic Deep Water (NEADW), which enters the DWBC via the Faroe Bank Channel overflow (Lazier et al., 2002; Yashayaev and Clarke, 2008) and the Iceland-Faroe Ridge (Dickson and Brown, 1994; Beaird et al., 2013); and 6) cold and dense Denmark Strait Overflow Water (DSOW) which is the densest component of the boundary current system (Dickson and Brown, 1994).

The definitions of these six water masses are given in Table 2.1. Given that the composition of the boundary current in this region has not been previously studied, we used upstream definitions as a first attempt at classification, but amended these values to reflect the slightly modified properties in the cores of the water masses at the OSNAP WG line. In particular, the IW and NEADW are fresher than their upstream 
Table 2.1: Water mass definitions used in the study; $S$ is salinity, $\sigma_{\theta}$ is potential density, and $X$ is offshore extent.

\begin{tabular}{|c|c|}
\hline Water mass & Definition \\
\hline Irminger Water (IW) & $S \geq 34.92 \& \sigma_{\theta}<27.74 \mathrm{~kg} / \mathrm{m}^{3}$ \\
Labrador Sea Water (LSW) & $27.68 \mathrm{~kg} / \mathrm{m}^{3}<\sigma_{\theta}<27.8 \mathrm{~kg} / \mathrm{m}^{3} \& S<34.92$ \\
Northeast Atlantic Deep Water (NEADW) & $S>34.92 \& \sigma_{\theta}>27.74 \mathrm{~kg} / \mathrm{m}^{3}$ \\
Denmark Strait Overflow Water (DSOW) & $\sigma_{\theta} \geq 27.8 \mathrm{~kg} / \mathrm{m}^{3} \& S<34.92$ \\
Upper Polar Water (UPW) & $S<34.92 \& X<60 \mathrm{~km}$ \\
Upper Ambient Water (UAW) & $\sigma_{\theta}<27.68 \mathrm{~kg} / \mathrm{m}^{3} \& S<34.92 \& X>60 \mathrm{~km}$ \\
\hline
\end{tabular}

counterparts. For IW, this is likely due to lateral mixing with LSW (e.g Lin et al., 2018). For example, IW has previously been defined as waters between $4^{\circ} \mathrm{C}$ and $5^{\circ} \mathrm{C}$ and salinities around 34.85 - 34.95 (Krauss, 1995; Buch et al., 2004). These definitions were generally applied on the east coast of Greenland. Buch et al. (2004) cite a different water mass, which they call Irminger Mode Water (or modified Irminger Water in the case of Ribergaard 2014), that exhibits slightly colder, fresher properties than its IW counterpart due to mixing along the IW pathway. Freshening of the NEADW could result from vertical mixing with the underlying DSOW and overlying LSW (e.g Yashayaev and Clarke, 2008; Yashayaev and Dickson, 2008). Additionally, it is possible that these previously used definitions are no longer appropriate, due to long-term changes to water mass properties (e.g. Myers et al., 2007).

LSW has a more established definition in the interior Labrador Sea, which we utilize here as the layer of water residing between the $27.68 \mathrm{~kg} / \mathrm{m}^{3}$ and $27.8 \mathrm{~kg} / \mathrm{m}^{3}$ isopycnals (e.g. Clarke and Gascard, 1983; Lazier et al., 2002; Pickart et al., 2003a,b). In previous studies, a distinction was made between upper and deep (also known as classical) LSW in order to represent waters formed convectively in the vicinity of the boundary current as opposed to the interior basin (Rhein et al., 1995; Pickart et al., 1996, 1997, 2002). For the purposes of this study, we will not distinguish between vintages of LSW, as we seek to address the seasonality of all recently formed LSW, regardless of origin. DSOW has historically been classified as all water denser than $27.8 \mathrm{~kg} / \mathrm{m}^{3}$ (Dickson and Brown, 1994), or sometimes more strictly as water denser than $27.88 \mathrm{~kg} / \mathrm{m}^{3}$ (Tanhua et al., 2005). Here we require that DSOW be denser than 

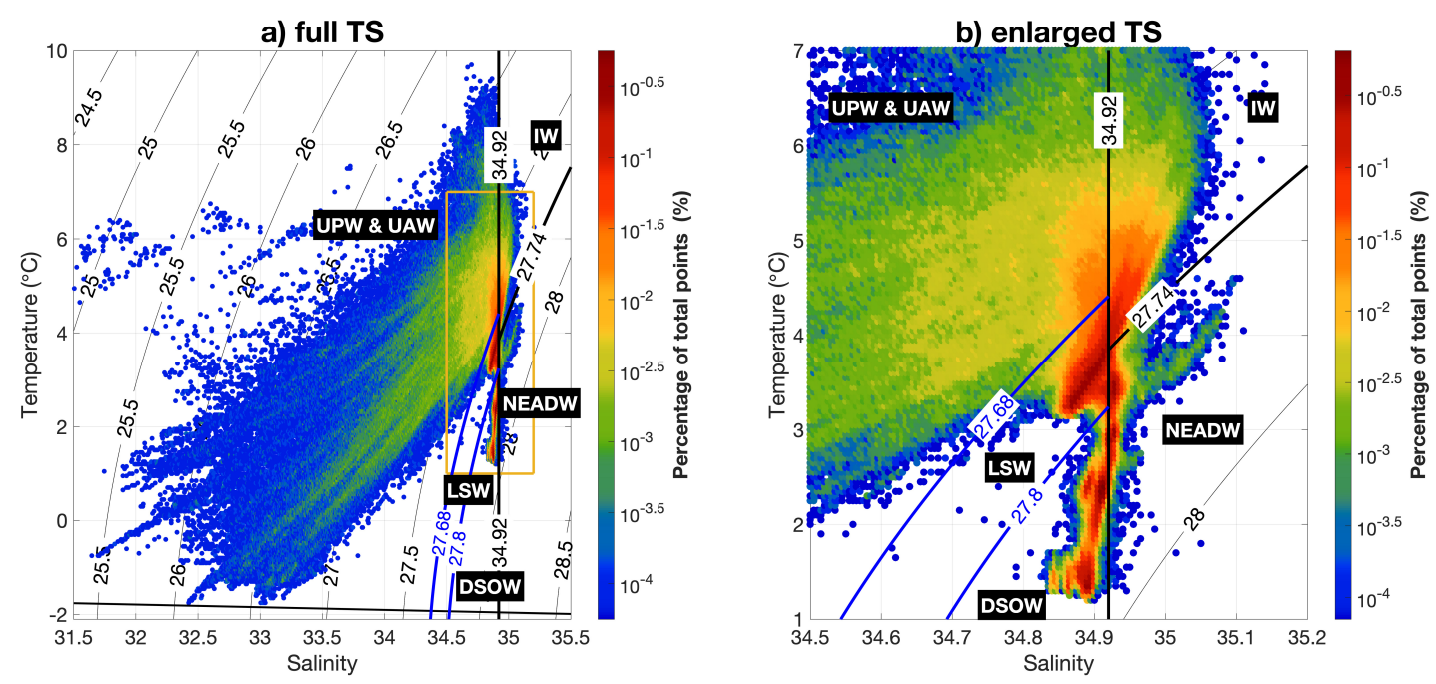

Figure 2-5: (a) 2014-18 volumetric TS diagram, with the identified water masses labeled (see Table 1). UPW and UAW cannot be separated purely in TS space so an offshore distance criterion was also utilized in their definition. The yellow rectangle encompasses the region highlighted in (b). (b) An enlarged view of the densest water masses. Note the logarithmic color axis.

$27.8 \mathrm{~kg} / \mathrm{m}^{3}$, but, as shown below, some of the NEADW is within this isopycnal layer as well.

Computationally, we documented the water masses present at the OSNAP WG line over the 4-yr period as follows. For each hourly vertical section, the grid points associated with the water masses in Table 2.1 were identified. We note that water masses are not classified solely by isopycnal bounds. For example, NEADW is bounded by an isohaline at its deepest extent, which is often denser than $27.8 \mathrm{~kg} / \mathrm{m}^{3}$. Therefore, it is not until the NEADW has been identified that all of the remaining water denser than $27.8 \mathrm{~kg} / \mathrm{m}^{3}$ is assigned to DSOW. This assures that the relatively salty overflow water from the Faroe Bank Channel/Iceland-Faroe Ridge is not mistakenly identified as originating from Denmark Strait. Similarly, the boundary between NEADW and LSW corresponds to an isohaline, which assures that the relatively light, and fresh, LSW is not identified as overflow water.

The resulting volumetric temperature-salinity (TS) diagram for the 4-yr deployment is shown in Figure 2-5a. The light upper waters (UPW and UAW) account for the large spread in properties fresher than 34.92. These water masses exhibit a large 
seasonal cycle in hydrographic properties, as might be expected of surface waters directly subject to varying atmospheric forcing. Focusing on the denser waters (Figure 2-5b), one sees the volumetric modes (i.e., $\mathrm{T} / \mathrm{S}$ bins most commonly sampled by the moorings) associated with LSW and DSOW. In addition, there are large amounts of IW and NEADW. This demonstrates that a sizable fraction of the water denser than $27.8 \mathrm{~kg} / \mathrm{m}^{3}$ stems from the Faroe Bank Channel and Iceland-Faroe Ridge.

To quantify the distribution of the water masses in the vertical, the percentage of time that each grid point sampled a given water type was tallied over the 4-yr mooring deployment (Figure 2-6). The IW, corresponding to the warmest and saltiest water in the boundary current, is found in the middepth portion of the WGC, spanning moorings LS4-LS6. The LSW is found in high concentrations on the offshore side of the array, particularly at LS8 between 500 and $1500 \mathrm{~m}$. It corresponds to a minimum in planetary potential vorticity, as would be expected for recently ventilated water (McCartney and Talley, 1984). However, this vorticity signal is too noisy to use as a robust diagnostic to define the LSW. Notably, there is a large LSW presence at mooring LS5 within the deepest part of the WGC, which is discussed further in section 2.3.4. Below the IW, the deep salinity maximum of the NEADW is present in large quantities between 1250 and $2250 \mathrm{~m}$. Below the NEADW, the DSOW is transported by the core of the DWBC and occupies the water column deeper than $2250 \mathrm{~m}$. 

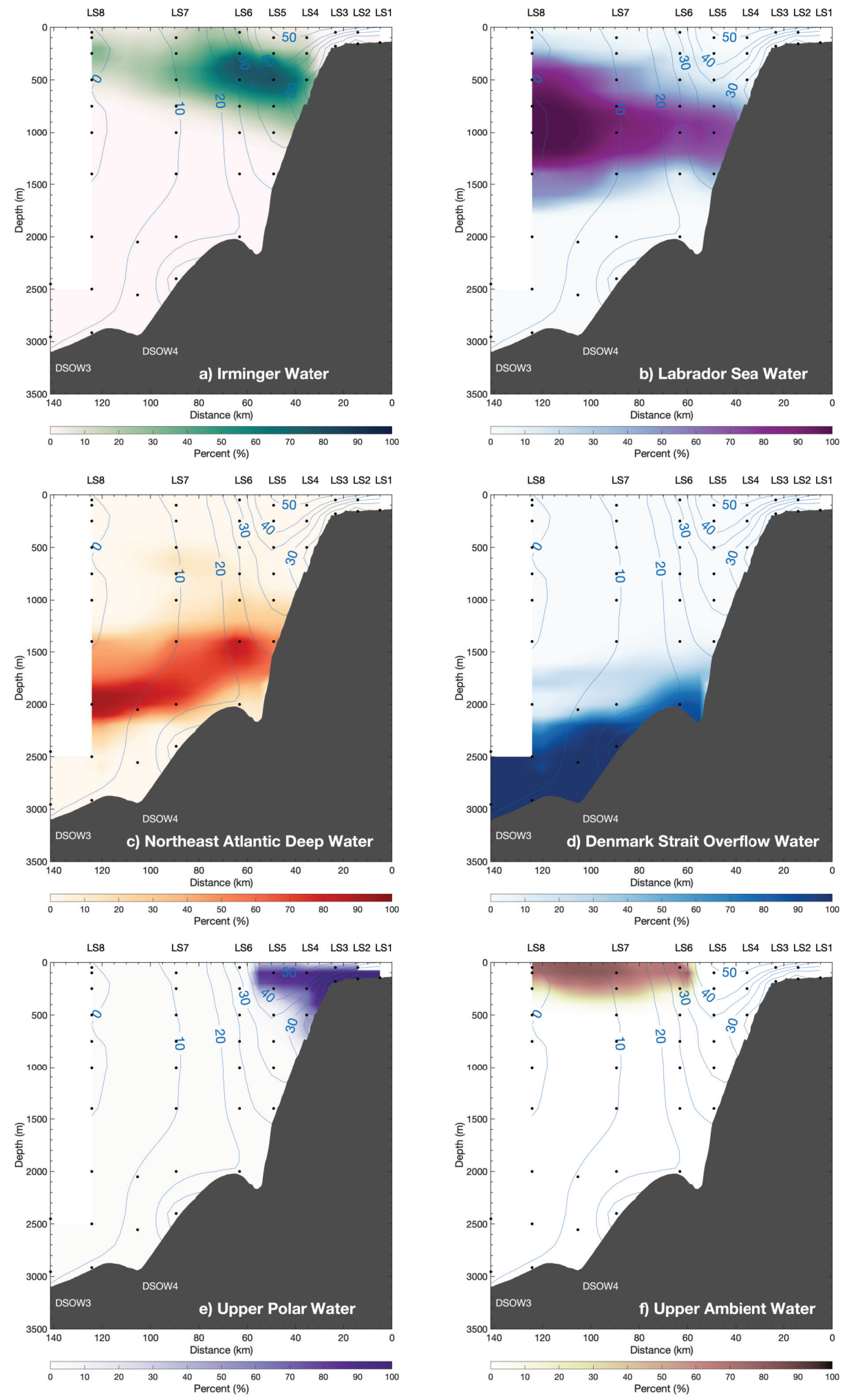

Figure 2-6: Locations of the six water masses sampled. The percentage (\%) of time that each grid point sampled a particular water mass over the 4-yr period is tallied. 


\subsubsection{Volume transport}

The 4-yr mean volume transport across the full array, computed by calculating the hourly transport and subsequently averaging these data, is $31.1 \pm 7.4 \mathrm{~Sv}\left(1 \mathrm{~Sv} \equiv 10^{6}\right.$ $\mathrm{m}^{3} / \mathrm{s}$ ), where the uncertainty is the standard deviation. The calculated integral time scale is 3 days, which results in a standard error of $0.4 \mathrm{~Sv}$. The closest comparison to this mean value is the average transport reported by Pickart and Spall (2007) using repeat occupations of the AR7W section from 1990 to 1997, adjusted with an inverse constraint. They computed a mean transport of 35.5 Sv. However, they did not have data shoreward of the 700-m isobath. Subtracting the transport measured here inshore of that isobath reduces our 4-yr value to $30.1 \mathrm{~Sv}$. The discrepancy between our value and the Pickart and Spall (2007) estimate (30.1 vs $35.5 \mathrm{~Sv}$ ) is sizable. However, the Pickart and Spall (2007) value is far less robust (computed using 10 vertical sections versus more than 30000 hourly vertical sections in our mooring dataset), and the spatial coverage is different. Nonetheless, the Pickart and Spall (2007) value falls within the envelope of one standard deviation of the transport calculated in this study.

The Lagrangian float study of Lavender et al. (2000) revealed the presence of a trough of absolute dynamic topography encircling the Labrador Basin, just offshore of the boundary current system. This corresponds to a series of cyclonic recirculation gyres that abut the boundary current. One of the gyres is situated offshore of the OSNAP WG array (see also Pickart and Spall 2007). In the along-stream velocity section of Figure 2-4, one sees that the zero-velocity contour is located just shoreward of mooring LS8. This implies that, in the mean, our mooring array captured the northward limb of this local recirculation gyre (instantaneously, this is not always the case). Here we take the boundary between the recirculation gyre and the boundary current to be the velocity contour corresponding to $10 \%$ of the maximum alongstream flow of the WGC at every time step. In the mean this corresponds to a value of approximately $8 \mathrm{~cm} / \mathrm{s}$. This is a reasonable choice in light of the results of Pickart and Spall (2007), who were able to determine this boundary objectively becasue their 
Table 2.2: Four-year mean transports of the different water masses, with their standard deviations, separated into the boundary current portion and the recirculation portion. The standard errors are presented in parentheses.

\begin{tabular}{|c|c|c|}
\hline Water mass & Boundary current transport $(\mathrm{Sv})$ & Recirculation transport $(\mathrm{Sv})$ \\
\hline Total & $28.8 \pm 7.1(0.3)$ & $1.2 \pm 2.4(0.2)$ \\
IW & $5.6 \pm 3.8(0.6)$ & $0.1 \pm 0.3(0.02)$ \\
NEADW & $5.5 \pm 3.3(0.5)$ & $0.4 \pm 0.6(0.04)$ \\
LSW & $7.5 \pm 3.9(0.5)$ & $0.3 \pm 1.4(0.06)$ \\
DSOW & $5.0 \pm 2.4(0.3)$ & $0.5 \pm 0.5(0.02)$ \\
UPW & $4.3 \pm 1.7(0.2)$ & $0.01 \pm 0.06\left(8.8 \times 10^{-4}\right)$ \\
UAW & $2.0 \pm 1.5(0.1)$ & $0.01 \pm 0.05(0.02)$ \\
$\sigma_{\theta}>27.8 \mathrm{~kg} / \mathrm{m}^{3}$ & $8.3 \pm 2.8(0.2)$ & $0.8 \pm 0.8(0.04)$ \\
\hline
\end{tabular}

section extended across the entire basin and balanced mass. Further rationale for our choice is presented below in section 2.3.4.

The mean transports (boundary current and recirculation) for the different water masses computed using the OSNAP WG array are presented in Table 2.2, based on the water mass definitions in Table 2.1. While numerous previous studies have estimated the transport of the different components of the West Greenland boundary current system, only a select number have broken this down by water mass constituents. Hence, there is limited basis for comparison with the results presented here. The exception is the transport of overflow water. According to the historical definition of overflow water (denser than $27.8 \mathrm{~kg} / \mathrm{m}^{3}$, Dickson and Brown 1994), we calculate 8.3 $\pm 2.8 \mathrm{~Sv}$, compared to $10.8 \pm 4.9 \mathrm{~Sv}$ calculated at the OSNAP East line northeast of Cape Farewell using the first two years of data (Hopkins et al., 2019). Using only the first two years of WG data, to be consistent with the Hopkins et al. (2019) study, the boundary current overflow water transport is $8.8 \pm 2.8 \mathrm{~Sv}$ at OSNAP WG. Although the standard deviations are large, this suggests that there is a net loss in transport of the dense water as it rounds Cape Farewell and interacts with Eirik Ridge, consistent with the results of Holliday et al. (2009) who computed a 30\% recirculation of transport in this density class at Cape Farewell. It is also in line with the findings of Hall et al. (2013) who computed a transport of 8.6 Sv on the eastern end of the AR7W line for waters denser than $27.8 \mathrm{~kg} / \mathrm{m}^{3}$. The total transport of NEADW and 

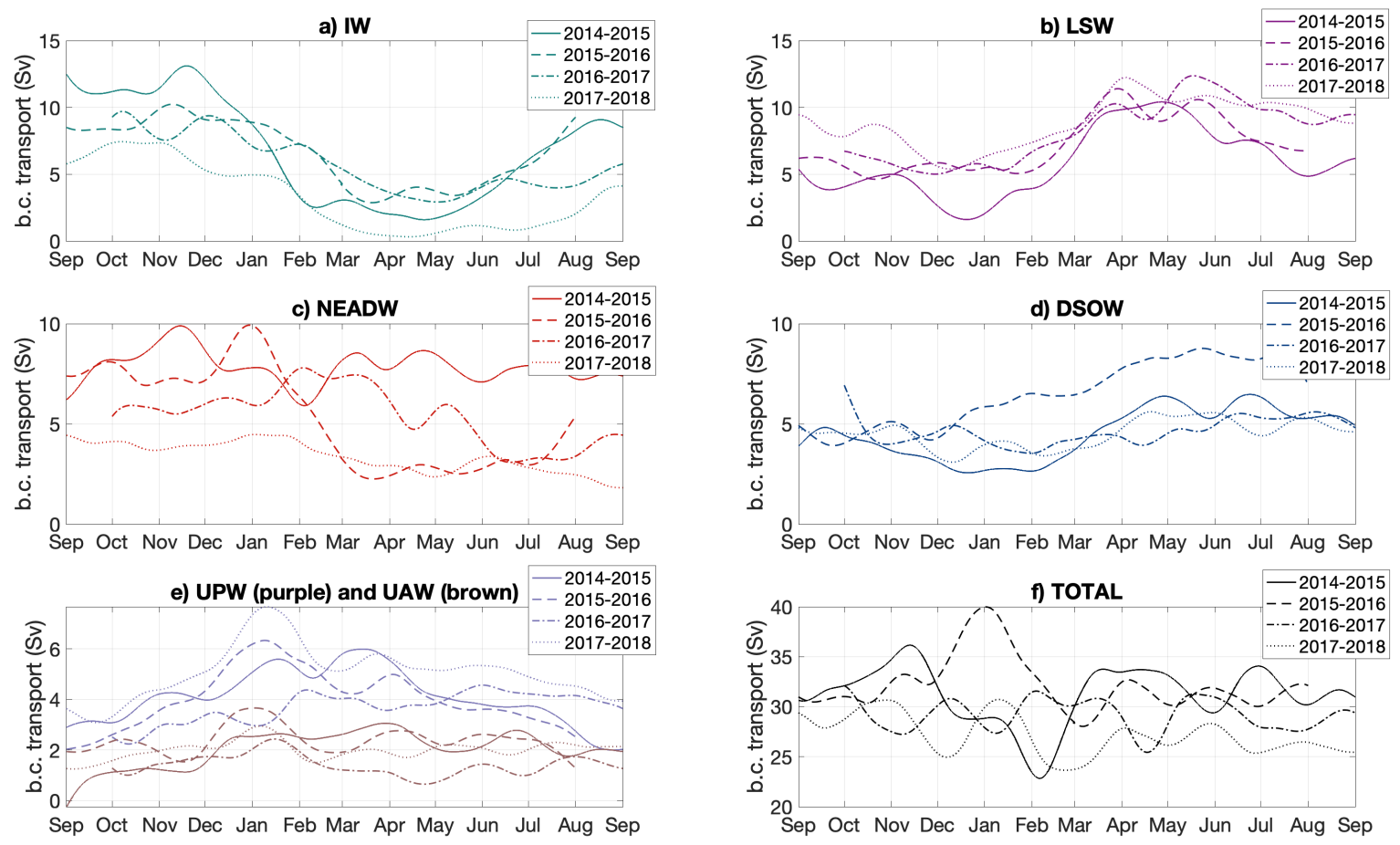

Figure 2-7: 2014-18 boundary current transport time series for the individual water mass components, as well as the total boundary current transport. The hourly data have been low-pass filtered with a 30-day Butterworth filter. Each year is plotted with a different line type (see the legend).

DSOW found here is $10.5 \pm 3.9 \mathrm{~Sv}$ (Table 2.2). We conclude, then, that waters stemming from the overflows across the Greenland-Scotland Ridge contribute 2.2 Sv more than one would obtain with the historical density definition. Interestingly, our results imply a similar contribution (after entrainment) from the eastern overflow versus the western overflow: $5.5 \pm 3.3$ for the NEADW versus $5.0 \pm 2.4$ for the DSOW.

The yearly time series of boundary current transport for the different water mass components, along with the total boundary current transport, are shown in Figure 27, where a 30-day low pass has been applied. While the total transport of the West Greenland boundary current system does not exhibit a seasonal signal, the individual water mass components do. This is because the individual components compensate each other. For example, when the transport of IW is strong, the transport of LSW 
is weak (cf. Figure 2-7a,b, which is discussed in more detail in subsection 2.3.4). Additionally, when the transport of NEADW declines, the transport of DSOW increases (cf. Figure $2-7 \mathrm{c}, \mathrm{d}$ ). This transport variability, as well as the variability in hydrographic properties, motivate a seasonal analysis of the boundary current system to understand how its composition and transport vary on a month-to-month basis. This will shed light on the production and export of ventilated waters and the seasonal transformation of these waters.

\subsubsection{Seasonality}

\section{Labrador Sea Water}

Using all of the grid points defined as LSW, the mean temperature, salinity, and boundary current transport were computed hourly, and the resulting time series were low-pass filtered using a 60-day second-order Butterworth filter to highlight the seasonal variability (Figure 2-8). This reveals that the LSW is coldest and freshest in spring (May-July), slightly after its transport peaks in April/May. The hydrographic signal is consistent with active convection ventilating the LSW during the previous winter. Notably, the changes in transport are predominantly due to increases in the amount of LSW present (referred to from here on as area), not to changes in the velocity of the LSW.

Seasonal renditions of the bin count tallies shown in Figure 2-6 indicate that, during the winter months, LSW is prevalent at the offshore end of the array (LS7 and LS8), but can also be found within the WGC. In fact, at times there are two distinct cores of LSW - one within the WGC and one at the edge of the array - with a minimum between the two features (Figure 2-9a). In this configuration the large offshore presence of LSW is confined to the recirculation gyre. The gyre tends to trap water, allowing it to be subject to air-sea heat loss for a sustained period. Deep mixed layers are indeed found locally within the gyre (Lavender et al., 2002). Figure 2-9a

offers further justification for our choice of the boundary between the gyre and the boundary current (note the $8 \mathrm{~cm} / \mathrm{s}$ velocity contour in the figure). 

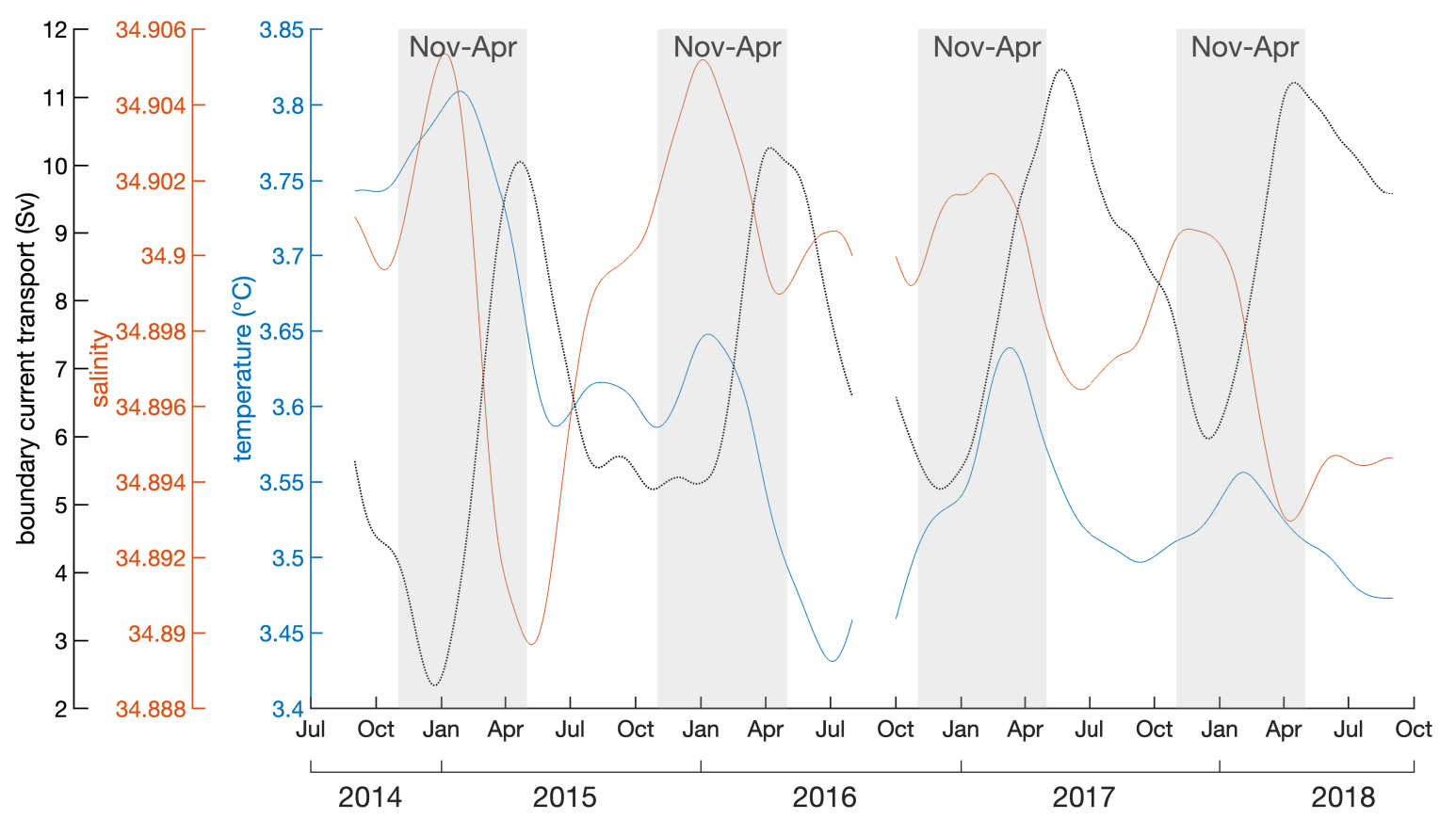

Figure 2-8: Temperature, salinity, and transport of LSW low-passed with a 60-day Butterworth filter. For ease of presentation, the cold months of the year (November-April) are indicated by gray shading. The data gap in August 2016 is due to the mooring turnaround.

The double core structure of Figure 2-9a implies that there is an upstream source of LSW that is distinct from the LSW in the neighboring recirculation gyre that enters the current through mixing/entrainment. The instances of two cores are intermittent and account for approximately $25 \%$ of the 4 -yr record. Interestingly, these occurrences tend to be present in early winter, well before the springtime peak in LSW transport. Later in the season there is a single core (Figure 2-9b), which indicates that LSW is penetrating into the boundary current from offshore.

To investigate this further, we divided the LSW signal into $\mathrm{LSW}_{b c}$ and $\mathrm{LSW}_{\text {recirc }}$, where the subscripts represent whether the water mass is found within the WGC or within the adjacent recirculation gyre, using the 10\% velocity criterion as described above. This partitioning demonstrates that the seasonal timing of the hydrographic signal remains the same whether the water is within the boundary current or gyre (not shown). However, the LSW within the boundary current tends to be slightly 

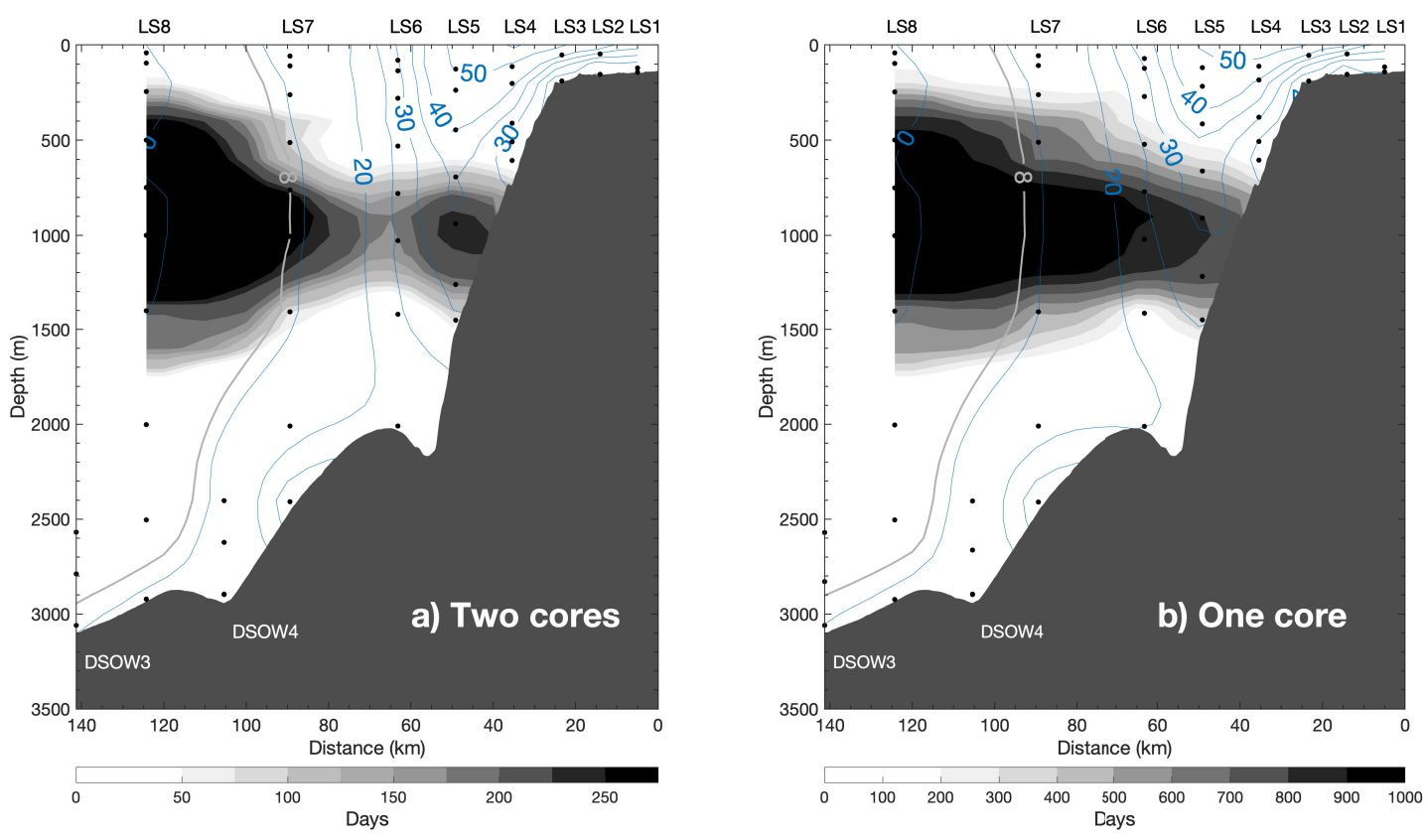

Figure 2-9: Number of days (gray shading) with (a) two cores of LSW and (b) one core of LSW, with the mean velocity contours in the two periods overlaid (blue contours). The $8 \mathrm{~cm} / \mathrm{s}$ velocity contour is shown in gray, which corresponds to the mean division between the boundary current and adjacent recirculation gyre (see text). Note the different gray-shading scales in the two panels.

warmer and saltier. The $\mathrm{LSW}_{b c}$ transport dominates that of $\mathrm{LSW}_{\text {recirc }}$ : the 4-yr mean transport of $\mathrm{LSW}_{b c}$ is $7.5 \pm 3.9 \mathrm{~Sv}$ compared to $0.3 \pm 1.4 \mathrm{~Sv}$ for the $\mathrm{LSW}_{\text {recirc }}$. The latter exhibits no seasonal cycle and has minimal variability. We note that, a priori, this large difference was not obvious because the area of the LSW recirc is far greater than that of the $\mathrm{LSW}_{b c}$ (Figure 2-6). Hence, even though the $\mathrm{LSW}_{b c}$ transport dominates because of its velocity signal (due to the seasonality in LSW presence in the fast-moving core of the WGC), its variability in transport - and that of the total LSW - is due to its area signal.

What is the origin of the LSW within the core of the WGC that did not emanate locally from mixing/entrainment from the recirculation gyre? Le Bras et al. (2020) demonstrate that newly ventilated LSW enters the boundary current east of Cape Farewell due to along-isopycnal ventilation, i.e., via isopycnals that outcrop seaward of the boundary current in the interior of the Irminger Sea. They identify two water masses, upper and deep Irminger Sea Intermediate Water, the latter of which is 
similar in definition to our LSW. Le Bras et al. (2020) argue that both types of newly ventilated water penetrate the boundary current through eddy exchange. It is likely that the LSW we observe within the WGC at OSNAP WG (the inner core in Figure 29a) is advected in the boundary current around Cape Farewell. Recall that the inner core tends to be present early in the winter, before the extensive local penetration of LSW occurs from the recirculation gyre (Figure 2-9b). An explanation for this is that LSW production in the southwest Irminger Sea is driven by the forward Greenland tip jet, which causes strong air-sea heat fluxes (Våge et al., 2008). In contrast, the heat fluxes in the eastern Labrador Sea due to the basin-scale westerly winds are more moderate, since the air has warmed so far from the Labrador landmass. Hence, convection on the eastern side of Cape Farewell may develop more rapidly than that on the western side - although as the winter season progresses, the convection within the recirculation gyre clearly dominates (Figure 2-9b).

\section{Irminger Water}

The temperature, salinity, and transport time series of the IW are shown in Figure 210. All of the IW properties exhibit peak values in midfall, between September and November, and minima in late winter, between March and May. IW originates in the North Atlantic Current as subpolar mode water formed during the winter months (McCartney and Talley, 1982, 1984; McCartney, 1992) and circulates around the subpolar gyre, eventually progressing into the Irminger and Labrador Seas in the upper portion of the water column (Krauss, 1995; Cuny et al., 2002; Våge et al., 2011). It is of interest to understand what sets the seasonal timing of the IW observed at the OSNAP WG site. Specifically, where and how are these properties set and when were the waters last in direct contact with the atmosphere?

To address this, we utilize data from five mooring arrays to investigate the seasonal signal of IW around the perimeter of the Irminger Sea (Figure 2-11). The arrays MA1, MA2, and MA4 are also part of the OSNAP mooring line, and thus are synchronous in time with our measurements (2014-16). The MA3 array was deployed from 2007 to 2008 (von Appen et al., 2014b,a; Harden et al., 2014b). At each array we identified 

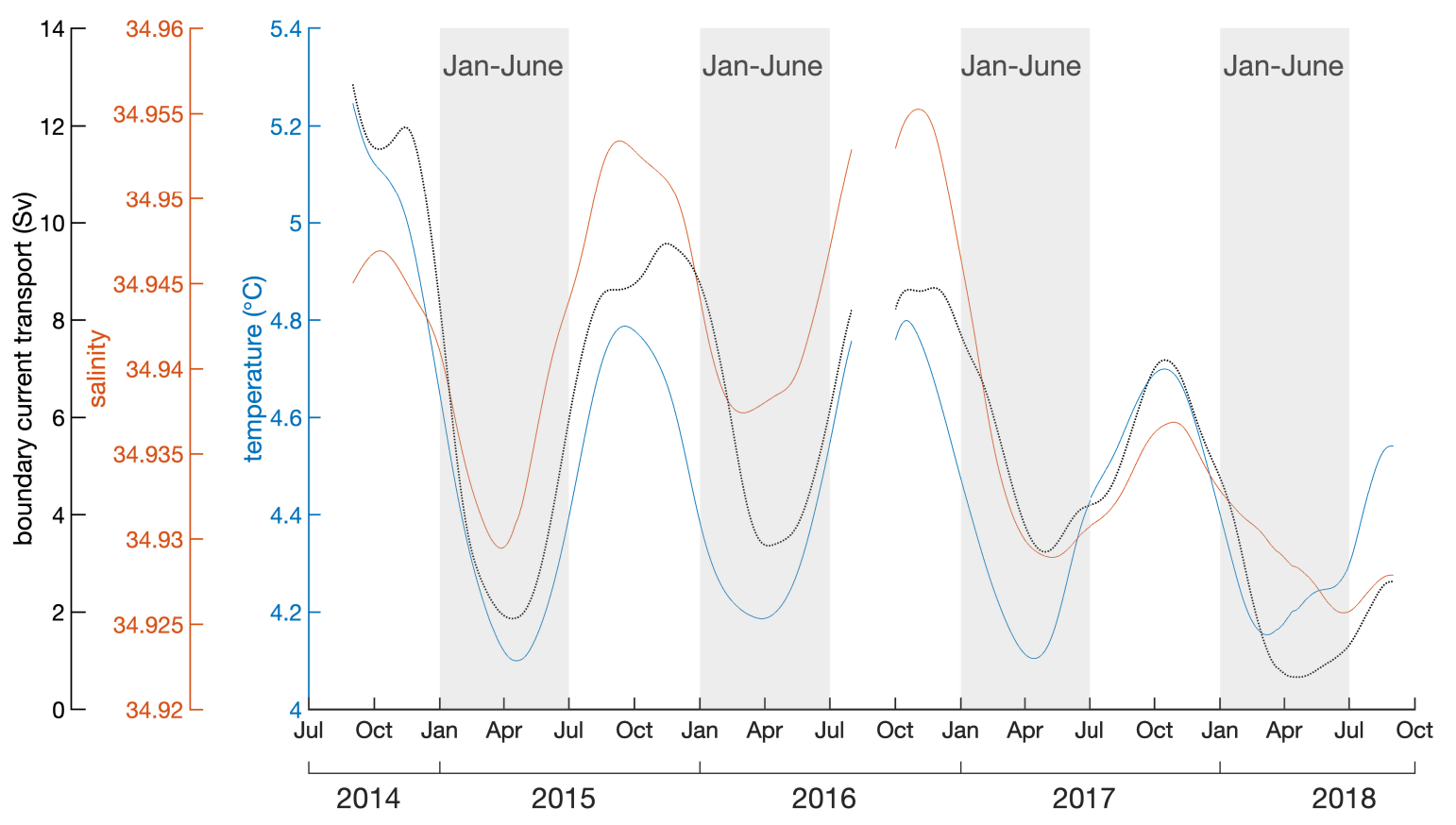

Figure 2-10: As in Figure 2-8, but for IW. For ease of presentation, the periods of minimum temperature, salinity, and transport have been highlighted (January-June).

a mooring in the core of IW (indicated by the black circles in Figure 2-11). The temperature, salinity, and density records at these sites revealed sustained wintertime convection down to at least $500 \mathrm{~m}$ at MA1, MA2, and MA3.

An example of this is shown in Figure 2-11 for the MA3 array, which contained moored CTD profilers. The development of the winter mixed layer over the course of the deployment can be seen by the cooling, freshening, and densification of the surface warm and saline layer. By the end of April the mixed layer had deepened to 500-600 m, ventilating the IW. The same thing occurred at MA1 and MA2 (which was deduced using discrete TS sensors). At MA4, intermittent vertical convection was observed down to $300 \mathrm{~m}$ for periods of 1-2 weeks at a time. Le Bras et al. (2020) demonstrated that the IW at this array is also ventilated laterally due to the outcropping of isopycnals seaward of the boundary current, as noted above. These results demonstrate that the IW is directly ventilated during winter along its pathway around the Irminger Sea. At each site along the pathway the mixed layer product is 


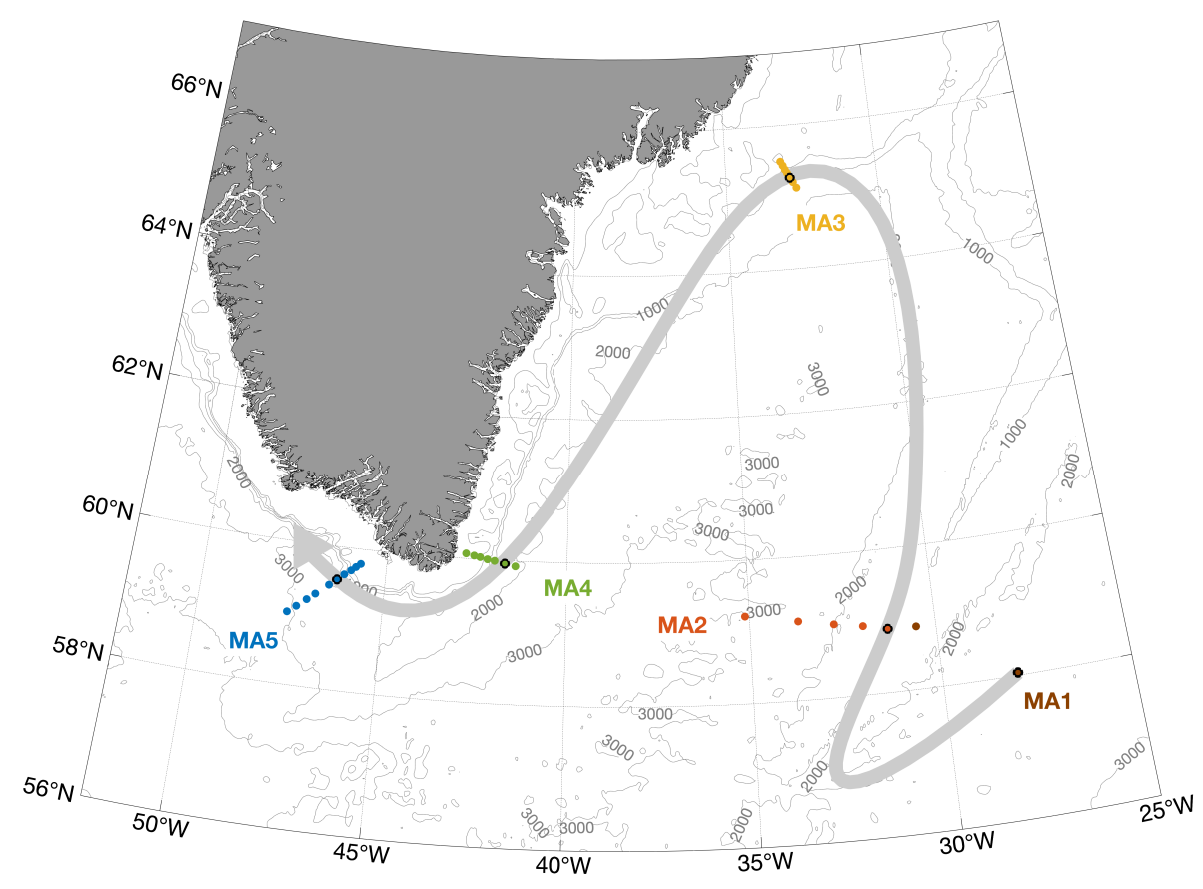

Figure 2-11: The five mooring arrays used in the seasonal analysis of IW. The shaded arrow represents the schematic pathway of the boundary current. The specific mooring in the core of the IW at each array is outlined in black. MA5 is the OSNAP WG array.

colder, fresher, and denser than at the previous array. This is in agreement with the study of Brambilla et al. (2008) that documented the evolution of this mode water, using historical shipboard data, as it circulated around the subpolar gyre, as well as with the coupled modeling and observational results of Grist et al. (2014).

At MA5 (the OSNAP WG array), however, there is no evidence of local convection into the IW layer at any of the moorings. This is because, between MA4 and MA5, the IW has subducted to a depth of $500 \mathrm{~m}$ and is capped by a layer of fresh water (UPW; Figure 2-4b). This layer, together with the more moderate atmospheric forcing in the eastern Labrador Sea, prohibits convection from penetrating into the IW layer. Consistent with this subduction of IW, the midfall maxima of IW properties found at MA5 are roughly in-phase with the seasonality of the Atlantic-origin water measured at Davis Strait (e.g. Curry et al., 2014). On the Labrador slope the air-sea heat fluxes 

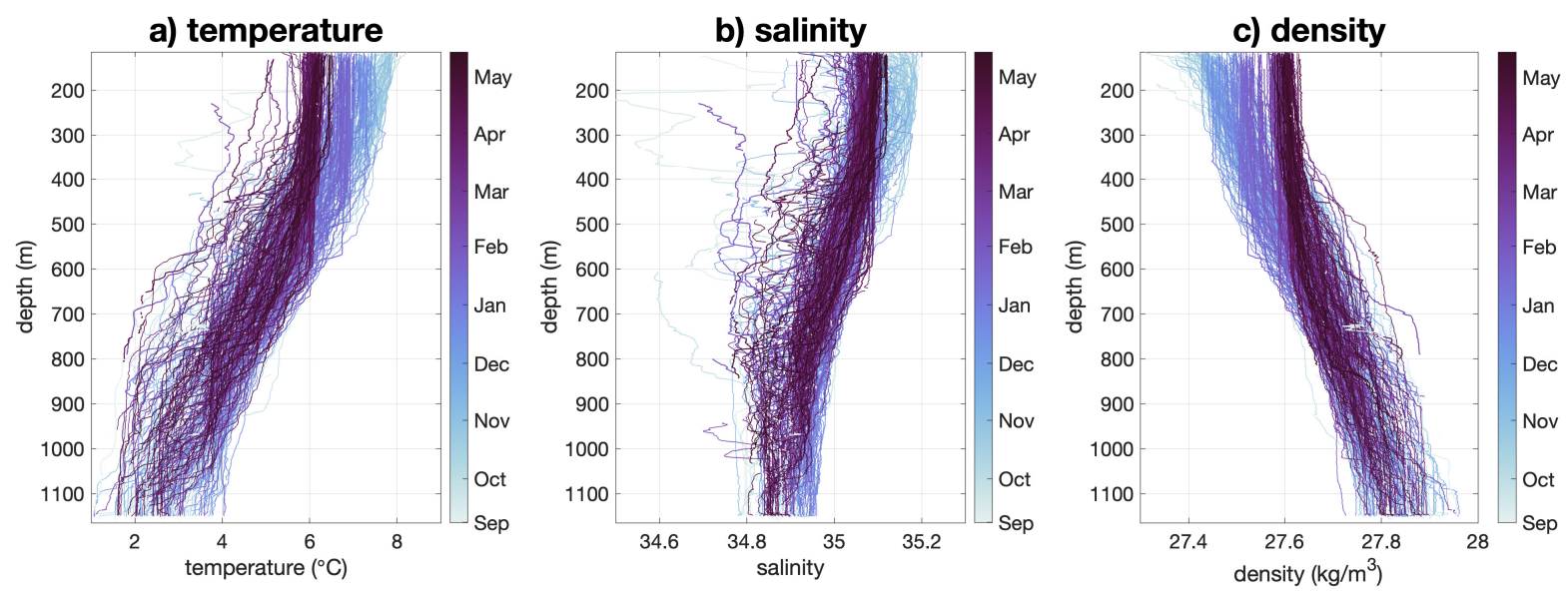

Figure 2-12: Profiles of (a) temperature, (b) salinity, and (c) density every $6 \mathrm{~h}$ at the mooring in the central part of the IW at array MA3 (circled black in Figure 2-11). The profiles are shaded by date from September through May.

are strong enough that the IW layer is ventilated there (Pickart et al., 2002). The pronounced freshwater surface layer (UPW) at the OSNAP WG site, which inhibits ventilation of the IW, is thought to be due in part to freshwater emanating locally from the shelf. Lin et al. (2018) demonstrated that the coastal current is diverted to the edge of the shelf as it rounds Cape Farewell, and that baroclinic instability can flux the freshwater offshore from the WGCC to the surface of the WGC.

These results suggest that the seasonal IW signatures of temperature and salinity at the OSNAP WG array, documented in Figure 2-10, are determined by the cumulative ventilation that occurs upstream in the Irminger Sea, with the final characteristics being set in the region of MA4. Comparing the seasonal signals of IW temperature, salinity, and density at MA4 and MA5, the lagged correlations of these properties exhibit peak values at 20 days, significant at the $95 \%$ confidence level. The distance between MA4 and MA5 along the pathway in Figure 2-11 is roughly $350 \mathrm{~km}$. This implies an advective speed of approximately $20 \mathrm{~cm} / \mathrm{s}$, which is consistent with the velocity signature of the IW in the EGC/IC and WGC.

The IW transport at OSNAP WG exhibits the same seasonal signal as the temperature and salinity, with maximum values in fall and minimum values in spring (Figure 2-10). As with LSW, the variability in transport of IW is driven by changes in the amount of the water present (cross-sectional area), not by changes in its veloc- 


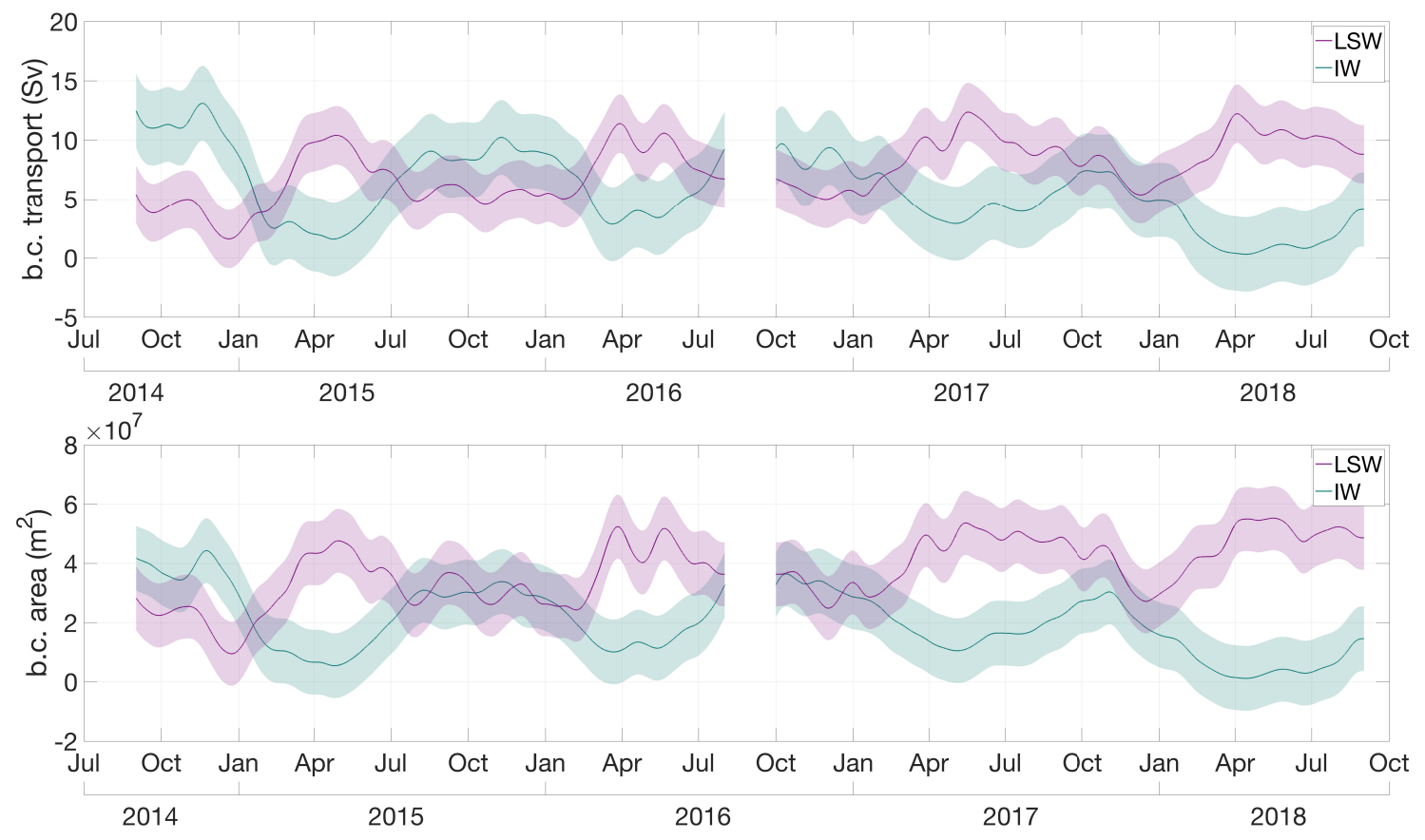

Figure 2-13: (a) Time series of LSW and IW transport, with standard deviation shaded. (b) Time series of area of LSW and IW, with standard deviation shaded. The data gap in August 2016 is due to the mooring turnaround.

ity. Comparing the transports and areas of the two water masses reveals that they are out of phase (Figure 2-13a,b). This is due to the fact that, when the IW is freshened and cooled during winter, part of it is converted to LSW. As described above, some of this conversion is due to the strong atmospheric forcing directly ventilating the IW layer in the boundary current. The remaining conversion is due to LSW laterally mixing into the boundary current from the recirculation gyre in late spring and modifying the IW. Both mechanisms lead to less transport of IW and greater transport of LSW, hence the out of phase relationship between the two time series - driven by the cross-sectional area of the two water masses (Figure 2-13b).

We return to the fact that Rykova et al.'s (2015) results show the IW banked against the topography in the WGC, whereas in our mean section the IW is isolated in a core between 400 and $600 \mathrm{~m}$ without connection to the topography (Figure 24b). Inspection of our time series of vertical sections reveals that, in late summer and early fall, the IW does make contact with the topography intermittently. This is the 
time period when the IW is warmest, saltiest, and greatest in transport (Figure 210). However, over the course of the winter, as this water is modified and some of it transformed into LSW, this newly formed LSW occupies the bottom portion of the WGC and replaces the IW as the water mass banked against the topography. Since most of the hydrographic sections used by Rykova et al. (2015) were occupied in summer, their mean fields were biased toward the configuration where IW is in contact with the topography.

\section{Upper Polar Water}

The temperature and salinity of the UPW at the OSNAP WG array exhibit maxima in October-November and minima in March-April of each year (Figure 2-14). When the UPW is coldest and freshest its transport is greatest. As with the IW, we seek to determine what factors dictate this seasonal timing. Importantly, we note that, unlike the LSW and IW, the transport of UPW is influenced by both the speed of the water and its cross-sectional area.

Previous studies have demonstrated that the transport of polar water in the EGCC is dependent on the along-stream wind stress, both through local and remote forcing. With regard to the former, downwelling-favorable winds along the east coast of Greenland intensify the EGCC via Ekman setup (Sutherland and Pickart, 2008; Daniault et al., 2011). With regard to the latter, the sea surface height anomaly generated by such winds trigger coastally trapped waves which propagate southward and lead to the enhancement of the EGCC downstream of the region of strong winds (Harden et al., 2014a,b, 2016; Le Bras et al., 2018). Seasonally, the wind stress field peaks in fall in the Irminger Sea, which is consistent with the increased EGCC transport measured at the MA4 array during that season (Le Bras et al., 2018). We now investigate the role of wind forcing for the WGCC using the ERA5 wind stress fields.

We considered first if the local winds influence the UPW transport at the OSNAP WG site. Using the component of wind stress parallel to the West Greenland coast, the velocity of UPW and the wind stress were compared. This revealed that there is indeed a UPW response to intensification of local winds on synoptic time scales 

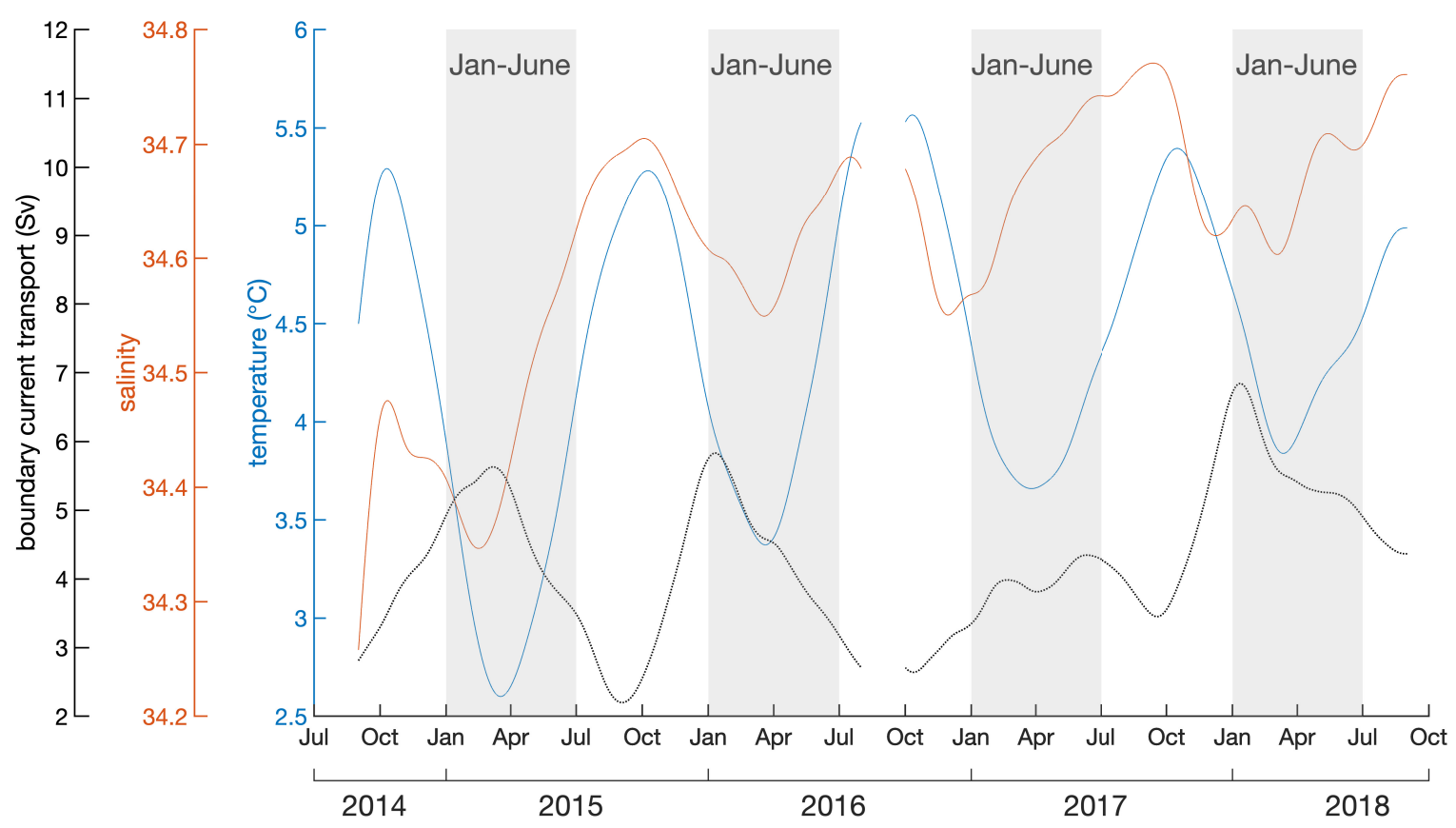

Figure 2-14: As in Figure 2-8, but for UPW. For ease of presentation, the winter and spring months have been highlighted (January-June).

(less than a day). This is presumably driven by storms: for example the reverse Greenland tip jet (Moore and Renfrew, 2005; Martin and Moore, 2007; Ohigashi and Moore, 2009), which would lead to downwelling events and Ekman set up that would impact the along-stream UPW velocity. On seasonal time scales, however, which is our interest here, there is no evidence of a local response.

Next, we considered remote forcing associated with the barrier winds along the east coast of Greenland. Specifically, we correlated the monthly mean UPW transport values at 0-, 1-, and 2-month lags with the 30-day low-passed ERA5 wind stress, rotated such that positive wind stress is along the east coast of Greenland, toward the southwest. This demonstrates that the transport is significantly correlated with the upstream along-coast wind stress at all three lag times (Figure 2-15, top row; positive correlation indicates wind stress leads WGCC signal). At time scales longer than this, the correlation is insignificant. As noted above, both the cross-sectional area of the UPW and its velocity influence the transport variability. Therefore, we 

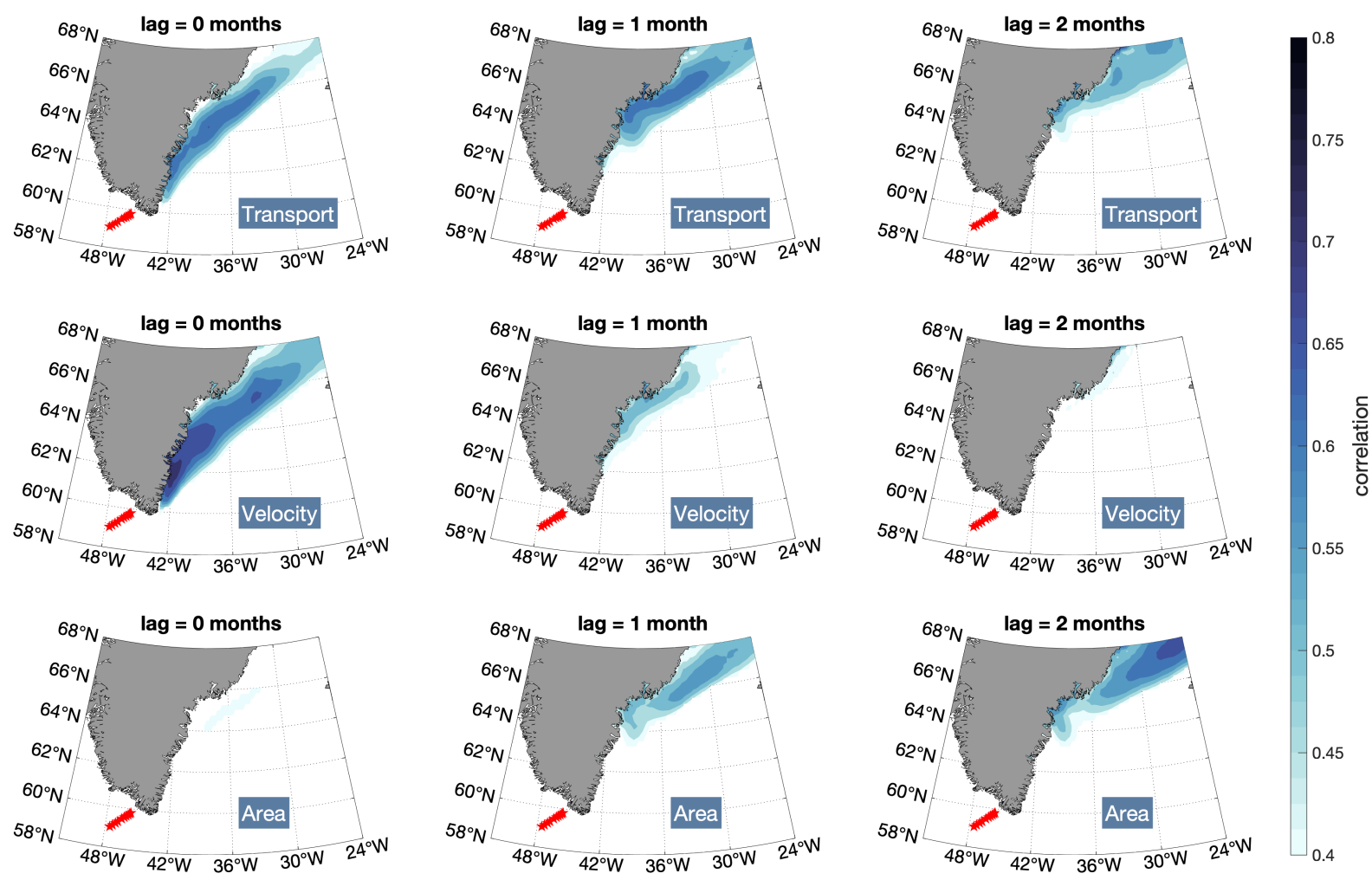

Figure 2-15: Correlation maps of monthly mean UPW (top) transport, (middle) velocity, and (bottom) area with along-stream wind stress. Positive along-stream wind stress is oriented along the coast of East Greenland. Positive correlation indicates wind stress leads the signal at the mooring array. Only regions of correlations with $p$ value $<0.01$ are shaded.

made analogous correlation maps for these two variables. The correlation between along-coast wind stress and the spatially averaged UPW velocity is strongest at 0 lag (Figure 2-15, middle row), whereas the correlation of along-coast wind stress and UPW area is strongest at 1-2-month lags (Figure 2-15, bottom row).

In an effort to explain this, we considered the coastal trapped wave model of Brink (2006). The model requires the cross-slope shape of the topography, the velocity structure, and the background stratification of the current in order to solve for the wave speeds. We used a simplified bathymetric profile, together with a surface-intensified current and a background buoyancy frequency, all based on the mean mooring data. 
Additionally, the user can select whether the model solves for a rigid lid or free surface, for open or closed boundaries, and for a strong or weak value for bottom friction. We chose a free surface, with a closed boundary on the onshore side of the domain and open boundary on the offshore side of the domain. For bottom friction we used a value of $0.05 \mathrm{~cm} / \mathrm{s}$ (weak friction). The solution for the coastal trapped barotropic wave speed is

$$
c_{o}=\frac{f L\left(H-h_{s}\right)}{H}
$$

where $L$ is the shelf width $(35 \mathrm{~km}), f$ is the Coriolis parameter $\left(1.25 \times 10^{-4} \mathrm{~s}^{-1}\right), H$ is the basin depth (1000 m), and $h_{s}$ is the shelf depth (200 m) (Brink, 1982). Based on these values, the barotropic wave speed is $3.5 \mathrm{~m} / \mathrm{s}$. This is consistent with the short time lag between the wind stress and velocity of the UPW (Figure 2-15, middle row). Specifically, the distance between $65^{\circ} \mathrm{N}$ along the East Greenland coast to the OSNAP WG mooring array is $1100 \mathrm{~km}$. This means that the barotropic wave, traveling at $3.5 \mathrm{~m} / \mathrm{s}$, would propagate between these locations in 4 days. It implies that the sea surface height anomaly caused by the intensification of the winds along the east coast of Greenland travels at the barotropic coastal trapped wave speed to the OSNAP WG site, and the these values, the barotropic wave speed is $3.5 \mathrm{~m} / \mathrm{s}$ WGCC adjusts accordingly.

The area signal instead travels slower, taking 1-2 months to travel from the Denmark Strait region to the OSNAP WG array site (Figure 2-15, bottom row). The Brink (1982) model is again used to compute the baroclinic wave speeds. The third mode has a phase speed of $\mathrm{c}=22.6 \mathrm{~cm} / \mathrm{s}$, which is consistent with the time scale of the calculated area signal propagation (56 days to travel the $1100 \mathrm{~km}$ at this phase speed). We note that Pickart et al. (2011) found a similar result regarding wave adjustment of the Beaufort Shelfbreak Jet due to remote wind forcing. In particular, the adjustment of the sea surface height occurred quickly, on the time scale of the barotropic mode, while the adjustment of the pycnocline took place on a slower time scale corresponding to the third baroclinic mode wave speed predicted by the Brink (1982) model. In our case the area of the UPW is dictated by the lateral displace- 
ment of the pycnocline associated with the WGCC, i.e., the movement of the 27.55 $\mathrm{kg} / \mathrm{m}^{3}$ isopycnal, which corresponds to the seaward boundary of the wedge of UPW (Figure 2-4). When the area is large, this isopycnal is displaced offshore, and when the area is small, this isopycnal is found closer to the shelfbreak. It should be noted that the arrival of the barotropic and baroclinic waves corresponds to the arrival of fronts, as derived in Allen (1976). The upstream, downwelling-favorable winds introduce a continual sea surface and isopycnal displacement to the water column due to the onshore Ekman transport, thus inhibiting the return to preforcing conditions on short time scales associated with waves of subinertial frequencies.

While these results explain the seasonality in transport of the UPW, it still remains to be determined what factors dictate the seasonal change in $\mathrm{T}$ and $\mathrm{S}$ documented in Figure 2-14. Unlike the IW, the UPW is not advected around the perimeter of the Irminger Sea, but instead progresses along the shelf and shelfbreak of East Greenland from Fram Strait to Cape Farewell. Analogous to our calculation for the IW, we used the mooring data at the MA3 array to investigate ventilation of UPW, in this case using the onshore-most mooring in the EGCC. This revealed that the stratification of the water column is eroded and the mixed layer deepens over the course of the winter season, until it is sporadically homogenous from top to bottom by March. Hence, UPW is actively ventilated at MA3 during winter. Additionally, onshore Ekman transport along East Greenland should act to modify the UPW properties along its trajectory. Unfortunately, since neither MA4 nor the OSNAP WG array had moored CTD profilers, plus the data return of the tethered MicroCATs at $50 \mathrm{~m}$ was sparse at both arrays, it is not possible to document how much of the UPW was ventilated east and west of Cape Farewell. However, given that there is no evidence of an advective lag in UPW hydrographic properties between MA4 and the OSNAP WG array, it is likely that UPW continues to be directly ventilated in winter along its trajectory from the Irminger Sea into the eastern Labrador Sea. Further insights on this will require additional sensors on the inshore Cape Farewell OSNAP moorings. 


\subsection{Summary and conclusions}

Using a high-resolution mooring array deployed between 2014 and 2018, we have characterized the structure, water mass composition, and seasonal variability of the West Greenland boundary current system. The boundary current system is comprised of three components, progressing from onshore to offshore: 1) the West Greenland Coastal Current (WGCC) advects cold and fresh UPW in the vicinity of the outer shelf and shelf-break; 2) the West Greenland Current (WGC) transports warm and salty IW along the upper-slope (with some UPW in the surface layer); and 3) the DWBC advects overflow waters emanating from Denmark Strait (relatively cold and fresh DSOW) and the Faroe Bank Channel and Iceland-Faroe Ridge (relatively warm and salty NEADW). LSW is prevalent at the seaward side of the array within the offshore recirculation gyre, and also present in the WGC beneath the IW.

Based on the lateral distribution of LSW, together with guidance from previous work, we divided the flow into the boundary current portion versus the northward arm of the cyclonic recirculation gyre at the edge of the array. The total mean transport of the boundary current is $31.1 \pm 7.4 \mathrm{~Sv}$. Of the six water mass components, LSW contributed the largest transport, followed by NEADW, IW, and DSOW. The remaining two water masses, UPW and UAW, were associated with smaller, comparable transports. Using the historical definition of overflow water (denser than 27.8 $\mathrm{kg} / \mathrm{m}^{3}$ ), we find that there is a loss of transport of this dense water as it rounds Cape Farewell, consistent with earlier studies. However, we demonstrated that some of the NEADW is lighter than $27.8 \mathrm{~kg} / \mathrm{m}^{3}$, meaning that this definition does not account for

all of the overflow water (plus entrainment) emanating from the Greenland-Scotland Ridge. Using our property definitions, we demonstrated that the true overflow component transports $2.2 \mathrm{~Sv}$ more than one would obtain using the historical density definition. We also determined that the transport of the entrained product deriving from the eastern overflow (NEADW) is comparable to that from the western overflow (DSOW).

While the total boundary current transport does not have a seasonal signal, the 
individual water mass components do vary seasonally in both transport and in their hydrographic properties. LSW transport reaches a maximum in spring, after strong wintertime convection during which the water becomes colder and fresher. This seasonality in transport is driven by fluctuations in the amount of LSW present, not by its velocity. Our results indicate that LSW penetrates the boundary current locally, through entrainment/mixing from the adjacent recirculation gyre, and also enters the current upstream in the Irminger Sea, where the newly ventilated water is subsequently advected around Cape Farewell.

In fall, the IW is warmest and saltiest, coincident with a maximum in transport. Using data from four different mooring arrays upstream of the OSNAP WG array, it was determined that IW is consistently modified through air-sea interaction during winter along the length of its trajectory around the Irminger Sea. This means that it is impossible to advectively track a seasonal signal of this water mass from site to site. Near Cape Farewell, however, the water mass subducts below cold and fresh UPW shed from the coastal current. As such, there is a clear advective lag in seasonal IW properties between the OSNAP WG array and the OSNAP mooring array northeast of Cape Farewell. The upstream wintertime ventilation cools, freshens, and densifies the IW, converting some of it to LSW. This conversion, together with the seasonal increase in LSW entering the current, results in an anticorrelation in transport between these two water masses.

The UPW in the WGCC also exhibits strong seasonality in its hydrographic properties, as well as its transport. The water is coldest, freshest, and its transport is maximum in the spring. The transport variability, which is dictated by both changes in cross-sectional area and speed of the UPW, is due to remote wind forcing. In particular, our analysis suggests that strong northerly winds off of East Greenland excite coastal trapped waves that propagate around Cape Farewell and adjust the WGCC. The sea surface height anomaly travels at the barotropic wave speed which enhances the velocity, while the pycnocline anomaly travels at a slower baroclinic wave speed which increases the area of the UPW. The observed timing of these changes agrees with that predicted by a coastal trapped wave model. It was documented that, dur- 
ing winter, the UPW is ventilated throughout the water column on the outer East Greenland shelf at the upstream MA3 mooring site near Denmark Strait. Due to sparse instrument coverage, it was impossible to determine if such ventilation also occurs at the two OSNAP Cape Farewell arrays. However, the lack of an advective signal between the two sites implies that UPW continues to be directly ventilated during winter as it progresses from the Irminger Sea into the Labrador Sea.

This study has provided the first robust accounting of the boundary current of the eastern Labrador Sea, including its mean state and seasonally varying components. As the current system in this region is part of the North Atlantic meridional overturning circulation, its variability has important implications for climate. Future work will compare the boundary currents on the two sides of the Labrador Sea using the OSNAP mooring data on the Labrador shelf/slope. It is also of interest to investigate further the role of the boundary current system in influencing the conditions in the interior Labrador Sea, including its role in modulating wintertime convection and in the subsequent restratification that takes place in spring and summer. Toward this end, future efforts will focus on the mesoscale processes in the current that help dictate shelf-basin exchange.

\subsection{Data availability}

The OSNAP mooring data are publicly available at www.o-snap.org through the Duke Digital Repository. The calibrated and quality-controlled data are provided by each participating institution. U.S. Labrador Sea eastern boundary array, ht tps://doi.org/10.7924/r4fj2dr7k, U.S. east Cape Farewell slope array, ht tps://doi.org/10.7924/r4fb50z9b, NIOZ western Mid-Atlantic-Ridge array, https://doi .org/10.4121/uuid:77b2c4fc-c253-4494-91bd-8d1ef66a014a, https://doi .org/10.4121/uuid:9ae97ceb-39e4-43ec-abdb-614103285c16; U.S. eastern Mid-Atlantic-Ridge array, https://doi.org/10.7924/r42n52w51. Mooring data from MA3 can be found at http://kogur.whoi.edu/php. 


\subsection{Acknowledgements}

The authors are thankful to Captain Kent Sheasley, Captain Derek Bergeron, and the entire crew of the $\mathrm{R} / \mathrm{V}$ Knorr and $\mathrm{R} / \mathrm{V}$ Neil Armstrong, for their efforts in making the OSNAP deployment and recovery cruises successful. We thank John Kemp, Jim Ryder, Brian Hogue, Andrew Davies, and Rick Trask for the design, fabrication, preparation of instruments, and deployment of the moorings. Leah McRaven and Carolina Nobre oversaw the shipboard CTD operations. A.P., R.S.P., F.B., D.J.T., and A.L.R. were funded by Grants OCE-1259618 and OCE-1756361 from the National Science Foundation. I.L.B, F.S., and J.H. were supported by U.S. National Science Foundation Grants OCE-1258823 and OCE- 1756272. Mooring data from MA2 was funded by the European Union 7th Framework Programme (FP7 2007-2013) under Grant 308299 (NACLIM) and the Horizon 2020 research and innovation program under Grant 727852 (Blue-Action). J.K. and M.O. acknowledge EU Horizon 2020 funding Grants 727852 (Blue-action) and 862626 (EuroSea) and from the German Ministry of Research and Education (RACE Program). G.W.K.M. acknowledges funding from the Natural Sciences and Engineering Research Council. 


\title{
Chapter 3
}

\section{Cyclones in the West Greenland Boundary Current System}

\begin{abstract}
The boundary current system in the Labrador Sea plays an integral role in modulating convection in the interior basin. Four years of mooring data from the eastern Labrador Sea reveal persistent mesoscale variability in the West Greenland boundary current. Between 2014 and 2018, 197 middepth intensified cyclones were identified that passed the array near the $2000 \mathrm{~m}$ isobath. In this study, we quantify these features and show that they are the downstream manifestation of Denmark Strait Overflow Water (DSOW) cyclones. A composite cyclone is constructed revealing an average radius of $9 \mathrm{~km}$, maximum azimuthal speed of $24 \mathrm{~cm} / \mathrm{s}$, and a core propagation velocity of $27 \mathrm{~cm} / \mathrm{s}$. The core propagation velocity is significantly smaller than upstream near Denmark Strait, allowing them to trap more water. The cyclones transport a 200-m thick lens of dense water at the bottom of the water column, and increase the transport of DSOW in the West Greenland boundary current by $17 \%$ relative to the background flow. Only a portion of the features generated at Denmark Strait make it to the Labrador Sea, implying that the remainder are shed into the interior Irminger Sea, are retroflected at Cape Farewell, or dissipate. A synoptic shipboard survey east of Cape Farewell, conducted in summer 2020, captured two of these features which shed further light on their structure and timing. This is the first time DSOW cyclones have been observed in the Labrador Sea - a discovery that could have important implications for interior stratification.
\end{abstract}

This chapter has been published as Pacini et al. (2021). Cyclones in the West Greenland Boundary Current System. Journal of Physical Oceanography, 51(7):2087-2102 (c) American Meteorological Society. Used with permission. 


\subsection{Introduction}

The boundary current system encircling the Labrador Sea plays a pivotal role in the warm-to-cold water mass transformation that occurs in the sea, which contributes to the Atlantic Meridional Overturning Circulation (AMOC). In the interior of the basin, newly-ventilated Labrador Sea Water is formed through deep convection (e.g. Clarke and Gascard, 1983; Lab Sea Group, 1998; Pickart et al., 2002). This weaklystratified water mass helps to maintain the hydrographic structure of the subpolar

North Atlantic (Talley and McCartney, 1982; Sy et al., 1997; Rhein et al., 2002) and serves to sequester carbon at depth (Takahashi et al., 2009; Khatiwala et al., 2013). The ability of the rim current to flux heat and freshwater into the interior basin (e.g. Pickart, 1992; Lilly et al., 1999; Kawasaki and Hasumi, 2014) modulates the convection by influencing both the preconditioning and restratification process (Katsman et al., 2004; Chanut et al., 2008).

Observations and models indicate that the overturning in depth and density space in the Labrador Sea are not co-located, though both are impacted by boundary current processes (Spall and Pickart, 2001; Pickart et al., 2002; Spall, 2004; Pickart and Spall, 2007). While the deepest mixing occurs in the middle of the basin (Clarke and Gascard, 1983), the diapycnal transformation there is impacted by eddies emanating from the boundary current that flux heat and freshwater to the interior (e.g. Lilly et al., 1999, 2003). At the same time, deep convection can occur directly within the western boundary current of the Labrador Sea (Pickart et al., 2002). By contrast, the overturning in depth space is limited to the boundary. This is because planetary geostrophic dynamics limit the degree of sinking in the interior, while dissipation and eddy fluxes over the continental slope can allow such constraints to be broken (Spall, 2010; Cessi and Wolfe, 2013).

The boundary current system of the Labrador Sea, part of the cyclonic circulation of the subpolar gyre, is comprised of several components. On the eastern side there is the West Greenland Coastal Current on the shelf (WGCC; e.g. Lin et al. 2018), the West Greenland Current (WGC) in the vicinity of the shelfbreak (e.g. Lazier 
and Wright, 1993; Rykova et al., 2015), and the Deep Western Boundary Current at depth (DWBC; Dickson and Brown 1994) (Figure 3-1). Part of the WGCC and WGC continue northward into Baffin Bay, while the remaining portion of these two components, along with the DWBC, flow cyclonically around the top of the basin to the Labrador side. There the flow is joined by the outflow from Baffin Bay. This consists of the Labrador Coastal Current and the Baffin Island Current near the shelfbreak, which merges with the recirculated WGC to form the Labrador Current.

A recent study of the West Greenland boundary current system, using four years of mooring data from the Overturning in the Subpolar North Atlantic Program (OSNAP) array west of Cape Farewell (Figure 3-1; OSNAP WG), quantified the different water masses and their transports (see Figure 2-5 of Pacini et al. 2020). Altogether there are five water masses in the boundary current system (Figure 3-2b), which vary in properties and transport on a seasonal basis. Cold and fresh Arctic-origin water and meltwater from Greenland combine to form Upper Polar Water (UPW; Rudels et al. 2002; Sutherland et al. 2009), which is found in the upper portion of the WGC as well as the WGCC. Labrador Sea Water (LSW), formed through wintertime convection in the Labrador and Irminger Seas, is found offshore of the boundary current and at the base of the WGC, with seasonally-varying transport. Irminger Water (IW), a form of subpolar mode water, is found in the core of the WGC (between 400-600 m), and its transport is inversely proportional to that of LSW (Pacini et al., 2020). In particular, when the transport of LSW is high (at the end of the convective winter period), the transport of IW is low. Conversely, when the transport of LSW is low (at the end of the summer), the transport of IW is high (Le Bras et al., 2020; Pacini et al., 2020).

The deep part of the boundary current system advects roughly equal amounts of Northeast Atlantic Deep Water (NEADW) and Denmark Strait Overflow Water (DSOW), both of which are important components of the AMOC (Dickson and Brown, 1994). NEADW represents overflow waters emanating from the eastern part of the Greenland-Scotland Ridge (Lee and Ellett, 1965), and DSOW represents overflow waters emanating from the Denmark Strait (Dickson and Brown, 1994; Tanhua 
(a)
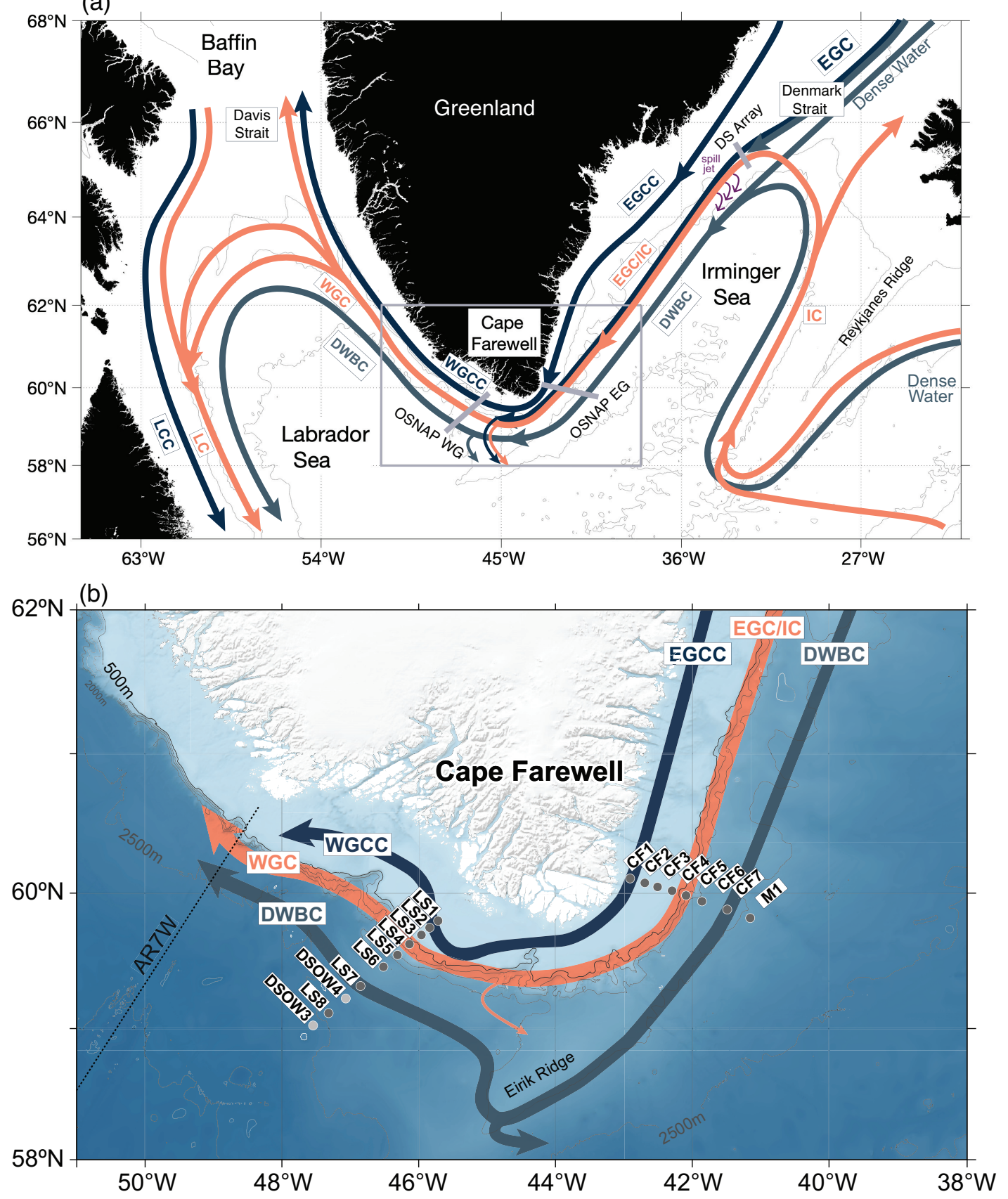

Figure 3-1: (a) Irminger and Labrador Sea circulation schematic, with the OSNAP WG, OSNAP EG, and DS arrays labeled. IC is the Irminger Current; EGCC is the East Greenland Coastal Current; EGC is the East Greenland Current; DWBC is the Deep Western Boundary Current; WGCC is the West Greenland Coastal Current; WGC is the West Greenland Current; LCC is the Labrador Coastal Current; LC is the Labrador Current. The grey box indicates the domain shown in (b). The red lines denote warm currents. (b) Zoomed-in schematic of the circulation near Cape Farewell, Greenland, with the moorings of the OSNAP EG and OSNAP WG arrays labeled. The bathymetry is from ETOPO2. 
et al., 2005; Hopkins et al., 2019). DSOW is denser, colder, and fresher than NEADW, and neither water mass exhibits seasonality in properties or transport. In the mean, the DWBC transports $5.5 \pm 0.5 \mathrm{~Sv}$ of NEADW and $5.0 \pm 0.3 \mathrm{~Sv}$ of DSOW (where the uncertainty is the standard error, Pacini et al. 2020). It should be noted that overflow waters are typically defined as waters denser than $27.8 \mathrm{~kg} / \mathrm{m}^{3}$ (Dickson and Brown, 1994), but, as shown in Pacini et al. (2020), this definition excludes the upper portion of NEADW transport in the West Greenland boundary current. Using this historical definition, the overflow transport of the boundary current is underestimated by more than $2 \mathrm{~Sv}$.

The Labrador Sea has long been identified as a region with high eddy kinetic energy (e.g. Gascard and Clarke, 1983; Lilly et al., 1999, 2003; Eden and Böning, 2002; Prater, 2002; Chanut et al., 2008). This has been demonstrated from moorings (Lilly et al., 1999; de Jong et al., 2014), drifting profilers and gliders (Prater, 2002; Hátún et al., 2007; Frajka-Williams et al., 2009), surface altimetry (Heywood et al., 1994; Brandt et al., 2004), and modeling studies (Katsman et al., 2004; Gelderloos et al., 2011; de Jong et al., 2014; Rieck et al., 2019). The mesoscale variability has been divided into three main categories: (1) Irminger Rings, which are large (30-60 $\mathrm{km}$ diameter) anticyclonic features shed from the WGC that carry warm, salty IW southwestward across the Labrador Sea (e.g. Lilly and Rhines, 2002; Lilly et al., 2003; Hátún et al., 2007; de Jong et al., 2016). They are formed due to the interaction of the boundary current system with the steepening topography of the continental slope near $61^{\circ} \mathrm{N}$ (Eden and Böning, 2002; Bracco and Pedlosky, 2003; Wolfe and Cenedese, 2006; Bracco et al., 2008); (2) Convective eddies, which are small-scale features (20-30 km diameter) formed via baroclinic instability of hydrographic fronts near sites of deep convection (Chanut et al., 2008); and (3) boundary current eddies, which arise due to baroclinic instability of the cyclonic boundary current as it flows around the basin (Chanut et al., 2008). Numerical sensitivity experiments have sought to diagnose the relative importance of these features in the transport of heat and freshwater to the convective region as well as their contribution to the stratification of the interior (e.g. Chanut et al., 2008; Gelderloos et al., 2011; Rieck et al., 2019). While results differ, 
it is clear that these features, in particular the Irminger Rings and boundary current eddies, are important for regulating the strength of convection, the production of LSW in the Labrador Sea, and the restratification of the basin in spring/summer.

Upstream, along the east coast of Greenland, a fourth kind of eddy has been identified: middepth intensified DSOW cyclones. These are formed as the dense overflow from the Nordic Seas descends from the Denmark Strait into the Irminger Sea and stretches, thereby generating cyclonic vorticity (Spall and Price, 1998). Similar features have been found due to cascading of dense shelf water in the northwestern Mediterranean Sea (Bosse et al., 2016). While these eddies arise from a steady outflow in the model of Spall and Price (1998), recent evidence suggests that their formation is triggered by mesoscale variability in the vicinity of the sill. Two dominant modes of variability have been identified in Denmark Strait, known as boluses and pulses, based on observations (von Appen et al., 2017; Mastropole et al., 2017) and models (Almansi et al., 2017). Both features are associated with increased DSOW transport through the sill (von Appen et al., 2017), and are formed by baroclinic instability of the hydrographic front between the warm northward-flowing water adjacent to Iceland and the cold southward-flowing water in the strait (Spall et al., 2019). von Appen et al. (2017) argue that boluses lead to strong DSOW cyclones downstream, while pulses result in weaker DSOW cyclones. Using a high-resolution numerical model, Almansi et al. (2020) found a one-to-one correspondence between boluses/pulses and the downstream cyclones.

Using data from a year-long mooring array $280 \mathrm{~km}$ south of Demark Strait (Figure 3-1a; DS array), von Appen et al. (2014b) quantified the statistics of the DSOW cyclones and found that, on average, the features passed by the array every other day, most often near the $900 \mathrm{~m}$ isobath. They propagate faster than the mean current and experience a vortex stretching of 40 percent as they descend from the sill to the array site. The self-propagation of these features is consistent with the topographic Rossby wave speed (Nof, 1983; Pedlosky, 2003), indicating that the self-propagation of DSOW cyclones is due to the restoring force provided by potential vorticity gradients to a vortex column stretching (Spall and Price, 1998; von Appen et al., 2014b). Evidence 
from satellites indicates that they move offshore as they progress southward (Bruce, 1995). Previously, the DSOW cyclones were thought to dissipate before reaching the southern tip of Greenland. However, during the initial deployment of the OSNAP mooring array east of Cape Farewell (Figure 3-1; OSNAP EG), shipboard measurements detected one of these features. Since then, the cyclones have been measured during subsequent OSNAP mooring recovery/deployment cruises, on both sides of Cape Farewell.

The extensive body of work on eddies of the Labrador Sea, described above, rarely documents instances of mid-depth intensified cyclonic features in the boundary current. This leads to questions such as: Do DSOW cyclones regularly progress around Cape Farewell? If so, how often and in what manner do they influence the boundary current and interior Labrador Sea? This study addresses these questions by first quantifying the statistics of cyclonic eddy presence in the OSNAP EG and OSNAP WG mooring arrays. Subsequently, a composite cyclone for the West Greenland boundary current is constructed, which highlights the relevant spatial and temporal scales associated with these features, as well as the azimuthal and core propagation velocities. The influence of the cyclones on the transport of the boundary current is then investigated, and, finally, a comparison with shipboard hydrographic data is presented. Together, this evidence reveals that DSOW cyclones are a ubiquitous feature of the Labrador Sea boundary current system and constitute the dominant source of subsurface mesoscale variability in the region near Cape Farewell.

\subsection{Data and methods}

\subsubsection{Mooring and shipboard data}

We focus on the OSNAP mooring array located on the West Greenland shelf and slope in the eastern Labrador Sea, to investigate cyclonic eddy activity (Figure 31; OSNAP WG). The array was deployed in August 2014 and has been serviced every two years since then. It consists of 10 moorings: three bottom tripods on the 

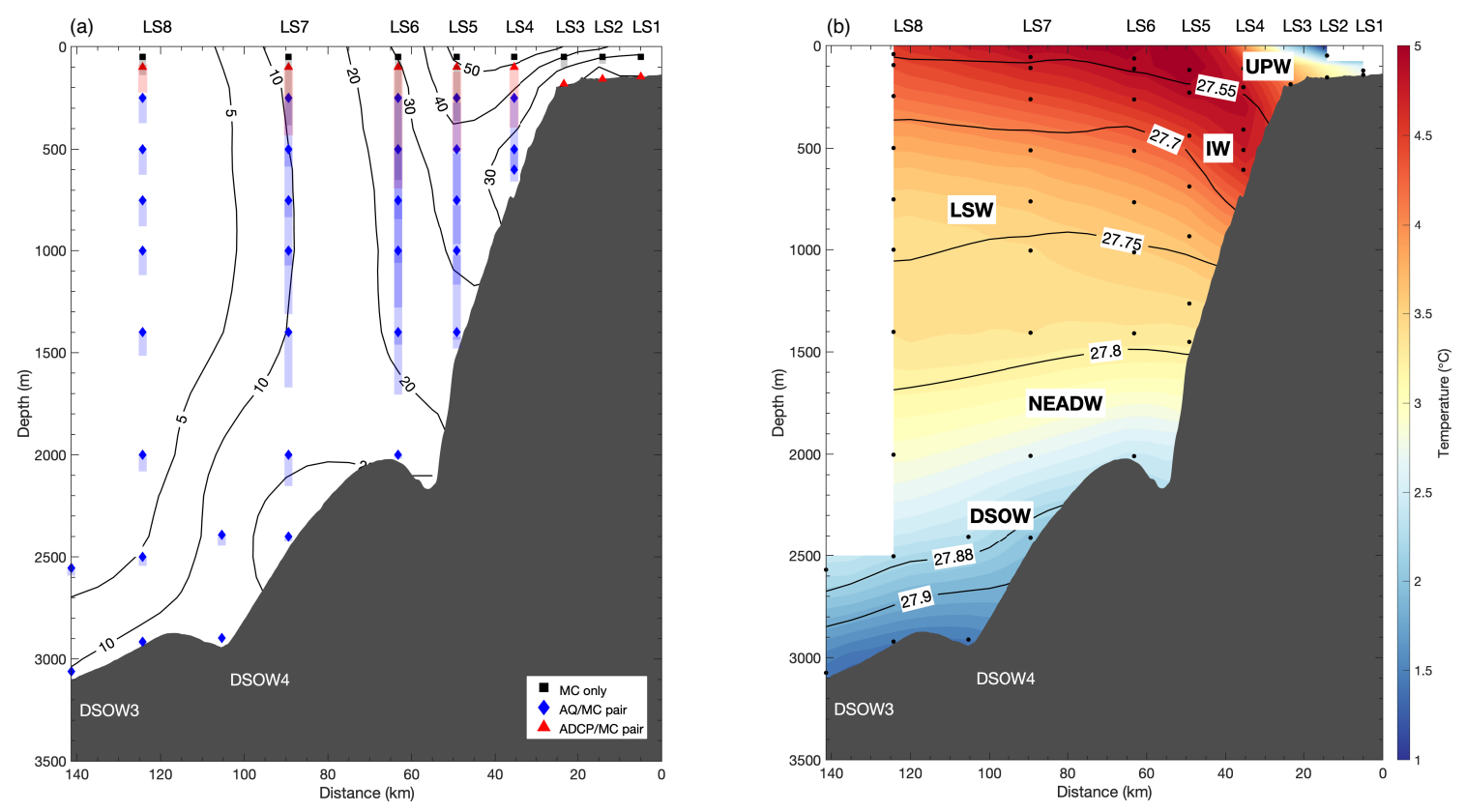

Figure 3-2: (a) Instrumentation of the OSNAP WG mooring array. The nominal depths of the sensors are indicated by the solid symbols (see the legend), and the shading indicates the instrumentation blowdown ranges. MC indicates MicroCAT, AQ indicates Aquadopp, ADCP indicates acoustic Doppler current profiler. Black contours denote the four-year mean along-stream velocity $(\mathrm{cm} / \mathrm{s})$ in the absence of eddy activity. The bathymetry is from the shipboard echosounder on R/V Knorr. (b) Mean vertical section of temperature (color, ${ }^{\circ} \mathrm{C}$ ) and isopycnals (contours, $\mathrm{kg} / \mathrm{m}^{3}$ ) in the absence of eddy activity. The location of the five water masses discussed in the text are labeled.

shelf (LS1-LS3), five full-depth moorings (LS4-LS8), and two bottom-instrumented moorings (DSOW3-DSOW4). The moorings are spaced $\sim 15 \mathrm{~km}$ apart, with tighter station spacing on the shelf and larger distances off the shelf and slope. In this study, we use the first four years of data, from August 2014 to September 2018 (subsequent to 2018, more shelf tripods were added to the array). The instrumentation in the array consists of 49 Seabird SBE37 MicroCATs that measure pressure, temperature, and conductivity; 33 Nortek Aquadopp Current Meters providing point measurements of velocity; and 8 acoustic Doppler current profilers (RDI ADCPs, $300 \mathrm{kHz}$ and 75 $\mathrm{kHz}$ ) that obtain vertical profiles of velocity (Figure 3-2a).

Hourly vertical sections were constructed using Laplacian-Spline interpolation 
(Smith and Wessel, 1990). The gridded product has $100 \mathrm{~m}$ vertical resolution and 5 $\mathrm{km}$ horizontal resolution. The variables are potential temperature referenced to the sea surface (hereafter referred to as temperature), practical salinity, potential density referenced to the sea surface (hereafter referred to as density), and along-stream and cross-stream velocity. The processing, data return, accuracy, and gridding are discussed in detail in Pacini et al. (2020). Overall, the data return and quality were excellent and provide hourly renderings of the boundary current system from August 2014 to September 2018. The velocity data were de-tided using the harmonic tidal routine T_TIDE (Pawlowicz et al., 2002), and then rotated such that the cross-stream velocity of the array was minimized. Positive along-stream velocity $(u)$ is directed towards the northwest $\left(318^{\circ} \mathrm{T}\right)$, and positive cross-stream velocity $(v)$ is directed offshore, towards the southwest $\left(228^{\circ} \mathrm{T}\right)$. Unless specified, the data presented in this study are from individual instrument timeseries. The gridded product is used to obtain transport estimates of the boundary current. Additionally, the gridded product is used to compute Ertel potential vorticity $\Pi$, defined as:

$$
\Pi=\frac{f}{g} \frac{\partial b}{\partial z}-\frac{1}{g} \frac{\partial u}{\partial y} \frac{\partial b}{\partial z}+\frac{1}{g} \frac{\partial u}{\partial z} \frac{\partial b}{\partial y}
$$

where the buoyancy is $b=-g \rho / \rho_{0}, \rho$ is the density, $\rho_{0}$ is the reference density, the cross-shelf direction is $y$, and the vertical direction is $z$ (e.g. Pickart et al., 2005; Spall and Pedlosky, 2008; Lin et al., 2018). This formulation neglects downstream variations, which cannot be measured with a two-dimensional array. We note, however, that assuming $\partial u / \partial y=-\partial v / \partial x$, as would be the case for a symmetric eddy, does not impact the results presented below. The value of $\Pi$ is smoothed using a 300 $\mathrm{m}$ filter in the vertical and a 3-hour temporal filter.

Additionally, the de-tided, non-gridded data from the OSNAP EG moorings are used to compare cyclone statistics between the east and west sides of Cape Farewell. Details on the processing of these data, as well as the mean conditions and seasonality at the array site, can be found in Le Bras et al. (2018) and Hopkins et al. (2019). The 
de-tiding has been performed using the same harmonic tidal routine as the OSNAP WG data.

Lastly, shipboard hydrographic data are used from the OSNAP mooring servicing cruise in summer 2020 aboard the R/V Neil Armstrong from 23 June to 27 July. Conductivity-temperature-depth (CTD) casts were occupied using a Sea-Bird 911+ mounted on a 24-position frame with 10-L Niskin bottles at $5 \mathrm{~km}$ station-spacing. Salinity samples were taken from the bottles to calibrate the conductivity sensors. The accuracy of the temperature and salinity measurements are estimated to be $0.001^{\circ} \mathrm{C}$ and 0.002, respectively. Armstrong's hull-mounted Ocean Surveyor 38 kHz ADCP provided velocity profiles of the upper $1000 \mathrm{~m}$. Vertical sections were constructed in the same manner as for the mooring data. The hydrographic variables have a horizontal spacing of $3 \mathrm{~km}$ and vertical spacing of $5 \mathrm{~m}$, and the velocity data have a horizontal spacing of $5 \mathrm{~km}$ and vertical spacing of $30 \mathrm{~m}$.

\subsubsection{Eddy identification graphical user interface}

Following the method used by von Appen et al. (2014b) to identify eddy variability at the mooring array south of Denmark Strait (Figure 3-1; DS array), we designed and implemented a graphical user interface (GUI) to select instances of cyclonic and anticyclonic eddy activity, as well as the presence of dipole pairs. Only the cyclones are addressed in the present study. The anticyclones and dipole pairs are a dynamically distinct phenomenon, and are being investigated in a separate study.

Dynamically, if the center of the feature passes close to a given mooring, the along-stream velocity is enhanced due to the core propagation speed of the eddy (the azimuthal flow is in the cross-stream direction in this case). If the eddy center passes offshore (onshore) of the mooring, the azimuthal flow enhances (reduces) the along-stream velocity. A feature must satisfy three criteria to be considered an eddy:

1. An intensification or reduction in the along-stream velocity.

2. A reversal in the cross-stream velocity (offshore to onshore for cyclonic; onshore to offshore for anticyclonic; offshore to onshore to offshore or vice versa for dipole 
pair).

3. An increased presence of dense water in the bottom $500 \mathrm{~m}$ of the water column, as deduced from the temperature record and isopycnal displacements (discussed in more detail below).

An example of a cyclonic eddy passing by mooring LS6 is shown in Figure 3-3 (details of these features are discussed in the section 3.3 below). The GUI displays timeseries of along-stream and cross-stream velocity as well as temperature at four different moorings, plotted over three days. The user selects the type of feature (cyclone, anticyclone, or dipole pair) and then chooses the start point, end point, and center time of the feature. In general, features only appeared at one mooring, meaning that the spacing of the mooring array was not sufficient to fully resolve the eddies. This indicates that the radius of the various features is smaller than the distance between moorings. However, the features typically have diameters close to $18 \mathrm{~km}$ (derived in section 3.3.2), while their cross-stream signals exhibit anomalously large values $(>10 \mathrm{~cm} / \mathrm{s})$ at diameters of up to $30 \mathrm{~km}$. At the EG array, the maximum spacing between moorings is $17 \mathrm{~km}(17 \mathrm{~km}$ between CF6 and CF7 and $16 \mathrm{~km}$ between CF7 and M1), and at the WG array, the maximum spacing between moorings is 26 $\mathrm{km}$ (14 km between LS5 and LS6 and $26 \mathrm{~km}$ between LS6 and LS7, see Figure 3-2). Hence it is unlikely that an eddy would pass the mooring array (either EG or WG) without detection. The user can select more than one feature at a given time step (for example, an anticyclone at LS5 and a cyclone at LS7).

Using the GUI, all four years of OSNAP WG and EG mooring data (2014-2018) were inspected and periods of eddy activity identified.

\subsection{Results}

\subsubsection{Statistics}

Using the GUI described in subsection 3.2.2, all mid-depth cyclones were identified at the two arrays, revealing 324 features at OSNAP EG and 197 features at OSNAP WG. 
LS8
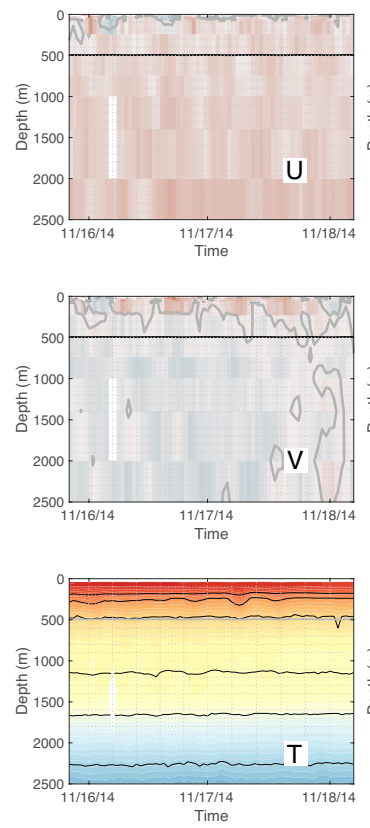

Load original data

Next timestep
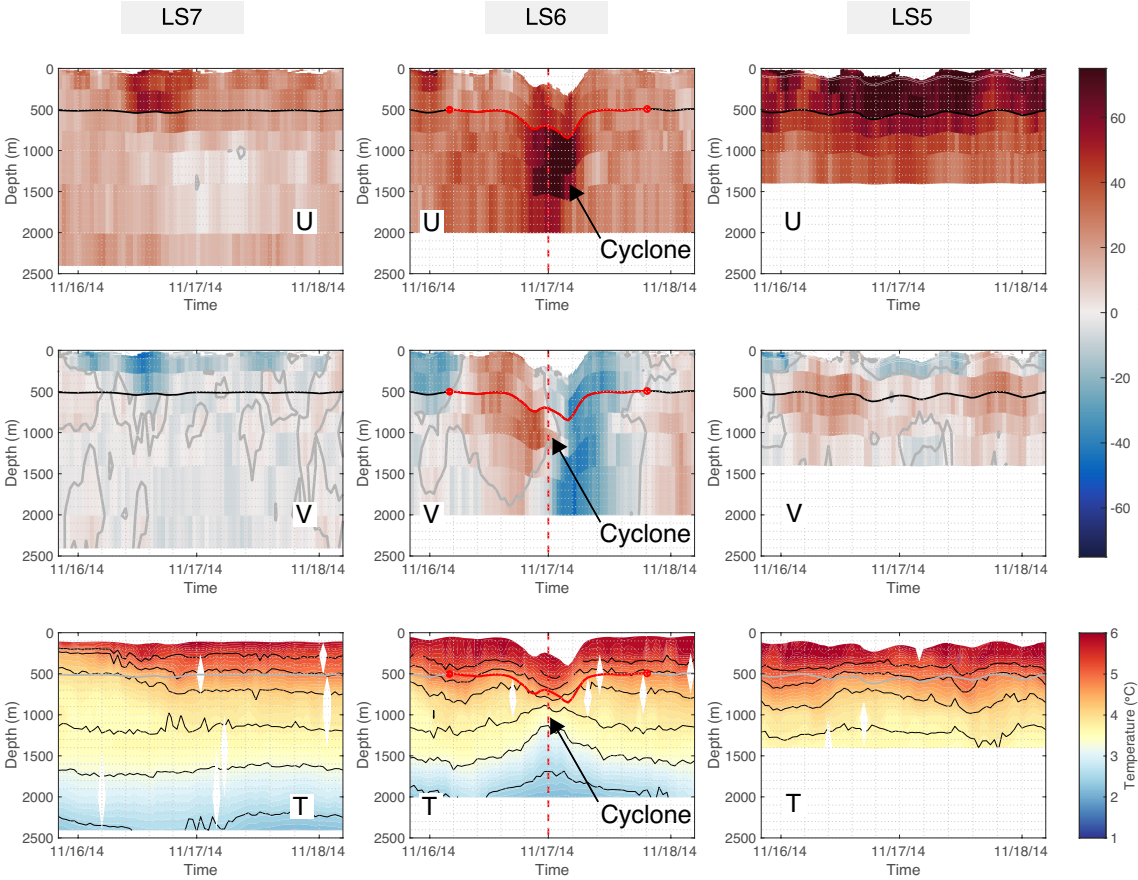

CYCLONIC

ANTICYCLONIC

DIPOLE

Click to select start of eddy, Cntrl + click to select end of eddy Shift + click to select center of eddy, Click on line to delete eddy

Export Data

Previous timestep

Figure 3-3: Example of a cyclonic eddy at LS6 in the graphical user interface (GUI) on 17 November 2014. The top row is along-stream velocity, middle row is cross-stream velocity, and bottom row is temperature (color) with density contoured $\left(\mathrm{kg} / \mathrm{m}^{3}\right)$. The depth of the $500 \mathrm{~m}$ instrument is plotted in each row (thick line) to highlight instrument blowdown. The user selects the start point, end point (filled circles), and center of feature (dashed line).

This translates into one cyclone every 4.5 days at EG and one cyclone every 7.6 days at WG. Assuming that the moorings do not miss features (see subsection 3.2.2) and that all of the features originate at Denmark Strait (see section 3.3.2), this indicates that $60 \%$ of cyclones identified along East Greenland are also observed along West Greenland (Figure 3-4). This reduction in the number of cyclones may be related to the observed loss in transport of the WGC and DWBC due to retroflection at Cape Farewell (Holliday et al., 2007, 2009).

There was no seasonality in the occurrence of the cyclones. At both arrays, the features were predominantly found offshore of the EGC/WGC near the $2000 \mathrm{~m}$ isobath, at moorings CF6/CF7/M1 (EGC) and LS6 (WGC) (Figure 3-4a,b). Feature tracking between the EG and WG arrays was attempted in order to connect the 

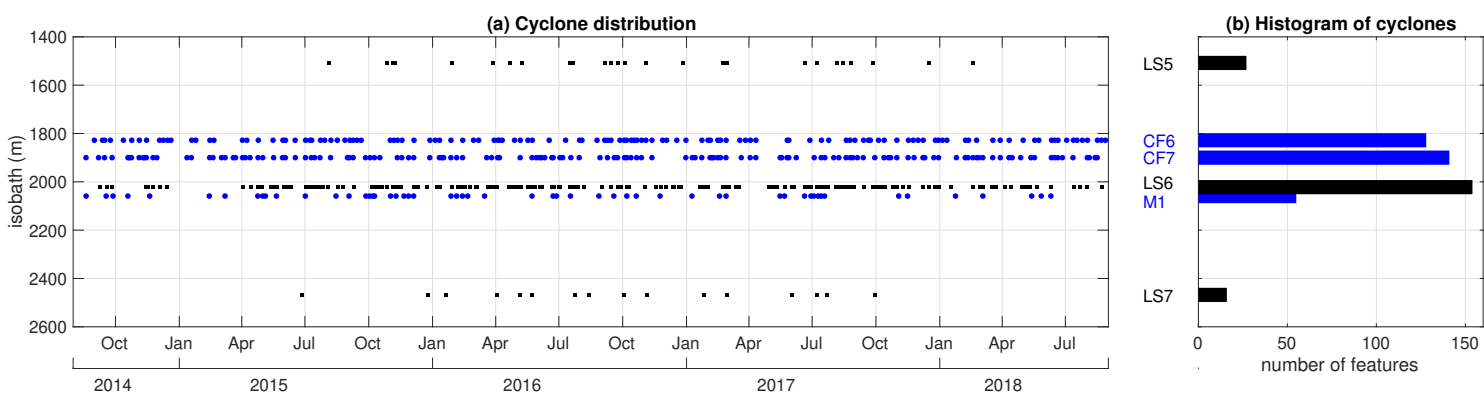

Figure 3-4: (a) Statistics and lateral distribution of the cyclones, as determined from the graphical user interface (GUI). Individual features are plotted as discrete symbols. The left axis is isobath, and the right axis indicates the corresponding mooring (blue lettering for the OSNAP EG moorings; black lettering for the OSNAP WG moorings). (b) Histogram of identified cyclones per mooring.

cyclones around Cape Farewell. We considered a range of core propagation speeds (discussed in more detail in section 3.3.2) to estimate when a given eddy sampled at OSNAP WG might have passed by the OSNAP EG array. However, it was impossible to match individual eddies at the two sites using this approach. At the OSNAP WG array, the focus of this study, cyclones typically take 70 hours to transit past the mooring array, and, in total, instances of cyclonic activity account for $29 \%$ of the four-year mooring record as defined by the identification method described in subsection 3.2.2.

\subsubsection{Cyclone characteristics}

\section{Model Eddy}

Of the 197 cyclones identified at OSNAP WG, 134 passed the array near LS6, which is located at the $2000 \mathrm{~m}$ isobath and is offshore of the main core of the WGC (Figure 32 ). To create an unbiased composite feature, we identified all of the instances where the center of the cyclone passed close to LS6, and only these realizations were used in the average. This was done based on a criterion of double-blowdown of the mooring and using a model eddy to test the sensitivity of this metric to a range of parameters.

When the center of an eddy passes close to the mooring, it blows the instrumentation down twice-once at the leading edge and once at the trailing edge-associated with 
the maximum offshore and onshore azimuthal velocity, respectively. By contrast, if an eddy passes onshore or offshore of the mooring, such that its center remains farther than the eddy radius away from the mooring location, it only blows the instrumentation down a single time, associated with the southward or northward azimuthal velocity. In our analysis, to be considered a centered feature, the eddy had to blow down the mooring's top float at $100 \mathrm{~m}$ to a depth of $240 \mathrm{~m}$ twice, with a rebound above $215 \mathrm{~m}$ between these maxima. Using a Gaussian model eddy, we can evaluate how successful this criterion is at capturing the centered features.

For a perfect Gaussian eddy, the azimuthal flow is given by

$$
v_{a}(r)=\frac{v_{0} r}{R_{0}} e^{.5\left(1-\left(\frac{r}{R_{0}}\right)^{2}\right)}
$$

where $R_{0}$ is the radius of maximum azimuthal velocity $v_{0}$, and $r$ indicates the distance from the center of the feature (Martin and Richards, 2001). We prescribed the radius and azimuthal velocity of the model eddy to be $9 \mathrm{~km}$ and $24 \mathrm{~cm} / \mathrm{s}$, respectively (Figure 3-5a). Next, a background velocity $u_{b}=23 \mathrm{~cm} / \mathrm{s}$ was applied throughout the domain, and a propagation velocity $u_{c}=27 \mathrm{~cm} / \mathrm{s}$ was imposed within the feature. These values are based on the mooring observations detailed below in sections section 3.3.2. The three velocities, $u_{b}, u_{c}$, and $v_{a}$ were then used to calculate the along-stream and cross-stream velocity at each grid point according to the following equations,

$$
\begin{gathered}
u(r, \theta)=u_{b}+u_{c}\left(r \leq 2 * R_{0}\right)+v_{a}(r) \cos \theta \\
v(r, \theta)=v_{a}(r) \sin \theta
\end{gathered}
$$

where $r=\sqrt{x^{2}+y^{2}}$ is the distance from the center of the feature, and $\theta$ is the angle measured clockwise from $y=0$ (von Appen et al., 2014b). The y-axis is converted from distance to time utilizing $u_{b}+u_{c}$, which is necessary in order to compare the results of the model to the mooring timeseries. As shown in Figure 3-5b, 

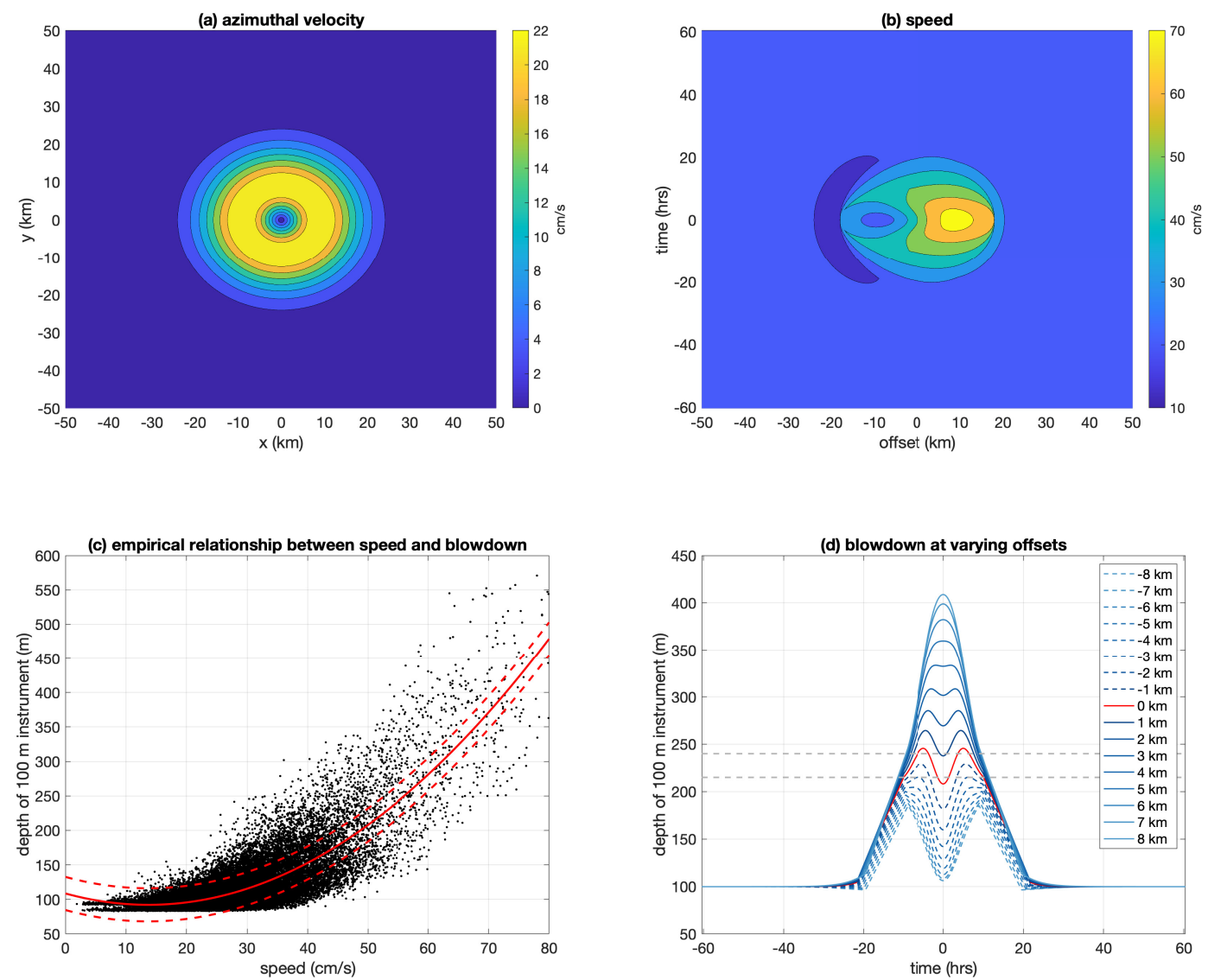

Figure 3-5: Model Gaussian eddy (a) azimuthal speed and (b) speed as a function of offset and time (axis converted using $u_{b}+u_{c}$, described in the text). (c) Empirical relationship between blowdown depth of the LS6 mooring top float (nominally at 100 $\mathrm{m}$, in actuality, the first deployment was at $89 \mathrm{~m}$ and the second deployment was at $97 \mathrm{~m}$ ) and the speed sampled by the mooring. A quadratic fit is shown in red, and the standard deviation of the fit is indicated by the red dashed lines. (d) Blowdown as a function of offset and time, following the quadratic relationship in (c). Grey dashed lines indicate the thresholds the instruments must meet to be considered centered. The curve for zero offset is colored red. Positive (negative) offset indicate the onshore (offshore) side of the eddy.

the projection of the azimuthal velocity onto the along-stream velocity at locations away from $x=0$ produces a resultant speed larger (smaller) than $u_{b}+u_{c}$ at locations onshore (offshore) of the center of the feature.

Subsequently, using the hourly mooring data, we derived a relationship between average speed measured by the mooring between $500 \mathrm{~m}$ and $1500 \mathrm{~m}$ and the depth to 
which the mooring instrumentation was blown down. This relationship is quadratic and has previously been documented for other moorings (e.g. Hogg, 1991, 1992). While the quadratic relationship is consistent among mooring arrays, the specific coefficients of the fit will vary as a function of mooring design. As shown in Figure 3$5 \mathrm{c}$, the quadratic fit to our mooring data is robust, with an $r^{2}$ of 0.7 , and provides a way to convert speed into blowdown depth for the model eddy. Doing so produces a map of blowdown as a function of time and offset from the center of the model eddy. Finally, we took slices through the feature at given offsets, where the resulting blowdown timeseries are shown in Figure 3-5d. This reveals that only features sampled less than $1 \mathrm{~km}$ from their center meet the specified criterion (blowdown to $240 \mathrm{~m}$ twice, with a rebound to shallower than $215 \mathrm{~m}$ between the two). To gauge the uncertainty, we performed the same analysis using the upper and lower confidence bounds on the quadratic relationship in Figure 3-5c, which indicate that only features sampled less than $2 \mathrm{~km}$ away from the center exhibit the blowdown signature described. This information is used below to compute error bounds on our eddy observations.

\section{Composite Feature}

Using the above blowdown criteria, we identified 26 features that passed by the array centered at LS6 (i.e. the eddy centers were within $1 \mathrm{~km}$ of the mooring). Since each of them took approximately 70 hours to do so, as the core propagation velocity was similar (see Figure 3-7a, described in section 3.3.2), no time normalization was necessary. Using the identified start, stop, and center points, these features were aligned, and a composite eddy was created. We note that the features do not exhibit significant differences between the OSNAP EG and WG lines, hence only the WG composite is presented.

As seen in Figure 3-6, the cyclones are associated with mid-depth intensification of the along-stream and cross-stream flow, coincident with pinching of the isopycnals and anomalously high Ertel potential vorticity with respect to non-eddy times. This region of high potential vorticity is the core of the eddy, bounded by the $27.65 \mathrm{~kg} / \mathrm{m}^{3}$ and $27.8 \mathrm{~kg} / \mathrm{m}^{3}$ isopycnals, and represents water that emanated from Denmark Strait 

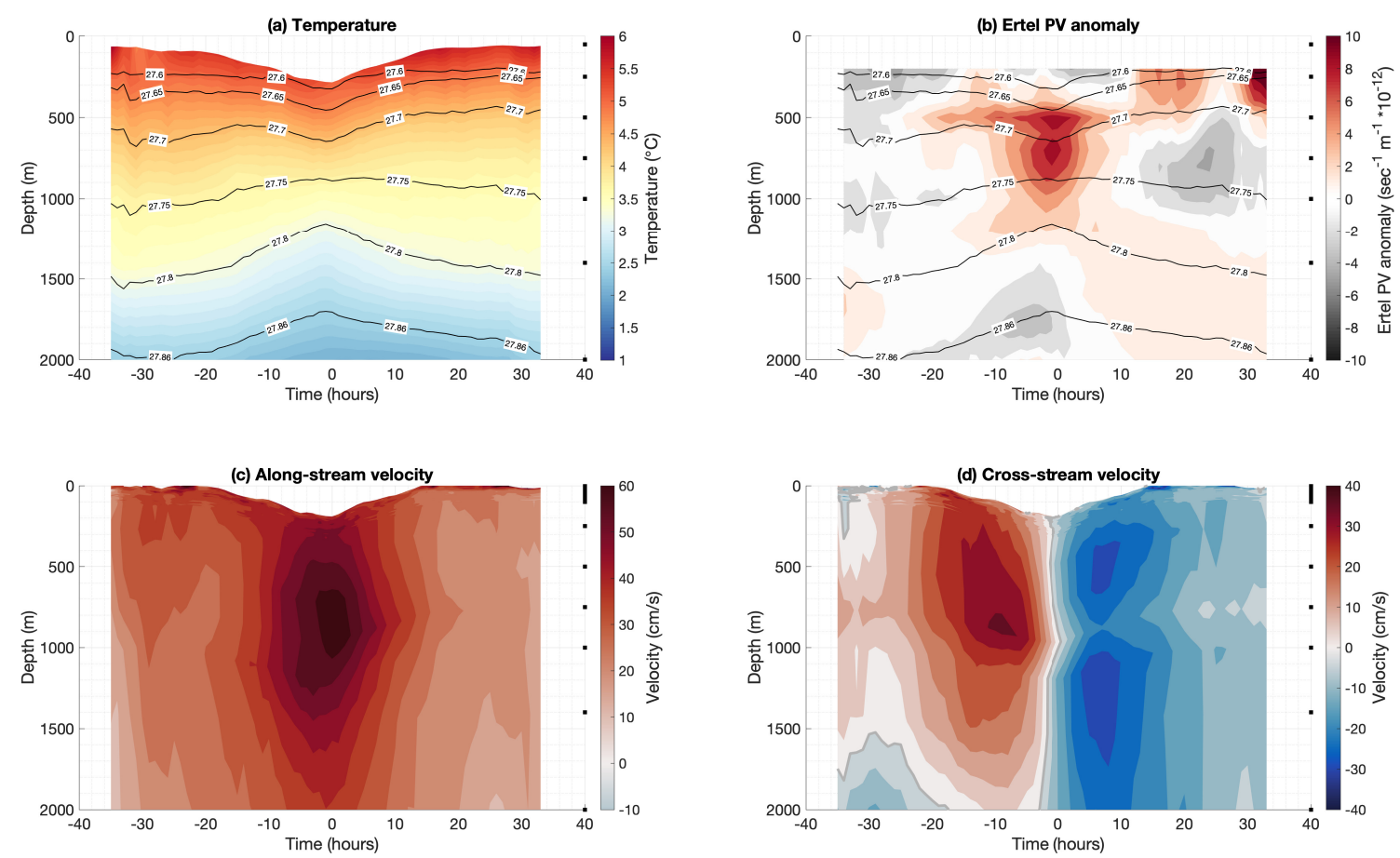

Figure 3-6: Composite cyclone at LS6, comprised of the 26 instances where the center of the feature passed less than $1 \mathrm{~km}$ to the mooring. The $\mathrm{x}$-axis is time (in hours); 0 indicates the center of the eddy passage, negative time indicates the leading edge of the feature (time before center), and positive time indicates the trailing edge (time after center). The black squares on the right axis indicate the nominal instrument depths. (a) Temperature (color) overlain by density (contours, $\mathrm{kg} / \mathrm{m}^{3}$ ). (b) Same as (a) except for Ertel potential vorticity anomaly (color, eddy PV - background PV in the absence of eddy activity). (c) Along-stream velocity. (d) Cross-stream velocity.

(Spall and Price, 1998) that became warmer and more saline due to entrainment downstream of the sill. Between the OSNAP EG and WG arrays, the T/S properties of this density class remain consistent. Additionally, the features exhibit a lens of anomalously dense water in the bottom $800 \mathrm{~m}$ of the water column (note, for example, the $200 \mathrm{~m}$ displacement of the $27.8 \mathrm{~kg} / \mathrm{m}^{3}$ isopycnal). The along-stream velocity has a maximum, between 500 and $1000 \mathrm{~m}$, as the center of the feature passes by. The cross-stream velocity has a maximum directed offshore (onshore) approximately 10 hours before (after) the center of the feature goes by.

The cross-stream velocity signature of the composite feature is not completely symmetric. In particular, at the leading edge of the cyclone there is a single core of 
maximum azimuthal velocity around $800 \mathrm{~m}$, while at the trailing edge, the feature has two cores of maximum velocity - one centered at $500 \mathrm{~m}$ and the second at 1200 m (Figure 3-6d). This is true of 22 of the 26 features used to create the composite. It is important to note that this minimum in the azimuthal velocity is sampled by the instrumentation (i.e. it is not an artifact of interpolation), as the $750 \mathrm{~m}$ MicroCAT and Aquadopp are blown down during eddy passage to sample this minimum. One possible explanation for this asymmetry is due to the fact that the cyclones typically pass the mooring array at a different angle than that of the mean flow, hence part of the along-stream flow of the eddy is projected into the cross-stream direction. This enhances the azimuthal velocity on one side of the feature and reduces it on the other side, while also altering the vertical distribution of the velocity signal. We investigated this effect by constructing a series of composites where the along-stream velocity was taken to be directed at an angle with respect to the mean flow (for a range $-15^{\circ}$ to $15^{\circ}$ off the direction of mean flow). However, this was not enough to explain the observed asymmetry. Another possibility is that the speed measured by the mooring, and thus the degree to which the instruments are blown down in the water column, is not symmetric over the course of the feature. This would lead to different sampling depths on either side of the feature, which could bias the results. While there were differences in some of the cases, overall the instrumentation blowdown was not significantly different on either side of the feature. As such, the asymmetry of the azimuthal flow structure of the eddies remains an open question.

\section{Velocity Structure}

Using the composite centered cyclone, we seek to decompose the flow field $(u, v)$ in order to determine the propagation speed and azimuthal speed of these features. For the following calculations, the time axis has been converted to a distance axis using the propagation speed derived below, and we consider the depth-averaged flow. Following von Appen et al. (2014b), the flow is decomposed into: 


$$
\begin{aligned}
& u(x)=u_{b}+u_{c}(x) \\
& v(x)=v_{b}+v_{a}(x)
\end{aligned}
$$

where $u_{b}$ and $v_{b}$ indicate the background along-stream and cross-stream velocity, in the absence of eddy activity (including anticyclonic and dipole activity), $u_{c}$ represents the along-stream propagation of the cyclones, and $v_{a}$ is the azimuthal flow of the eddy. The maximum of $u_{c}$ is the core propagation velocity, which represents the flow at which the volume of trapped water in the eddy moves along the slope. Given the ability of our criterion to identify centered features, the offset $(\theta)$ in Equation 3.3.2 and Equation 3.3.2 is $90^{\circ}$ and thus the projection of the azimuthal velocity onto the alongstream direction can be neglected, resulting in the simplified formulation presented in Equation 3.3.2 and Equation 3.3.2. The sum of the background flow and the core propagation velocity is the translation speed of the feature. We note that in von Appen et al. (2014b) the moorings were spaced close enough together that the lateral structure of a feature could be described (i.e. cyclones were observed simultaneously at more than one mooring), but they did not resolve the depth structure due to moored CTD profiler failure during strong blowdowns. This allowed them to create a lateral composite eddy (in the $\mathrm{x}-\mathrm{y}$ plane), as opposed to the depth composite (in the $\mathrm{X}-\mathrm{z}$ plane) presented here.

Figure 3-7a shows the components of depth-averaged flow in Equation 3.3.2 and Equation 3.3.2, where the time axis has been transformed to a distance axis using the deduced translation speed, $u_{b}+u_{c}$. The background time- and depth-averaged alongstream velocity in the absence of eddies $\left(u_{b}\right)$ is order $20 \mathrm{~cm} / \mathrm{s}$, much larger than the background time- and depth-averaged cross-stream velocity $\left(v_{b}\right)$, which is near zero. Subtracting $u_{b}$ from the composite along-stream velocity of the centered features (Figure 3-6c) gives the propagation velocity of the cyclone, $u_{c}(x)$. This reaches a maximum of $27 \pm 8 \mathrm{~cm} / \mathrm{s}$ at the center of the feature (the core propagation velocity), then returns to near zero outside of the core radius of the eddy. In the region outside of the core, $u_{c}$ reflects the dynamically-induced circulation due to the translation of 

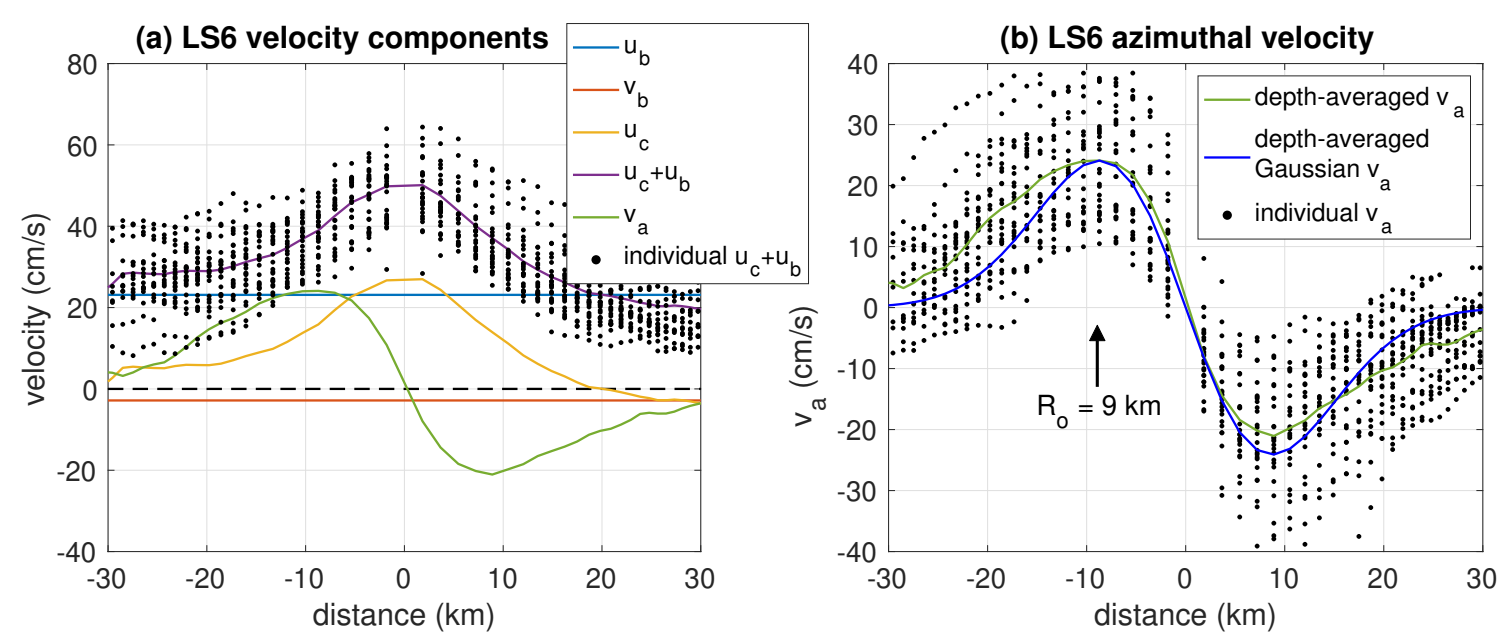

Figure 3-7: (a) Decomposed depth-averaged velocity components for centered cyclones at LS6 (see the legend). (b) The azimuthal velocity from (a) (green curve) and the fitted perfect Gaussian (blue curve). The radius of maximum azimuthal flow $\left(R_{0}\right)$ is indicated. The black dots in (a) and (b) are the values of $u_{c}+u_{b}$ and $v_{a}$, respectively, from the individual eddies used to compute the composite feature.

the eddy. A similar $u_{c}(x)$ profile is obtained when doing the analogous calculation at mooring LS5 $\left(u_{c, \max }=30 \mathrm{~cm} / \mathrm{s}\right)$ and LS7 $\left(u_{c, \max }=35 \mathrm{~cm} / \mathrm{s}\right)$. It should be noted, however, that only one feature passed centered at LS5 and one at LS7. Subtracting $v_{b}$ from the composite cross-stream velocity of the centered features (Figure 3-6d) gives the azimuthal flow of the cyclone, $v_{a}(x)$. This reveals a maximum azimuthal velocity of $24 \pm 0.6 \mathrm{~cm} / \mathrm{s}$ at a radius of $9 \pm 1 \mathrm{~km}(21 \mathrm{~cm} / \mathrm{s}$ at $6 \mathrm{~km}$ for LS5; $25 \mathrm{~cm} / \mathrm{s}$ at 12 $\mathrm{km}$ for LS7). Additionally, included in Figure 3-7a,b are the depth-averaged velocity profiles for each of the 26 cyclones that constitute the composite feature. Table 3.1 presents the derived velocities for the composite cyclone, as well as the average and standard deviation of these properties for the 26 individual features that make up the composite. As these statistics reveal, the derived properties $\left(u_{c, \max }, v_{a, \max }\right.$, and $\left.R_{0}\right)$ are consistent between the composite and the average of the individual features.

Returning to the perfect Gaussian eddy introduced in equation (2), we take $R_{0}$ to be $9 \mathrm{~km}$ and $v_{0}$ to be $24 \mathrm{~cm} / \mathrm{s}$, based on the composite at LS6 (Figure 3-7a). The resulting azimuthal flow of the perfect Gaussian eddy shows excellent agreement with the data (compare the blue and green curves in Figure 3-7b). The value of $R_{0}$ (for each of the moorings) is consistent with the fact that the cyclones were only detected 
Table 3.1: Composite properties and statistical average and standard deviation for the 26 centered eddies.

\begin{tabular}{|l|l|l|l|l|l|l|}
\hline & $\begin{array}{l}\text { Total } \\
\text { along- } \\
\text { stream } \\
\text { flow } \\
u_{b}+u_{c, \max } \\
(\mathrm{cm} / \mathrm{s})\end{array}$ & $\begin{array}{l}\text { Core prop- } \\
\text { agation } \\
\text { velocity } \\
u_{c, \max }\end{array}$ & $\begin{array}{l}\text { Azimuthal } \\
\text { speed } \\
v_{a, \max } \\
(\mathrm{cm} / \mathrm{s})\end{array}$ & $\begin{array}{l}\text { Radius } \\
(\mathrm{km})\end{array}$ & $\begin{array}{l}\text { DSOW } \\
\text { Transport } \\
(\mathrm{Sv})\end{array}$ & $\begin{array}{l}\text { Rossby } \\
\text { Number }\end{array}$ \\
\hline $\begin{array}{l}\text { Composite } \\
\text { Cyclone } \\
\begin{array}{l}\text { Individual } \\
\text { Cyclones }\end{array}\end{array}$ & $51 \pm 8$ & $27 \pm 8$ & $24 \pm 0.6$ & $9 \pm 1$ & $\mathrm{NA}$ & 0.44 \\
\hline
\end{tabular}

at a single site; i.e. their radii are smaller than the mooring spacing $(\sim 15 \mathrm{~km})$. Using both the composite feature and the individual features, Rossby numbers are found to lie between 0.4-0.6, indicating that the cyclostrophic effects are important and the centrifugal term impacts the velocity structure within the features (e.g. McWilliams, 1985).

The derived core propagation velocity of these cyclonic features $(27 \mathrm{~cm} / \mathrm{s})$ can be compared to that of a topographic Rossby wave in the long-wave, linear limit,

$$
c=\frac{g^{\prime}}{f} \frac{d H}{d y}
$$

where $g^{\prime}$ is the reduced gravity and $d H / d y$ is the topographic slope (Nof, 1983; Pedlosky, 2003). Using the mooring and shipboard echosounder data, respectively, to determine values of $g^{\prime}\left(9.5 * 10^{-4} \mathrm{~m} / \mathrm{s}^{2}\right.$, calculated using a layer-wise approximation near the $27.75 \mathrm{~kg} / \mathrm{m}^{3}$ isopycnal) and $d H / d y(0.03)$, a Rossby wave propagation of 23 $\mathrm{cm} / \mathrm{s}$ is estimated. This compares well with the observed core propagation velocity of the cyclones.

It is enlightening to compare these derived eddy properties to those discussed in von Appen et al. (2014b) for DSOW cyclones $280 \mathrm{~km}$ south of Denmark Strait. Using their mooring data (Figure 3-1; DS Array), von Appen et al. (2014b) diagnosed a mean radius $R_{0}$ of $7.8 \mathrm{~km}$, a maximum azimuthal velocity of $22 \mathrm{~cm} / \mathrm{s}$, and an eddy core propagation velocity of $45 \mathrm{~cm} / \mathrm{s}$. While the first two estimates are very similar to the 
values deduced here $(9 \mathrm{~km}$ and $24 \mathrm{~cm} / \mathrm{s}$, respectively), the core propagation velocity near Cape Farewell is significantly slower $(27 \mathrm{~cm} / \mathrm{s})$. This is important because at the DS array the cyclones are less able to kinematically trap water, i.e. $u_{c, \max }>$ $v_{a, \max }\left(\right.$ Flierl, 1981). By contrast, one sees in Figure 3-7a that $u_{c, \max }$ is comparable to $v_{a, \max }$ at the WG array. This suggests that, as the features progress southward, they slow to the point where they may be able to trap water in a wider radius. However, in both regions the water mass at the core of the eddies must be translated with the features since it is this high potential vorticity water that is responsible for the eddy itself. We note that both the translational speed and azimuthal flow of the composite eddy are depth dependent (Figure 3-6c,d). However, the background velocity is also depth-dependent, such that the vertical profile of $u_{c, \max } / v_{a, \max }$ remains order one versus depth (Figure 3-8). Hence, water can be trapped throughout the water column, including the DSOW in the bottom layer.

Using the vertical profiles of velocity obtained from the observations, we extended the formulation of the model eddy in section 3.3.2 so that it varies with depth. To do so, we fit a Gaussian to the vertical profiles of $u_{c}$ and $v_{a}$, and applied a linear fit to the vertical profile of $u_{b}$ (see Figure 3-8a for the Gaussian fit to $u_{c}$ ). In the reference frame moving with the eddy, the streamlines were then computed at different depths. Closed streamlines represent regions where fluid can be trapped, and our calculation revealed that the model cyclone traps water at all depths below $400 \mathrm{~m}$, with a maximum trapping radius of $20 \mathrm{~km}$ from the center at $900 \mathrm{~m}$ depth. This further demonstrates that these features can trap water throughout much of the water column.

\subsubsection{Influence on transport}

We now investigate the impact of the cyclones on the transport of the boundary current system. The OSNAP WG array measures all of the components of the West Greenland boundary current, as well as an offshore cyclonic recirculation gyre (Pacini et al., 2020). The division between the boundary current regime and the gyre can be defined as the contour of $10 \%$ of the maximum boundary current velocity, which on average is the $8 \mathrm{~cm} / \mathrm{s}$ contour (Pickart and Spall, 2007; Pacini et al., 2020). Using 
(a)

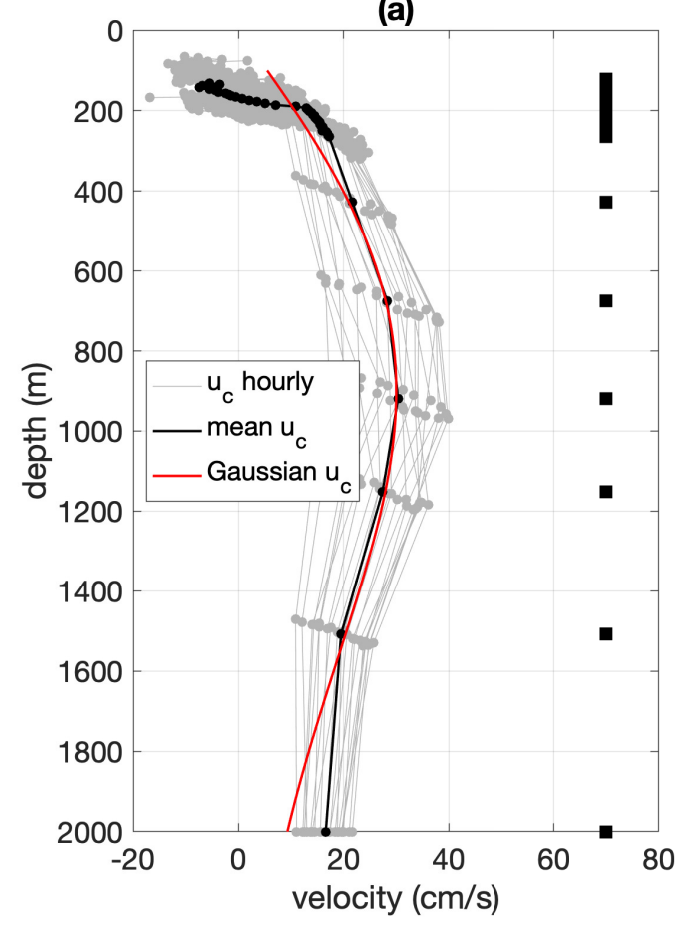

(b)

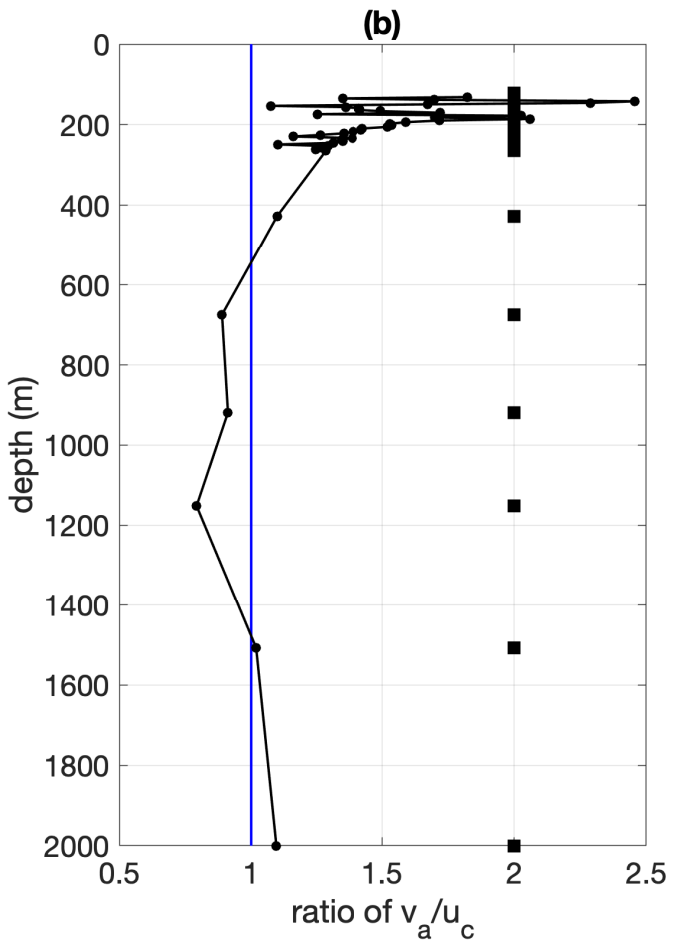

Figure 3-8: Depth-dependent velocity structure of composite cyclone. (a) Depthdependent profiles of $u_{c}$ from $10 \mathrm{~h}$ before to $10 \mathrm{~h}$ after the center of the feature (gray lines), average profile of $u_{c}$ during this 20 -h period (black line), and the Gaussian fit to the depth-dependent $u_{c}$ (red line). Black squares indicate mean instrument depths. (b) Depth-dependent ratio of $v_{a} / u_{c}$.

this criterion, Pacini et al. (2020) calculated a total boundary current transport of $29.9 \pm 0.3 \mathrm{~Sv}$ and a recirculation transport of $1.2 \pm 0.2 \mathrm{~Sv}$ using the gridded product described in Section 2.1. Following Pacini et al. (2020), we define NEADW as water more saline than 34.92 and denser than $27.74 \mathrm{~kg} / \mathrm{m}^{3}$, and DSOW as water fresher than 34.92 and denser than $27.8 \mathrm{~kg} / \mathrm{m}^{3}$. These definitions account for the reduction in density of NEADW through entrainment along its pathway around the subpolar gyre.

As discussed in subsection 3.3.2, each cyclone is associated with an anomalous lens of overflow water at the base of the feature. This can be seen in the composite cyclone of Figure 3-6, as well as for individual features propagating past the array. Shown in Figure 3-9 is a depth versus time plot of along-stream velocity, cross-stream velocity, and temperature over a three-month period (Sep-Nov 2014), where the passage of 
Table 3.2: Composite properties and statistical average and standard deviation for the 26 centered eddies.

\begin{tabular}{|l|l|l|l|l|}
\hline & Total $(\mathrm{Sv})$ & $\begin{array}{l}\text { Without all } \\
\text { cyclones }(\mathrm{Sv})\end{array}$ & $\begin{array}{l}\text { Only cen- } \\
\text { tered cy- } \\
\text { clones }(\mathrm{Sv})\end{array}$ & $\begin{array}{l}\text { Difference } \\
(\mathrm{Sv})\end{array}$ \\
\hline Total & $29.9 \pm 0.3$ & $29.7 \pm 0.4$ & $32.5 \pm 0.7$ & 2.8 \\
NEADW & $5.5 \pm 0.5$ & $5.5 \pm 0.4$ & $6.6 \pm 0.4$ & 1.1 \\
DSOW & $5.0 \pm 0.3$ & $4.7 \pm 0.3$ & $5.5 \pm 0.3$ & 0.8 \\
$\sigma_{\theta}>27.8 \mathrm{~kg} / \mathrm{m}^{3}$ & $8.3 \pm 0.2$ & $8.0 \pm 0.2$ & $9.4 \pm 0.2$ & 1.4 \\
\hline
\end{tabular}

cyclones is indicated along the top. All but one of the cold anomalies at depth (between $1200 \mathrm{~m}$ and $2000 \mathrm{~m}$ ) were associated with an identified cyclone.

We assess the influence of the eddies on the transport by considering only the centered cyclones at LS6. This is because the core propagation velocity of non-centered features will be misrepresented by the mooring, since some of the azimuthal flow will be folded into the alongstream transport and the mooring could sample outside the region of core propagation. The results are presented in Table 3.2, where only the water within the boundary current is considered (i.e. excluding the recirculation gyre). The first column is the four-year mean transport of the specified component of the boundary current, discussed in detail in Pacini et al. (2020). When the 26 centered cyclones identified and described in section 3.3.2 are considered, it indicates that the cyclonic eddies enhance the total transport of the boundary current by 2.8 Sv. Broken down by water mass, $0.8 \mathrm{~Sv}$ of this increase is found in the DSOW, while the transport of NEADW increases by $1.1 \mathrm{~Sv}$. Hence, the overflow water transport is enhanced by 1.9 Sv over that of non-eddy periods, a $19 \%$ increase. (When considering the traditional definition of overflow water, $\rho>27.8 \mathrm{~kg} / \mathrm{m}^{3}$, the increase is $1.4 \mathrm{~Sv}$ or $18 \%)$.

von Appen et al. (2014b) estimated that the DSOW cyclones enhance the transport of overflow waters (denser than $27.74 \mathrm{~kg} / \mathrm{m}^{3}$ ) by $0.7-1.2 \mathrm{~Sv}$ at the DS mooring array south of Denmark Strait, seemingly consistent with our result. However, when restricting their density criterion to $27.8 \mathrm{~kg} / \mathrm{m}^{3}$, they calculate an increase in DSOW transport of 0.01-0.26 Sv due to the cyclones, significantly less than that measured 

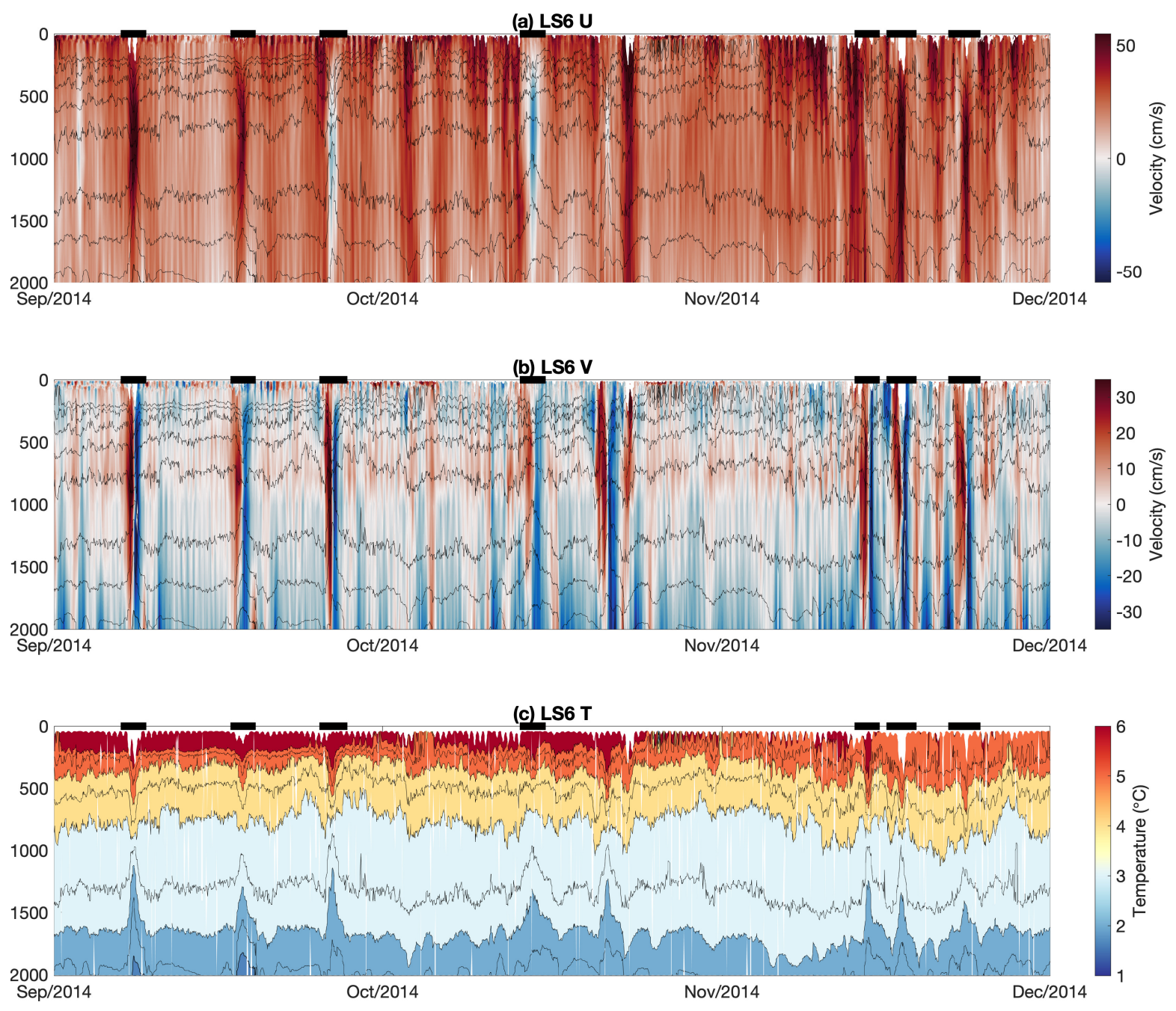

Figure 3-9: Depth-time plot of (a) along-stream velocity, (b) cross-stream velocity, and (c) potential temperature. Potential temperature is contoured, with identified cyclones at LS6 denoted by the black bars along the top, for September through November 2014. The feature on October 22, not identified as a cyclone, was a dipole pair.

here. It is worth noting that the CTD profilers on their moorings did not function when an eddy center passed close to a mooring (due to the significant mooring blowdown). Hence, their transport estimates are biased low by not measuring the full extent of the dense water lens. This makes a transport comparison between our site and the DS array problematic. Interestingly, most of the features measured at the DS array were located near the $900 \mathrm{~m}$ isobath, while the vast majority of cyclones 
detected at both OSNAP arrays were near the $2000 \mathrm{~m}$ isobath. It is plausible that these are the same train of cyclones, since the eddies move downslope as they progress equatorward (Bruce, 1995). In particular, Bruce (1995) deduces a descent rate of 2.3 m/km from satellite SST imagery, and von Appen et al. (2014b) deduce a downslope motion of $2.7 \mathrm{~m} / \mathrm{km}$. Integrated over the $750 \mathrm{~km}$ between the DS array and OSNAP EG, this suggests the cyclones would descend from $900 \mathrm{~m}$ to approximately $2800 \mathrm{~m}$ by the time they reach the OSNAP EG array (where they are sampled at $2000 \mathrm{~m}$ ). While this predicted descent is somewhat larger than the actual descent observed, it is important to note that the descent rate, which is a function of local topography, translational velocity of the feature, and background along- and cross-stream velocity, likely changes along the feature's trajectory. There were also a significant number of cyclones sampled deeper on the continental slope at the DS array, extending to nearly $1600 \mathrm{~m}$ (von Appen et al., 2014b). We saw no such offshore spread of cyclones at the OSNAP WG array, suggesting that these deeper features did not progress around Cape Farewell.

\subsubsection{Synoptic realization of cyclones from shipboard data}

High-resolution hydrographic surveys of the boundary current east and west of Cape Farewell have been performed during each of the OSNAP mooring turn-around cruises (2014, 2016, 2018, and 2020; e.g. Lin et al. 2018). Notably, during three of these four cruises at least one mid-depth intensified cyclonic eddy, transporting enhanced overflow water at depth, was sampled. During the 2020 cruise, a synoptic survey of the EGC was carried out over a period of 56 hours (Figure 3-10a). Shipboard ADCP data were collected along each of the lines, including measurements from the $38 \mathrm{kHz}$ instrument which extended to $1000 \mathrm{~m}$, while CTD stations extending to $500 \mathrm{~m}$ depth were occupied on two of them (the goal was to carry out the velocity survey quickly, with limited hydrographic coverage). As it happens, on both of the CTD lines we sampled a DSOW cyclone.

These synoptic crossings of cyclones are consistent with the individual and composite features observed at the OSNAP EG and WG arrays. Shown in Figure 3-10 

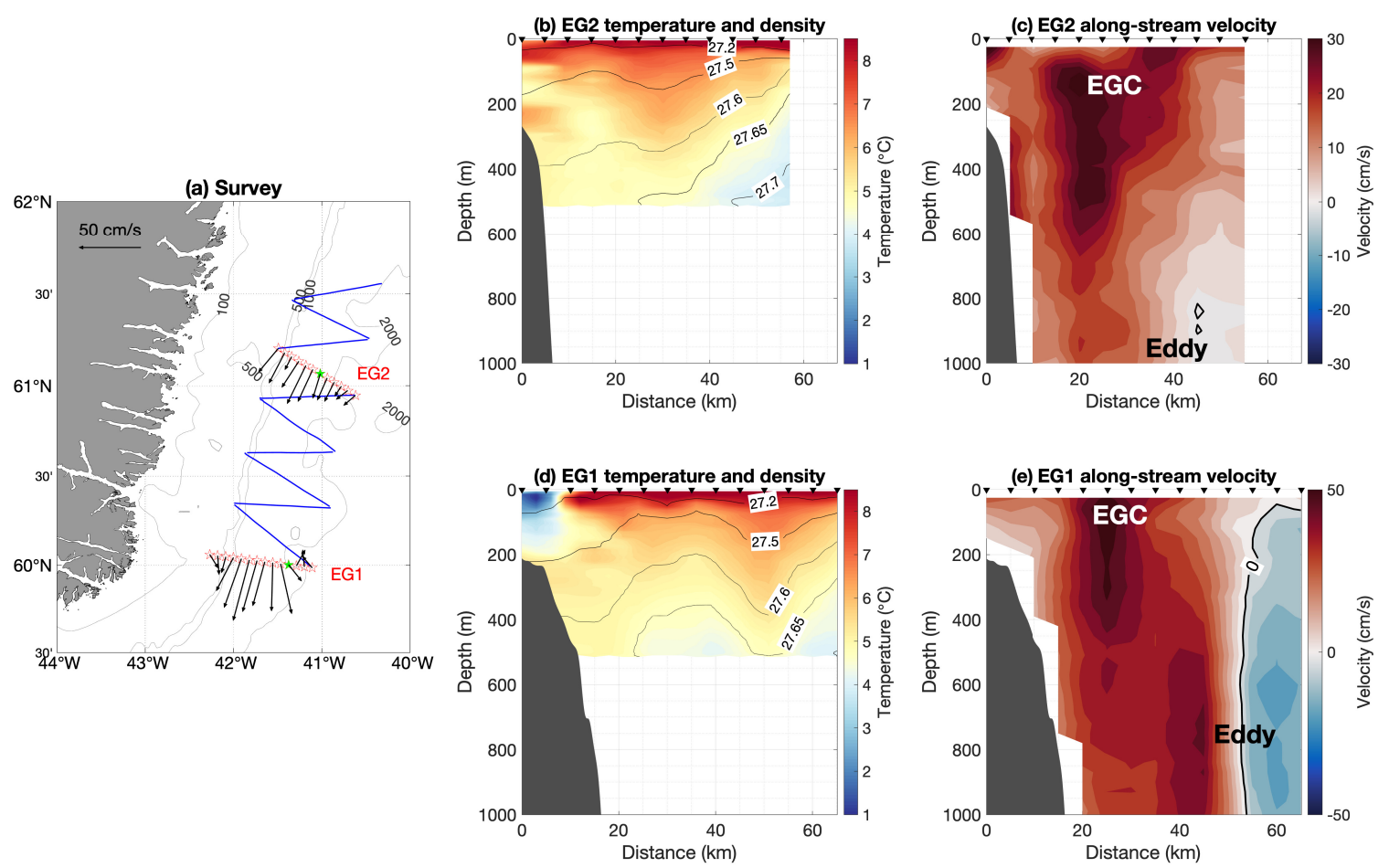

Figure 3-10: Results from the EGC survey performed during the July 2020 OSNAP mooring cruise. (a) Map of the survey, where blue lines indicate ADCP sections, and red stars mark the stations of the two hydrographic sections. The two green stars indicate the center of the EG1 and EG2 eddies. Vectors are depth-mean velocity vectors from 0-1000 $\mathrm{m}$. The bathymetry is from ETOPO2. (b) Temperature (color) overlain by isopycnals (contours, $\mathrm{kg} / \mathrm{m}^{3}$ ) for the EG2 transect. The bathymetry is shown in grey (from the Multibeam echosounder on R/V Neil Armstrong), and inverted triangles indicate the locations of the CTD stations. (c) Along-stream velocity from the $38 \mathrm{kHz}$ ADCP for the EG2 transect. (d) Same as (b) for the EG1 transect. (e) Same as (c) for the EG1 transect. Note that the hydrographic casts extend to 500 $\mathrm{m}$, while the ADCP coverage reaches $1000 \mathrm{~m}$.

are the temperature and along-stream velocity vertical sections for both transects. The southern cyclone, sampled at transect EG1 (Figure 3-10d,e) was sampled first. In this realization the surface-intensified EGC was flowing southward (order $50 \mathrm{~cm} / \mathrm{s}$ ) associated with upward-sloping isopycnals extending offshore of the shelfbreak (Figure 3-10d,e). Seaward of this, the isopycnals plunge $200 \mathrm{~m}$ and then rebound over a $20 \mathrm{~km}$ range, indicating the top portion of a cyclonic feature with a radius of $\sim 10$ $\mathrm{km}$. This is corroborated by the ADCP data, which extend deeper than the CTD 
data and reveal a symmetric region of enhanced flow centered near $800 \mathrm{~m}$ (where we would expect to see the isopycnals pinching if the hydrographic coverage extended this deep). The velocities are directed strongly to the south on the onshore side of the bowling isopycnals and to the north on the offshore side. This is consistent with our observations of DSOW cyclones at the LS6 mooring (Figure 3-6), suggesting that this transect sliced the eddy close to its center.

The EG2 transect did not sample through the core of the northern cyclone, as evidenced by the discrepancy between its northward and southward flow (the velocity at the offshore side of the feature was barely reversed, Figure 3-10c). The bowling of the isopycnals was much less pronounced, again consistent with the notion that the transect did not pass through the center of the feature. The isopycnal bowling was closer to the shelfbreak than for the EG1 transect, indicating that the cyclone was situated closer to the EGC than the feature to the south. Again, the cyclonic flow measured by the ADCP was situated directly below the bowling isopycnals, where the pinching of isopycnals of a cyclonic feature is expected. The shallow signature of the cyclone is masked by the EGC. While the northern cyclone is immediately adjacent to the EGC and the southern cyclone is $20 \mathrm{~km}$ offshore of the jet, the two features were propagating along the same isobath, $2030 \mathrm{~m}$, in line with the OSNAP EG and WG mooring data indicating that the majority of cyclones pass near the $2000 \mathrm{~m}$ isobath.

The OSNAP EG data revealed that a cyclonic feature goes by the array on average every 4.5 days. Is this consistent with the two cyclones sampled during our synoptic EGC survey? Using the background and core propagation velocity for the composite feature computed above, we assume that the two cyclones measured in the EGC survey are traveling southward at a speed of $u_{b}+u_{c, \max }$. This allows us to estimate the distance that the southern feature traveled between the time it was sampled and when the northern feature was sampled. Adding this to the distance between the two CTD sections gives the spacing between the cyclones, which, when divided by $u_{b}+u_{c, \text { max }}$, provides the temporal offset between the cyclones. Using $u_{b}=23 \mathrm{~cm} / \mathrm{s}$ and $u_{c, \max }=27 \mathrm{~cm} / \mathrm{s}$ from the LS6 composite (Figure 3-7a), this gives a separation time of 4.3 days, which agrees well with the value of 4.5 days deduced from the OSNAP 
EG mooring data.

\subsection{Discussion and conclusions}

Using four years of mooring data from the OSNAP WG mooring array, abundant cyclonic eddies have been observed throughout the length of the deployment. These features have not been described in the Labrador Sea prior to this study, either from an observational or modeling perspective. The features are mid-depth intensified, have no apparent seasonality in presence, can kinematically trap water, and are associated with a $2.8 \mathrm{~Sv}$ increase in boundary current transport, $1.9 \mathrm{~Sv}$ of which corresponds to overflow waters. Most of the features were detected by the mooring situated near the $2000 \mathrm{~m}$ isobath. A composite centered eddy was constructed for this site, revealing the structure and relevant length scales of these features. On average they have a radius of $9 \pm 1 \mathrm{~km}$, core propagation velocity of $27 \pm 8 \mathrm{~cm} / \mathrm{s}$, and maximum azimuthal velocity of $24 \pm 0.6 \mathrm{~cm} / \mathrm{s}$.

These same features are also found upstream at the OSNAP EG mooring array. Their kinematic and hydrographic properties, as revealed by the mooring arrays and a synoptic shipboard survey, indicate that they are downstream manifestations of DSOW cyclones, which are mid-depth-intensified features formed by mesoscale variability in Denmark Strait. von Appen et al. (2014b) reported that these features occur every 2 days at a mooring array $280 \mathrm{~km}$ south of Denmark Strait at the 900 $\mathrm{m}$ isobath, while the OSNAP EG array measures them every 4.5 days at the $2000 \mathrm{~m}$ isobath and the OSNAP WG array samples them every 7.6 days, also near the 2000 $m$ isobath. Thus, not all DSOW cyclones are able to reach the OSNAP EG array, and fewer still are able to round Cape Farewell into the Labrador Sea. This leads us to hypothesize that the remainder of the eddies either dissipate, are shed into the interior Irminger Sea, or are retroflected at Cape Farewell along with part of the mean $\mathrm{EGC} / \mathrm{DWBC}$.

The equatorward flow of dense water constitutes the lower limb of the AMOC, and

this study has revealed that DSOW cyclones in the Labrador Sea contribute signifi- 
cantly to the export of overflow water (a 19\% increase at OSNAP WG during cyclonic activity). Using repeat occupations of the AR7W section across the Labrador Sea, Pickart and Spall (2007) observed increased variance of the boundary current near the $2000 \mathrm{~m}$ isobath along the West coast of Greenland. While the authors speculated that this variability is driven by bottom-trapped topographic Rossby waves, it is possible that the deduced variability can be attributed to the presence and propagation of DSOW cyclones (see Figure 3b, Pickart and Spall 2007). Given the role of the Labrador Sea as a site for deep convection, it is critical that we understand the variability of the boundary current system encircling the sea and how this could affect the interior stratification. Now that these features have been discovered, we need to understand how they influence the boundary current and what role they might play in transporting heat and freshwater into the interior of the basin - and ultimately how they dissipate. This must be factored into modeling studies in order to properly simulate and quantify the overturning in the Labrador Sea.

\subsection{Data availability}

The calibrated mooring and hydrographic data are available at www.o-snap.org. Specifically, the 2014-2016 OSNAP WG data can be found at https://doi.org/ 10.7924/r4fj2dr7k and the 2016-18 OSNAP WG data can be found at https: //doi.org/10.35090/fz80-6c32. The OSNAP EG data can be found at https: //doi.org/10.7924/r4fb50z9b, and the U.K. M1 mooring data can be found at https://doi.org/10.5285/6cb6dc0c-7bed-3ca4-e053-6c86abc0b9f0.

\subsection{Acknowledgements}

The authors thank the captain and crew of the R/V Knorr and R/V Neil Armstrong for the success of the OSNAP deployment and recovery cruises. John Kemp, Jim Ryder, Brian Hogue, Andrew Davies, and Rick Trask designed, fabricated, and deployed the moorings and instruments. Leah McRaven processed the shipboard CTD data 
and Frank Bahr processed the shipboard ADCP data. We would like to acknowledge the two anonymous reviewers whose input substantially improved the paper. A.P. and R.S.P. were funded by National Science Foundation Grants OCE-1259618 and OCE-1756361. I.L.B. and F.S. were funded by National Science Foundation Grants OCE-1258823 and OCE-1756272. N.P.H. was supported by the Natural Environment Research Council U.K. OSNAP program (NE/K010875/1 and NE/K010700/1). M.A.S. was supported by NSF Grants OCE-1558742 and OPP-1822334. 


\title{
Chapter 4
}

\section{Meanders of the West Greenland Current near Cape Farewell}

\begin{abstract}
The cyclonic boundary current that circumnavigates the Labrador Sea plays an important role in modulating the strength of wintertime convection in the interior basin, as well as restratifying the newly ventilated water in spring. Modeling studies indicate that meso and sub-mesoscale processes in the boundary current flux a significant amount of heat and freshwater offshore, although observations of this small-scale variability are lacking. Using four years of data from a mooring array west of Cape Farewell, Greenland, together with satellite altimetry and sea surface temperature measurements, we present the first observations of a meandering West Greenland Current. We describe the statistics, structure, characteristics, and formation mechanism of these features. The meanders occur roughly $30 \%$ of the time and are more prevalent in winter and early spring, with an increasing trend over the four-year record. It is shown that baroclinic instability of the boundary current is the cause of the meanders, triggered by seasonal steepening of the isopycnals between the interior basin and the boundary due to offshore convection. We argue that the meandering leads to the formation of small-scale eddies, and estimate the resulting seaward heat flux. Finally, possible connections between the meanders and the production of Irminger Rings are explored.
\end{abstract}

This chapter has been published as Pacini, A. and Pickart, R.S. (2022). Meanders of the West Greenland Current near Cape Farewell. Deep-Sea Research I, 179, 103664. (C) Elsevier. Used with permission. 


\subsection{Introduction}

Open-ocean convection in the Labrador Sea produces intermediate waters that contribute to the lower limb of the Atlantic Meridional Overturning Circulation (AMOC). The formation and subsequent spreading of these intermediate waters helps to regulate the circulation and stratification of the subpolar North Atlantic (Talley and McCartney, 1982; Sy et al., 1997; Rhein et al., 2002) and sequester carbon from the atmosphere to the deep ocean (Takahashi et al., 2009; Khatiwala et al., 2013). The production of this water mass, known as Labrador Sea Water (LSW; e.g. Clarke and Gascard 1983; Lab Sea Group 1998; Pickart et al. 2002), is influenced by airsea heat fluxes and wind stress in the subpolar gyre, which vary in concert with the North Atlantic Oscillation (Hurrell, 1995; Våge et al., 2009a). Convection in density space (diapycnal transformation) occurs both in the interior Labrador Sea and in the boundary current that circumnavigates it (Spall and Pickart, 2001; Pickart et al., 2002; Spall, 2004; Pickart and Spall, 2007), while overturning in depth space occurs only in the boundary current, where planetary geostrophic dynamics break down (Spall, 2010; Cessi and Wolfe, 2013).

The boundary current system that transports waters cyclonically around the Labrador Sea plays a crucial role in the production and export of LSW (Pickart, 1992; Dickson and Brown, 1994; Cuny et al., 2002; Fischer et al., 2010). In particular, it is responsible for fluxing heat and freshwater to the interior basin (Prater, 2002; Hátún et al., 2007; Lilly et al., 1999; Lilly and Rhines, 2002; Lilly et al., 2003) that then helps dictate the preconditioning of the water column to convection, as well as the restratification that occurs after the wintertime overturning (Lilly et al., 1999; Lilly and Rhines, 2002; Lilly et al., 2003; Katsman et al., 2004; Chanut et al., 2008; Gelderloos et al., 2011). The boundary current system is composed of three different branches. A coastal current, known as the West Greenland Coastal Current (Labrador Coastal Current), is found on the shelf on the eastern (western) side of the basin. This coastal current transports cold and fresh Arctic-origin and Greenland melt waters on the shelf (Fig 1; Lin et al. 2018; Florindo-López et al. 2020). 
This surface-intensified jet is tied to the shelfbreak and transports cold, fresh waters at the surface, and warm, saline, Atlantic-origin waters at depth (Colbourne et al., 1994; Rykova et al., 2015). The Atlantic-origin water mass (known as Irminger Water (IW); e.g. Lazier et al. 2002) is important due to its impact on stratification. While previous literature refers to the Labrador Coastal Current as the inshore branch of the Labrador Current (e.g. Lazier and Wright, 1993) we follow the convention of Florindo-López et al. (2020) and refer to it as a coastal current, due in part to the governing dynamics differing between the offshore and inshore branches. Finally, the Deep Western Boundary Current (DWBC), centered near the $3000 \mathrm{~m}$ isobath, transports cold, dense overflow waters formed north of the Greenland Scotland Ridge that are advected around the subpolar gyre at depth (Dickson and Brown, 1994).

Observational and modeling studies have highlighted the high levels of eddy kinetic energy (EKE) found in the boundary current and interior Labrador Sea (e.g. Gascard and Clarke, 1983; Lilly et al., 1999; Eden and Böning, 2002; Prater, 2002; Lilly et al., 2003; Chanut et al., 2008). In particular, this EKE is a consequence of energetic mesoscale and submesoscale processes that can be divided into four main categories: (1) Irminger Rings (IRs), (2) Convective Eddies (CEs), (3) Boundary Current Eddies (BCEs), and (4) Denmark Strait Overflow Water Cyclones (DSOW Cyclones). While the first three features have a surface signature, the DSOW cyclones are mid-depth intensified. Models often overestimate the production of ventilated water in the Labrador Sea (Li et al., 2019), due to their inability to resolve these mesoand submesoscale processes. This large LSW production in models is in contrast with recent observations highlighting the eastern portion of the subpolar gyre as the dominant region for overturning, versus the Labrador Sea (Lozier et al., 2019). In a comparison between four models with differing resolution, Tagklis et al. (2020) demonstrated a linear dependence between vorticity fields (and associated frontogenesis) in the boundary currents and the production of LSW in the interior basin. As the model resolution increased, the vorticity in the boundary current increased, and the convected volume shrank, consistent with the notion that small-scale eddies from the boundary current are responsible for transporting buoyant water that limits the 
lateral extent of the convective patch (e.g. Rieck et al., 2019). Similarly, Pennelly and Myers (2020) compared eddy kinetic energy in a $1 / 60^{\circ}$ model of the Labrador Sea with lower resolutions, emphasizing the importance of resolving eddies in order to properly quantify fluxes important for deep water formation. It is critical to understand the driving mechanisms behind this variability in order to accurately represent the production of dense water in climate models.

IRs are large $(30-40 \mathrm{~km})$, predominantly anticyclonic eddies shed from the West Greenland Current near $61^{\circ} \mathrm{N}$ (Figure 4-1), and transport IW southwestward (e.g. Lilly and Rhines, 2002; Lilly et al., 2003; Hátún et al., 2007; de Jong et al., 2016). While studies disagree as to their exact formation mechanism (whether it is baroclinic or barotropic instability), it is clear that they are an important source of buoyancy to the interior basin (e.g. Katsman et al., 2004; Gelderloos et al., 2011) and play a critical role in determining the location of the convective patch (e.g. Chanut et al., 2008; Tagklis et al., 2020). IRs have been observed from mooring data (de Jong et al., 2014), shipboard surveys (Rykova et al., 2009), glider transects (Hátún et al., 2007), and altimetry measurements (Prater, 2002; Lilly et al., 2003).

CEs are formed at the edge of the convective patch at the base of the mixed layer. Theoretical studies demonstrate that small-scale (on the order of the baroclinic deformation radius, $<10 \mathrm{~km}$ ) cyclonic and anticyclonic features develop due to the baroclinically-unstable rim current around the convected region that acts to restratify the patch (Send and Marshall, 1995; Jones and Marshall, 1997; Lilly et al., 2003; Chanut et al., 2008). A small number of anticyclonic CEs have been observed with a mooring (Lilly et al., 2003), and modelling studies at high resolution have found their presence to have varying degrees of influence on the restratification process (e.g. Chanut et al., 2008; Gelderloos et al., 2011).

DSOW cyclones are formed as dense water cascades over the Denmark Strait sill and spins up cyclonic vorticity (Spall and Price, 1998). The features then propagate along the East Greenland slope (Bruce, 1995; von Appen et al., 2014b), and, while previously thought to spin down in the Irminger Sea, they have recently been observed in the West Greenland boundary current system in mooring observations 


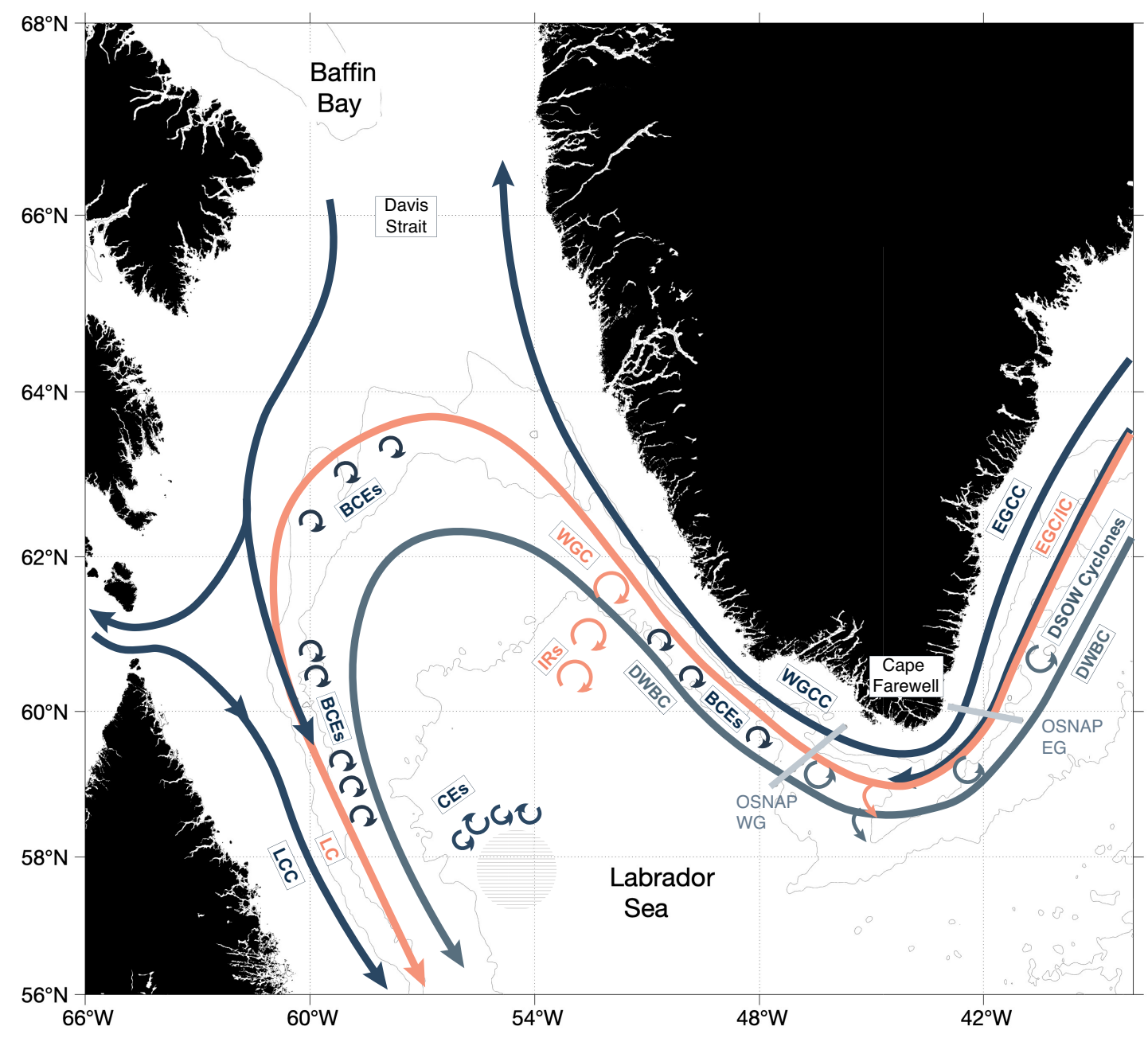

Figure 4-1: Schematic circulation of the Labrador Sea. EGCC is the East Greenland Coastal Current; EGC/IC is the East Greenland Current/Irminger Current; DWBC is the Deep Western Boundary Current; WGCC is the West Greenland Coastal Current; WGC is the West Greenland Current; LCC is the Labrador Coastal Current; LC is the Labrador Current; DSOW Cyclones are Denmark Strait Overflow Water Cyclones; IRs are Irminger Rings; CEs are Convective Eddies; and BCEs are Boundary Current Eddies. The hatched area in the western/central Labrador Sea represents the area of deepest convection. Grey lines across the boundary current with OSNAP EG and WG labels indicate the locations of the OSNAP East and West Greenland mooring arrays, respectively. 
(Pacini et al., 2021) and drifter tracks (Zou et al., 2021). The DSOW cyclones in the boundary current system can trap water and are responsible for a significant increase in overflow water transport as compared to non-cyclonic periods (Pacini et al., 2021). The ultimate fate of DSOW cyclones entering the Labrador Sea is unknown, as is their impact on the stratification of the interior.

Finally, BCEs are small-scale (order $10 \mathrm{~km}$ ) features formed along the boundary between the West Greenland Current/Labrador Current and the interior due to baroclinic instability. Modeling studies with significantly high resolution $\left(<1 / 12^{\circ}\right)$ show the production of such features and associated levels of high EKE offshore of the boundary current system (Chanut et al., 2008; Gelderloos et al., 2011; Rieck et al., 2019). As wintertime convection continues in the interior Labrador Sea, the density gradient between the interior and the boundary current sharpens, which leads to increased baroclinic instability and the production of BCEs (Eden and Böning, 2002; Spall, 2004; Gelderloos et al., 2011; Thomsen et al., 2014). These features are smaller, shallower, and less related to local topography than the Irminger Rings found int he northeastern corner of the Labrador Sea. The importance of BCEs in the heat and freshwater budget of the interior Labrador Sea is an active topic of research, as some modelling studies argue they play a critical role in controlling the extent of convection and the timing of restratification (Chanut et al., 2008), whereas other models indicate they are not important outside of the small area where the Labrador Current is adjacent to the convective patch (Gelderloos et al., 2011; Rieck et al., 2019). However, a fundamental knowledge gap exists in our understanding of BCEs, as they have never been observed.

In this study, we use four years of mooring data from the West Greenland shelf and slope to present the first observations of a meandering West Greenland Current (WGC) and argue that this meandering generates BCEs. The structure of the paper is as follows. The data and methods are presented first, and the statistics and structure of the mesoscale features are subsequently characterized. Following this, the question of whether the features are coherent anticyclones or meanders is investigated. Formation mechanisms are then addressed, and the seasonality of the 
instability is documented. Finally, implications for the interior heat budget of the Labrador Sea are considered, long-term trends are investigated, and the relationship with downstream IR production is explored.

\subsection{Data and methods}

\subsubsection{Mooring data}

A high-resolution mooring array was deployed in the West Greenland boundary current system as part of the Overturning in the Subpolar North Atlantic Program (OSNAP; Lozier et al. 2017, 2019) (Figure 4-1 and Figure 4-2). The moorings were deployed in 2014 and have been serviced every two years. In this study we use the first four years of hourly data. The array consists of ten moorings (Figure 4-2): three tripods on the shelf (moorings LS1-LS3), five tall moorings located between the 500 $\mathrm{m}$ and $3000 \mathrm{~m}$ isobaths (moorings LS4-LS8), and two short bottom-instrumented moorings in the DWBC (moorings DSOW3-4). A total of 49 Sea-Bird Scientific MicroCATs recorded pressure, temperature, and conductivity, 33 Nortek Aquadopps recorded pressure and zonal and meridional velocity components, and $375-\mathrm{kHz}$ LongRanger acoustic Doppler current profilers (ADCPs) (LS1, LS2, and LS3) and 5 300$\mathrm{kHz}$ Workhorse ADCPs (LS4 through LS8) measured pressure and velocity profiles in the upper part of the water column. The data and processing are described in detail in Pacini et al. (2020). Hourly gridded vertical sections of different variables were constructed by Pacini et al. (2020); both the individual instrument data and the gridded product will be utilized in this study. The velocity data have been rotated into an alongstream and cross-stream coordinate system which minimizes the integrated cross-stream velocity, and the data were de-tided using the harmonic tidal routine T-TIDE (Pawlowicz et al., 2002). Positive along-stream velocity $(u)$ is oriented par-

allel to the isobaths towards the northwest $\left(318^{\circ} \mathrm{T}\right)$, and positive cross-stream velocity $(v)$ is directed offshore perpendicular to the isobaths, towards the southwest. The gridded product, computed using a Laplacian-spline interpolator (Smith and Wessel, 
1990) has a resolution of $100 \mathrm{~m}$ in the vertical and $5 \mathrm{~km}$ in the horizontal (Pacini et al., 2020).

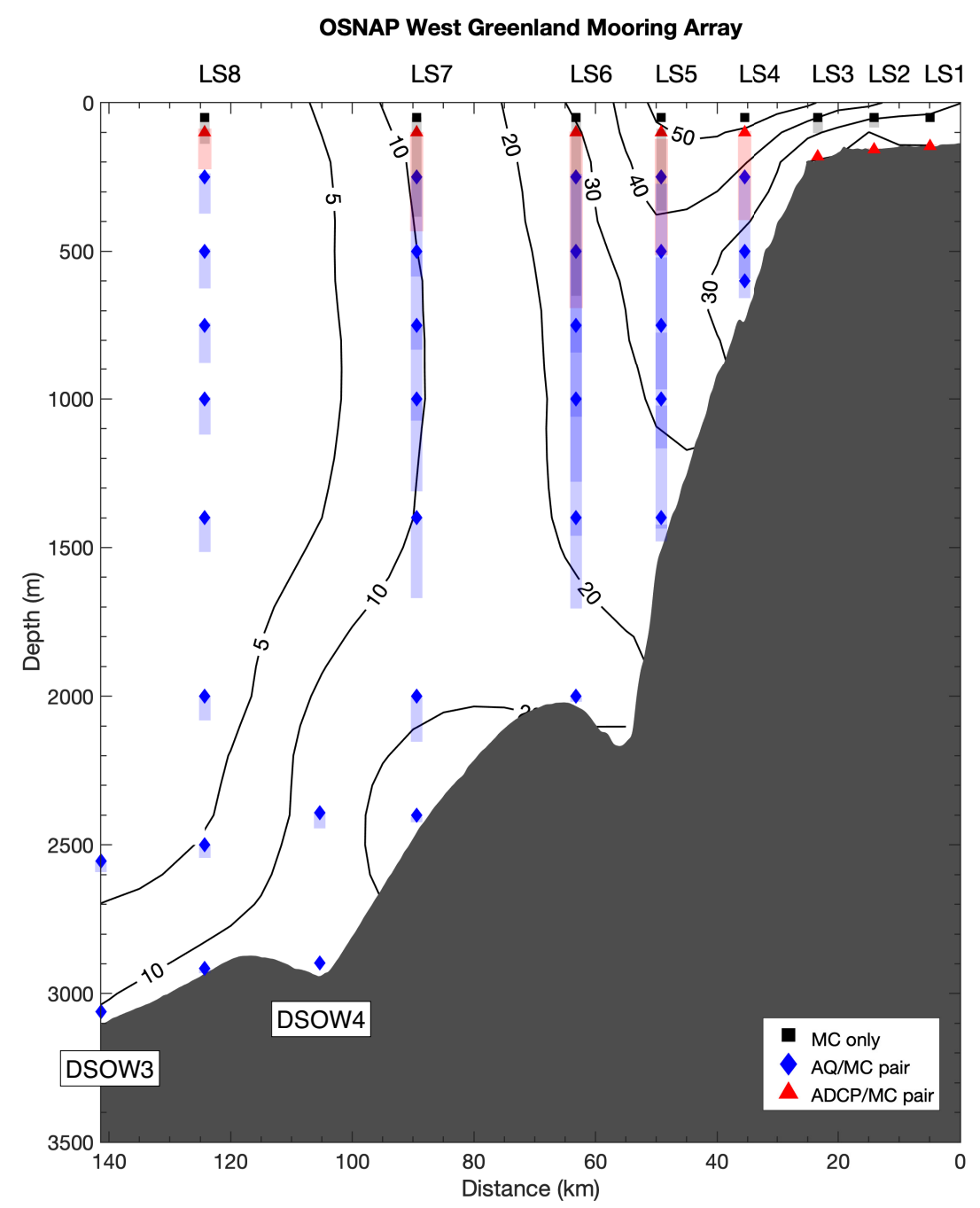

Figure 4-2: Vertical section of instrumentation across the OSNAP WG mooring array. The names of the moorings are labeled and the bathymetry is plotted in grey (derived from a shipboard echosounder). LS1-LS3 are tripods on the shelf; LS4-LS8 are tall moorings; and DSOW4 and DSOW3 are short bottom-mounted moorings. Instrument types are identified in the legend: $\mathrm{MC}=$ MicroCAT; $\mathrm{AQ}=$ Aquadopp; and ADCP = acoustic Doppler current profiler. Shading indicates the range over which the individual instruments were blown down over the course of the two deployments. The contours indicate the four-year mean along-stream velocity outside of eddy periods. The horizontal axis origin, located on the far right of the vertical section, indicates the onshore-most grid cell of the gridded product (defined in the text). 


\subsubsection{Satellite data}

Satellite data are used in parts of the study. Level 2 Modis $4 \mu \mathrm{m}$ Aqua and Terra nighttime sea surface temperature (SST) data are used to investigate along-track SST variability at a nadir resolution of $1 \mathrm{~km}$ (Brown and Minnett, 1999). The data are provided with a data quality flag, which uses sharp gradients to detect the presence of clouds. However, given the strong temperature gradients between the West Greenland Coastal Current (WGCC) and WGC, the algorithm tends to over-reject pixels near the frontal zone of interest to this study. Following von Appen et al. (2014b), a modified processing algorithm is applied, such that temperatures between $-2^{\circ} \mathrm{C}$ and $12^{\circ} \mathrm{C}$ are retained. Sutherland et al. (2013) have shown that sea surface temperature data and observed ocean temperatures remain correlated down to $200 \mathrm{~m}$ in the region near Cape Farewell. Only periods when $75 \%$ of the region of interest $\left(53^{\circ} \mathrm{N}-68^{\circ} \mathrm{N}\right.$, $\left.35^{\circ} \mathrm{W}-69^{\circ} \mathrm{W}\right)$ is not cloud-covered are considered. Based on this criterion, $40 \%$ of the time the region is cloud-covered and does not return a usable satellite pass.

The daily, gridded surface altimetric data product provided by the EU Copernicus Marine Service (CMEMS) is used to investigate surface geostrophic velocities and eddy kinetic energy (EKE) (as in Rieck et al. 2019). The lateral resolution of the grid is $0.25^{\circ}$ and the time period considered is 1 January 2014 to 1 January 2019. EKE is calculated as

$$
E K E=0.5\left(u^{\prime 2}+v^{\prime 2}\right)
$$

where primes indicate deviations from the corresponding yearly mean, in order to avoid the influence of long-term trends on the calculation of EKE (e.g. Penduff et al., 2004; Rieck et al., 2015, 2019).

\subsubsection{Feature detection method}

Instances of enhanced mesoscale activity in the boundary current are identified using a graphical user interface (GUI). The GUI is described in detail in Pacini et al. (2021) who used it to characterize DSOW cyclones at the array location. At each hourly 
timestep, three days of mooring data (depth vs. time) are visualized for the moorings seaward of the shelfbreak, and the user selects instances of mesoscale activity by the mooring number, nature (cyclonic feature, anticyclonic feature, or dipole pair-which is an anticyclonic feature immediately followed by a cyclonic feature), and start and stop times. The user also selects the center of the feature. Instances of such mesoscale activity are identified for all four years for moorings LS5, LS6, LS7, and LS8 (there was no pronounced signal of these features at mooring LS4).

\subsection{Results}

\subsubsection{Statistics and structure of anticyclonic features and dipole pairs}

Using the GUI described in subsection 4.2.3, instances of enhanced mesoscale activity in the boundary current were identified. Abundant anticyclonic features, as well as dipole pairs, were observed within the core, and just offshore, of the WGC. Distinct from this, cyclonic features were observed offshore of the WGC, near $2000 \mathrm{~m}$ at mooring LS6. The latter are the DSOW cyclones referred to above that are presented in Pacini et al. (2021). Here we focus on the anticyclonic features and dipole pairs.

A total of 147 anticyclonic features and 54 dipole pairs were identified, which together account for $31 \%$ of the four-year record (Figure 4-3). The anticyclones were predominantly observed at LS5 (123 at LS5, 24 at LS6), at the location of the core of the mean WGC (Figure 4-2), while the dipole pairs were more often sampled at LS6 (13 at LS5, 41 at LS6), offshore of the mean core location of the WGC (Figure 4-2). The dipoles are composed of a leading anticyclone and a trailing cyclone. We create an index, referred to as the meander index, to quantify the variation in feature presence over the four-year record, defined as the 28-day lowpass of the feature identification logical. This lowpass converts the logical (a binary value of 1 or 0 , corresponding to presence or absence of features, respectively) to a timeseries with values between 0 and

1 that indicate sustained periods of anticyclonic or dipole pair activity (Figure 4-3c). 

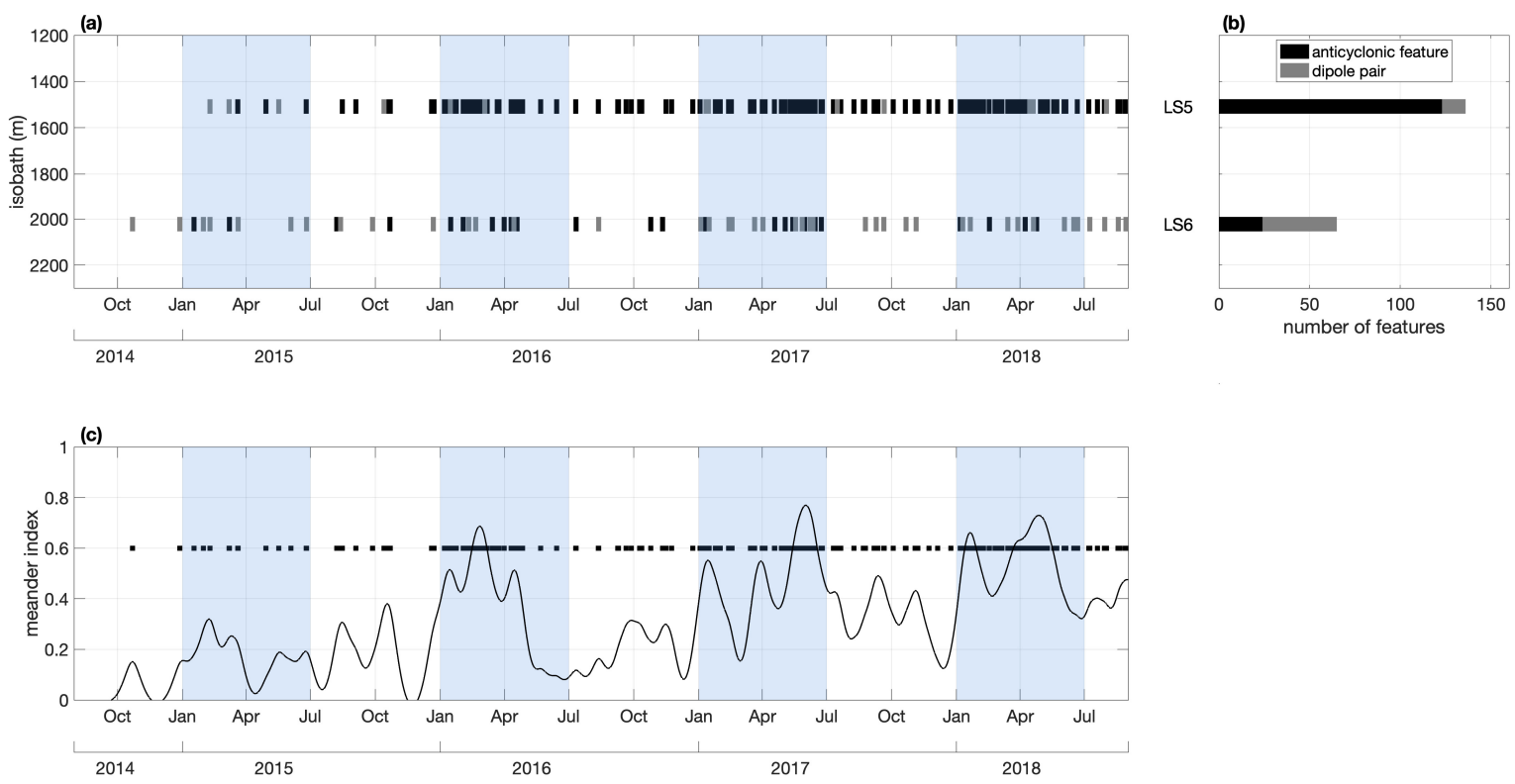

Figure 4-3: (a) Statistics of anticyclonic and dipole features observed at moorings LS5 and LS6 over the four years of data. Black bars indicate anticyclonic features; grey bars indicate dipole pairs. (b) Histogram of features at LS5 and LS6. (c) Timeseries of the meander index (black line; defined as the 28-day lowpass of the feature identification logical) with individual features (both anticyclonic and dipole features) denoted by the black squares. The time period Jan-Jul is indicated each year (blue shading).

Note in Figure 4-3c that there are three periods of enhanced activity that generally occurred during the winter/spring of 2016, 2017, and 2018.

Figure 4-4 shows a Hovmöller plot of the monthly mean eddy kinetic energy (EKE) of the WGC at $300 \mathrm{~m}$. This reveals that the winter/spring time period of all four years exhibited elevated EKE (as high as $300 \mathrm{~cm}^{2} / \mathrm{s}^{2}$ ). The peak in the timing of this EKE maximum shifts between years, as does the magnitude and duration of elevated variability. In 2016 and 2018, the peak in EKE occurs between January and April, while in 2017 the period of elevated EKE extends through June. This is true as well for the presence of anticyclones/dipole pairs (Figure 4-3), which shows enhanced feature activity as identified by the GUI between Jan and April in 2016 and 2018, and a longer period of enhanced activity between January and June in 2017. The EKE signature in winter/spring 2015 is less extensive, which is the year when there 
was no enhanced feature presence. This is addressed further in section 4.3.3

(a) EKE at $\mathbf{3 0 0} \mathrm{m}$

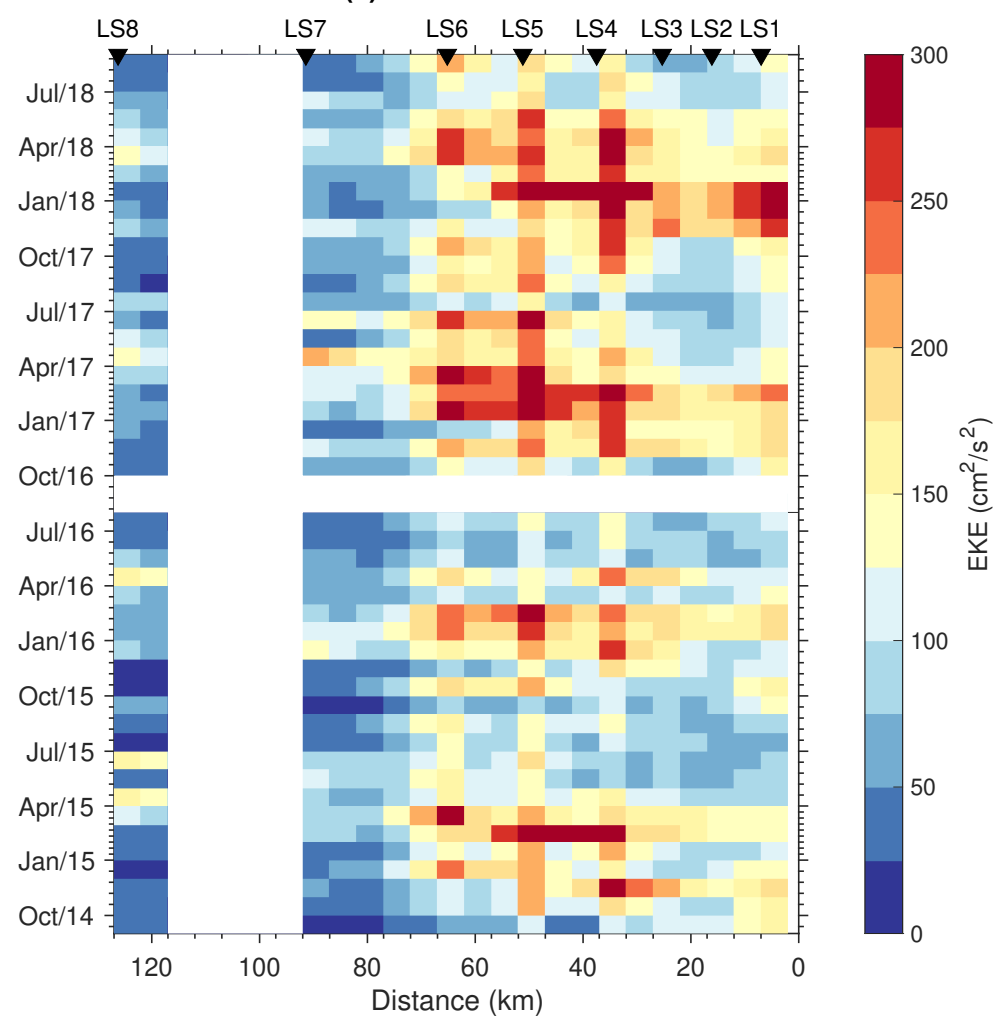

(b) Array configuration

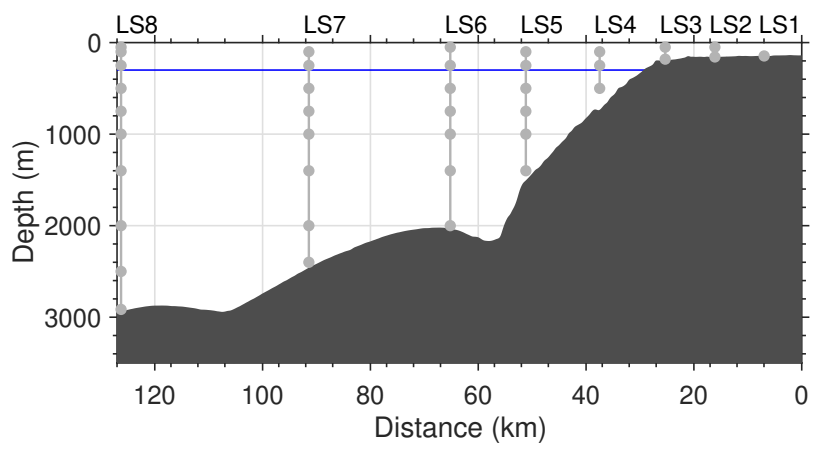

Figure 4-4: (a) Monthly eddy kinetic energy at $300 \mathrm{~m}$ as a function of time and distance across the array. (b) Mooring array configuration in the vertical. The blue line indicates the depth of the EKE timeseries in (a).

Using the identified anticyclonic features, a composite feature was created in order to diagnose its structure and composition. All of the features took approximately 60 hours to transit past the mooring array, thus time normalization was not necessary. 

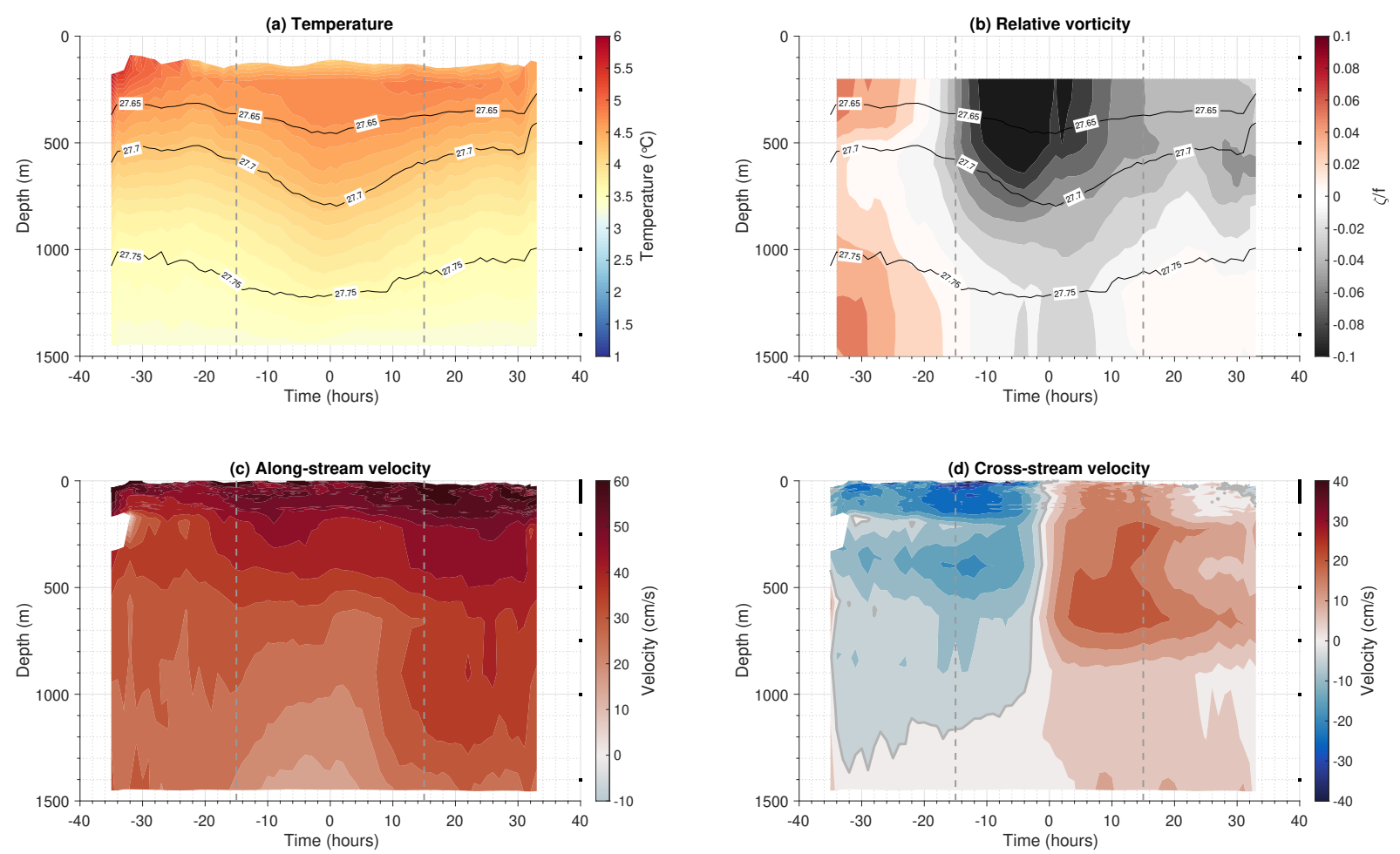

Figure 4-5: Composite anticyclonic feature at LS5. The composite is made up of 116 features. (a) Temperature, plotted as a function of depth and time (hours) from the center of the feature (at 0 hours), with isopycnals contoured every $0.05 \mathrm{~kg} / \mathrm{m}^{3}$. Negative time indicates the leading edge, positive time indicates the trailing edge. (b) Same as (a) but for the ratio of relative vorticity to stretching vorticity $(\zeta / f)$. (c) Along-stream velocity. (d) Cross-stream velocity. Black squares indicate nominal instrument depths. The vertical dashed lines bracket the core of the feature

The individual features were aligned along their center time, and an average was taken along this time axis. Seven features were excluded from the composite that occurred very close to nearby features (one in each pair was retained). The resulting composite anticyclone at LS5, constructed using 116 features, is shown in Figure 4-5. This reveals that, as the features pass by, there is a bowling of the isopycnals between the surface and $1000 \mathrm{~m}$, a slight reduction in along-stream flow, and a reversal in the cross-stream velocity from onshore (negative $v$ ) at the leading edge to offshore (positive $v$ ) at the trailing edge. Using the along-stream flow averaged between the surface and $700 \mathrm{~m}$ (thus the core of the features) to convert the time axis to a distance axis, a characteristic length scale of $20 \mathrm{~km}$ is derived.

The composite anticyclonic feature at LS6, constructed using 24 instances (none 
were excluded) and shown in Figure 4-6, exhibits the same bowling of isopycnals between the surface and $1000 \mathrm{~m}$ depth as the anticyclonic feature at LS5, but instead exhibits an intensification in the along-stream velocity over this depth range. The reversal in cross-stream velocity follows the same pattern as the feature at LS5. The leading anticyclone from the dipole pairs has the same structure as the composite anticyclonic feature at LS6 (not shown). The trailing cyclone does not have a distinctive hydrographic signature, and is instead reflective of the ambient temperature/salinity structure.
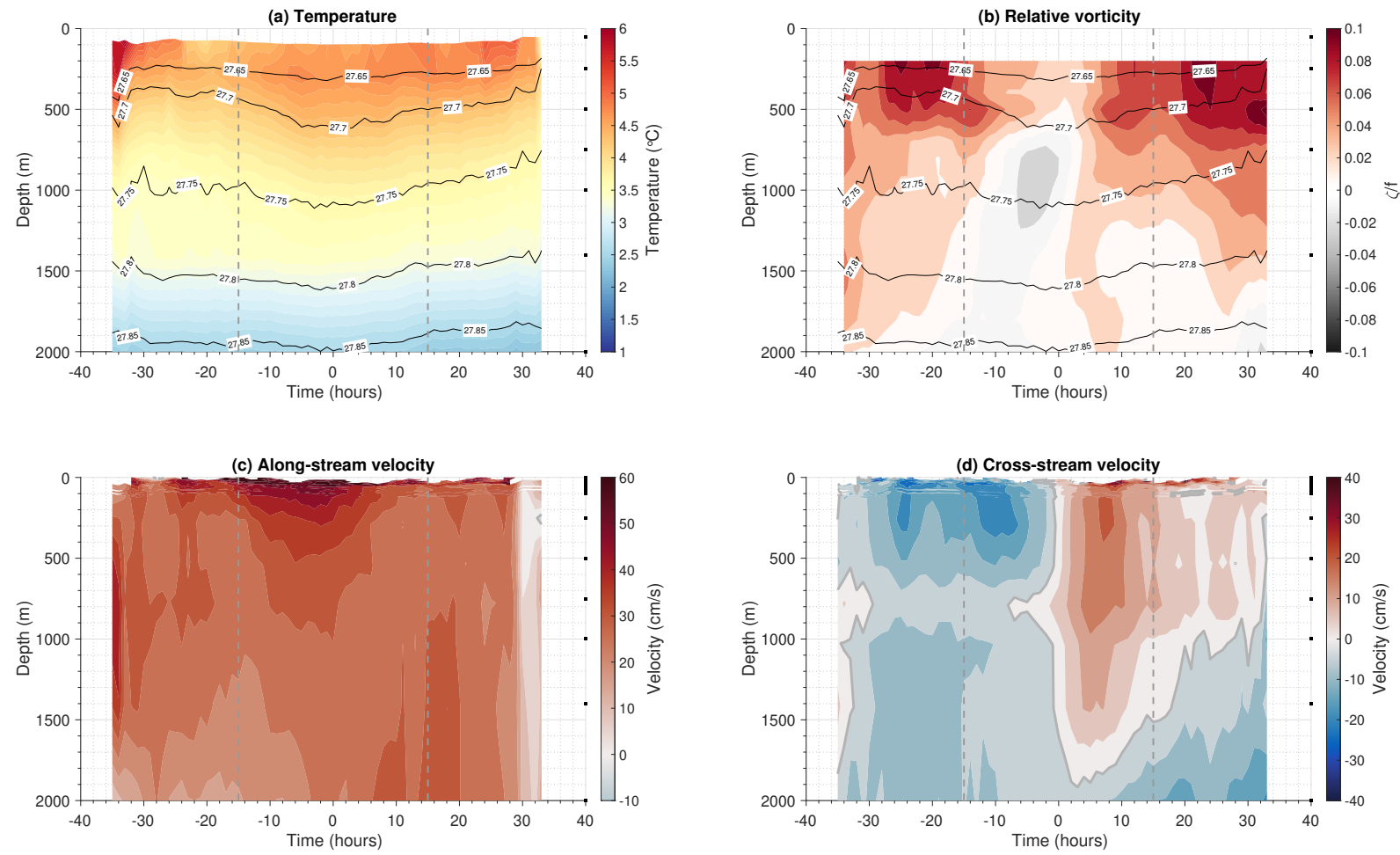

Figure 4-6: Same as Figure 4-5 but for LS6. The composite is made up of 24 features.

\subsubsection{Meanders or coherent features?}

We now argue that the features identified by the GUI predominantly reflect meandering of the WGC rather than the passage of coherent eddies. This is based on several lines of evidence. First of all, if the features were discrete eddies then one would expect to see evidence of oppositely signed azimuthal flow at successive moor- 
ings. However, of the 123 anticyclones sampled at LS5, only 14 produced negative along-stream flow at mooring LS4, as would be expected of a coherent eddy. We hasten to say that the spacing between these two moorings is $15 \mathrm{~km}$, while the deduced diameter of the features from the composite is $20 \mathrm{~km}$. As such, if discrete eddies were passing by the array over a range of cross-stream locations, it is likely that LS4 would sometimes miss the onshore signature. Nonetheless, such a small percentage of cases with return flow (11\%) implies that coherent eddies were not the dominant process being measured.

To shed more light on this we consider the Ertel potential vorticity, $\Pi$, calculated using the gridded product as:

$$
\Pi=\frac{f}{g} \frac{\partial b}{\partial z}-\frac{1}{g} \frac{\partial u}{\partial y} \frac{\partial b}{\partial z}+\frac{1}{g} \frac{\partial u}{\partial z} \frac{\partial b}{\partial y}
$$

where $u$ is the along-stream velocity, $b$ is the buoyancy term, $y$ is the cross-shelf direction, and $z$ is the vertical coordinate (e.g. Pickart et al., 2005; Spall and Pedlosky, 2008; Lin et al., 2018). The buoyancy is $b=-g \rho / \rho_{0}$, where $\rho$ is the density, $\rho_{0}$ is the reference density, and $g$ is the gravitational acceleration. The first term in Equation 4.3.2 represents the stretching vorticity, the second term represents the relative vorticity, and the third term represents the tilting vorticity. Each term is smoothed using a 3-hour temporal filter and a $300 \mathrm{~m}$ vertical filter. We note that this forumation of $\Pi$ does not account for variations in vorticity in the downstream direction. Given the two-dimensional nature of the mooring array, it is not possible to estimate $\frac{\partial v}{\partial x}$. However, we explored the role of this term using an idealized representation of a feature progressing past a mooring array. At both LS5 and LS6, the full relative vorticity is qualitatively similar to the $\frac{\partial u}{\partial y}$ term; thus, our conclusions are not impacted by this limitation.

The four-year mean vertical section of the ratio of relative vorticity to stretching $\operatorname{vorticity}(\zeta / f$, where $\zeta=\partial u / \partial y)$ across the array, in the absence of mesoscale activity, is shown in Figure 4-7. This nicely reveals the expected regions of positive and negative $\zeta / f$ in the WGC: the offshore edge of the WGC is associated with cyclonic 


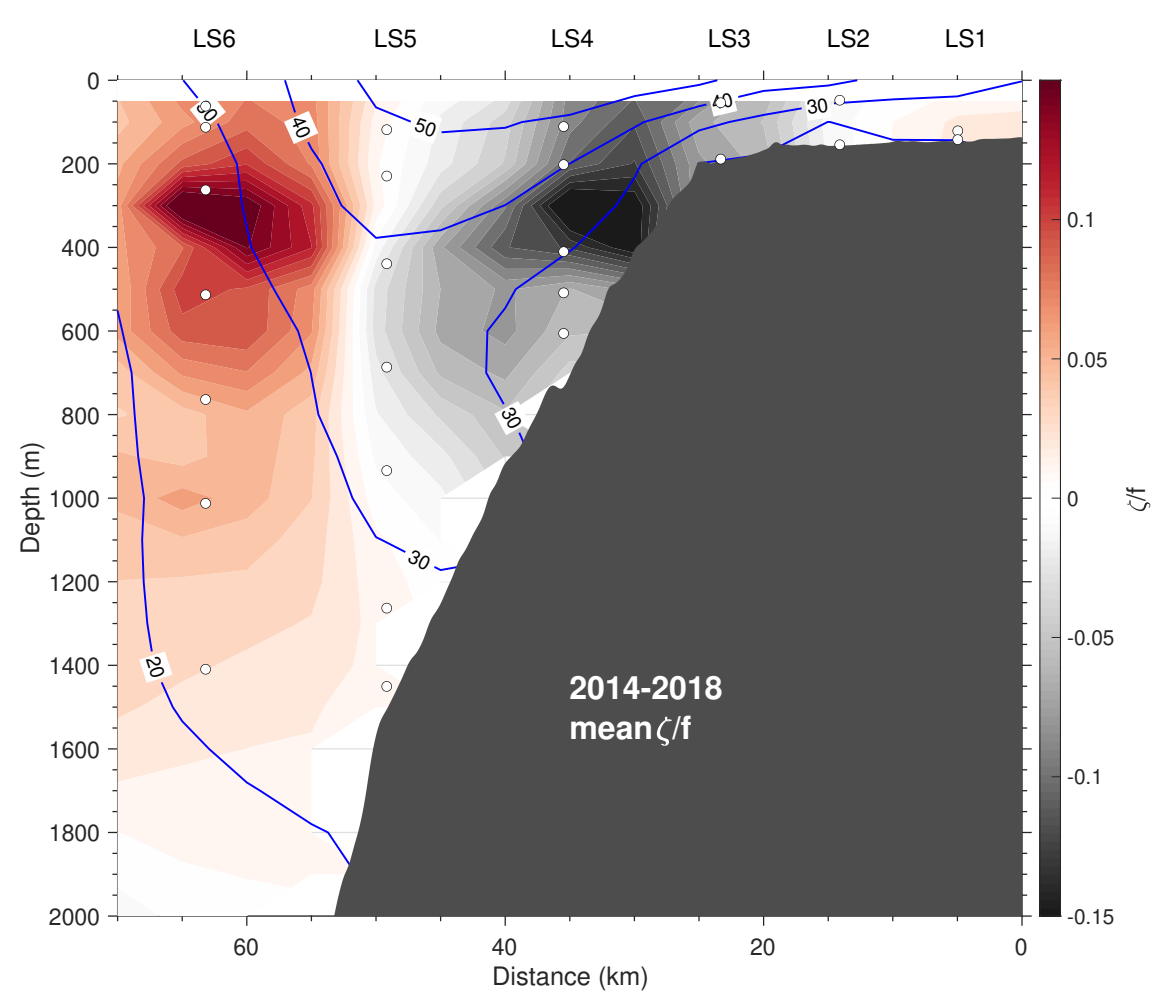

Figure 4-7: Mean vertical section of the ratio relative vorticity to stretching vorticity $(\zeta / \mathrm{f})$ in the absence of mesoscale activity between 2014-2018. The mean along-stream velocity in the absence of mesoscale variability is contoured. See text for details on calculation of $\zeta$.

relative vorticity (positive $\zeta / f$ ), while the onshore side of the WGC is associated with anti-cyclonic relative vorticity (negative $\zeta / f$ ). The zero-contour is located at the core of the WGC near LS5. Using the hourly gridded product of $\zeta / f$, an analogous timedepth composite was constructed of the relative vorticity at the grid point closest to mooring LS5 for the 116 anticyclonic features comprising the composite anticyclone at that mooring (Figure 4-5b). This reveals that, outside of the feature, the relative vorticity is close to zero, while during the passage of the feature $\zeta / f$ becomes strongly negative. Simultaneously, the along-stream velocity is reduced (Figure 4-5c)

The situation is markedly different at mooring LS6. In the mean this mooring is situated in the region of positive relative vorticity on the offshore side of the WGC (Figure 4-7). The analogous composite of $\zeta / f$ at the grid point closest to LS6 for the 24 anticyclones passing that mooring shows that, on either side of the feature, the relative vorticity is positive, while at the core of the feature $\zeta / f$ is close to zero 
(Figure 4-6b). Simultaneously, the along-stream velocity is enhanced (Figure 4-6c). As such, the vorticity composites at both moorings are consistent with an offshore shift of the WGC; i.e., a leftward shift of the vorticity field of Figure 4-7. In particular, the region of negative vorticity previously situated at mooring LS4 is now located at LS5, while the region of near-zero relative vorticity previously situated at LS5 has moved to LS6. This is indicative of a meandering WGC.

At the same time, if these were coherent anticyclones, one would expect them to impinge on a particular mooring in a variety of different ways - i.e., they could be sampled directly through their center, or could pass onshore or offshore of the mooring. Depending on which of these cases applies, the along-stream velocity measured by the mooring would either stay the same, increase, or decrease. This in turn would result in an ill-defined along-stream velocity composite, with the varied impingement angles and associated along-stream velocity profiles averaged together. This is in contrast to the robust composites presented above. We note that in their analysis of coherent Denmark Strait Overflow Water cyclones passing by the OSNAP WG array, Pacini et al. (2021) developed a methodology for identifying centered eddies for a given mooring. This technique did not work in the present case of the anti-cyclonic features, further suggesting that they are not discrete eddies.

Additional evidence of meandering is provided by the high-resolution (order 1 $\mathrm{km})$ satellite SST data. While cloud cover in the region is present roughly $40 \%$ of the time (see subsection 4.2.2), we inspected every good satellite pass during the four-year mooring deployment and found sustained evidence of meanders of the SST front associated with the WGC. At the same time, there were only limited instances of discrete eddies. An example of an image revealing meanders is shown in Figure 4$8 \mathrm{a}$, where the $3^{\circ} \mathrm{C}$ contour corresponds to the center of the surface front associated with the WGC in winter. This particular example, on 24 December 2015, coincided with the detection of an anticyclonic feature at LS5 and a dipole pair at LS6. The repeated cusping of the $3^{\circ} \mathrm{C}$ isotherm near $59^{\circ} \mathrm{N}$ is the surface representation of this train of features. A series of three good passes at this time over the course of 6 hours, shown superimposed in Figure 4-8b, provided the ability to track the propagation 


\section{(a) SST on 24-Dec-2015 00:45:01}

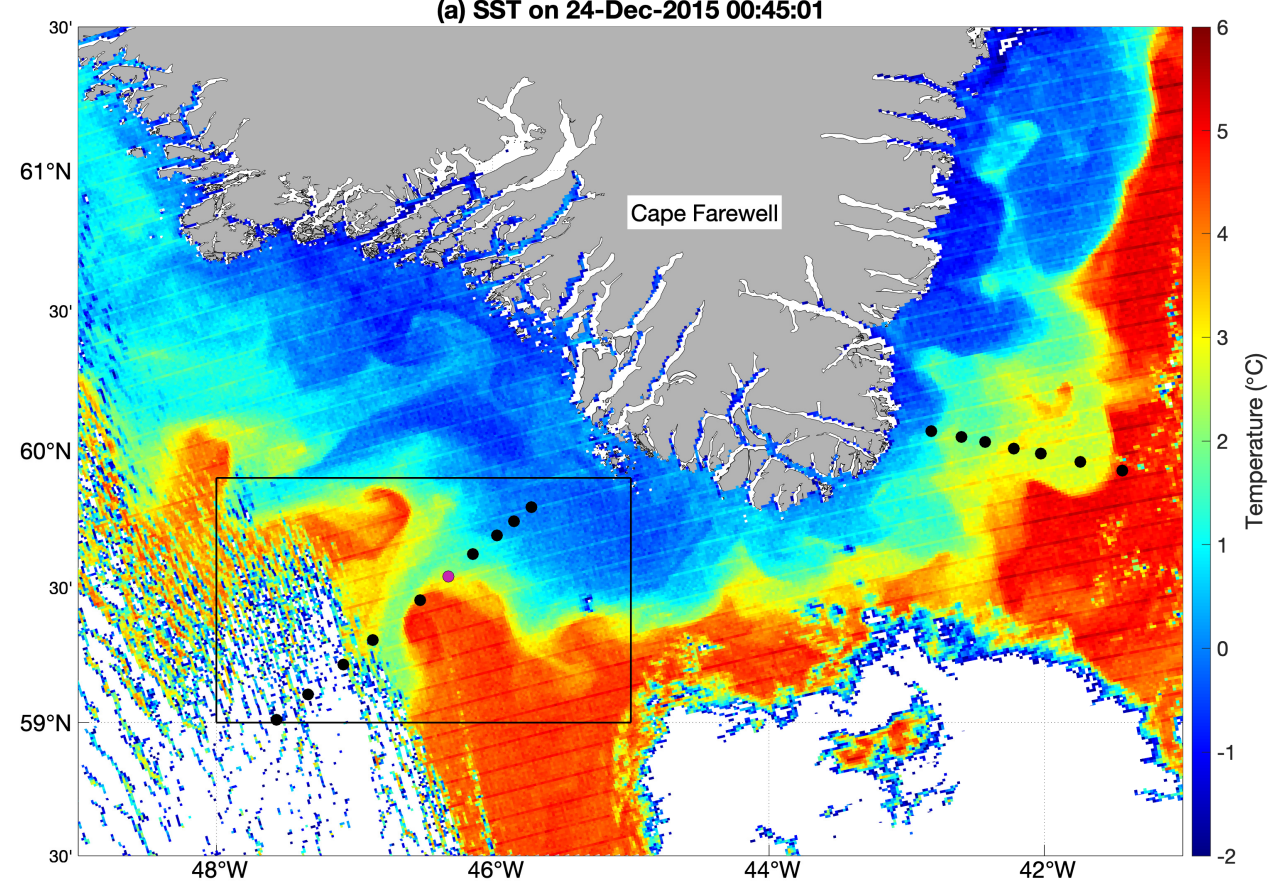

(b) Propagating front

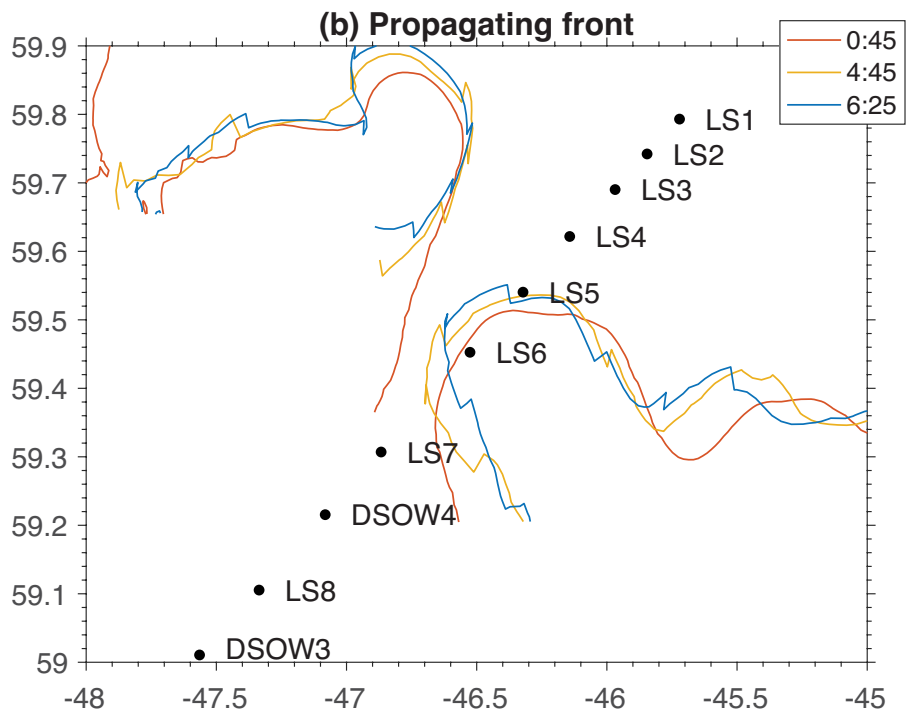

Figure 4-8: (a) Example SST pass from 24 December 2015 illustrating a meandering front at the OSNAP WG mooring array (black circles). The satellite pass, coincided with the detection of an anticyclonic feature at LS5 (purple circle) and a dipole pair at LS6. Note the data are not contoured, and instead plotted at their native resolution. (b) Evolution of the $3{ }^{\circ} \mathrm{C}$ isotherm over the course of three consecutive satellite passes within the box in (a), smoothed over 5 pixels. The time of each pass is indicated in the legend. 
of this cusping front, and a velocity of $50 \mathrm{~cm} / \mathrm{s}$ was deduced. This compares well to the propagation velocity of $\sim 50 \mathrm{~cm} / \mathrm{s}$ of the particular feature identified at LS5 during the same period, where this velocity is the maximum velocity observed by the mooring array (at LS5 and LS6) during the passage of the feature. Additionally, the length scale of the cusping in the SST front is order $25 \mathrm{~km}$, consistent with the derived wavelength of the anticyclonic features in the mooring record of $20 \mathrm{~km}$. It is important to recall that it is rare for the mooring array to sample a feature at more than one mooring at a given timestep. This can be seen in Figure 4-3a, where features at LS5 tend to appear at different times than features at LS6. This is because the spacing between LS4, LS5, and LS6, is $14 \mathrm{~km}$ and thus a $20 \mathrm{~km}$ feature has only a slight chance of impinging on more than one mooring.

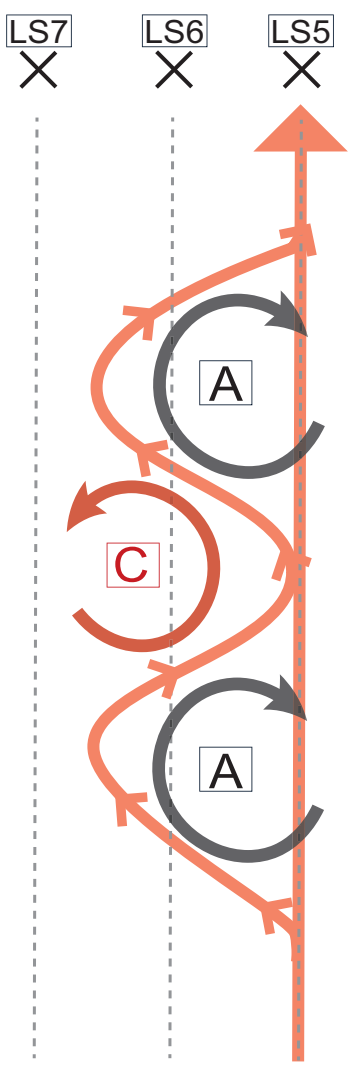

Figure 4-9: Schematic depicting the evolution of a meander past moorings LS5, LS6, and LS7 as viewed from the surface. The mean flow is represented by the straight arrow at LS5. The meandering is shown by the sinusoidal orange curve. The dashed lines indicate the location that each mooring samples over time. The black circles indicate anticyclonic features, and the red circle indicates a cyclonic feature in the dipole train at LS6. 
Finally, the fact that anticyclonic features were predominantly observed at LS5 while dipole pairs were mainly measured at LS6 represents further evidence that the features are meanders. As shown schematically in Figure 4-9, when the WGC meanders offshore, a mooring at the mean location of its core (LS5) would only observe a train of features with anticyclonic rotation. By contrast, at a mooring offshore of the mean WGC (LS6), a meander would appear as a dipole pair where the leading feature has anticyclonic rotation and the trailing feature has cyclonic rotation. Given that features are not observed onshore of LS5, we suspect that the boundary current cannot meander onshore of LS5 due to the steep topography in this region, as was the case in a numerical model of the shelfbreak jet in the Beaufort Sea (Spall et al., 2008). A similar asymmetry is observed in the Agulhas Current, where submesoscale meanders are observed only on the offshore side of the jet and are hypothesized to be topographically-constrained (Elipot and Beal, 2015).

Cimoli et al. (2017) used a model shelfbreak jet to derive a parameter space that distinguishes between regions of stable flow, meandering flow, and eddying flow. The parameter space is a function of $\gamma$, which is a measure of the baroclinicity of the flow, and $T_{p}$, which is a measure of the bottom topography, WGC speed, and stratification. Specifically,

$$
\begin{gathered}
\gamma=\frac{H_{j e t}}{H-H_{j e t}} \\
T_{p}=\frac{-s f R_{d}^{2}}{H U_{\max }}
\end{gathered}
$$

where $H_{\text {jet }}$ is the depth of the jet, $H$ is the bottom depth, $s$ is the topographic slope, $R_{d}$ is the baroclinic Rossby radius, $f$ is the Coriolis parameter, and $U_{\max }$ is the maximum velocity of the jet. We estimated the values of $\gamma$ and $T_{p}$ for the WGC using the four-year mean vertical sections of alongstream velocity and buoyancy frequency. Error bars were estimated by considering a range of values for the depth of the jet (450-550 m) and choosing different averaging regions for the stratification. Based on this, we calculate a $\gamma$ of $0.5 \pm 0.08$ and a $T_{p}$ of $-0.15 \pm 0.07$; thus, the WGC is found 
to be near the edge of the theoretical meandering and eddying regimes.

Given the various lines of evidence presented above, we conclude that the features observed at the OSNAP WG mooring array are meanders of the WGC, and that they are on the verge of breaking off to become anticyclonic eddies. Indeed, it is likely that the 14 features displaying negative along-stream flow at mooring LS4 onshore of the core of the WGC represent instances of detached eddies from the boundary current, i.e. the BCEs described in the modeling literature.

\subsubsection{Formation mechanism}

Modeling studies have addressed the formation mechanisms responsible for the production of eddies along a rim current. For example, Spall (2004) documented the development of boundary current eddies within a circular domain with a warm boundary current progressing cyclonically around a cold interior basin (meant to represent the Labrador Sea). In that analysis, Spall (2004) demonstrated that small-scale BCEs are formed all along the front due to baroclinic instability as the density gradient between the interior and the boundary current is sharpened during wintertime convection. This process results in offshore transport of heat from the boundary current to the interior basin, which ultimately contributes to restratification in the interior after convection.

Other modeling studies similarly describe the connection between an accelerating boundary current and the production of BCEs (e.g. Chanut et al., 2008; Gelderloos et al., 2011; Rieck et al., 2019). de Jong et al. (2016) demonstrated that in the $1 / 12^{\circ}$ configuration of the Family of Linked Atlantic Models Experiment (FLAME), the variability in boundary current density was double that of the interior density, and thus was primarily responsible for the changes in the density gradient between boundary current and interior. Using a combination of model output and data in the Labrador Current (LC; Figure 4-1), Thomsen et al. (2014) performed a linear stability analysis and found that three instability modes exist in the LC. They found that an interior mode, best explained by baroclinic instability with maximum growth

rates of 1 day $^{-1}$, can explain the observed wintertime enhancement of EKE in the 
LC. Is baroclinic instability the formation mechanism responsible for the generation of WGC meanders, and, if so, does it have a seasonal signal?

\section{Instability of the WGC}

To investigate the processes involved in generating the meanders, we first checked to see if the WGC meets the necessary criteria for barotropic and baroclinic instability. Barotropic instability is responsible for the conversion of kinetic energy to eddy momentum flux (Spall et al., 2008) and is dampened by steep bathymetry and aided by strong horizontal velocity gradients (von Appen et al., 2016). Specifically, the value of $\beta-\partial^{2} u / \partial y^{2}$ must change sign within the domain, where $\beta$ is topographic beta, $u$ is the along-stream velocity, and $y$ is the cross-stream direction (e.g. Vallis, 2006). The OSNAP WG mooring data reveal that the boundary current meets this criterion in all months of the year (not shown). However, a metric for the tendency of the boundary current to exhibit barotropic instability is the ratio of the relative vorticity to the stretching vorticity (a measure of the Rossby number). If this ratio exceeds 0.5 , then it is likely the boundary current is barotropically unstable (e.g. Pickart et al., 2005; Lin et al., 2018). For the hourly sections of the WGC, this ratio never exceeds 0.5 ( $\max$ value 0.45 ), and the four-year mean value is 0.1 (Figure 4-7).

Baroclinic instability results in the conversion of mean available potential energy to eddy density flux (Spall et al., 2008) and is dampened by stratification and aided by vertical shear of the horizontal velocity von Appen et al. (2016). A necessary, but not sufficient, criterion for baroclinic instability is that the gradient of total Ertel potential vorticity, $\partial \Pi / \partial y$, change sign within the domain. The WGC satisfies this criterion for all months (not shown).

Given that the boundary current meets the necessary criteria for both barotropic and baroclinic instability, we now perform an energetics analysis following Spall et al. (2008) to diagnose the relative importance of these instabilities to the meandering of the WGC. The baroclinic conversion term represents conversion from mean available potential energy to eddy energy following: 


$$
\begin{gathered}
P=-\frac{1}{2} g \bar{\rho}^{2}\left(\rho_{0 z}\right)^{-1} \\
B C=-g \gamma \overline{v^{\prime} \rho^{\prime}}
\end{gathered}
$$

where $P$ is the mean available potential energy, $\rho$ is the deviation of the density profile from the mean density profile outside the WGC $\left(\rho_{0}\right)$ (see also von Appen and Pickart 2012), $\rho_{0 z}$ is the vertical gradient of the density outside the WGC, $\gamma=\partial z / \partial x$ is the isopycnal slope, and $v^{\prime} \rho^{\prime}$ is the eddy density flux. Overbars denote the time mean, and primes denote the deviations from the mean.

The barotropic conversion term represents conversion from mean kinetic energy to eddy energy following:

$$
\begin{gathered}
K=-\frac{1}{2} \rho_{0}\left(\bar{u}^{2}+\bar{v}^{2}\right) \\
B T=\overline{v^{\prime} u^{\prime}} U_{y} \rho_{0}
\end{gathered}
$$

where $K$ is the mean kinetic energy, $\rho_{0}$ is the density profile outside the boundary current, $u$ is the along-stream velocity, $v$ is the cross-stream velocity, $v^{\prime} u^{\prime}$ is the eddy momentum flux, and $U_{y}$ is the cross-stream gradient of the mean along-stream flow (Spall et al., 2008; von Appen et al., 2016; Håvik et al., 2017; Huang et al., 2019).

Using these equations, the different energetics terms were calculated using the hourly gridded fields for the four years of mooring data. The resulting vertical sections are displayed in Figure 4-10. The region of greatest mean available potential energy is where the isopycnals exhibit the steepest slopes, in the core of the WGC. The eddy density flux is negative throughout the water column, indicating the transfer of lighter water from the inshore side of the boundary current to the offshore side (i.e., positive $v^{\prime}$, negative $\rho^{\prime}$ ). The associated baroclinic conversion is positive throughout the upper portion of the WGC, with particularly strong conversion at LS4 inshore of the core of the WGC (Figure 4-10a-c).

The mean kinetic energy of the boundary current is largest in the core of the 

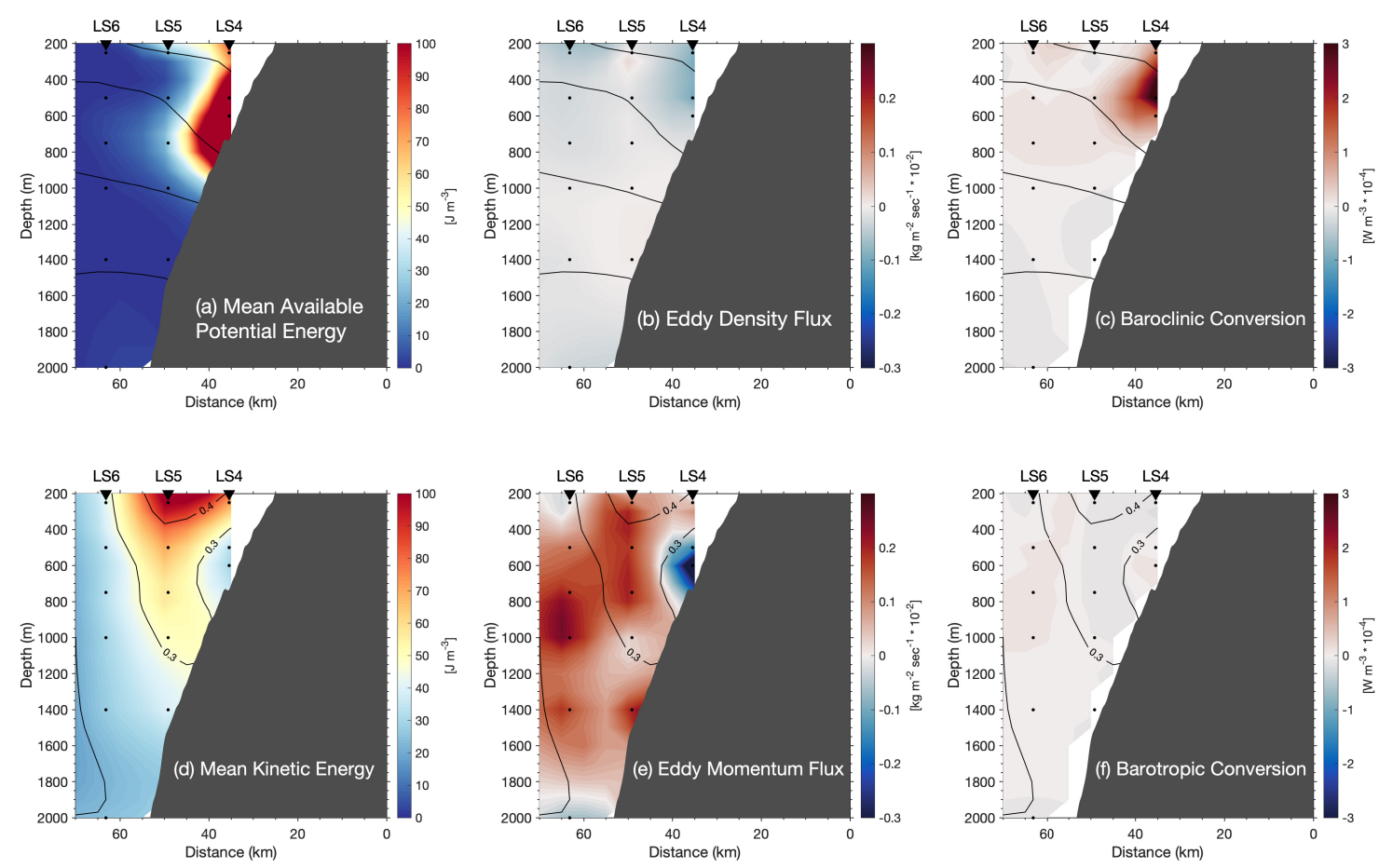

Figure 4-10: Energetics components. (a) Mean available potential energy of the boundary current, (b) eddy density flux, and (c) baroclinic conversion rate. The mean isopycnals $\left(\mathrm{kg} / \mathrm{m}^{3}\right)$ are contoured (a-c). (d) Mean kinetic energy of the boundary current, (e) eddy momentum flux, and (f) barotropic conversion rate. The mean along-stream flow $(\mathrm{m} / \mathrm{s})$ is contoured $(\mathrm{d}-\mathrm{f})$.

WGC, with a positive eddy momentum flux on the offshore side of the WGC and a negative eddy momentum flux on the inshore side of the WGC. This indicates that when the WGC shifts offshore (positive $v^{\prime}$ ) the boundary current is stronger at LS5/LS6 (positive $u^{\prime}$ ) and weaker at LS4 (negative $u^{\prime}$ ). This is consistent with the meandering of the WGC diagnosed above. The barotropic conversion is positive offshore of the WGC and negative onshore of the WGC, but significantly weaker than the baroclinic conversion (Figure 4-10d-f). The order of magnitude difference between the two conversion terms indicates that baroclinic instability is the dominant mechanism responsible for the formation of the WGC meanders. 


\section{Seasonality of the instability}

Recall that the meandering of the WGC is seasonal in nature. What causes the seasonality in the baroclinic instability that drives this? To investigate this question, we revisit the meander index defined above in subsection 4.3.1. This is compared to the average EKE computed at $300 \mathrm{~m}$ depth between LS5 and LS6 (lowpassed with the same 28-day filter) in Figure 4-11a. The correlation between these two timeseries is high $(0.64)$ and statistically significant $(\mathrm{p}<0.01)$. This confirms that the periods of elevated meander activity are, in fact, correlated with periods of enhanced WGC EKE, as was suggested by the EKE evolution of the WGC shown in Figure 4-4. It should be noted that the EKE of the WGC is significantly baroclinic, with ratios of $\sim 3$ when the EKE at $300 \mathrm{~m}$ is compared with EKE at $1500 \mathrm{~m}$. This shear in EKE indicates that variability of the boundary current has a tendency to be surfaceintensified, as would be expected for the production of baroclinic eddies (von Appen et al., 2016).

Eady (1949) calculated the e-folding growth rate $\omega$ for a two-layer flow in the quasi-geostrophic limit as a function of Richardson number, $R i=N^{2} / S^{2}$, where $N^{2}=$ $-g \partial \rho / \rho \partial z$ is the square of the buoyancy frequency and $S^{2}=(\partial u / \partial z)^{2}+(\partial v / \partial z)^{2}$ is the square of the shear. Using the thermal wind relation, Stone (1970) provided a modification to the growth rate for cases where stratification is weak. The modified Eady growth rate is defined as $\omega^{2} \approx 0.09 f^{2} /(1+R i)$, where $f$ is the Coriolis parameter. In a model of the LC, this growth rate was found to be 1 day $^{-1}$ in winter and 0.2 day $^{-1}$ in summer (Thomsen et al., 2014).

To compute $\omega$ for the WGC, the gridded mooring data were used to calculate the stratification $N^{2}$ and shear $S^{2}$, and hence $R i$. This was done for each hourly timestep. For the purposes of this analysis, the values between LS5 and LS6 at 300 $\mathrm{m}$ are averaged together, and the hourly growth rate and 28-day lowpassed growth rate are shown in Figure 4-11b in relation to the meander index. The timeseries of $\omega$

exhibits periods of large growth rate (1-1.5 day $\left.^{-1}\right)$ during the winter/spring, roughly coincident with periods of enhanced meandering activity. The correlation coefficient 
(a) $300 \mathrm{~m}$ EKE at LS5 and LS6
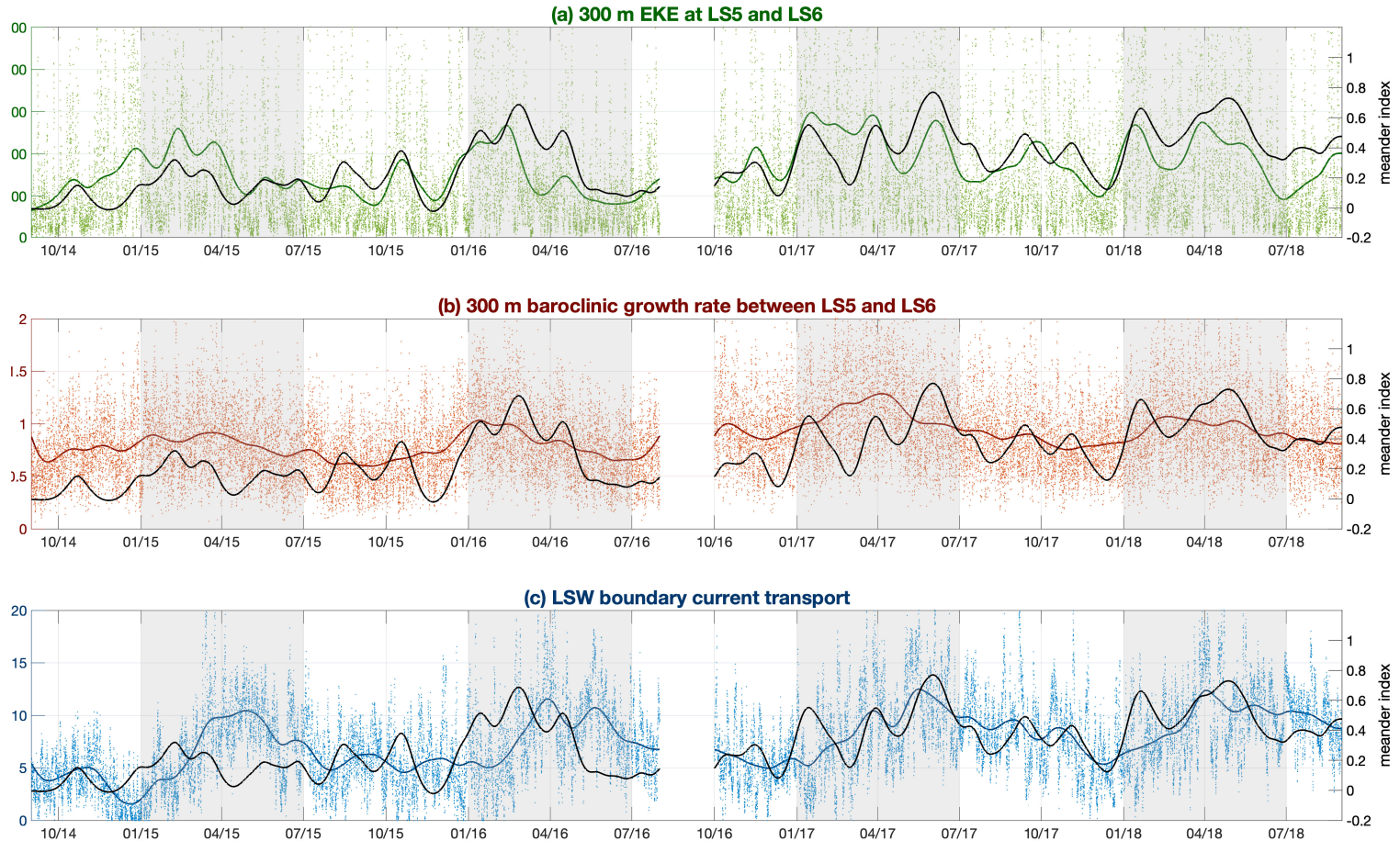

Figure 4-11: (a) Timeseries of the meander index (defined in the text, black line in all three panels) compared against the EKE at $300 \mathrm{~m}$ averaged between moorings LS5 and LS6. (b) Timeseries of the meander index compared against baroclinic growth rate (see text for calculation details). (c) Timeseries of the meander index compared against LSW transport in the boundary current. In all three panels, the hourly data are plotted as points, and the 28-day lowpassed timeseries are plotted as solid curves.

between the meander index timeseries and the baroclinic growth rate is $0.58(\mathrm{p}<0.01)$.

We note that when $N^{2}$ is small, $S^{2}$ is large and vice-versa; thus, the shear acts in concert with the stratification to increase or decrease the Richardson number of the WGC. However, the mooring data indicate that the stratification is an order of magnitude larger than the shear, as is its variability, and thus drives the changes in the baroclinic growth rate. Hence, the seasonal changes in the stratification of the WGC are responsible for the wintertime tendency for meanders to develop. The next question is, what causes the seasonal changes in stratification?

As demonstrated by Pacini et al. (2020), using the same mooring data presented in this study, the two main water masses in the WGC are the LSW and IW, which together dictate the stratification of the water column. LSW is the weakly strat- 
ified winter product formed by convection in the interior Labrador Sea, within the boundary current in the Labrador Sea, and upstream in the Irminger Sea (e.g. Pickart et al., 2003a; Le Bras et al., 2020). IW is the more highly stratified warm, saline, Atlantic-origin water mass advected around the subpolar gyre. While varying property definitions for LSW and IW exist (e.g. Clarke and Gascard, 1983; Krauss, 1995; Lazier et al., 2002; Pickart et al., 2003a,b; Buch et al., 2004), for consistency we follow the definitions presented in Pacini et al. (2020) for LSW $\left(27.68 \mathrm{~kg} / \mathrm{m}^{3}<\rho<\right.$ $27.8 \mathrm{~kg} / \mathrm{m}^{3}$ and salinity $<34.92$ ) and IW (salinity $\geq 34.92$ and $\rho<27.74 \mathrm{~kg} / \mathrm{m}^{3}$ ). Pacini et al. (2020) computed the volume transport of these two water masses and found that they are anti-correlated: when LSW transport is high (near the end of the winter convective season), IW transport is low, and, conversely, when LSW transport is low (in the fall), IW transport is high. This can be explained by two mechanisms: 1) the production of LSW and subsequent entrainment of this water into the boundary current as the convective season progresses, and 2) the direct cooling of IW through air-sea heat fluxes and through lateral mixing with LSW that alters the hydrographic properties of IW and converts it to LSW (Pacini et al., 2020). Notably, the seasonally-varying transport signals are dictated by the amount of each water mass in the boundary current, not the speed at which they travel.

We compare the LSW transport timeseries calculated by Pacini et al. (2020) to our meander index in Figure 4-11c. One sees that when LSW transport is high - i.e. enhanced LSW presence and decreased IW presence in the boundary current - meander activity of the WGC is high (the correlation coefficient is 0.53 , with $\mathrm{p}<0.01$ ). This provides a dynamical link between the seasonal production of LSW, the decreased stratification of the WGC, the enhanced baroclinic growth rate, and the development of boundary current meanders. This is consistent with previous model results (e.g. Spall, 2004).

\section{What about 2015?}

As noted in subsection 4.3.1, the winter/spring periods of 2016, 2017, and 2018 exhibited enhanced boundary current meandering, while this was not the case for 2015 
(Figure 4-3b). At the same time, the boundary current EKE was elevated all four years in winter/spring; however, the maximum in 2015 was less extensive than in the subsequent three years (Figure 4-4). Furthermore, the seasonal increase in baroclinic growth rate was less pronounced in 2015 compared to the following three years (Figure 4-11b).

A possible explanation for this lies in the recent trend in convective conditions in the Labrador and Irminger Seas. The period between 2012 and 2016 exhibited progressively deepening mixed layers and associated progressively denser newlyventilated LSW production in the Labrador Sea, due to a persistent positive NAO phase and associated strong wintertime surface heat fluxes (Yashayaev and Loder, 2016). Additionally, convection was observed in the Irminger Sea and south of Cape Farewell beginning in winter 2015, with the deepest mixed layers observed in the 21st century in these regions (de Jong and de Steur, 2016; Fröb et al., 2016; Piron et al., 2017). Zunino et al. (2020) demonstrated that the period between 2015-2018 exhibited persistent deep convection south of Cape Farewell, due to strong air-sea buoyancy loss in 2015 and a preconditioned water column in the subsequent years.

This return to a regime of strong deep convection in the Labrador and Irminger Seas is consistent with the timeseries of LSW transport in the WGC, which displayed a linear increase of $1.21 \mathrm{~Sv} / \mathrm{yr}$ over the four-year mooring measurement period (Figure $4-12 \mathrm{~b}, R^{2}=0.41$; see also subsection 4.3 .5$)$. We thus hypothesize that there was not enough weakly stratified LSW entering the WGC to destabilize the flow to the point of significant meander production in the winter of 2015, when LSW production was just beginning in the Irminger Sea and south of Cape Farewell and was still growing in the Labrador Sea. Recall that the presence of LSW in the boundary current affects the baroclinic growth rate in two ways, by influencing the stratification and by influencing the shear. Specifically, the more LSW that is present in the boundary current, the weaker the stratification is. At the same time, the more LSW is present offshore, the stronger the density gradient between the boundary current and the interior, and thus the stronger the shear is (via thermal wind). While in 2016, 2017, and 2018, the minimum in stratification is coincident with the maximum in shear, 
in 2015 these peaks are offset, such that the maximum in shear is achieved before the minimum in stratification, resulting in a weaker baroclinic growth rate. We note that if the timeseries of LSW transport is compared against the meander index for the first two years of data collection vs. the last two years, the correlation coefficient increases from 0.22 in 2015 and 2016 to 0.64 in 2017 and 2018 (compared to 0.53 when the four years are considered together).

\subsubsection{Implications for the interior Labrador Sea}

Given the importance of the WGC to the stratification of the interior Labrador Sea (e.g. Chanut et al., 2008; Gelderloos et al., 2011; Rieck et al., 2019), we seek to estimate the possible contribution that the BCEs have to the heat content of the interior basin. The assumption is that some fraction of the meanders form oppositely signed pairs of eddies that then self-propagate into the interior (e.g. Spall et al., 2008), and that the anticyclone partner transports heat from the IW layer into the basin. The heat content of an individual eddy per unit area, relative to the temperature of interior LSW, $\Delta H_{e}$, can be estimated following Hátún et al. (2007) and de Jong et al. (2014, 2016):

$$
\begin{gathered}
\Delta H_{e}=\rho_{0} c_{p}\left(\overline{\theta_{e}}-\theta_{L S W}\right) D\left(\frac{r_{e}}{r_{L S}}\right)^{2} \\
\text { where } \theta_{e}=\frac{1}{\pi r_{e}^{2}} \int_{0}^{r_{e}} 2 \pi r \theta(z, r) d r
\end{gathered}
$$

the quantity $\theta_{e}$ is the average temperature for a radially symmetric eddy, $r_{e}$ is the radius of the eddy, $\rho_{0}$ is a reference density, $c_{p}$ is the specific heat of water,

$r_{L S}$ is the radius of the convection region in the interior Labrador Sea, $\theta_{L S W}$ is the average temperature of 2016 LSW, and $D$ is the depth of the eddy. Taking values of $\theta_{e}=4.2^{\circ} \mathrm{C}$ (estimated from the vertical section of a composite feature, see Figure 4$5 \mathrm{a}), r_{e}=10 \mathrm{~km}$ (calculated above), $\rho_{0}=1027 \mathrm{~kg} / \mathrm{m}^{3}, c_{p}=4000 \mathrm{~J} /\left(\mathrm{kg}^{\circ} \mathrm{C}\right), r_{L S}=300$ $\mathrm{km}$ (Lilly et al., 2003), $\theta_{L S W}=3.2^{\circ} \mathrm{C}$ (Yashayaev and Loder, 2017), and $D=1000$ $\mathrm{m}$, this yields a heat content of approximately $4.6 \mathrm{MJ} / \mathrm{m}^{2}$ per BCE. This is roughly 
an order of magnitude less than the estimated heat content of a single IR (order 40 MJ $/ \mathrm{m}^{2}$; Hátún et al. 2007; de Jong et al. 2014, 2016). As the boundary current circumnavigates the Labrador Sea, the temperature of the IW cools. Consequently, BCE's formed downstream of the OSNAP WG array will contain a smaller amount of heat. Assuming a linear decrease in temperature between the OSNAP array to the value presented in Pickart and Spall (2007) of $3.6^{\circ} \mathrm{C}$ on the eastern side of the basin, we can account for this alongstream change in heat content.

Taking the length of the boundary current along which this process can occur to be $1500 \mathrm{~km}\left(d_{b c}\right)$, we then calculate how many features fit along the boundary current by computing $d_{b c} /\left(2^{*} r_{e}\right)$ (75). This is repeated 50 times (due to an average rate of 50 features identified per year). Finally, we assume that $10 \%$ of these features evolve to form eddies, based on the fact that only 14/123 of the features identified at LS5 displayed negative alongstream flow at LS4 (implying that they were discrete anticyclonic eddies). This yields a total heat transfer $1.2 \mathrm{GJ} / \mathrm{m}^{2}$ per year. This value compares favorably with the results of Straneo (2006), who computed an interior heat flux of $1 \mathrm{GJ} / \mathrm{m}^{2}$ per year for a boundary current encircling a basin, meant to represent the Labrador Sea.

\subsubsection{Trends}

Past studies have addressed long-term trends in the hydrographic structure of the rim current system in the Labrador Sea. Myers et al. (2007) documented increasing temperature and salinity of the IW between 1995 and 2005. Similarly, in the FLAME model, de Jong et al. (2016) demonstrated an increasing density gradient between the interior Labrador Sea and the WGC due to a warming boundary current during a 15-year model run. In addition, Rykova et al. (2009) showed an increase in IR heat content using hydrographic data during the period 1990-2004.

Using the OSNAP WG mooring data, we now consider trends over the four-year period. As noted earlier, 2015 exhibited weak meandering compared to the subsequent years, possibly due to a regime shift in the prevalence of deep convection in 2015. This can be seen in Figure 4-12a, where the meander index has been lowpassed using a 

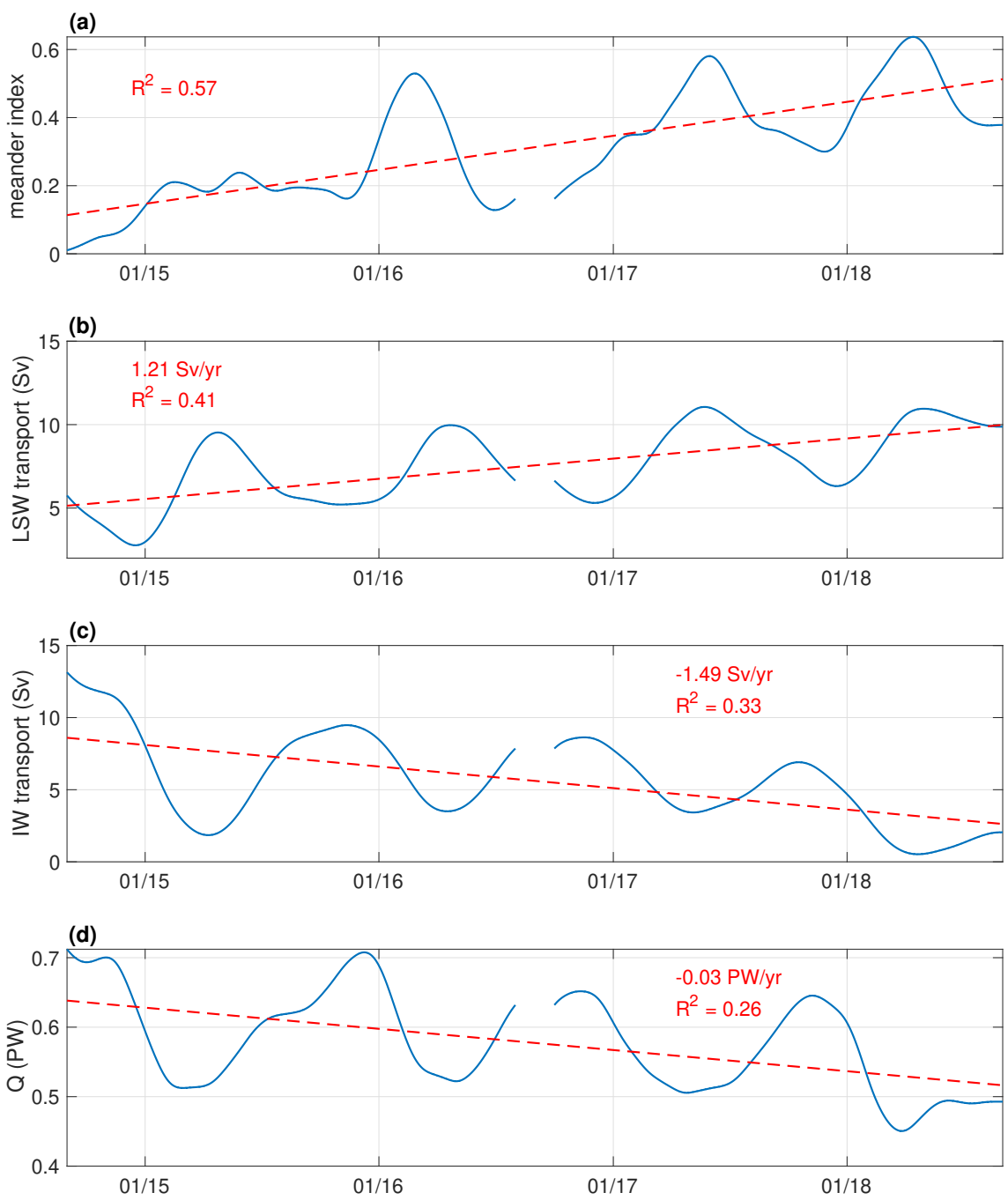

Figure 4-12: Timeseries of 3-month lowpassed quantities. (a) meander index, (b) LSW transport, (c) IW transport, and (d) heat content of the boundary current. The linear fits are plotted as dashed red lines, and the yearly trends are indicated.

3-month filter (to highlight seasonality and long-term trends). The timeseries is well modeled with a linear fit, showing an increasing meander index over the four years of the record. Such an increase in meandering could help explain the trends observed in the model results of Rühs et al. (2021), where decreased convection is found in the northern and eastern Labrador Sea in recent years, coincident with a negative salinity trend (freshening) in the region. The idea is that more BCEs have been forming, transporting enhanced amounts of freshwater offshore within the surface layer of the eddies. 
As previously described, meanders are triggered by baroclinic instability generated by the presence of LSW. Pacini et al. (2020) demonstrated that when transport of LSW is high seasonally, transport of IW is low and vice-versa. Here we see that as the transport of LSW increases linearly over the four years of data by $1.21 \mathrm{~Sv} / \mathrm{yr}$ (Figure 4-12b), the transport of IW decreases linearly by $1.47 \mathrm{~Sv} / \mathrm{yr}$ (Figure 4-12c). Since IW is the primary source of heat and salt to the boundary current, changes in the transport of IW can have implications for the heat content of the boundary current. We calculate the boundary current heat content according to

$$
Q=\int_{z_{w}}^{z_{e}} \int_{-H}^{0} u \theta c_{p} \rho_{0} d x d y
$$

where $u$ is the along-stream velocity at each grid point, $\theta$ is the associated temperature at each grid point, $\rho_{0}$ is the density, $c_{p}$ is the heat capacity of sea water, $H$

is the water column depth, and $z_{e}$ and $z_{w}$ are the eastern and western ends of the mooring array, respectively. The timeseries of heat content of the boundary current so calculated is shown in Figure 4-12d and demonstrates that, concurrent with the long-term increase in LSW transport and decrease in IW transport, the heat content of the boundary current decreases by $0.03 \mathrm{PW} / \mathrm{yr}$ between 2015 and 2018. Hence, less heat can be fluxed to the interior to compensate for wintertime heat loss and production of LSW.

\subsubsection{Downstream consequences}

Previous work has shown that the EKE of the IR hotspot is enhanced in winter/spring (e.g. Brandt et al., 2004; de Jong et al., 2016), which is also the time of year when there is enhanced meandering of the WGC, as shown above. It is thus natural to wonder if the meanders are acting to trigger the formation of IRs.

To address this, we used the satellite altimetric data in conjunction with our mooring data. While the satellite-derived surface EKE clearly captures the IR hotspot signal (Figure 4-13a, see also Brandt et al. 2004), it is unable to properly capture the variability of the WGC due to the small spatial scales of the meanders (there is only 

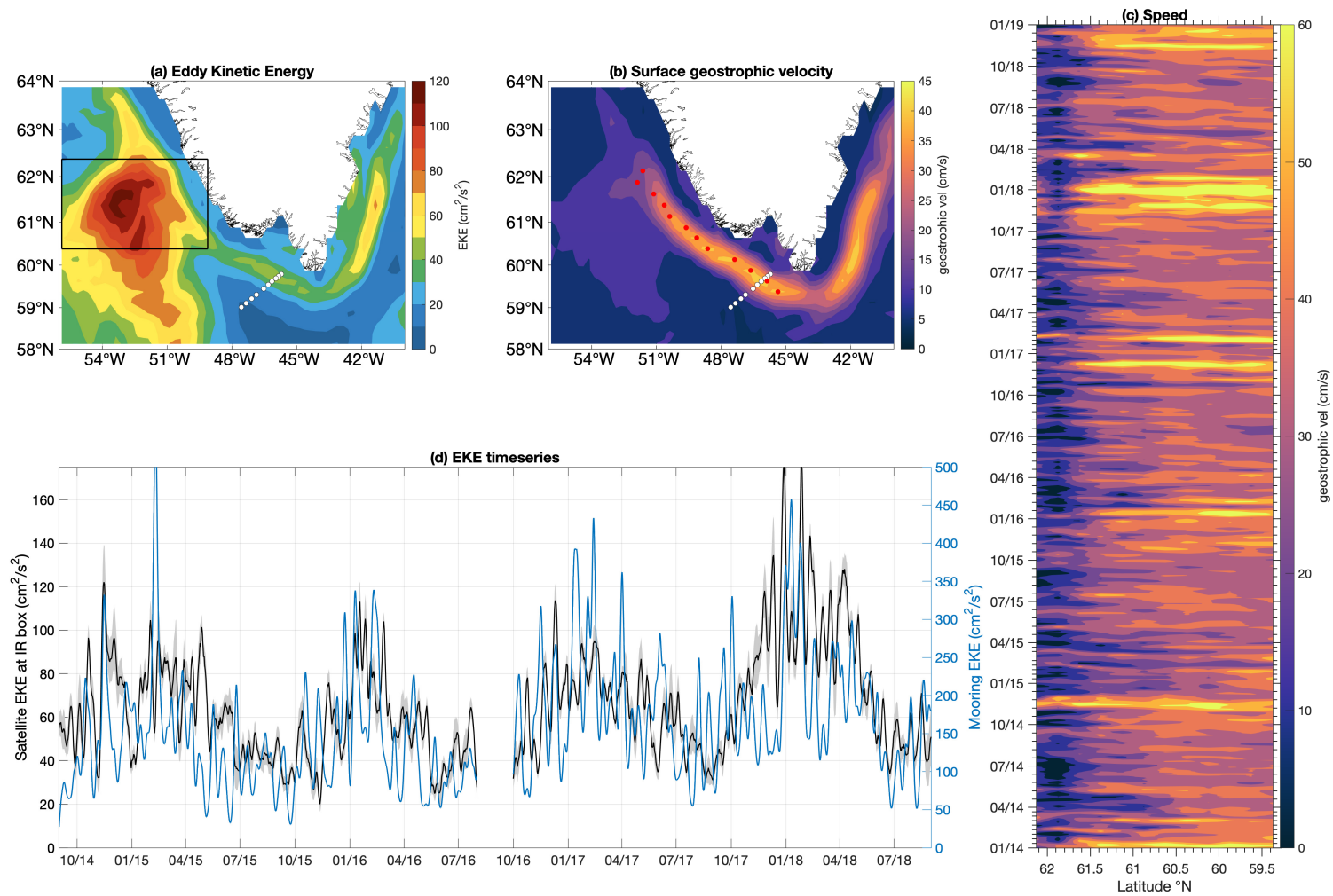

Figure 4-13: (a) Map of the time-mean mean satellite-derived eddy kinetic energy, averaged between 2014-2018. The white dots indicate OSNAP WG mooring array. (b) Same as (a) but for surface geostrophic velocity. The red dots indicate the core of the WGC, defined in the text. (c) Hövmoller diagram of geostrophic surface velocity along the WGC. (d) Comparison of satellite EKE at the IR box (defined in (a), black curve) with the mooring EKE in the WGC (blue curve). Grey shading on the black curve indicates the average error on the EKE measurement in the IR box, at each timestep.

a weak surface EKE signature of the WGC in Figure 4-13a). However, as seen in Figure 4-13b, the satellite data do accurately depict the surface geostrophic velocity signal of the WGC. (North of the IR hotspot the boundary current signal weakens, which is also seen in the surface drifter data of Cuny et al. (2002). This could be due to a disruption of the flow by the IR formation mechanism).

Using the satellite data, the core of the surface WGC is defined as the grid point of maximum average surface velocity at each latitudinal cell (the red dots in Figure 413b). We then constructed a latitude/time Hovmöller plot of WGC surface speed 
(Figure 4-13c). While we are unable to construct an analogous Hovmöller plot for surface EKE, we can compare the timeseries of surface EKE at the IR hotspot with the mooring EKE at $300 \mathrm{~m}$ between LS5 and LS6 (Figure 4-13d). In order to make the mooring EKE more comparable with the IR hotspot timeseries, we lowpassed the mooring data with a 7-day Butterworth filter (results are not sensitive to the exact choice of the filter width).

This highlights the coherence in seasonality of the two signals, with elevated values in winter and early spring. Care must be taken, however, to statistically quantify the relationship between the two timeseries. This is because, while the EKE product is daily, it is dependent on satellite pass density. However, the error estimates in the gridded product take this into account (Pujol et al., 2016). The daily average error of sea level height anomaly within the IR hotspot region (black box in Figure 4-13a) is 5\%. Propagating this into our EKE timeseries calculation gives the error bars shown in Figure 4-13d (grey shading), indicating a large signal to noise ratio.

Figure 4-14 shows the lagged correlation between the surface EKE at the IR hotspot and the mooring EKE at $300 \mathrm{~m}$. This reveals two significant peaks: one at zero lag and the other at a lag of -15 days, where negative lags mean that the signal at the mooring array leads the signal at the IR hotspot. This indicates that there is both a simultaneous physical process at work and a propagating signal (note that these can't be distinguished in the Hovmöller plot). We suspect that the simultaneous process is due to offshore convection and LSW formation, which increases the lateral density gradient across the continental slope and therefore strengthens the WGC shear (through thermal wind). This would increase the instability everywhere along the current. The lagged signal could be due to the presence of LSW within the boundary current. In particular, when this water mass reaches a given site along the current, it alters the stratification and thus leads to local instability. Notably, 15 days is the mean advective timescale for LSW to travel from the OSNAP WG site to the IR hotspot (at an advective speed of $30 \mathrm{~cm} / \mathrm{s}$, Pacini et al. 2020). Hence, as the water mass is advected by the current, it causes the instability to propagate with it. Our results thus suggest that enhanced meandering activity in the boundary current 


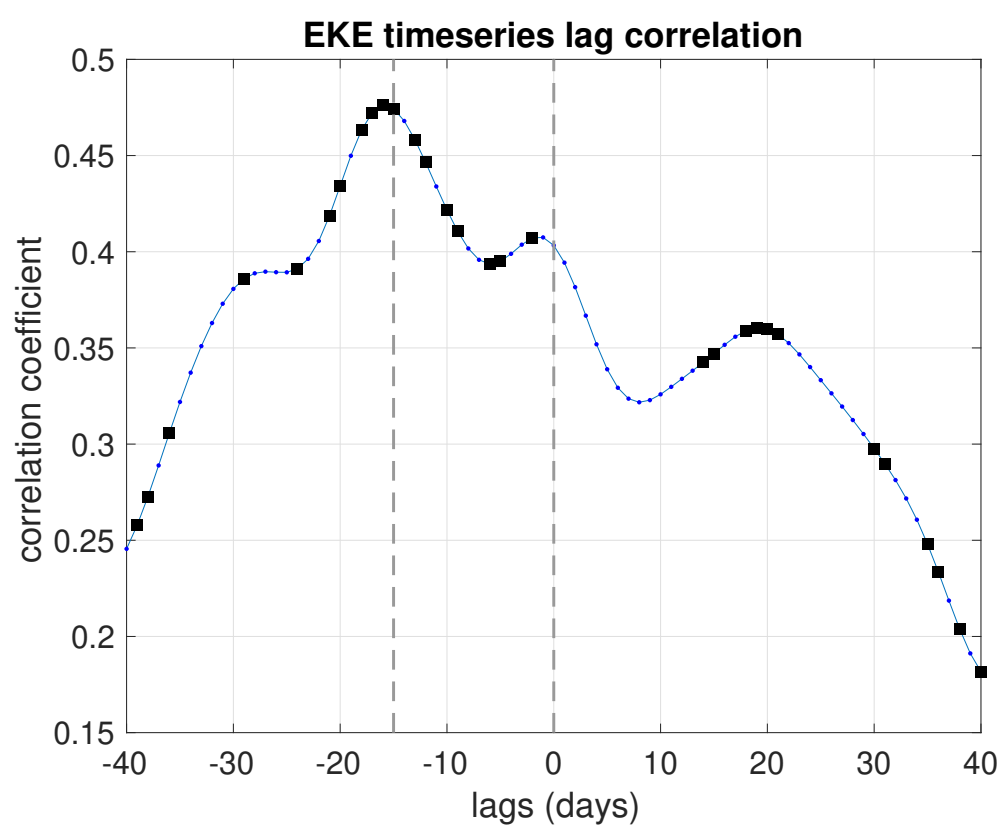

Figure 4-14: Lagged correlations between the two EKE timeseries in Figure 4-13d. The blue dots indicate the computed correlation at each lag, and the black squares indicate the statistically-significant values (based on the $95 \%$ confidence intervals calculated using the effective degrees of freedom).

leads to enhanced formation of IRs. That said, more work is needed to investigate the dynamics by which this happens, including the role of the abrupt change in topographic slope at the formation location (e.g. Eden and Böning, 2002; Bracco and Pedlosky, 2003; Katsman et al., 2004).

\subsection{Conclusions and discussion}

Using four years of OSNAP mooring array data, abundant anticyclonic features and dipole pairs were observed at two moorings located in and seaward of the core of the mean WGC. The prevalence of these features was shown to be seasonal in nature, with increased activity during winter/spring of 2016, 2017, and 2018, consistent with enhanced boundary current EKE during these periods. The anticyclonic features diagnosed at the mooring within the core of the WGC exhibit decreased along-stream velocity, a reversal in cross-stream velocity, and bowling isopycnals from the surface to $1000 \mathrm{~m}$. The features detected on the offshore edge of the WGC tended to occur 
in pairs - a leading anticyclonic feature and a trailing cyclonic feature. The anticyclonic portion of these features exhibited the same isopycnal and thermal structure as those at the core of the WGC, but instead exhibited enhanced along-stream velocity coincident with a reversal in cross-stream velocity. The features have an average wavelength of $20 \mathrm{~km}$ and account for $31 \%$ of the four-year mooring record.

Using kinematic evidence, together with potential vorticity considerations and satellite SST data, it was shown that the features are predominantly meanders of the WGC. This is consistent with the notion that the current can readily meander offshore, but is prohibited from meandering significantly onshore due to the steep bathymetry of the continental slope. It was argued that roughly $10 \%$ of the features corresponded to isolated vortices, suggesting that the meanders are able to grow to large enough amplitude to spawn eddies. These results constitute the first observational evidence for the existence of the BCEs that are commonly found in models of the Labrador Sea.

A stability analysis was performed revealing that baroclinic instability is responsible for the formation of the meanders. Furthermore, investigation of the stratification and shear of the boundary current demonstrated that the seasonal nature of the meandering can be explained by the decreased stratification in the boundary current due to increased LSW production and transport during winter/spring. The LSW contributes to a reduction in boundary current $R i$ and an increase in the baroclinic growth rate. It also helps to explain the lack of meandering observed in the first year of mooring observations (2015). During that time, LSW production was just starting to increase in the interior Labrador Sea as well as south of Cape Farewell and in the Irminger Sea. As such, the boundary current had not entrained enough LSW to destabilize it to the point of meander generation.

The importance of the meanders, and the associated BCEs that they form, for transferring heat into the interior basin was assessed by estimating the heat content of a given eddy. The average heat content of an individual feature at the mooring array was found to be $4.6 \mathrm{MJ} / \mathrm{m}^{2}$. When summed over the length of the boundary current and the frequency of events, and taking into account the progressive cooling 
of the IW as it moves cyclonically around the basin, it was estimated that $1.2 \mathrm{GJ} / \mathrm{m}^{2}$ of heat is transferred seasonally into the interior via BCEs. This is consistent with earlier high-resolution model results. It also implies that climate models must resolve these dynamics in order to accurately characterize LSW production and the lateral extent of the interior convective patch.

Finally, longer-term trends were investigated, revealing that the increased meandering over the four-year record is consistent with increased LSW presence in the boundary current. Simultaneously, increased LSW means decreased IW, which indicates decreased heat content of the boundary current, since IW has a higher heat content than LSW. This could result in two possible feedback loops, one positive and one negative. In the positive loop, increased convection results in increased LSW transport in the WGC, which in turn yields decreased heat transport in the boundary current, and thus restratification is less effective given the weaker heat fluxes associated with boundary current instabilities. In the negative loop, increased convection results in increased LSW transport in the WGC, which in turn yields increased BCE formation and thus increased heat flux from the boundary current to the interior. This would be more effective for restratification. Presently, it is unknown which of these scenarios dominate and if one might give way to the other; more data are required to track continued trends. In any event, models must account for the changes in boundary current heat content by including LSW entrainment into the WGC and not relaxing boundary conditions back to a fixed value at at Cape Farewell.

\subsection{Data availability}

All mooring data from the OSNAP WG array can be found at www.o-snap.org. The 2014-2016 mooring data are stored at https://doi .org/10.7924/r4f j2dr7k, and the 2016-2018 mooring data are stored at https://doi .org/10.35090/fz80-6c32. EU Copernicus Marine Service (CMEMS) sea surface height and geostrophic velocities are downloaded from https://resources.marine. copernicus.eu/?option=com_c sw\&task=results. Level 2 Modis $4 \mu \mathrm{m}$ Aqua and Terra nighttime sea surface 
temperature (SST) data are downloaded from https://oceancolor.gsfc.nasa.g ov/cgi/browse.pl?sen=amod.

\subsection{Acknowledgements}

We thank John Kemp, Jim Ryder, Bryan Hogue, Andrew Davies, and Rick Trask for the design, fabrication and deployment of the mooring array. We thank the captain and crew of the RV Knorr and RV Neil Armstrong for the successful recovery and deployment of the OSNAP WG moorings in 2014, 2016, 2018, and 2020. We are grateful to three anonymous reviewers whose comments have strengthened the manuscript. A.P. and R.S.P. were funded by the National Science Foundation Grants OCE-1259618 and OCE-1756361. 


\title{
Chapter 5
}

\section{Wind-forced upwelling along the West Greenland shelfbreak: The role of tip jets and implications for Labrador Sea Water formation}

\begin{abstract}
Arctic-origin and Greenland meltwaters circulate cyclonically in the boundary current system encircling the Labrador Sea. The ability for this freshwater to penetrate the interior basin has important consequences for dense water formation and the lower limb of the Atlantic Meridional Overturning Circulation. However, the precise processes by which the freshwater is transported offshore, and the magnitude of this flux, remain uncertain. Here we investigate wind-driven upwelling northwest of Cape Farewell using four years of data from the Overturning in the Subpolar North Atlantic Program (OSNAP) West Greenland mooring array, deployed from September 2014-2018, along with Argo, shipboard, and atmospheric reanalysis data. A total of 49 upwelling events were identified corresponding to enhanced northwesterly winds, followed by reduced along-stream flow of the boundary current and anomalously dense water present on the outer shelf. The events occur during the development stage of the forward Greenland tip jet. During the storms, a cross-stream Ekman cell develops that transports freshwater offshore in the surface layer and warm, saline, Atlanticorigin waters onshore at depth. The net fluxes of heat and freshwater are computed for a representative storm. Using a one-dimensional mixing model, it is shown that the freshwater input resulting from the locus of winter storms significantly limits the wintertime development of the mixed layer and the production of Labrador Sea Water in the southeastern part of the basin.
\end{abstract}




\subsection{Introduction}

The Labrador Sea, and the formation of the intermediate ventilated water mass known as Labrador Sea Water, play an important role in the Atlantic Meridional Overturning Circulation (AMOC; e.g. Talley and McCartney 1982; Sy et al. 1997; Rhein et al. 2002). The formation of this water mass through open ocean convection and the spreading of these ventilated waters via boundary currents (Pickart, 1992; Dickson and Brown, 1994; Fischer et al., 2010) and interior pathways (Lavender et al., 2000; Bower et al., 2009) have important implications for the circulation of the subpolar gyre as well as the sequestration of carbon from the atmosphere to the ocean (Takahashi et al., 2009; Khatiwala et al., 2013).

Labrador Sea Water (LSW) production is driven by buoyancy exchange at the airsea interface (e.g. Clarke and Gascard, 1983; Lab Sea Group, 1998; Pickart et al., 2002, 2003a). In the western Labrador Sea, it is formed by air-sea heat fluxes that result from low pressure systems that advect cold air off the Labrador land mass and extract

buoyancy from the surface waters (e.g. Pickart et al., 2002; Schulze et al., 2016). A water mass indistinguishable from LSW is also formed in the southwest Irminger Sea (e.g. Pickart et al., 2003a; Våge et al., 2008; de Jong et al., 2012; Piron et al., 2017). The convection there is more tightly coupled to the presence of the forward Greenland tip jet (Pickart et al., 2003a; Våge et al., 2008), an atmospheric phenomenon that occurs when low pressure systems following the north Atlantic storm track impinge on the high topography of southern Greenland. As this happens, air parcels accelerate around the tip of Greenland (Våge et al., 2009b), resulting in large air-sea heat fluxes and wind stresses in a localized region east of Cape Farewell (e.g. Doyle and Shapiro, 1999; Moore, 2003; Moore and Renfrew, 2005). Various observations also point to LSW production within a small recirculation gyre in the southeastern Labrador Sea (Lavender et al., 2000; Pickart and Spall, 2007; Zunino et al., 2020). Deep wintertime mixed layers have also been measured within the boundary current system of East Greenland (Le Bras et al., 2020) and along the Labrador slope (Pickart et al., 2002).

The strength of convection and annual production of LSW depend not only on the 
strength of the surface forcing, but also on the preconditioning of the water column prior to the winter season (e.g. Lilly et al., 1999). The strength of the stratification in the interior basin dictates the amount of energy required to penetrate the surface layer and homogenize the underlying water. For this reason, it is critical to understand the processes responsible for pre-conditioning the water column prior to deep convection, and for restratifying the water column after periods of strong ventilation (Lilly et al., 1999; Lilly and Rhines, 2002; Lilly et al., 2003; Katsman et al., 2004; Chanut et al., 2008; Gelderloos et al., 2011). This stratification is predominantly dictated by the water mass composition of the boundary currents, and the offshore flux of properties from these currents (Lilly et al., 1999; Lilly and Rhines, 2002; Prater, 2002; Lilly et al., 2003; Straneo, 2006; Hátún et al., 2007).

The cyclonic boundary current system that circumnavigates the Labrador Sea is composed of three branches on the east (west) side of the basin: the West Greenland Coastal Current (Labrador Coastal Current) that advects cold and fresh meltwaters of both Arctic and Greenland origin on the inner shelf (WGCC/LCC; Lin et al. 2018; Florindo-López et al. 2020); the West Greenland Current (Labrador Current) which advects warm, saline, Atlantic-origin water at depth and cold and fresh melt waters at the surface (WGC/LC; Colbourne et al., 1994; Cuny et al., 2002; Myers et al., 2007, 2009; Rykova et al., 2015); and the Deep Western Boundary Current that advects overflow waters ventilated in the Nordic Seas at depth (DWBC; Dickson and Brown 1994) (Figure 5-1). Mesoscale to submesoscale variability is responsible for the offshore transport of properties from the surface and mid-depth components of the boundary currents into the interior (e.g. Gascard and Clarke, 1983; Lilly et al., 1999; Eden and Böning, 2002; Prater, 2002; Lilly et al., 2003; Chanut et al., 2008; Thomsen et al., 2014; Rieck et al., 2019).

The strong eddy kinetic energy (EKE) signature in the Labrador Sea can be subdivided into four main categories: Irminger Rings (IRs); Convective Eddies (CEs); Boundary Current Eddies (BCEs); and Denmark Strait Overflow Water (DSOW) cyclones. For a summary of these different eddy signatures the reader is referred to Pacini and Pickart (2022), who also present the first observational evidence of 


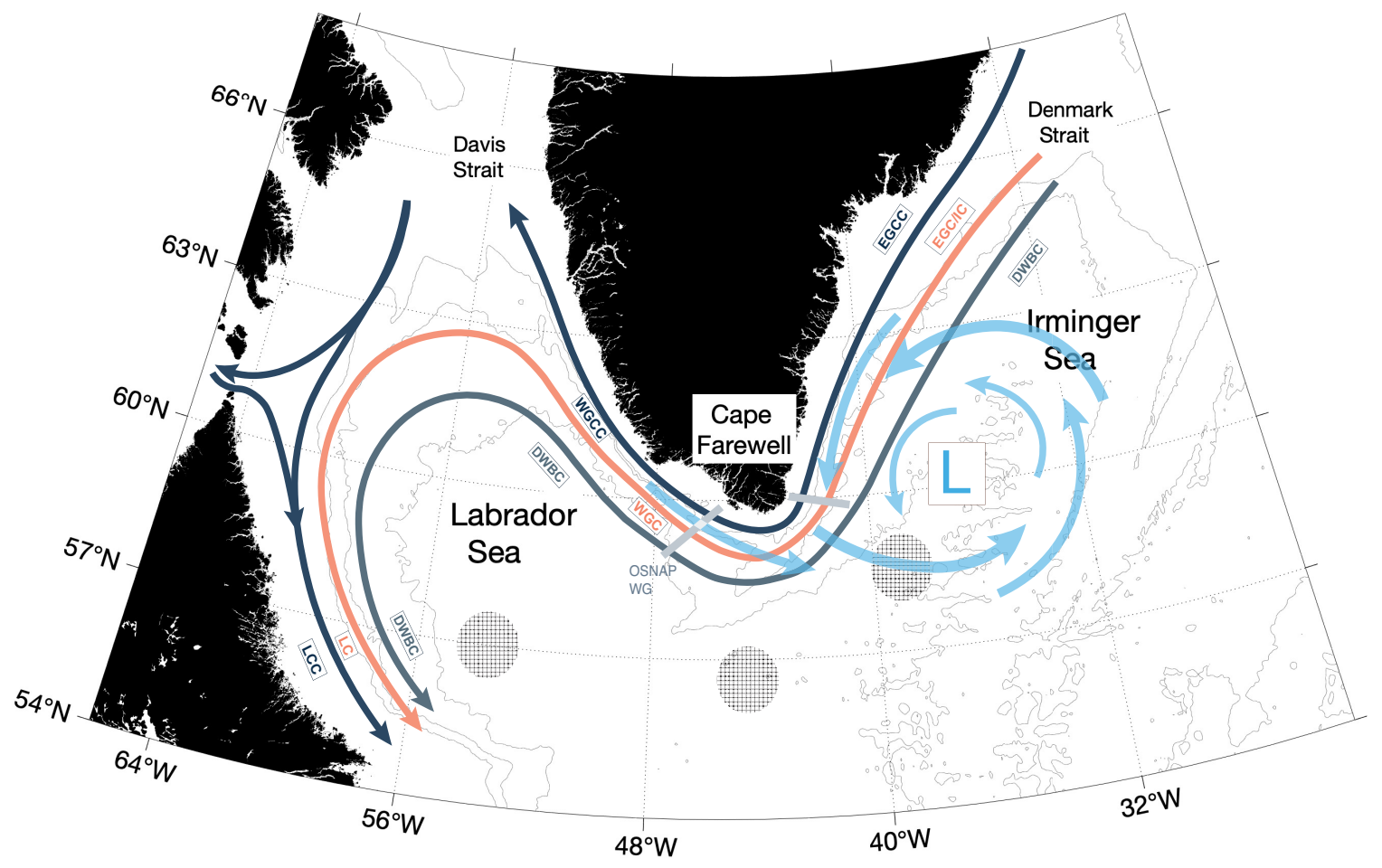

Figure 5-1: Schematic circulation of the boundary current system in the Labrador and western Irminger Seas. EGCC is the East Greenland Coastal Current; EGC/IC is the East Greenland Current/Irminger Current; DWBC is the Deep Western Boundary Current; WGCC is the West Greenland Coastal Current; WGC is the West Greenland Current; LCC is the Labrador Coastal Current; LC is the Labrador Current. The grey lines across the boundary current system indicate the locations of the OSNAP East and West Greenland mooring arrays. The hatched areas represent the regions of deep convection in the Labrador and Irminger Seas. Also shown is the schematic wind field of a low-pressure system causing a forward tip jet in the vicinity of Cape Farewell and barrier winds along the southeast Greenland coast. 
BCEs along the West Greenland continental slope. Together, the IRs and BCEs transport cold, fresh water near the surface and warm, saline water at depth from the WGC, both of which can influence winter mixed layer development (Lilly et al., 2003; Katsman et al., 2004; Chanut et al., 2008; Kawasaki and Hasumi, 2014; Pennelly and Myers, 2020). While some studies are able to account for most of the necessary heat transport from the boundary current to the interior via eddy mechanisms (e.g. Lilly et al., 2003; Katsman et al., 2004), to date no studies can account for the freshwater transport needed to balance the interior Labrador Sea freshwater budget annually (Lilly et al., 2003; Straneo, 2006; Hátún et al., 2007; Schulze Chretien and FrajkaWilliams, 2018).

In addition to the intrinsic eddy variability within the Labrador Sea, there is strong wind forcing; to wit, Cape Farewell is the windiest place in the World Ocean (Sampe and Xie, 2007; Moore et al., 2008). Various modelling studies have addressed the role of winds in the export of freshwater from the surface WGC and WGCC into the interior Labrador Sea. For instance, Luo et al. (2016) and Castelao et al. (2019) find a preferential pathway for meltwater originating along east Greenland to be fluxed offshore due to wind events, as compared to meltwater originating along west Greenland, which tends to enter Baffin Bay along the shelf. Luo et al. (2016) stress that large variability in wind forcing could explain changes in freshwater export on interannual timescales. In particular the orientation of the predominant winds during the melt season has a large impact on the offshore export of meltwaters: years with upwelling favorable winds exhibit a large offshore freshwater signal, whereas years with downwelling-favorable winds constrain meltwater to the coast.

The model results of Böning et al. (2016) demonstrate that meltwater entering the Labrador Sea from the west Greenland shelf has triggered a small but significant freshening trend at the surface of the Labrador Sea that has not yet influenced AMOC but could in the future, as more freshwater fills the west Greenland shelf. Schulze Chretien and Frajka-Williams (2018) perform a Lagrangian analysis using a highresolution $1 / 12^{\circ}$ ocean model to demonstrate that $60 \%$ of the freshwater in the top $100 \mathrm{~m}$ in the interior basin emanates from the top $30 \mathrm{~m}$ of the West Greenland shelf 
due to Ekman transport versus eddy processes. While Castelao et al. (2019) also show that upwelling-favorable winds transport meltwater from the shelf into the WGC, the freshwater is subsequently fluxed into the interior basin by eddies.

From the observational perspective, drifter tracks near Cape Farewell show that freshwater is diverted seaward from the coast on both sides of Greenland, likely due to wind (Duyck and De Jong, 2021). Similarly, Majumder et al. (2021) use satellite and historical in-situ data (from CTD casts, Argo floats, gliders, and moorings made available by the National Oceanographic Data Center, NODC) to investigate freshwater fluxes into the Labrador Sea on seasonal to interannual timescales. They document the westward transport of freshwater from southwest Greenland between $60-62^{\circ} \mathrm{N}$ and $63-64.8^{\circ} \mathrm{N}$ due to the large-scale, geostrophically-balanced flow coincident with the 1000-2000 $\mathrm{m}$ isobaths.

To date, none of the models or observational studies address the role of synopticscale wind events on the freshwater budget of the interior Labrador Sea. Synopticscale low pressure systems are responsible for a variety of high-speed wind events in the vicinity of Cape Farewell, including forward tip jets, reverse tip jets, and barrier winds (e.g. Moore and Renfrew, 2005). The type of event depends on the angle of impingement of the low relative to the orography of southern Greenland. Forward tip jets are characterized by a narrow band of strong westerly winds extending from Cape Farewell across the Irminger Sea, while reverse tip jets have a similarly narrow band of strong easterly winds extending from Cape Farewell across the Labrador Sea (Moore and Renfrew, 2005). Barrier winds are geostrophically-balanced flows along the east coast of Greenland (Moore and Renfrew, 2005) Studies have shown that forward tip jet and reverse tip jet frequency is elevated in years of high North Atlantic Oscillation (Bakalian et al., 2007; Våge et al., 2009b) when the north Atlantic storm track is shifted to the northeast, making low pressure impingement on southern Greenland more likely (Moore, 2003; Pickart et al., 2003a).

In this paper, we investigate the wind-driven variability of the WGC using four years of data from a high-resolution mooring array situated west of Cape Farewell, along with Argo data and atmospheric reanalysis data. We focus on upwelling events 
driven by synoptic storms, which are frequent during the cold season. We begin by presenting the method for identifying the events, and present their statistics. We then describe the kinematic and hydrographic response, including a case study of a single event. The nature of the atmospheric forcing is then investigated, followed by quantification of the cross-stream fluxes of heat and freshwater due to a typical storm. Lastly, we explore the impacts of this wind-driven freshwater flux on interior convection in the Labrador Sea.

\subsection{Data and methods}

\subsubsection{Mooring data}

The mooring data used in this study consist of four years of hourly pressure, temperature, salinity, and velocity measurements from the 10 moorings that comprise the Overturning in the Subpolar North Atlantic Program (OSNAP) West Greenland array (Lozier et al. 2019; Pacini et al. 2020; Figure 5-1). The moorings cover the shelf and slope of the eastern Labrador Sea near $59^{\circ} \mathrm{N}$, from $130 \mathrm{~m}$ water depth on the shelf to the $3000 \mathrm{~m}$ isobath at the offshore end of the array. The moorings sample the DWBC, the WGC, and the seaward side of the WGCC (Figure 5-2). They were first deployed in August 2014, were serviced again in 2016, 2018, and 2020, and remain in the water to date. The array consists of three shelf tripods (LS1-LS3), five full-depth moorings (LS4-LS8) and two bottom-instrumented moorings (DSOW3-DSOW4) that together have 49 Sea-Bird SBE37 MicroCATs measuring pressure, temperature, and conductivity, 33 Nortek Aquadopps measuring point-values of velocity, and 8 acoustic Doppler current profilers (RDI ADCPs, 300 and $75 \mathrm{kHz}$ ) measuring vertical profiles of velocity (Figure 5-2). The moorings are spaced on average $15 \mathrm{~km}$ apart. After the 2018 turnaround, additional tripods were deployed inshore of LS1 on the shelf. In this study, we use data from LS1-LS8 over the time period 2014-2018.

Vertical sections of potential temperature referenced to the surface (hereafter referred to as temperature), salinity, potential density referenced to the surface (here- 


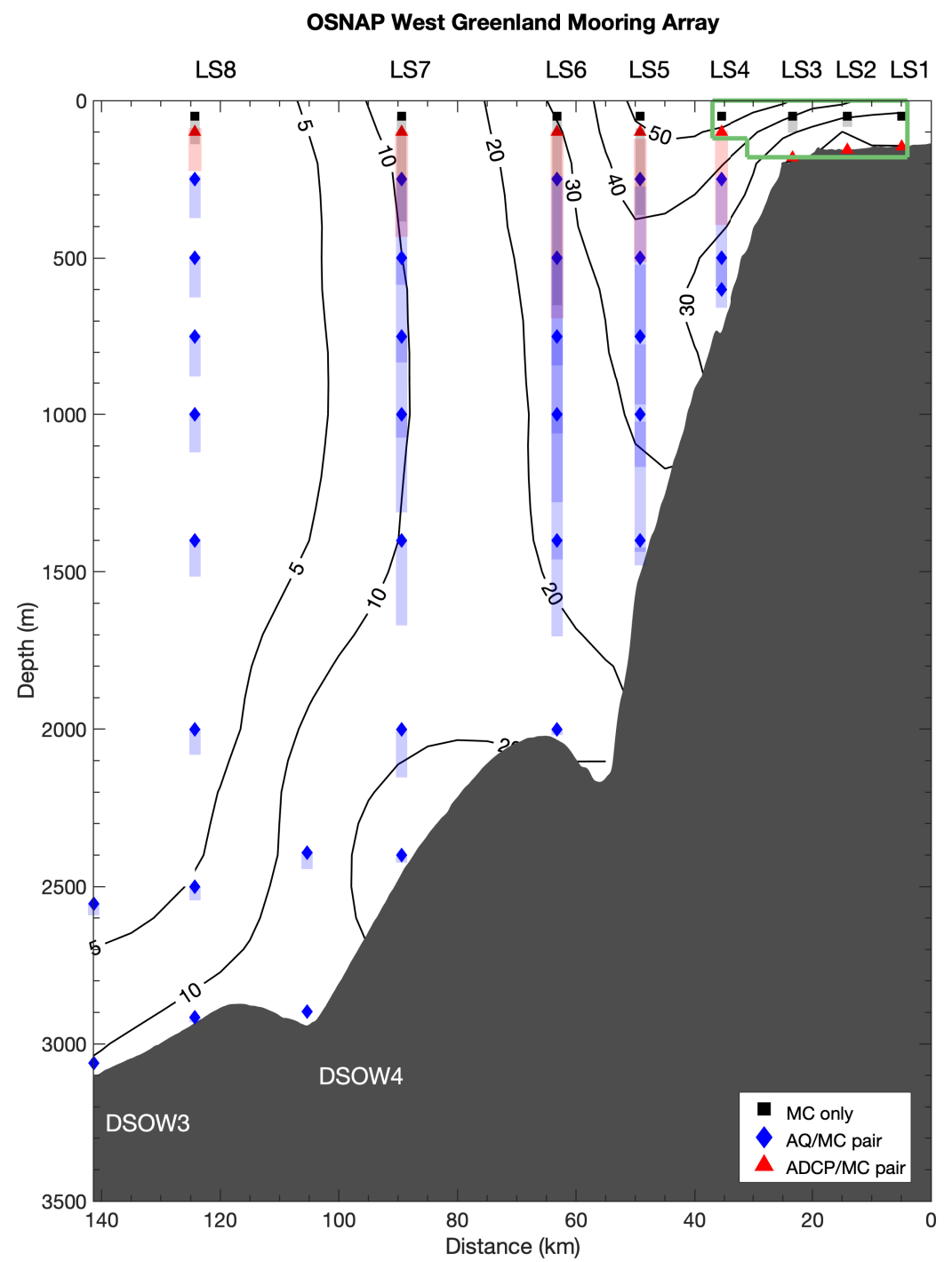

Figure 5-2: Vertical section showing the mooring array instrument configuration. The solid symbols denote the instrument deployment locations, and the shading indicates the depth range over which instruments sampled due to mooring blowdowns. The mean section of along-stream velocity is contoured $(\mathrm{cm} / \mathrm{s}$, positive values indicate flow to the north). The green polygon denotes the region within which the higher-resolution velocity grid is constructed.

after referred to as density), along-, and cross-stream velocity were created for each time step with Laplacian-Spline interpolation (Smith and Wessel, 1990). For the full mooring array, the gridded product has $5-\mathrm{km}$ resolution in the horizontal and $100-\mathrm{m}$ resolution in the vertical. The velocity data were de-tided using the harmonic tidal routine T_TIDE (Pawlowicz et al., 2002) and rotated such that the cross-stream 
transport was minimized. Positive along-stream velocity $u$ is along $318^{\circ} \mathrm{T}$ (northwest), and positive cross-stream velocity $v$ is directed offshore at $228^{\circ} \mathrm{T}$ (southwest). The processing, accuracy, de-tiding, rotating, and gridding are described in detail by Pacini et al. (2020). Additionally, in this study we take advantage of the high vertical resolution of the ADCPs to create a finer grid with $10 \mathrm{~km}$ horizontal resolution and $20 \mathrm{~m}$ vertical resolution for along- and cross-stream velocity on the shelf and near the shelfbreak, in the subset of the domain shown by the green box in Figure 5-2. We use both of the gridded products, as well as individual timeseries from the instruments.

\subsubsection{Atmospheric data}

The atmospheric data used in this study are from the European Centre for Medium Range Weather Forecasting (ECMWF) ERA5 atmospheric reanalysis product (Figure 5-3; Hersbach and Dee 2016). This product has $0.25^{\circ}$ resolution in both latitude and longitude, and hourly temporal resolution of sea level pressure (SLP), $10 \mathrm{~m}$ zonal and meridional winds, and heat flux components (latent, sensible, solar, and longwave). Earlier studies have shown good agreement between observations and Integrated Forecast System (IFS)-based reanalysis products around Greenland (Renfrew et al., 2002, 2009). We subsample the data to every 3 hours.

\subsubsection{Shipboard data}

Shipboard hydrographic measurements are used to provide high-resolution vertical profiles of temperature and salinity. In particular, we use conductivity-temperaturedepth (CTD) casts from a 2018 fall survey of the West Greenland boundary current system carried out by R/V Neil Armstrong, conducted from 27 August - 2 October 2018. This survey used a Sea-Bird 911 + CTD mounted on a frame with 24 10-L Niskin bottles. The temperature sensors were calibrated at Sea-Bird, and the conductivity sensors were calibrated using water sample salinity measurements collected during the cruise. The estimated accuracy for temperature and salinity is $0.001^{\circ} \mathrm{C}$ and 0.002 , respectively. 

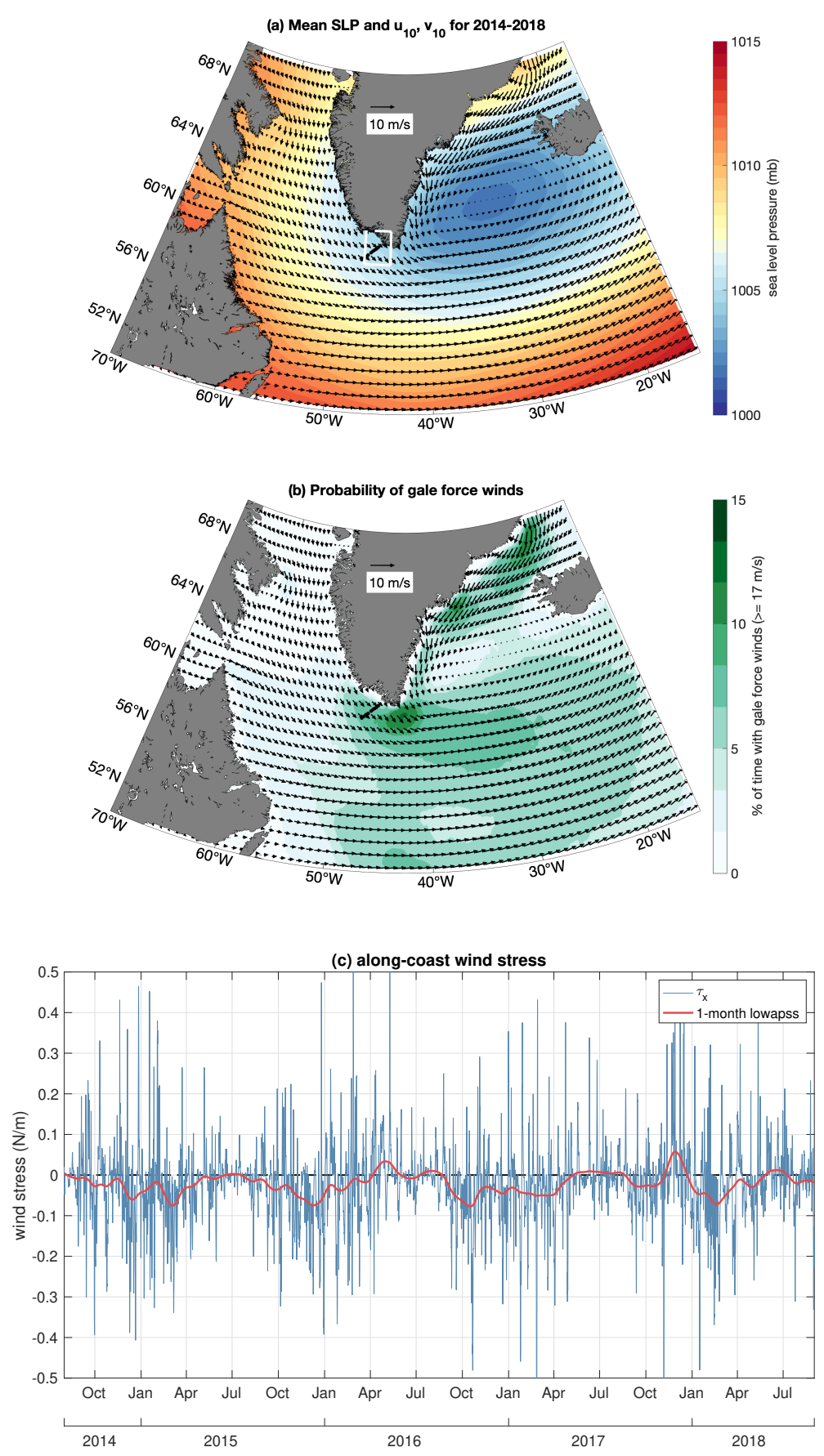

Figure 5-3: (a) 2014-2018 mean sea level pressure (color) and $10 \mathrm{~m}$ wind vectors from ERA5. Every third wind vector is shown. The black line indicates OSNAP mooring array. The white box denotes the domain over which the along-coast winds were averaged (see text for details). (b) Percentage of time subject to gale force winds ( $>17 \mathrm{~m} / \mathrm{s}$ ) over the time period 2014-2018, with the mean $10 \mathrm{~m}$ wind vectors from (a) overlaid. (c) Timeseries of along-coast wind stress within the white box in (a). Upwelling favorable wind stress is negative. 


\subsubsection{Interior Labrador Sea data}

All Argo profiles within the western Labrador Sea (defined as the region from 55$59.5^{\circ} \mathrm{N}$ and $52-55^{\circ} \mathrm{W}$ ) and within the recirculation gyre in the southeastern Labrador Sea (defined as the region from $57.6-59.5^{\circ} \mathrm{N}$ and $45-49.5^{\circ} \mathrm{W}$ ) from November 2014 were downloaded (see Figure 5-4a). The data are made freely available by the International Argo Program (Argo, 2021) and the national programs that contribute to it (https: //argo.ucsd.edu, https://www.ocean-ops.org). The Argo Program is part of the Global Ocean Observing System. We excluded profiles that exhibited unrealistic spikes in salinity (salinity < 33). This resulted in 728 profiles from 13 floats in the western Labrador Sea, and 255 profiles from 14 floats in the recirculation gyre. These individual profiles were gridded, then averaged together to create mean profiles of temperature and salinity at $10 \mathrm{~m}$ vertical resolution in the recirculation gyre (Figure 5$4 \mathrm{~b}, \mathrm{c})$ and in the western Labrador Sea (Figure 5-4d,e). Sensitivity tests were run by selecting a subset of profiles to see if the general vertical structure of the average profile changed, but there were no substantial differences among composite profiles.

\subsubsection{One-dimensional mixed layer model}

To study the wintertime evolution of the mixed layer in the interior Labrador Sea, the one-dimensional mixing model of Price et al. (1986) is used (hereafter referred to as PWP). The model is initialized with the average Argo temperature and salinity profiles and forced with the atmospheric heat flux and windstress timeseries from ERA5, extracted from the same domain as the Argo profiles (see subsection 5.2.4 for domain boundaries). At each timestep, the model calculates the bulk and gradient Richardson numbers to adjust the density profile until static stability has been achieved. For the purposes of the following analysis, the mixed layer is defined as the first location where the vertical density gradient exceeds $0.5 \times 10^{-3} \mathrm{~kg} / \mathrm{m}^{3}$. 

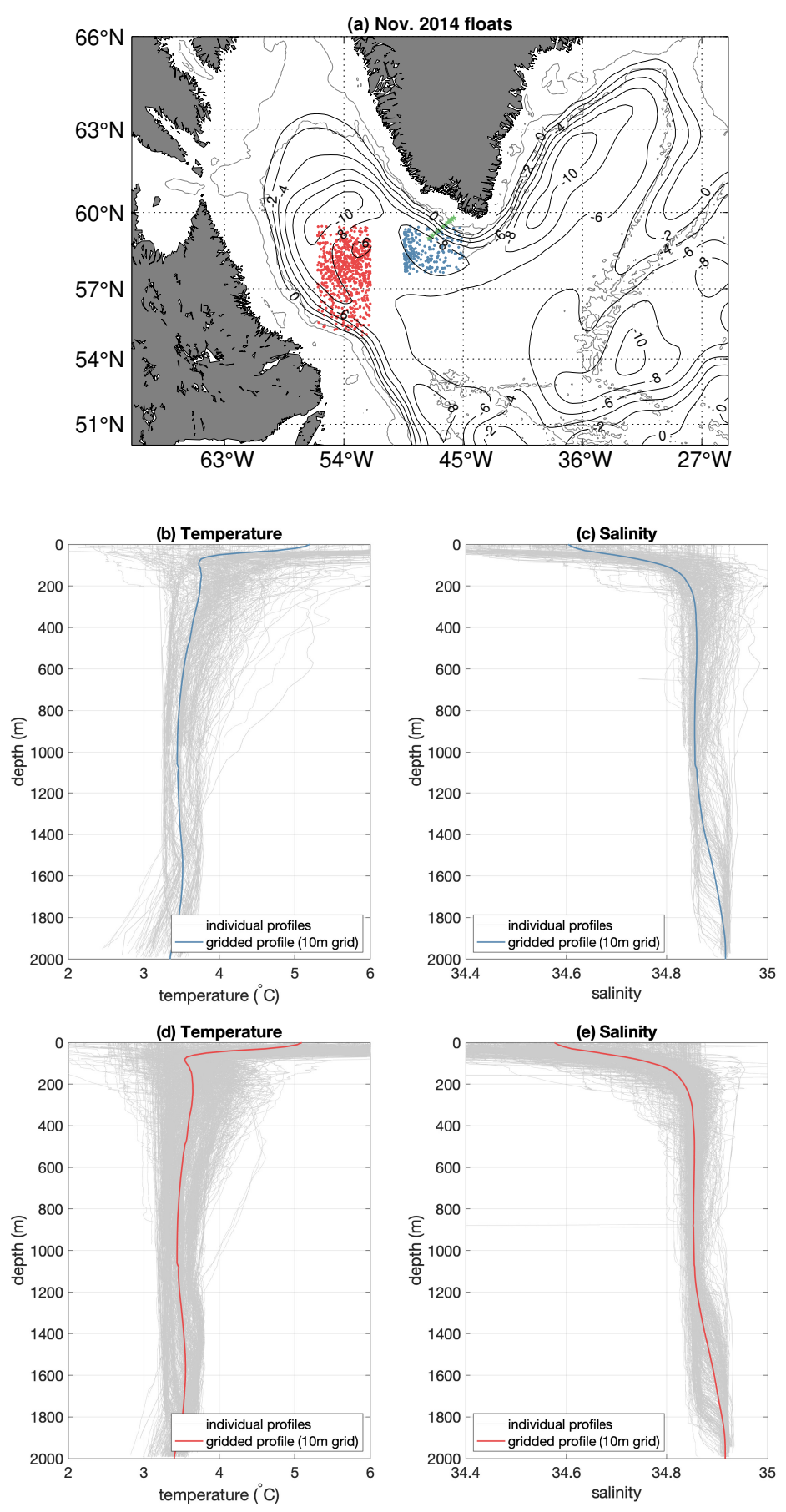

Figure 5-4: (a) Locations of all Argo profiles in the western Labrador Sea (red dots) and within the recirculation gyre in the eastern Labrador Sea (blue dots). The contours of absolute pressure anomaly from Lavender et al. (2000) are shown in black, and the bathymetric contours are shown in grey. The green stars denote the moorings of the OSNAP West Greenland array. (b) Mean November profile of temperature within the recirculation gyre (blue curve), with all available profiles shown in light grey. (c) Same as (b) except for salinity. (e) Same as (b) except for western Labrador Sea. (e) Same as (c) except for western Labrador Sea. 


\section{$5.3 \quad$ Results}

\subsubsection{Diagnosing upwelling events}

The North Atlantic Oscillation (NAO) index was strongly positive during the study period (2014-2018), indicating a strengthened sea level SLP gradient between the Icelandic Low and the Azores High. A strong positive NAO is associated with more frequent and stronger storms and a northward shift in the North Atlantic storm track (e.g. Rogers, 1990; Serreze et al., 1997; Moore, 2003), which has resulted in upwelling-favorable winds over the 2014-2018 mooring deployment period (Figure 5$3 \mathrm{c})$. It is thus likely that the increased occurrence of synoptic storms could energize the boundary current system and induce a water column response beyond the seasonal and interannual mean wind fields described in the modeling literature (e.g. Luo et al., 2016; Böning et al., 2016). Figure 5-3b shows the probability of gale force winds within the subpolar gyre. Two regions of strong storm activity are evident: a band along the east coast of Greenland associated with the barrier winds (with local enhancement near $64^{\circ} \mathrm{N}$ and $68^{\circ} \mathrm{N}$ ), and one at the southern tip of Greenland, where forward tip jets and reverse tip jets occur (Moore and Renfrew, 2005). Many studies have examined the connection between forward tip jets and the hydrographic conditions east of Greenland (e.g. Pickart et al., 2003a; Våge et al., 2008; Josey et al., 2019), but observations describing how these storms affect the west coast of Greenland are lacking.

Here we objectively define upwelling events using the mooring and reanalysis data as follows. First, the density anomaly at the base of the water column is computed for all three shelf tripods (LS1, LS2, LS3; see Figure 5-2) by subtracting the 30-day lowpass of density from each hourly measurement for the respective MicroCATs. This removes any seasonal biases in the anomaly signature (see also Lin et al. 2019 and Foukal et al. 2019). The three anomalies are then averaged together at each time step, providing an hourly density anomaly at the base of the water column on the outer west Greenland shelf. (The results below are not sensitive to the choice of mooring for the density anomaly.) Next, the analogous calculation is performed to 
obtain a timeseries of along-stream velocity anomaly; in this case the timeseries is depth-averaged over the water column. Finally, we compute a timeseries of average along-coast wind speed within the box shown in Figure 5-3a, where the rotation angle is the same as that used for the ocean velocity (see subsection 5.2.1 for details). Again, the 30-day lowpass was subtracted to create an anomaly timeseries.

Previous studies of shelfbreak upwelling at high latitudes (e.g. Lin et al., 2016) have found a lag between the hydrographic and velocity signatures relative to the wind forcing. In particular, the velocity response lags the wind, followed later by the response of the density. We thus computed the lagged correlations between our three timeseries to understand their relative signatures. This revealed that, over the four-year record, the wind leads the ocean velocity response by 6-9 hours, and the ocean velocity response leads the ocean density response by 12-15 hours (these are similar to the lags found by Lin et al. (2019) for the shelfbreak jet of the Beaufort Sea).

Guided by the lagged correlations, we defined an upwelling event based on the following criteria: for every time period associated with a positive density anomaly greater than $0.05 \mathrm{~kg} / \mathrm{m}^{3}$, we stipulate that, in the temporal range spanning 24 hours before the onset of the anomaly to 24 hours after the onset of the anomaly, 12 of those hours must have a negative along-stream velocity anomaly (i.e., the northwardflowing boundary current weakens). Additionally, we require 12 of the hours spanning the time period 48 hours before the onset of the density anomaly to 24 hours after the onset of the anomaly to have a negative anomaly in along-coast winds (i.e., enhanced northwesterlies). Finally, the density anomaly must last for at least 48 hours. While this set of criteria are taken to be the most effective for objectively identifying the upwelling events, we stress that the results below are not sensitive to the detailed definitions. When the four criteria are applied, 49 upwelling events between September 2014 and September 2018 are identified, as shown in Figure 5-5.

It is important to note that, upon inspection of each event, we are able to distinguish between upwelling events driven by the passage of one low pressure system versus events produced by a train of cyclones. Such trains of low pressure systems act 

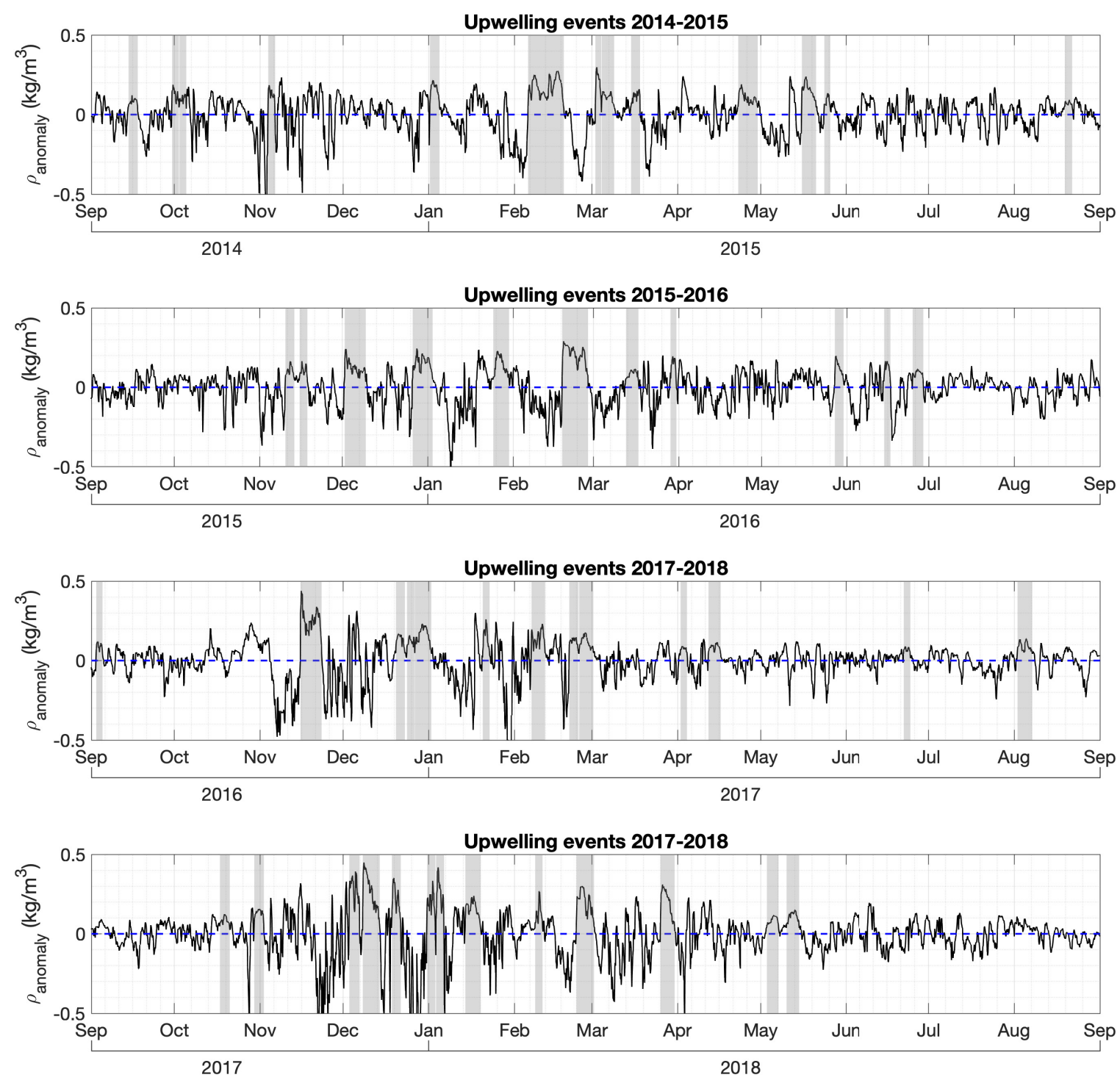

Figure 5-5: Timeseries of bottom density anomaly averaged between LS1, LS2, and LS3, over the four-year deployment (2014-2018). The upwelling events are indicated by grey shading (see text for details on defining the upwelling periods).

to keep the bottom density elevated for longer periods of time than in the single-storm scenario. In the subsequent analysis, we distinguish between events associated with a single storm versus multiple storms. 


\subsubsection{General characteristics of upwelling events}

\section{Effect of wind}

For each of the 49 upwelling events identified using the above set of metrics, a stormdependent rotation angle was computed for the depth-averaged water column flow. This was necessary in order to more effectively identify the cross-stream Ekman cell for each event (see also Schulze and Pickart 2012). The storm-dependent rotation angle was defined as the direction of the mean flow in the center half of the storm event (i.e., between $1 / 4$ of the way through the storm to $3 / 4$ of the way through the storm). On average, the rotation angles only deviate from the original orientation of the flow by $3.2^{\circ}$.

We assess the relative strength of each event and its correlation to the along-coast winds by computing the upwelling index (following Lin et al. 2019) and the cumulative velocity anomaly (following Ovall et al. 2021) and compare them to the cumulative Ekman transport (Huyer et al., 1979). The upwelling index $(U I)$ is defined as the integral in time of the bottom density anomaly over the course of the event,

$$
U I=\int_{t_{s}}^{t_{e}} \rho d t
$$

where $\rho$ is the bottom density anomaly, and $t_{s}$ and $t_{e}$ are the start and end of the event, defined as when the bottom density anomaly crosses above and below 0.05 $\mathrm{kg} / \mathrm{m}^{3}$, respectively. Similarly, the cumulative velocity anomaly $(C V A)$ is defined as the time integral of the velocity anomaly

$$
C V A=\frac{1}{H} \int_{t_{s}-t_{v}}^{t_{e}-t_{v}} v d t
$$

where $H$ is the bottom depth, $v$ is the depth-averaged velocity anomaly, and $t_{v}$ is the average lag $(9 \mathrm{hr})$ between the wind signal and the velocity response of the water column. The cumulative Ekman transport $\left(T_{C E}\right)$ is defined as 


$$
T_{C E}=\int_{t_{s}-t_{h}}^{t_{e}-t_{h}} \frac{\tau_{s}(t)}{\rho_{0} f} d t
$$

where $\tau_{s}$ is the along-coast wind stress, $f$ is the Coriolis parameter, $\rho_{0}$ is the reference density $1025 \mathrm{~kg} / \mathrm{m}^{3}$, and $t_{h}$ is the average lag (18 hr) between the hydrographic response of the water column and the wind. Note that $U I, C V A$, and $T_{C E}$ take into account both the duration and the strength of the upwelling event.

When $C V A$ and $T_{C E}$ are compared, a statistically-significant log-linear relationship between these metrics of intensity is revealed (Figure 5-6a). Similarly, when $U I$

and $T_{C E}$ are compared, a statistically-significant log-log correlation between these two metrics of storm intensity is observed (Figure 5-6b). This emphasizes the fact that the upwelling diagnosed in this study is wind-driven, with a stronger water column response associated with stronger and/or longer along-coast winds. Not surprisingly, the type of event, single vs. multiple lows, impacts the strength of the response. Approximately half of the upwelling events are associated with one low pressure system, while the other half are driven by multiple low pressure systems. Figure 5-6 shows that multiple low storms generally exhibit larger $C V A$ and $U I$ values than their single low counterparts. Note that some events exhibit positive $C V A$, indicating an acceleration of the WGC over the event. This is because the duration of the velocity anomaly can be significantly shorter than the duration of the density anomaly; the dynamics behind this are explained in section 5.3.6.

\section{Composite event}

In order to characterize the general features of the upwelling, all of the events associated with a single low pressure system (28 total) were combined to create a composite event (not surprisingly, when including the multiple storm events the composite was less-well behaved). To do so, each event in question was normalized onto a temporal grid ranging from 0 to 1 . We then computed the spatially-averaged along-coast winds, depth-averaged ocean velocity anomaly, and bottom density anomaly on this 

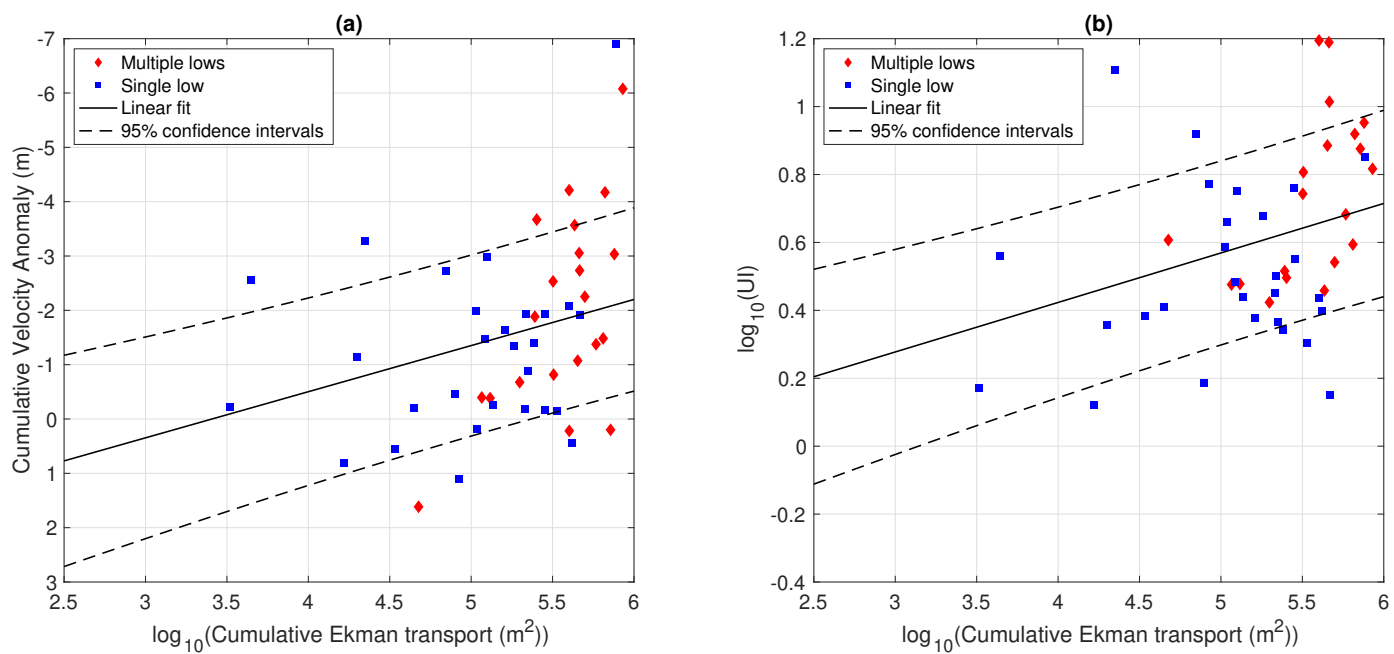

Figure 5-6: (a) Cumulative Ekman transport $\left(T_{C E}\right)$ compared with cumulative velocity anomaly $(C V A)$ for all of the upwelling events, with the linear fit and error bars superimposed. The events are distinguished as to whether they were associated with a single storm (blue symbols) or multiple storms (red symbols). (b) Same as (a) except for the upwelling index $(U I)$.

normalized grid. Given that each event is independent of the others, the signals of the normalized event are presented with standard errors.

The composite is consistent with the statistical analysis of correlations between the wind and the mooring timeseries, in that the velocity weakens after the wind picks up, followed later by the presence of anomalously dense water near the bottom of the outer shelf (Figure 5-7). The maximum along-coast wind speed is $7 \mathrm{~m} / \mathrm{s}$ out of the northwest, while the depth-averaged speed of the WGC weakens by roughly 10 $\mathrm{cm} / \mathrm{s}$. The maximum density anomaly is $0.15 \mathrm{~kg} / \mathrm{m}^{3}$. The vertical dashed lines in the figure denote the start and end of the event, but keep in mind that these are defined by the density signal. The average length of the events in non-normalized time is 79 $+/-30$ hours. By way of comparison, a similarly constructed composite of upwelling along the Beaufort Sea shelfbreak had a peak along-coast wind speed of $7 \mathrm{~m} / \mathrm{s}$ and a depth-averaged velocity signal of $10 \mathrm{~cm} / \mathrm{s}$, the same as the values obtained here. However, the density anomaly in the Beaufort Sea composite was much stronger, 0.5 $\mathrm{kg} / \mathrm{m}^{3}$. This is because the depth of the Beaufort shelfbreak is much shallower than the west Greenland shelfbreak (50 m versus $150 \mathrm{~m}$ ), hence more strongly stratified water is upwelled. 

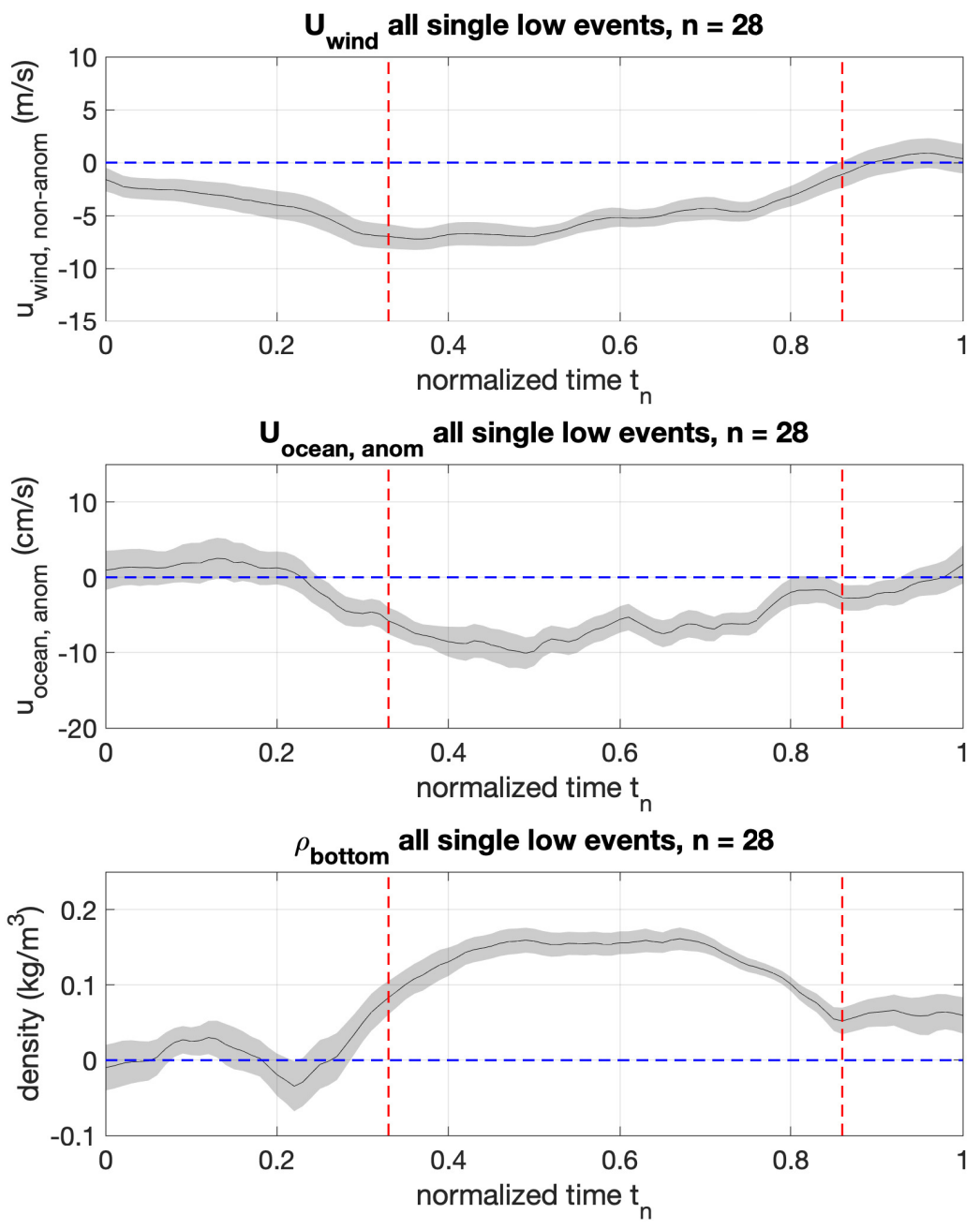

Figure 5-7: Composite upwelling event for all of the single-low cases, presented in normalized time over the duration of the event. The top row is along-coast wind speed, averaged over the region outlined by the white box in Figure 5-3. The second row is depth-averaged velocity anomaly on the outer shelf. The third row is bottom density anomaly on the outer shelf. The shading indicates the standard error.

\subsubsection{Hydrographic response to upwelling-favorable winds}

The three shelf tripods in the OSNAP West Greenland array were designed with an additional MicroCAT situated at a depth of $50 \mathrm{~m}$. The line holding these instruments was connected to the tripods with a weak link, so that they would break free if snagged by a passing iceberg (rather than dragging the tripod). Unfortunately, the common presence of icebergs in the WGCC resulted in the loss of most of these upper 


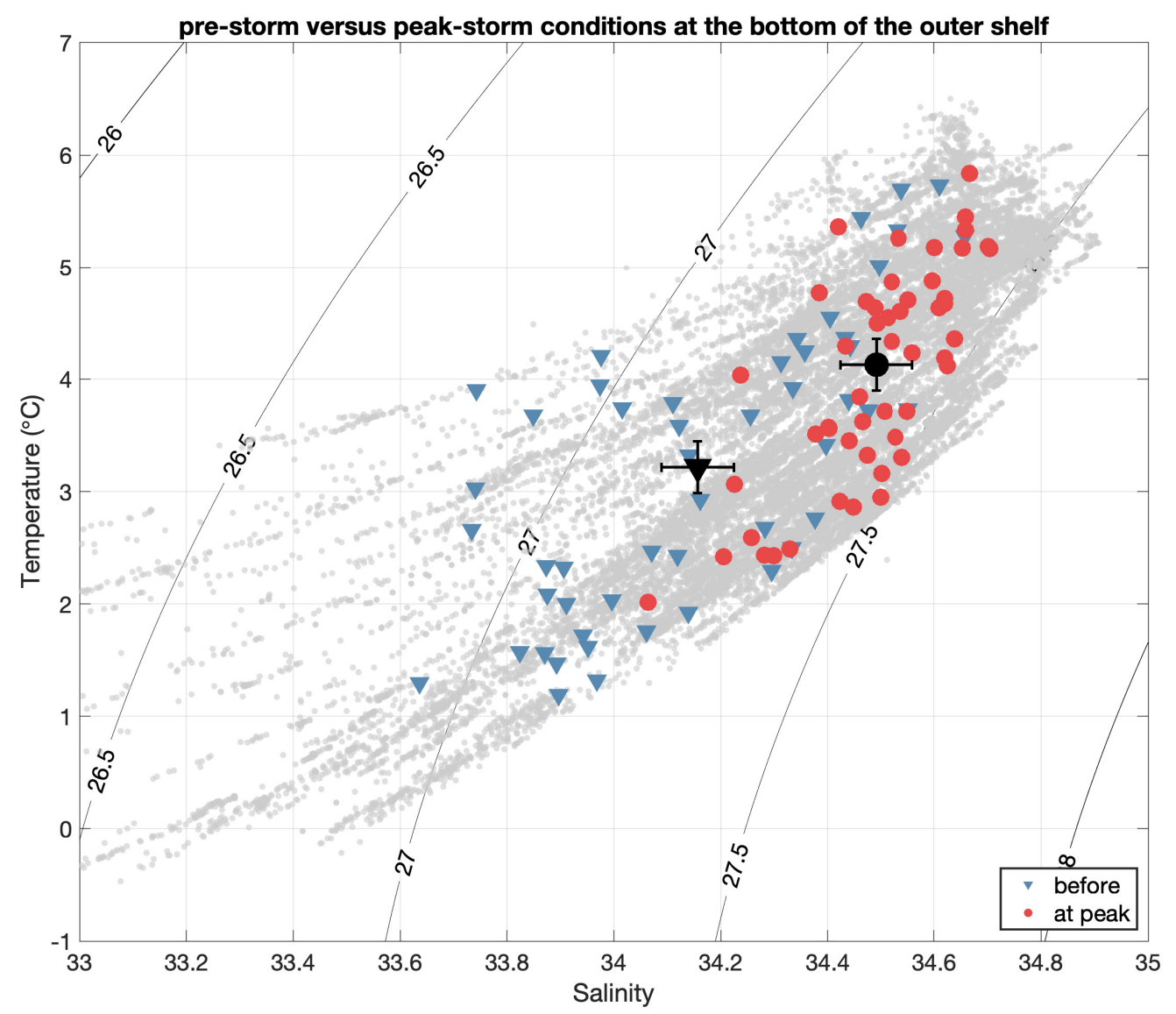

Figure 5-8: Mean hydrographic properties for the 24 hours before an upwelling event (blue triangles) and during the 24 hours surrounding the peak of each upwelling event (red circles) averaged at the base of the shelf (LS1, LS2, and LS3). The overall mean values prior to and during the storm are shown by the black symbols, where the error bars represent the standard error. The grey dots indicate all of the hydrographic measurements from the tripod MicroCATs at LS1, LS2, and LS3 during the 49 upwelling events.

MicroCATs. Hence, it is not possible to show the mid water column hydrographic response using the mooring data. However, in subsection 5.3.5 we use data from a shipboard survey occupied during an upwelling event to shed light on the vertical structure of the hydrographic response.

The MicroCATs mounted directly on the tripods successfully recorded data at all three sites for all four years of deployment. This permits characterization of the hydrographic response to upwelling-favorable winds at the base of the water column. 
For each identified storm, we define the pre-storm temperature and salinity as the average values for LS1, LS2, and LS3 over the 24 hours before the onset of the density anomaly. The peak storm conditions are defined as the average over the 24 hours that surround the maximum density anomaly during the event. As seen in Figure 5-8, the peak storm conditions exhibit warmer and saltier water compared to pre-storm conditions. This is consistent with upwelling of the warm, saline Atlanticorigin water in the WGC onto the shelf during the storm events. On average, the base of the water column attains a temperature and salinity of $4.1^{\circ} \mathrm{C}$ and 34.5 , respectively, in the vicinity of the shelfbreak (Figure $5-8$ ). This is $0.8^{\circ} \mathrm{C}$ warmer and 0.33 saltier than during pre-storm conditions. We can use the wintertime mean vertical sections of temperature and salinity across the array to deduce the depth from which this water was drawn, as most of the events occur during the winter months. This implies that upwelling events typically draw water from roughly $250 \mathrm{~m}$ depth and $25 \mathrm{~km}$ offshore of the shelfbreak. Note that while these warm, saline waters are a bit too fresh to be deemed canonical Irminger Water (Pacini et al., 2020), they nonetheless have a clear influence of this Atlantic-origin signature.

\subsubsection{Nature of the wind forcing}

As previously discussed, the winds along the west coast of Greenland are predominantly upwelling-favorable, and were consistently so during the 2014-2018 mooring deployment (Figure 5-3c). We thus ask: what wind conditions are necessary to trigger upwelling at the shelfbreak along West Greenland. Our criterion for upwelling simply stipulates that the winds must be northwesterly for a portion of the upwelling event, but it is of interest to examine the strength of the winds as well as the associated low pressure signatures in order to understand the specific atmospheric dynamics that are responsible for the upwelling.

To do this, we examine the 3-hourly maps of SLP and $10 \mathrm{~m}$ winds during the upwelling events. Detailed inspection of each individual event reveals that upwelling is driven by synoptic-scale low pressure systems that enter the region along the North Atlantic storm track and enhance the northwesterly winds along west Greenland. The 
shorter upwelling events correspond to only one low pressure system, while the longer events are the result of a train of cyclones that does not allow the density signature to relax back to pre-event conditions (see section 5.3.2). Of the 49 upwelling events, 28 were due to one low pressure system, while the remaining 21 were driven by between 2 and 9 distinct low pressure systems. Notably, 16 of the events ended by a transition to downwelling conditions induced by strong southeasterly winds. These winds are also the result of low pressure systems progressing along the storm track, but, in this scenario, the low has impinged on Cape Farewell farther to the north and thus the strong southeasterlies on the eastern end of the low act to reverse the density anomaly. Future work will address the downwelling that occurs along the west Greenland shelfbreak.
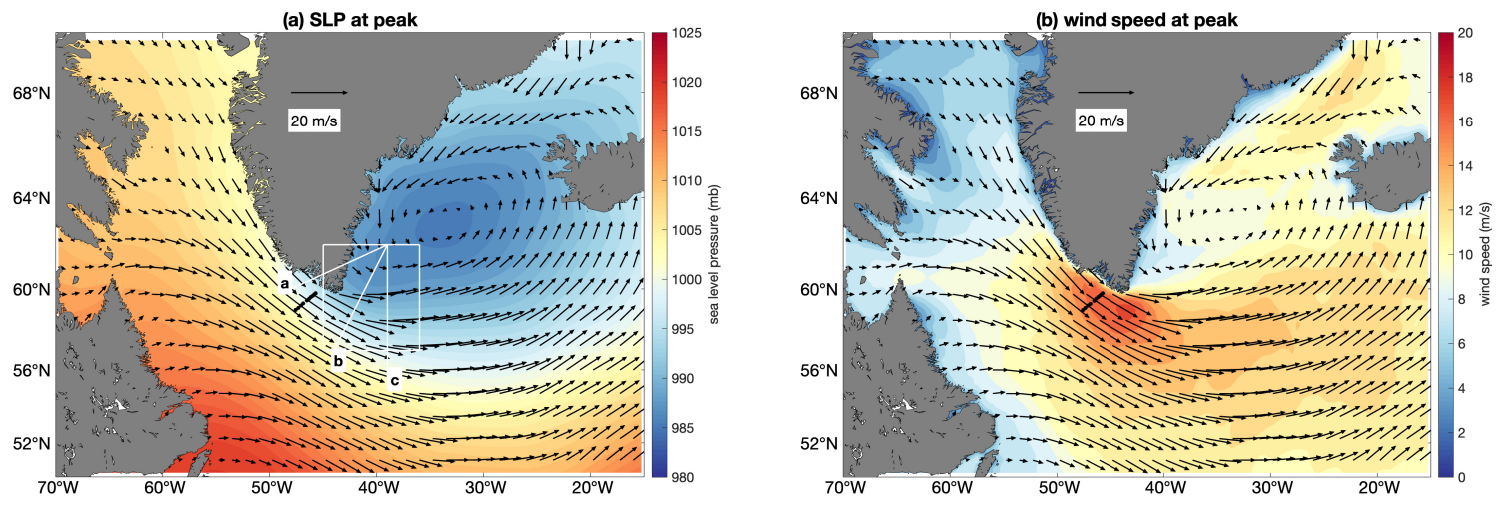

Figure 5-9: (a) Composite SLP (color) and $10 \mathrm{~m}$ wind vectors during peak upwelling for all 49 events. Every fifth velocity vector is plotted. The box and lines labeled a, b, c are used for the EOF detection of forward tip jets (see text for details). (b) Same as (a) except for wind speed (color), with the wind vectors superimposed.

To diagnose the atmospheric conditions during upwelling, we created composite SLP and $10 \mathrm{~m}$ wind fields for the different phases of the event. The peak storm period is defined as the timestep at which the winds reach their maximum value (note that this differs from the period of peak water column response because of the lag between the wind and water column conditions). The composite of all 49 upwelling events during peak conditions reveals a strengthened Icelandic low relative to the mean state (compare Figure 5-9a with Figure 5-3a; note the differing colorbars). Associated with 
this deep low is a region of high $(>15 \mathrm{~m} / \mathrm{s})$ northwesterly wind extending from the west coast of Greenland to southeast of Cape Farewell (Figure 5-9b). This wind pattern is strikingly reminiscent of a forward tip jet.

To investigate this further, we constructed similar composites at 12-hour intervals surrounding the event (Figure 5-10). The resulting series of composites show the evolution of a canonical forward tip jet, demonstrating that upwelling along west Greenland occurs at the initial stages of tip jet development. This is consistent with Våge et al. (2008) and Våge et al. (2009b), who presented the evolution of forward tip jets using composite maps. In both of these studies the composite winds 12 hours prior to peak tip jet conditions southeast of Cape Farewell resemble the conditions during peak upwelling in Figure 5-9b.
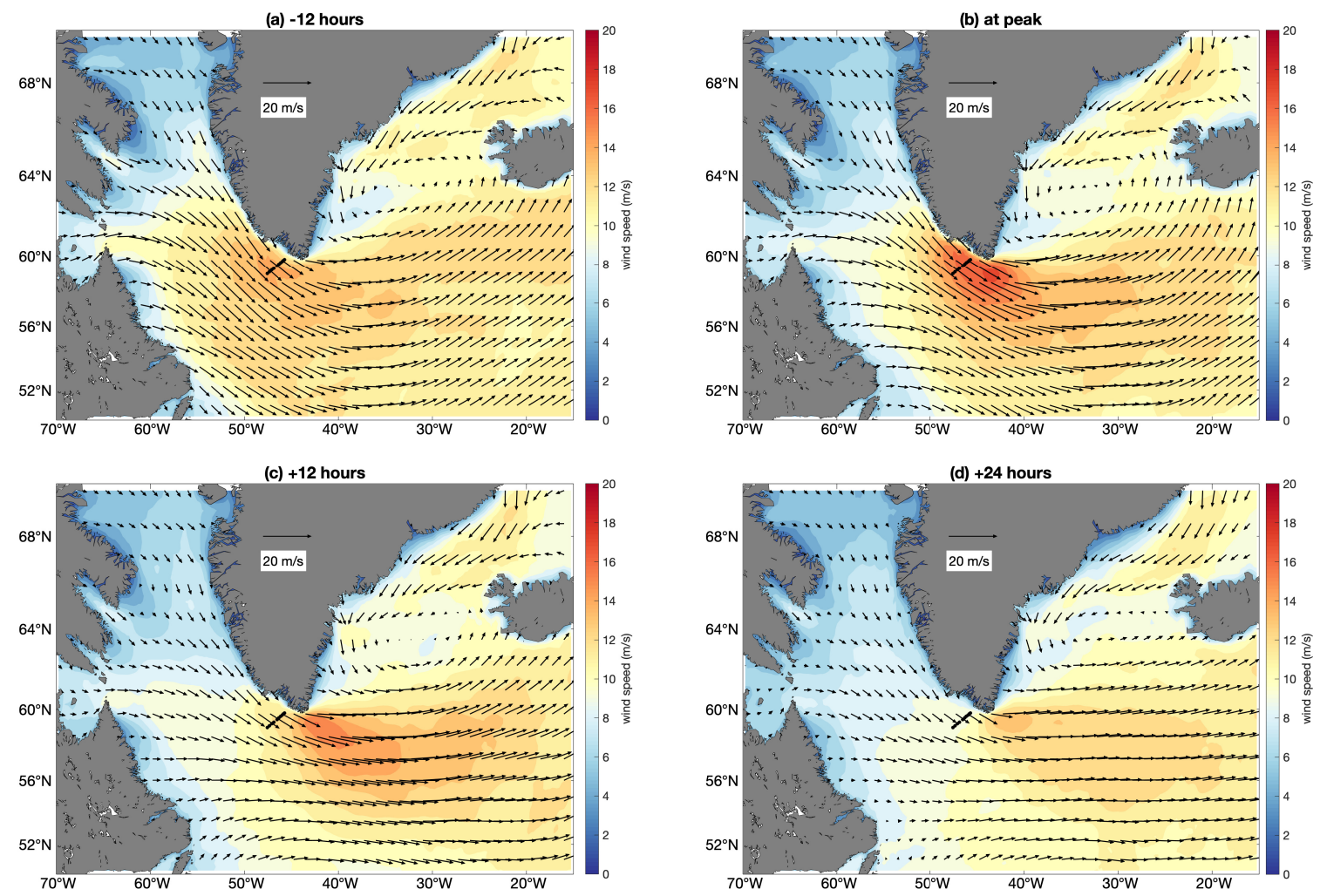

Figure 5-10: Composite wind speed (color) and wind vectors for all 49 upwelling events (a) 12 hours before peak upwelling winds, (b) at peak upwelling winds, (c) 12 hours after peak upwelling winds, and (d) 24 hours after peak upwelling winds. Every fifth velocity vector is plotted. 
Do all early-stage forward tip jets result in upwelling? We can answer this by applying the method of Vage et al. (2008) to objectively define forward tip jet events using an empirical orthogonal function (EOF) analysis. In particular, the EOF is computed corresponding to the following three timeseries: (1) the maximum zonal wind in the black box shown in Figure 5-9a; (2) the mean sea level pressure gradient along lines a, b, and c within the box; and (3) the temperature at the location of the maximum zonal wind within the box. Robust forward tip jets are defined as those where the reconstructed zonal wind speeds are in excess of $25 \mathrm{~m} / \mathrm{s}$. Våge et al. (2008) used QuikSCAT data from the SeaWinds scatterometer, a dataset which typically exhibits stronger wind speeds in this region than reanalysis products do (e.g. Moore and Renfrew, 2005; Våge et al., 2008). For this reason, we adjust the definition of a robust forward tip jet such that it must exhibit reconstructed zonal winds exceeding 20 $\mathrm{m} / \mathrm{s}$. When the occurrence of EOF-defined tip jets is compared with the occurrence of mooring-defined upwelling events along West Greenland, a clear relationship is revealed: 41 of 49 upwelling events correspond to early-stage forward tip jets. The 8 upwelling events that are not associated with tip jets occurred in the summer months, hence they did not meet the criteria of robust tip jets, although they are tip jets nonetheless (we note that the analysis of Våge et al. (2008) did not include summer months).

Our analysis thus reveals that, over the four-year period, all of the observed upwelling events occurred during the development of a forward tip jet. This places even more importance on these small-scale features, which, in their fully-developed stage, strongly influence conditions in the Irminger Sea, including LSW formation and downwelling along the east coast of Greenland. As shown below in section 5.3.5, this downwelling in fact plays a role in the evolution of the upwelling events considered here.

\subsubsection{Case studies of two September storms}

We now present two case studies to shed light on the vertical redistribution of properties due to upwelling-favorable winds. The first is an upwelling event in September 
2014 described using the mooring timeseries, and the second is an upwelling event in September 2018 described using shipboard data. The two studies offer complimentary views since the former has high temporal resolution, while the latter has high spatial resolution.

\section{4 storm}

This event lasted from 14-18 September 2014. The three diagnostic timeseries defined in subsection 5.3.1 are shown in Figure 5-11 (we have included the 48-hour segment before the onset of upwelling). During the event the wind peaked at $15 \mathrm{~m} / \mathrm{s}$, the depth-averaged along-stream velocity decreased by $30 \mathrm{~cm} / \mathrm{s}$, and the bottom density anomaly reached $0.12 \mathrm{~kg} / \mathrm{m}^{3}$ (the corresponding values from the composite event of Figure $5-7$ are $7 \mathrm{~m} / \mathrm{s}, 10 \mathrm{~cm} / \mathrm{s}$, and $0.15 \mathrm{~kg} / \mathrm{m}^{3}$, respectively). The event ended due to the arrival of a downwelling-favorable low pressure system. This can be seen in the zero-crossing of the along-coast winds on 16 September, which ultimately causes the density anomaly to return to zero about 1.5 days later.

Three 12-hour periods during the event are shown to highlight important features and the development of the water column response. Period 1 represents pre-storm

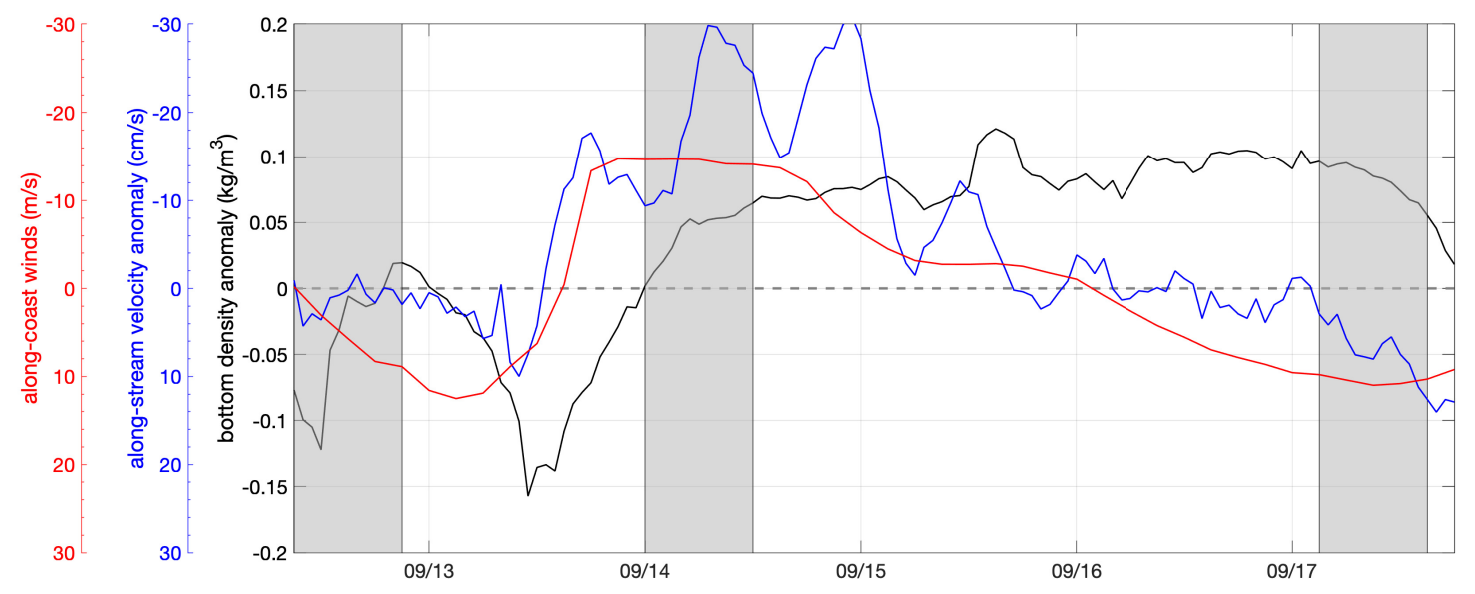

Figure 5-11: Timeseries of along-coast winds (red) averaged in the white box shown in Figure 5-3a, along-stream velocity anomaly on the shelf (blue), and bottom density anomaly on the shelf (black) for an upwelling event in September 2014. The grey bars mark the periods of the three composites shown in Figure 5-12. 
conditions, period 2 represents peak storm conditions, and period 3 represents end of storm conditions (see the grey bars on Figure 5-11). Prior to the storm the alongcoast winds are weakly positive (southeasterlies; Figure 5-11). At this point, the low pressure system that will ultimately result in the upwelling is situated off the Canadian landmass with a central pressure of $\sim 990 \mathrm{mb}$ (Figure 5-12a). The along-stream velocity is approximately $30 \mathrm{~cm} / \mathrm{s}$ (Figure $5-12 \mathrm{~b}$ ), and the cross-stream velocity is near zero (Figure 5-12c), both of which are representative of the mean flow conditions (Pacini et al., 2020).
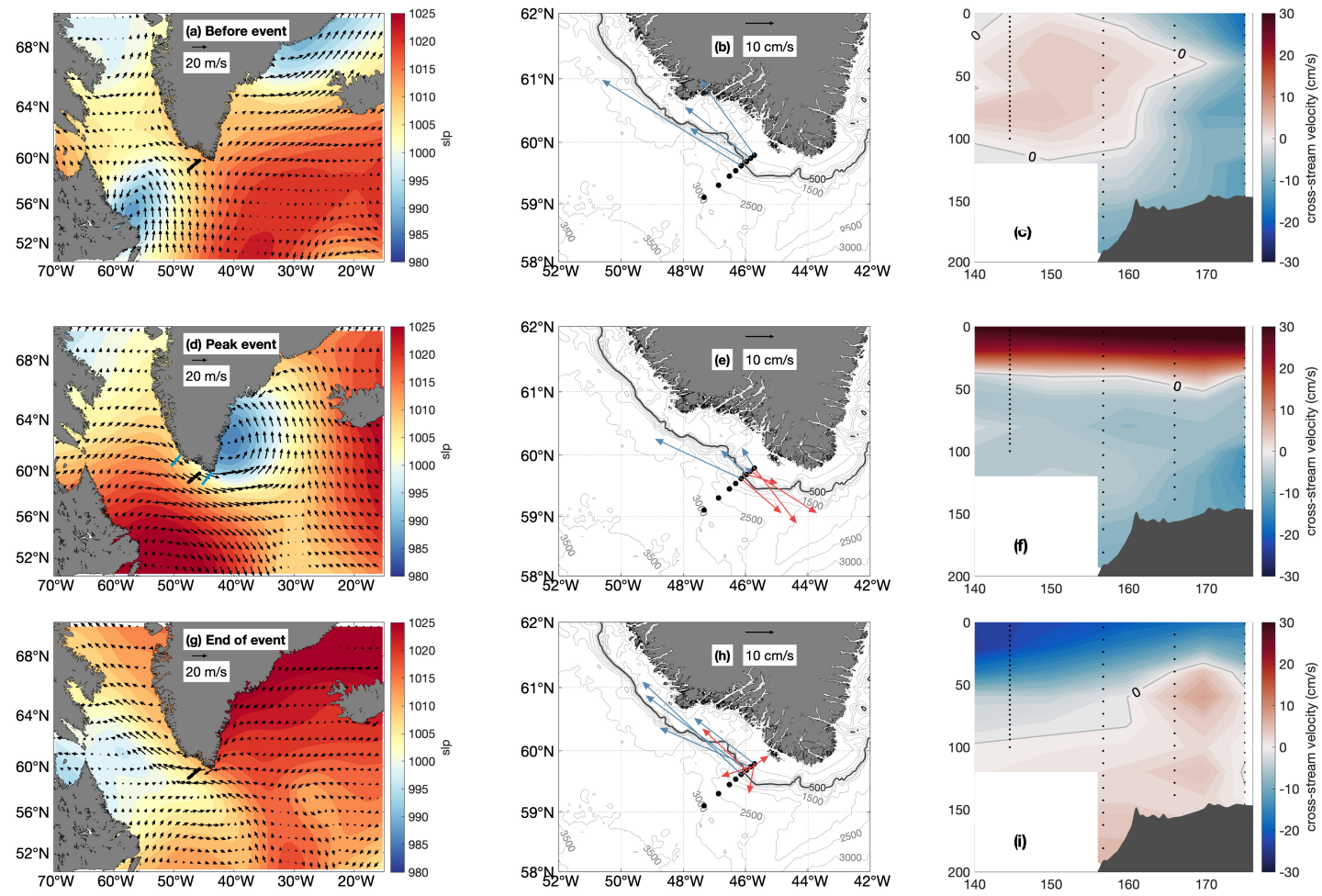

Figure 5-12: Evolution of the September 2014 upwelling event. Top row: pre-event conditions (averaged over the 12-hours represented by the first grey bar in Figure 511). Middle row: peak-event conditions (middle grey bar in Figure 5-11). Bottom row: end of event conditions (last grey bar in Figure 5-11). (a, d, g) SLP (color) and wind vectors. The black symbols are the OSNAP West Greenland moorings, and the blue lines denote the boundaries of the high wind speed region used for the flux calculations of subsection 5.3.6. (b, e, h) Depth-averaged velocity vectors (blue) and velocity anomaly vectors (red), where the anomalies are relative to the velocity vectors in (b). (c, f, i) Vertical section of cross-stream velocity (color) with the zero-value contoured. The black dots are the ADCP data points. 
Approximately 48 hours later, at the peak of the storm, the low pressure system is now in the lee of Greenland in the Irminger Sea, with a central pressure of 986 mb, causing strong northwesterly winds at Cape Farewell and along west Greenland (Figure 5-12d). The along-stream flow is significantly reduced (note the anomaly vectors indicating a reduction of $20 \mathrm{~cm} / \mathrm{s}$, where the anomaly is computed relative to the pre-storm conditions; Figure 5-12e). During this particular event, the winds were strong enough to reverse the flow at LS2 for 12 hours. Notably, there is now a clear presence of an Ekman cell, with strong offshore flow $(\sim 30 \mathrm{~cm} / \mathrm{s})$ in the top 40 $\mathrm{m}$ and weaker, bottom-intensified onshore flow beneath this (Figure 5-12f).

The vertical structure of this secondary circulation can be characterized as a function of bottom slope and hydrography of the water column. Specifically, Lentz and Chapman (2004) demonstrate that the deep return flow during upwelling is either spread over a significant portion of the water column or confined to a bottom boundary layer, in which case the surface and bottom stress balance each other. To quantify this, we compute the slope Burger number, $B=\alpha N / f$, where $\alpha$ is the bottom slope and $N$ is the stratification (calculated from the hydrographic sections presented in section 5.3.5). When $B$ is $\mathrm{O}(1)$ or greater, the return flow at depth is expected to extend vertically above the bottom boundary layer. By contrast, when $B \ll 1$, the return flow is confined to the bottom boundary layer. We find that $\mathrm{B}$ is $~$ 0.1 throughout the shelf, indicating that the return flow should be confined to the bottom boundary layer. This is consistent with the composite in figure 5-12f, where the strongest return flow is confined to the bottom $50 \mathrm{~m}$ of the water column. This result is in contrast to the upwelling across the Beaufort Sea shelfbreak investigated by Pickart et al. (2013). In that case $B$ was $\mathrm{O}(1)$ due to the stronger stratification (associated with the shallower shelfbreak), and the return flow extended above the bottom boundary layer.

In the third period, associated with ramp-down conditions, the parent low has completely filled, and a second low has developed in the vicinity of Hudson Strait. This causes strong southeasterly winds along the west coast of Greenland (Figure 5$12 \mathrm{~g}$ ). While the along-stream flow in the vicinity of the shelfbreak has been re- 
established (Figure 5-12h), the cross-stream flow does not return to near-zero as it was at the start of the event. Rather, there is now a reverse Ekman cell, triggered by the downwelling-favorable winds (Figure 5-12i).

\section{8 storm}

As noted above, due to the presence of icebergs in the region we were unable to consistently maintain any MicroCATs above the shelf tripods. Hence, it is not possible to describe the evolution of hydrographic properties higher in the water column during storm events using the mooring data. However, high resolution hydrographic shipboard surveys have been carried out during each deployment and recovery cruise (2014, 2016, 2018, and 2020; e.g., Lin et al. 2018; Pacini et al. 2021). During the 2018

cruise, the OSNAP West Greenland mooring line was occupied twice with closely spaced CTD stations ( 3.5 km station spacing). Since none of the tripods were deployed during this time period (they were being refurbished on the ship), we cannot use the same criteria for defining upwelling events as was applied to the mooring data. However, the ERA5 wind data indicate that the first CTD section was occupied during the ramp-up to a tip jet, while the second section was done as the upwelling winds subsided, referred to as the ramp-down (Figure 5-13a).

The vertical sections of temperature and salinity for both crossings are shown in Figure 5-13b-e. The hydrographic conditions during the ramp-up period reflect canonical conditions at the shelfbreak and on the shelf, where warm, saline waters reside offshore and a cold, fresh wedge is seen between the surface and inshore-most point on the line. A few days later, the hydrographic properties were re-arranged: the cold, fresh wedge was shifted offshore at the surface, while the warmer, more saline water was found on the outer shelf in the lower part of the water column. This redistribution of properties is highlighted in the anomaly sections, shown in Figure 513f-g. This change in properties is consistent with the presence of an Ekman cell during upwelling conditions where the surface waters are advected offshore and waters at depth are advected onshore. Additionally, the magnitudes of these hydrographic anomalies $\left(\sim 1^{\circ} \mathrm{C}\right.$ in temperature and $\sim 0.3$ in salinity) are consistent with the results 


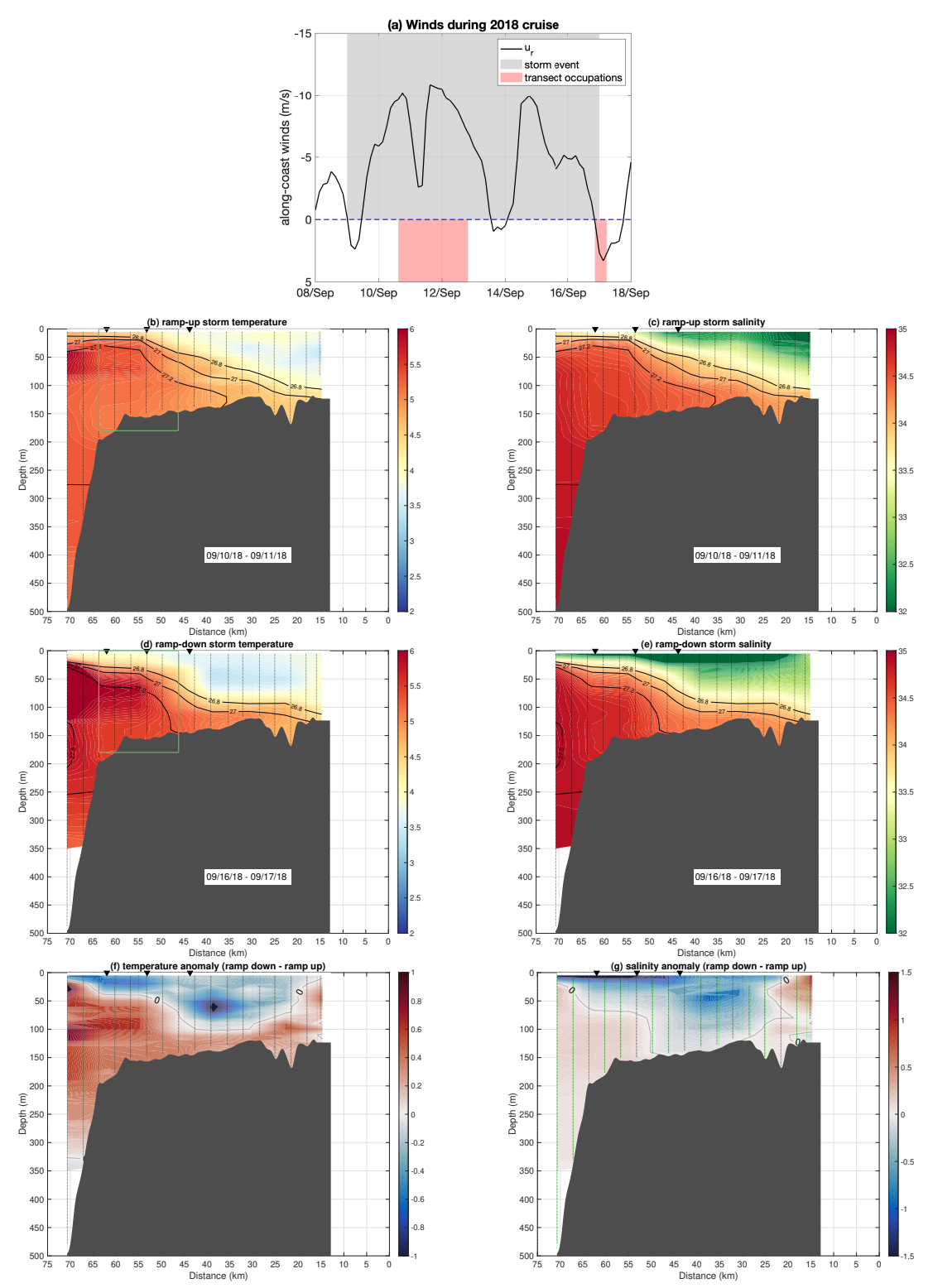

Figure 5-13: (a) Timeseries of along-coast winds averaged within the white box in Figure 5-3a from September 8 to September 18 during the 2018 OSNAP cruise. The grey shading indicates the upwelling event, and the red shading indicates the time period of the two CTD sections. (b) Temperature (color, ${ }^{\circ} \mathrm{C}$ ) during the first occupation, overlain by density (contours, $\mathrm{kg} / \mathrm{m}^{3}$ ). The black triangles indicate the locations of LS1-LS3 moorings, and the thin vertical lines denote the CTD casts. The $\mathrm{x}$-axis represents distance offshore, with $0 \mathrm{~km}$ corresponding to the coast. The green boxes in (b) and (d) indicate the regions used for calculation of the hydrographic profile during the storm event used in Section 3.6. (c) Salinity (color) during the first occupation, overlain by density (contours). (d) Same as (b) except for the second occupation. (e) Same as (c) except for the second occupation. (f) Difference in temperature between the second and first occupations of the line (the zero value is contoured). (g) Same as (f) except for salinity. 
of subsection 5.3.3 where, on average, the near-bottom water was $0.8^{\circ} \mathrm{C}$ warmer and 0.33 saltier during peak storm conditions as compared to pre-storm conditions.

\subsubsection{Cross-stream property fluxes}

Upwelling events flux freshwater offshore in the surface layer and heat onshore at depth. It is of interest to quantify these fluxes in order to create property budgets and assess the implications for both the interior Labrador Sea and the West Greenland shelf. Using our mooring timeseries together with the shipboard CTD data, we now estimate the net flux of freshwater and heat associated with a single autumn upwelling event. In order to do this, we need to combine information from the two events presented in the previous section, both of which occurred in September (albeit in different years: 2014 for the mooring record and 2018 for the shipboard survey). Using the mooring record, we computed a mean vertical profile of cross-stream velocity averaged over the 12-hour interval corresponding to the peak of the 2014 storm (middle grey bar of Figure 5-11) and averaged spatially over the vicinity of the shelfbreak (the domain of Figure 5-2, green box). From the shipboard survey, we computed an average vertical profile of temperature and salinity over the region encompassing LS1-LS3 (green box in Figure 5-13b,d) for each occupation, then subsequently averaged the ramp-up and ramp-down profiles together. We note that these average September 2018 profiles compare favorably with the two $50 \mathrm{~m}$ MicroCAT records and three bottom MicroCAT records available during the September 2014 storm event (not shown).

Using the mean vertical profile of cross-stream velocity, the volume flux per unit depth was computed for the segment of the west Greenland shelf subject to the upwelling winds (approximately $500 \mathrm{~km}$ long, see Figure 5-12d). For a balanced Ekman cell, the vertical integral of this curve should be zero. This was nearly so for our average profile, but, realizing that the data are not perfect, a small barotropic offset was applied throughout the water column to adjust the profile to exactly balance mass (Figure $5-14 \mathrm{a}$; the offset of $0.85 \mathrm{~cm} / \mathrm{s}$ is only $2.7 \%$ of the total velocity). An analogous offset was used by Pickart et al. (2013) in their flux calculations for an 
upwelling storm along the Beaufort slope. As seen in Figure 5-14a, the amplitude of the Ekman cell is $4.5 \mathrm{~Sv}$.
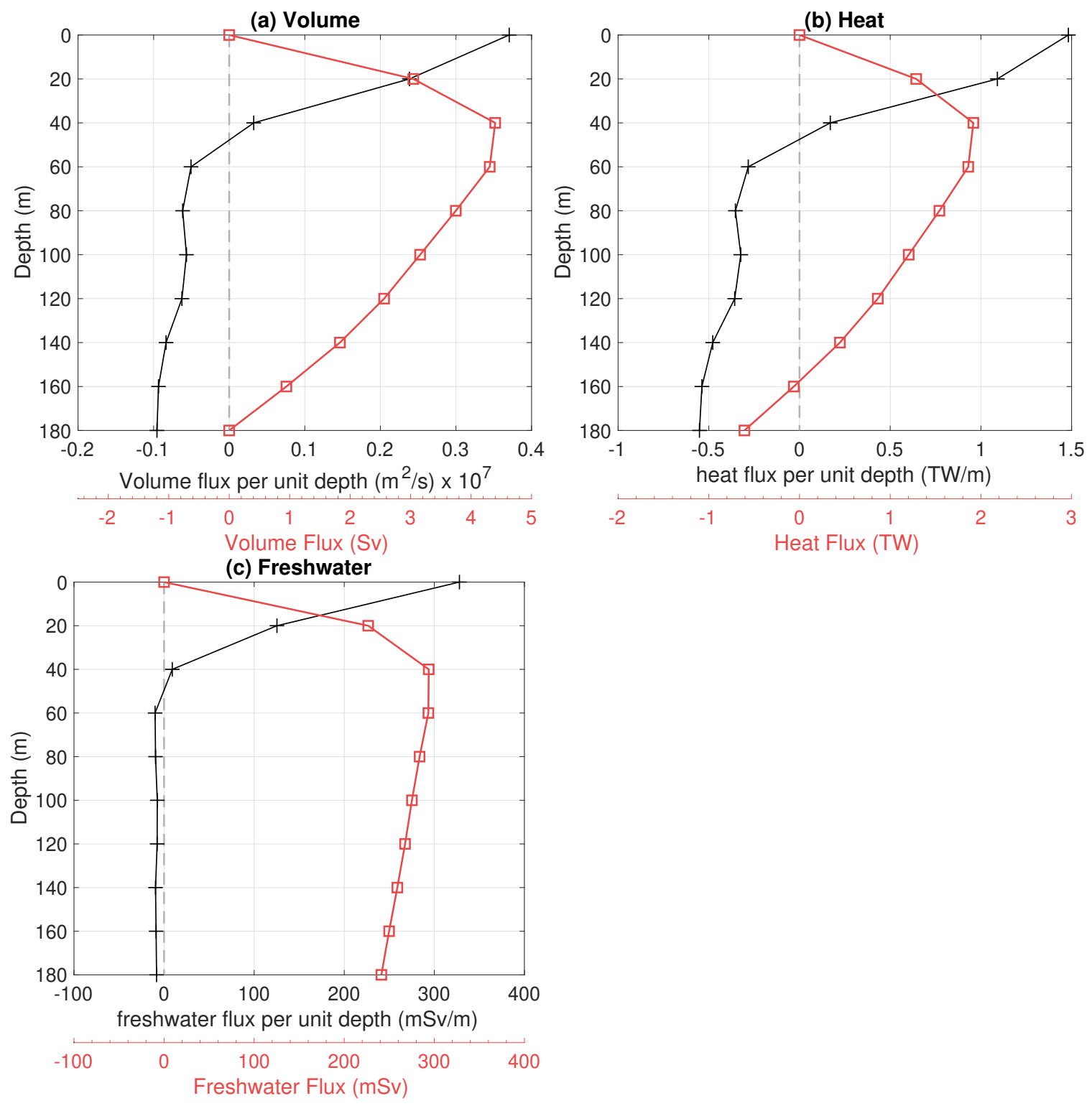

Figure 5-14: (a) Volume flux per unit depth (black curve) and depth-integrated volume flux (red curve) for the September storm. (b) Heat flux per unit depth (black curve) and depth-integrated heat flux (red curve). A reference temperature of $0^{\circ} \mathrm{C}$ was used for the heat flux per unit depth calculation (the total heat flux is not sensitive to this choice since the integrated volume flux in (a) is zero). (c) Freshwater flux per unit depth (black curve) and depth-integrated freshwater flux (red curve). A reference salinity of 34.8 used for the freshwater flux per unit depth calculation (the total freshwater flux is not sensitive to this choice). 
A consequence of this balanced-mass profile is that we can compute heat and freshwater fluxes that are not dependent on a reference temperature or salinity. To do so, we used the average hydrographic profiles from the shipboard survey. The resultant heat flux per unit depth and freshwater flux per unit depth are shown in Figure 5-14b,c. These curves were then vertically integrated to obtain the absolute heat and freshwater fluxes. As expected, there is an onshore transport of heat and an offshore transport of freshwater. To obtain the net transfer of properties, we integrated the fluxes over the 12-hour period that the Ekman cell was present (see section 5.3.6 for an explanation of why the Ekman cell lasted only 12 hours). This results in a total of $190 \mathrm{~km}^{3}$ of water exchanged across the shelfbreak, $2.62 \times 10^{16} \mathrm{~J}$ of heat fluxed onshore, and $10.48 \mathrm{~km}^{3}$ of freshwater fluxed offshore (Table 5.1, column 1). To provide context, the volume of water exchanged by a single storm represents $3.5 \%$ of the total volume of the West Greenland shelf subject to the wind forcing. Hence it would take 28 such storms to completely flush this portion of the shelf. Since there are on average 12 upwelling events per year, this implies that $42 \%$ of the shelf is replenished.

Table 5.1: Volume, heat, and freshwater flux for an autumn upwelling storm (left) and for the same storm without Cape Farewell (right).

\begin{tabular}{|l|l|l|}
\hline & $\begin{array}{l}\text { single storm, 12 hours } \\
(\text { with Cape Farewell) }\end{array}$ & $\begin{array}{l}\text { single storm, 80 hours } \\
\text { (without Cape Farewell) }\end{array}$ \\
\hline Volume & $190 \mathrm{~km}^{3}$ & $1267 \mathrm{~km}^{3}$ \\
Heat & $-2.62 \times 10^{16} \mathrm{~J}$ & $-1.75 \times 10^{17} \mathrm{~J}$ \\
Freshwater & $10.48 \mathrm{~km}^{3}$ & $69.5 \mathrm{~km}^{3}$ \\
\hline
\end{tabular}

We note that the small-scale Boundary Current Eddies (BCEs) investigated by Pacini and Pickart (2022) flux heat from the shelf to the basin, while the upwelling events studied here flux heat from the basin to the shelf. One then wonders to what degree these fluxes offset each other. Both synoptic-scale events are more common in winter. Pacini and Pickart (2022) found that in a given year, BCEs could transport $1.2 \mathrm{GJ} / \mathrm{m}^{2}$ of heat offshore, when spread over the entire Labrador Sea. We performed 
the analogous calculation using the net heat flux for a given storm as calculated above. In particular, we summed this over 10 storms (the average frequency for one winter), and divided by the area of the Labrador Sea. We find that upwelling over the winter season results in a net onshore flux of heat of $9.3 \times 10^{-4} \mathrm{GJ} / \mathrm{m}^{2}$. This is only $0.08 \%$ of the offshore flux of heat due to BCEs, indicating that the eddy heat flux completely dominates that due to wind forced upwelling.

\section{Upstream impact on the cross-stream fluxes}

As noted above, the Ekman cell associated with the September storm event persisted for only 12 hours, even though the actual event duration (as defined by the density anomaly) was approximately 72 hours. Inspection of all of the single-storm events reveals that, on average, the Ekman cell lasts $21 \pm 2.1 \mathrm{hr}$, while the along-stream velocity signal lasts $11.3 \pm 2.5 \mathrm{hr}$. This is in contrast to the average length of the events, based on the density signal, of $79 \pm 5.6 \mathrm{hr}$, as well as the average length of the wind forcing which is $77 \pm 6.7 \mathrm{hr}$. What causes the shutdown of the velocity response prior to the relaxation of the local storm winds? This is of importance because it impacts the magnitude of cross-shelf fluxes: the longer the persistence of the Ekman cell, the more water is exchanged across the shelfbreak.

Because of the pronounced change in coastline orientation on either side of Cape Farewell, the low pressure systems in the Irminger Sea that drive forward tip jets and upwelling-favorable winds along west Greenland also result in downwelling conditions along east Greenland (see Figure 5-9). Numerous studies have investigated the propagation of coastal trapped waves along the east coast of Greenland in response to such barrier winds (Harden et al., 2014a,b; Le Bras et al., 2018; Pacini et al., 2020; Gelderloos et al., 2020). The barotropic wave travels at roughly $3.5 \mathrm{~m} / \mathrm{s}$, which is the speed at which the velocity response to wind intensification (the SSH anomaly) would travel along east Greenland, and the speed at which this signal would round Cape Farewell. The distance between the northeast side of Cape Farewell and the OSNAP West Greenland mooring array is $\sim 200 \mathrm{~km}$. A barotropic wave traveling this distance would take $\sim 16$ hours to propagate from Cape Farewell to the OS- 
NAP West Greenland mooring array, which is on the order of the average shutdown timescale for the upwelling velocity response at the array (keep in mind that there is uncertainty in the wave speed). This strongly suggests that the Ekman cell and the along-stream flow signature are prematurely shut off due to the orientation of the Greenland coastline and the propagation of the downwelling signal from upstream. If the coastline were instead straight (i.e., no Cape Farewell), we would expect the velocity response to last as long as the enhanced winds (which is the case for upwelling along the relatively straight Beaufort Sea coast; Pickart et al. 2013).

To highlight the effect that Cape Farewell has, we did as second set of cross-stream flux calculations where the Ekman Cell lasts as long as the enhanced local winds (80 hours instead of 12 hours). This results in $1267 \mathrm{~km}^{3}$ of water exchanged, $-1.75 \mathrm{x}$ $10^{17} \mathrm{~J}$ of heat fluxed onshore, and $69.5 \mathrm{~km}^{3}$ of freshwater fluxed offshore (Table 5.1, column 2). The implications of this for convection in the basin are considered below.

\subsubsection{Impact on stratification in the basin}

Given the offshore flux of freshwater due to the regular occurrence of upwelling along the southwest Greenland coast, we now seek to quantify the impact that this has on the wintertime development of the mixed layer and the production of newly ventilated LSW. Deep convection regularly occurs in the western portion of the Labrador Basin (e.g. Clarke and Gascard, 1983; Pickart et al., 2002; Yashayaev and Loder, 2016), and has also been observed in the region south of Cape Farewell (Piron et al., 2017; Zunino et al., 2020). By contrast, wintertime mixed layers in the eastern Labrador basin are generally shallower (less than 800 m; Lavender et al. 2002; Piron et al. 2017; Zunino et al. 2020). There is no a priori reason why this should be the case, however. The buoyancy forcing is just as strong (or stronger) in the eastern basin as it is south of Cape Farewell (Pickart et al., 2002). Furthermore, there is a local cyclonic recirculation situated over the deep continental slope of West Greenland, extending from approximately Cape Farewell to Cape Desolation (Figure 5-4a; Lavender et al. 2000), which is associated with domed isopycnals. Hence, both the buoyancy forcing and the hydrographic preconditioning are conducive for deep convection (Marshall 
and Schott, 1999).

We suspect that the freshwater fluxed off the boundary due to the regularly occurring upwelling storms acts to inhibit the mixed layer depths in the vicinity of the recirculation gyre. This notion is consistent with the model results of Schulze Chretien and Frajka-Williams (2018) in which wind forcing is the predominant mechanism for surface particles to be fluxed offshore from the West Greenland shelf. In particular, water parcels in the model are able to be transported roughly $50 \mathrm{~km}$ offshore of the $2500 \mathrm{~m}$ isobath, which is far enough to penetrate the recirculation gyre.

To investigate this, we invoked the one-dimensional mixed layer model (PWP, see subsection 5.2.5). To obtain an initial fall profile of temperature and salinity, we averaged together all Argo data within the region of the recirculation gyre from November 2014 (see subsection 5.2.4 and Figure 5-4 for details). The resulting mean profiles (blue curves in Figure 5-4b,c) display a warm, fresh surface layer extending to roughly $50 \mathrm{~m}$, beneath which lies the Irminger Water from roughly 100-600 m. This is the remnant warm, salty Atlantic-origin water that has been transported cyclonically around the subpolar gyre.

The model was forced with daily ERA5 heat flux and wind velocity timeseries for the winter of 2014-2015, spatially averaged within the same domain (Figure 5-15). P-E was neglected as it has very little impact (e.g. Lazier et al., 2002; Pennelly and Myers, 2021). We begin with a control run in which there is no source of freshwater emanating from the boundary. Figure 5-16 (blue curve) shows the evolution of the mixed layer depth (MLD) from late-fall to late-spring (lowpassed using a 14-day running mean in order to reduce the noise in MLD). The mixed layer progressively deepens beginning in December until it reaches its maximum depth of $\sim 1400 \mathrm{~m}$ in early March. Following this, the MLD rapidly decreases, and the water column completely re-stratifies by early May. (Excursions from this seasonal deepening/shoaling of the mixed layer over the course of the PWP run are due to variations in the air-sea forcing during this particular winter.)

For comparison we did a second run without freshwater forcing corresponding to the western Labrador Basin (with the initial hydrographic profiles and air-sea forcing 


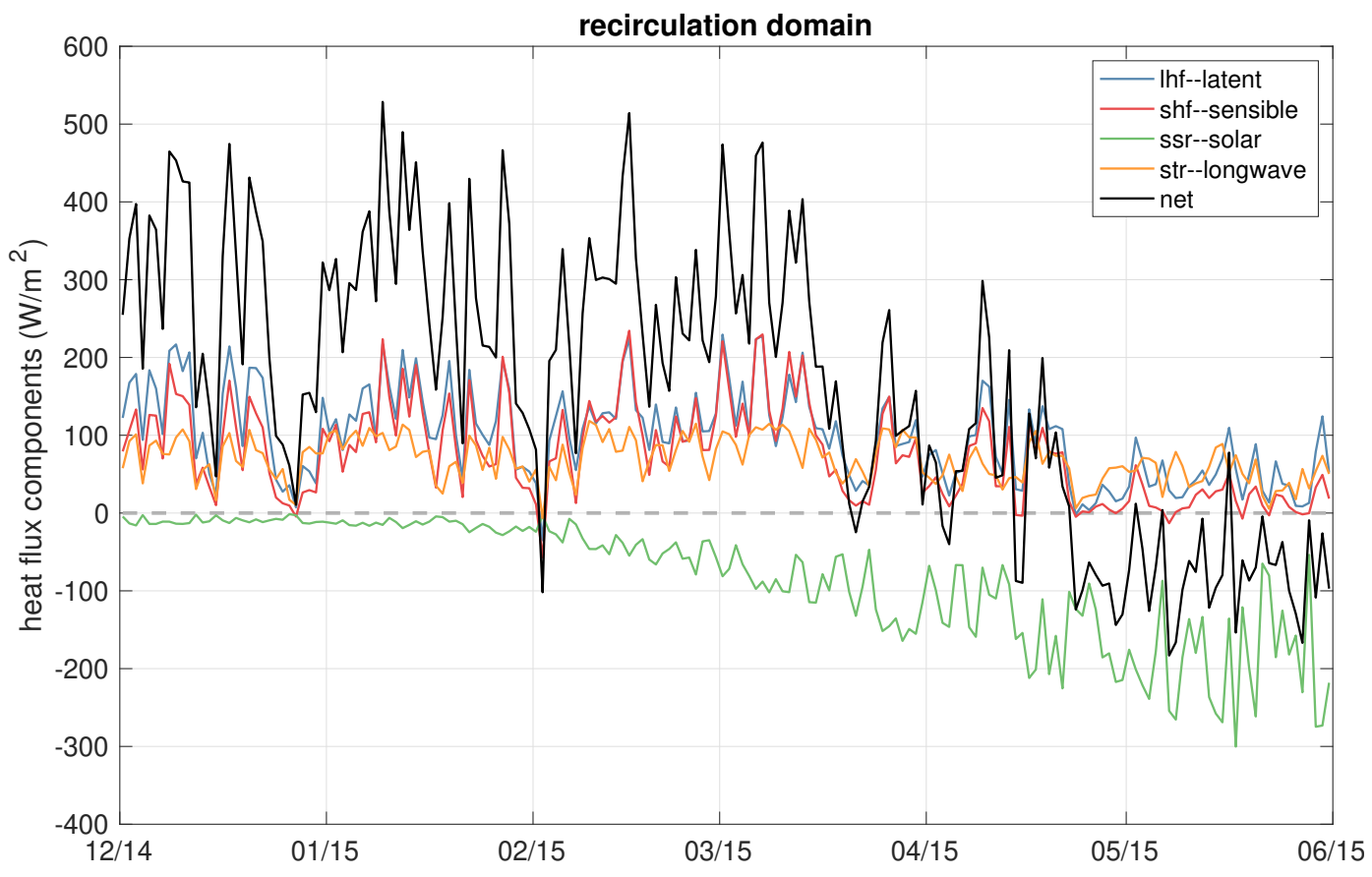

Figure 5-15: Daily average heat flux components within the recirculation gyre of the southeastern Labrador Sea from ERA5. The net flux is shown by the thick black curve.

appropriate for that region). In this case the MLD extends approximately $200 \mathrm{~m}$ deeper to a depth of $\sim 1600 \mathrm{~m}$ (Figure 5-16, red curve). This occurred almost two weeks sooner than in the eastern basin. Encouragingly, the results of this second PWP run compare well with the MLD observations of Yashayaev and Loder (2016) for winter of 2015, which showed maximum convective depths of $1500 \mathrm{~m}$ in the interior Labrador Sea. This gives us confidence in the fidelity of our PWP simulations.

To assess the impact of the freshwater flux from upwelling events on the development of the MLD in the eastern basin, we carried out the following exercise. Recall that there were 49 upwelling events over the four-year study period. Of these, 39 events occurred during the months of November to May, implying 10 events per winter. Using the freshwater flux calculation from subsection 5.3.6 for a single storm (column 1 of Table 5.1), this amount freshwater was injected into the surface PWP grid point 10 times at regularly spaced intervals throughout the winter season. In particular, we injected $0.129 \mathrm{~m}$ of freshwater $\left(10.48 \mathrm{~km}^{3}\right.$ divided by the area of the recirculation gyre, $8.12 \times 10^{4} \mathrm{~km}^{2}$ ) for each event. Similarly, we applied a temperature 


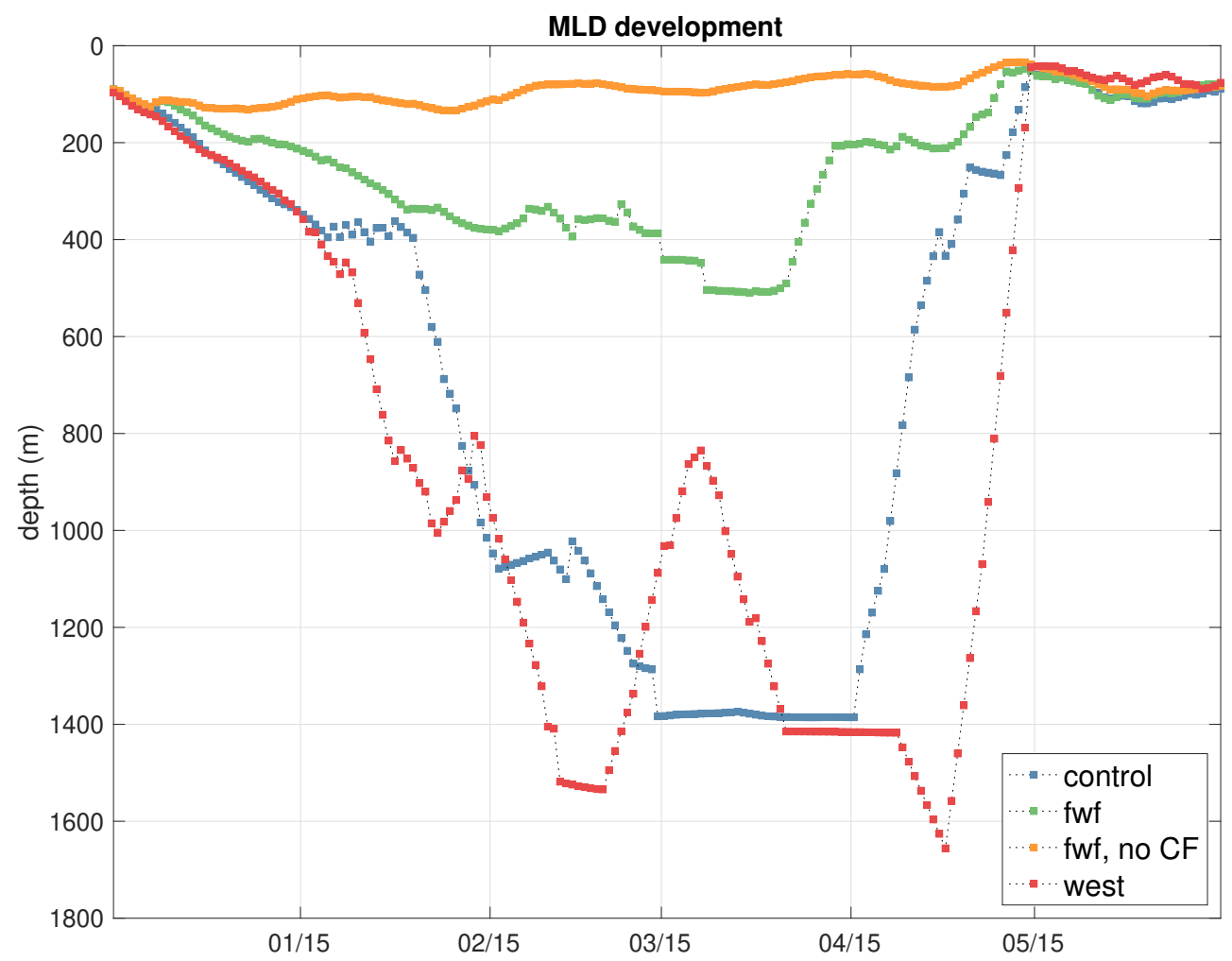

Figure 5-16: 14-day running mean mixed layer depth development over the 20142015 winter convective season using PWP. Four cases are shown: the control run for the recirculation gyre of the southeastern Labrador Sea (control); the western basin run (west); the freshwater run with upwelling events included (fwf); and the freshwater run with no Cape Farewell (fwf, no CF).

anomaly of $-0.12^{\circ} \mathrm{C}$ to the surface PWP grid point for each of the 10 events since the freshwater is anomalously cold. This value was obtained using the density and heat capacity of water, and spreading this heat flux over the same area and depth layer (1 m) as the freshwater flux calculation. However, this did not have a significant effect on the development of the mixed layer.

We note that the exact area over which the freshwater is spread is subjective. This choice is guided by various modeling studies that address the penetration of freshwater off the West Greenland shelf (e.g. Schulze Chretien and Frajka-Williams, 2018). This water would preferentially become trapped within the recirculation gyre just offshore of the West Greenland slope, due to the closed contours of absolute dynamic topography (see Figure 5-4a). Hence, choosing this area for both the initial eastern Labrador Sea profile and lateral region over which to spread freshwater is a 
reasonable assumption.

As seen in Figure 5-16 (green curve), this addition of freshwater had a marked effect on the depth of convection. The mixed layer development was much slower, and the deepest MLD was only $500 \mathrm{~m}$. This result is in line with the relatively shallow MLD observations within the recirculation gyre (e.g. Piron et al., 2017; Zunino et al., 2020). Our analysis thus implies that the repeated occurrence of wind-driven upwelling along the west coast of Greenland prohibits deep convection from occurring in the southeastern Labrador Sea.

As discussed above, it appears that a barotropic wave emanating from the region of downwelling northeast of Cape Farewell - also driven by forward tip jets - causes the relatively quick shutdown of the cross-shelf Ekman cell northwest of Cape Farewell. This motivated us to conduct a final PWP run wherein we added the amount of freshwater that would have been fluxed offshore due to storm events not interrupted by the barotropic wave. In particular, the Ekman cell was assumed to persist for 80 hours (column 2 of Table 5.1). With this increased freshwater signal, convection is essentially shut down completely (maximum MLD on the order of $100 \mathrm{~m}$; Figure 516, orange curve). This underscores the important role of the topography of Cape Farewell in controlling the offshore freshwater flux to the interior Labrador Sea.

\subsection{Conclusions}

Using data from the OSNAP West Greenland mooring array, 49 upwelling events were identified over the four-year period 2014-2018. The events are characterized by intensified northwesterly winds, a reduction in the along-stream velocity in the vicinity of the shelfbreak, and a positive density anomaly at the base of the outer shelf. The secondary circulation present during the upwelling fluxes cold, fresh meltwater offshore at the surface and warm, saline Atlantic-origin water onshore at depth. On average, these upwelling events warm the base of the shelf by $\sim 0.8^{\circ} \mathrm{C}$ and increase the salinity by $\sim 0.33$.

This redistribution of hydrographic properties was shown to have a substantial 
impact on the development of the mixed layer in the interior Labrador Sea. Using a one-dimensional mixed layer model, we demonstrated that the freshwater flux can delay the onset, and reduce the overall depth, of deep convection in the interior Labrador Sea. This synoptic-scale freshwater source therefore explains why deep mixed layers are not observed in the southeastern Labrador Sea. As such, models need to account for this small-scale variability in order to accurately reproduce wintertime production of LSW.

The upwelling events occur during the development stage of a forward tip jet, a common atmospheric phenomenon in the vicinity of Cape Farewell during the winter season. While previously shown to impact LSW production in the Irminger Sea (e.g Pickart et al., 2003a,b; Våge et al., 2008), our study reveals that forward tip jets also impact LSW formation in the Labrador Sea. While they enhance LSW production in the southwestern Irminger Sea, they reduce LSW production in the southeastern Labrador Sea.

\subsection{Data availability}

All data from the OSNAP WG array can be found at www.o-snap.org. The 2014-2016 mooring data are located at https://doi.org/10.7924/r4f j2dr7k, and the 20162018 mooring data are located at https://doi .org/10 .35090/fz80-6c32. The Argo data were downloaded from the U.S. Global Ocean Data Assimilation Experiment (USGODAE) data browser (https://nrlgodae1.nrlmry.navy.mil/cgi-bin/ar go_select.pl). The ERA5 data are available on the ECMWF server at: https: //www.ecmwf.int/en/forecasts/datasets/reanalysis-datasets/era5.

\subsection{Acknowledgements}

We thank John Kemp, Jim Ryder, Brian Hogue, Andrew Davies, and Rick Trask for the design, fabrication, and deployment of the mooring array. We also acknowl-

edge the captain and crew of the $\mathrm{R} / \mathrm{V}$ Knorr and $\mathrm{R} / \mathrm{V}$ Neil Armstrong for making 
the mooring recovery and deployment cruises a success. Funding for the study was provided by National Science Foundation Grants OCE-1259618 and OCE-1756361. 


\section{Chapter 6}

\section{Conclusions}

The circulation and dynamics of the subpolar gyre play a critical role in the Atlantic Meridional Overturning Circulation (AMOC), including the ventilation and subsequent export of intermediate and dense waters. Given our changing climate, it is important that we understand how the AMOC works presently in order to predict how it might change in the future. This thesis has sought to characterize the role of the boundary current system along the west coast of Greenland and investigate its influence on overturning. The boundary current system transports heat in the form of warm, saline Atlantic-origin waters and freshwater in the form of Arctic and Greenland meltwaters. These hydrographic signatures are important for the ventilation of intermediate waters within and around the Labrador Sea, hence we need to understand the pathways of these properties into and around the basin. In this dissertation, we sought answers to the following questions:

1. What are the annual and seasonal composition and kinematics of the boundary current system? (chapter 2).

2. What are the intrinsic modes of variability within the boundary current system, and how do they impact the along- and cross-stream flux of properties? (chapter 3 and chapter 4 ).

3. What are the externally forced modes of variability of the boundary current system and how does this variability influence the cross-stream flux of properties? 
(chapter 5).

First, we outline the major findings of this thesis, then discuss the questions raised by this work and the need for sustained measurements of the boundary currents in this region.

\subsection{Summary}

Cape Farewell is the windiest place in the World Ocean (Sampe and Xie, 2007; Moore et al., 2008), and, combined with hostile working conditions that include icebergs, darkness, and sub-zero temperatures, observations of the boundary currents in the region are generally lacking. In particular, wintertime observations of the West Greenland Boundary Current System are rare, and existing studies point to lack of spatial and temporal resolution required to detect and explain the dynamics at work (e.g. Myers et al., 2007, 2009; Rykova et al., 2015). This thesis has sought to characterize the boundary current system across a range of spatio-temporal scales, estimate slopebasin exchange of properties, and assess the associated impacts on interior convection in the Labrador Sea. The primary data used were four years of timeseries (2014-2018) from the high-resolution mooring array deployed as part of the Overturning in the Subpolar North Atlantic Program (OSNAP).

In chapter 2 , we quantified the mean hydrographic and velocity structure of the boundary current system. The year-round existence of the West Greenland Coastal Current (WGCC), the West Greenland Current (WGC), and the Deep Western Boundary Current (DWBC) was documented. The boundary current is composed of six different water masses that vary seasonally in presence. We focused on the seasonality of three of these water masses: the warm, saline, Atlantic-origin water known as Irminger Water (IW), the intermediate ventilated water mass referred to as Labrador Sea Water (LSW), and Upper Polar Water (UPW) which transports waters stemming from the Arctic Ocean as well runoff from Greenland. We found that the presence of IW and LSW were anti-correlated; when LSW transport is high (in late spring), IW transport is low, and, conversely, when IW transport is high (in late fall), 
LSW transport is low. This is explained by two processes: (1) wintertime convection that produces LSW offshore of the boundary current, which is then entrained into the WGC by the end of the convective season; and (2) continuous along-pathway modification of IW as it circumnavigates the Irminger Sea, which cools and freshens the water mass until it is no longer identifiable as IW and instead falls within the LSW class. The seasonality in transport of UPW - a water mass that is found in the WGCC and at the surface of the WGC - is shown to be the result of coastal trapped waves emanating from upstream. The waves are triggered by seasonal variability in the along-coast winds along East Greenland, which trigger barotropic and baroclinic waves. The waves then propagate around Cape Farewell at different speeds, which explains the seasonal timing of the velocity of UPW and the amount of UPW, respectively.

The remainder of the thesis addressed the mesoscale variability in the boundary current system. In chapter 3, we presented the first observations of Denmark Strait Overflow Water cyclones in the West Greenland Boundary Current System. These are mid-depth intensified features that are triggered as dense water cascades over the Denmark Strait sill and stretches, generating cyclonic vorticity in the process. While previously believed to spin down in the Irminger Sea or retroflect at Cape Farewell, we demonstrated that about half of the features are able to round Cape Farewell and enter the Labrador Sea, where they have a significant impact on the transport of overflow waters.

In chapter 4, we presented the first observations of a meandering West Greenland Current. The meandering is seasonally-enhanced, and ultimately results in the production of small-scale, surface-intensified eddies known as boundary current eddies. We show that the meandering, and subsequent eddy formation, are driven by baroclinic instability within the WGC, which results from the seasonal presence of LSW within and offshore of the boundary current that destabilizes the flow. These eddies are shown to have an important impact on the offshore heat transport from the WGC into the interior basin. An increase in LSW content of the boundary current system over the four-year study period explains the observed increase in meandering activity 
observed over this time frame. The meanders are also found to be responsible for the triggering of larger eddies downstream of the OSNAP West Greenland array, known as Irminger Rings.

In chapter 5 we investigated the influence of winds on the structure of the boundary current near the shelfbreak. We demonstrated that strong atmospheric features known as forward tip jets trigger upwelling along the shelfbreak, due to enhanced northeasterly winds. These upwelling events, and the resultant Ekman cells and cross-stream flux of properties, have an impact on the hydrography of the shelf and of the region offshore of the boundary current system. On average, the wind events cause a $0.8^{\circ} \mathrm{C}$ increase in temperature and 0.33 increase in salinity at the base of the outer shelf. We quantified the amount of freshwater fluxed offshore due to a single event, and demonstrated that, based on the average number of storms per winter, this severely limits the development of the mixed layer. This explains why LSW production is not observed in the eastern Labrador Sea.

The findings in this thesis emphasize the role of small-scale, high-frequency processes in fluxing properties into the interior and subsequently influencing wintertime mixed layer development and restratification. Models tend to overestimate the production of LSW in the Labrador Sea, and often fail to reproduce the observed mixed layer distribution in the basin (e.g. Li et al., 2019). The results presented here demonstrate that it is critical for models to accurately capture seasonal and interannual trends in water mass properties, as well as small-scale processes, in order to accurately represent LSW production.

\subsection{Questions raised by this work}

This thesis has highlighted the need for high-resolution measurements of the boundary currents within the subpolar gyre in both space and time. At the same time, long-term monitoring is required to document and understand the nature of the interannual-todecadal variability. One outstanding issue in this regard is the role of feedback loops in the strength of overturning in the Labrador Sea. As demonstrated in chapter 4, 
as convection persists year after year, this produces an increasing reservoir of LSW which acts to reduce the amount of warm, saline Atlantic-origin water in the boundary current system. With less heat in the boundary current, there is less heat to flux offshore to impede further LSW production and restratify the water column after the convective season ends. On the other hand, the more LSW that resides in the WGC, the less stable the boundary current is, which enhances small-scale instabilities. This in turn implies a greater turbulent flux of heat offshore. Presently, it is unclear which of these feedback loops dominates, and over what timescales.

Similarly, freshwater fluxes associated with upwelling-favorable storms were shown to play an important role in inhibiting LSW production in the eastern Labrador Sea. These events are driven by forward tip jets which form when low pressure systems impinge on the high topography of southern Greenland (e.g. Rogers, 1990; Serreze et al., 1997; Moore, 2003). This scenario tends to occur more frequently during positive NAO phases when the north Atlantic storm track is shifted northward. However, a positive NAO phase is also generally associated with increased convective activity in the Labrador Sea, due to enhanced westerly winds off of the Canadian landmass and stronger concomitant air-sea buoyancy fluxes (e.g. Dickson et al., 1996; Våge et al., 2009b). Thus, it is unclear how to reconcile increased LSW production with increased freshwater flux from West Greenland due to upwelling during high phases of the NAO.

There remain many open questions regarding the dynamics of the AMOC, the role of the Labrador Sea in the lower limb of this overturning circulation, and the contribution of small-scale boundary current-interior exchange in regulating the AMOC. High-resolution, long-term monitoring systems such as OSNAP are critical for providing the data necessary to constrain models, validate theories, and predict how our oceans will respond to the warming climate. 


\section{Bibliography}

Allen, J. (1976). Some Aspects of the Forced Wave Response of Stratified Coastal Regions. Journal of Physical Oceanography, 6:113-119.

Almansi, M., Haine, T. W., Gelderloos, R., and Pickart, R. S. (2020). Evolution of Denmark Strait Overflow Cyclones and Their Relationship to Overflow Surges. Geophysical Research Letters, 47(4).

Almansi, M., Haine, T. W., Pickart, R. S., Magaldi, M. G., Gelderloos, R., and Mastropole, D. (2017). High-frequency variability in the circulation and hydrography of the Denmark strait overflow from a high-resolution numerical model. Journal of Physical Oceanography, 47(12):2999-3013.

Argo (2021). Argo float data and metadata from Global Data Assembly Centre (Argo GDAC).

Årthun, M., Eldevik, T., Smedsrud, L. H., Skagseth, Ø., and Ingvaldsen, R. B. (2012). Quantifying the influence of atlantic heat on barents sea ice variability and retreat. Journal of Climate, 25(13):4736-4743.

Asbjørnsen, H., Årthun, M., Skagseth, Ø., and Eldevik, T. (2020). Mechanisms Underlying Recent Arctic Atlantification. Geophysical Research Letters, 47(15).

Bacon, S. (2002). A freshwater jet on the east Greenland shelf. Journal of Geophysical Research, 107(C7):3068.

Bakalian, F. M., Hameed, S., and Pickart, R. (2007). Influence of the Icelandic Low latitude on the frequency of Greenland tip jet events: Implications for Irminger Sea convection. Journal of Geophysical Research: Oceans, 112(4):1-6.

Bamber, J., Van Den Broeke, M., Ettema, J., Lenaerts, J., and Rignot, E. (2012). Recent large increases in freshwater fluxes from Greenland into the North Atlantic. Geophysical Research Letters, 39(19):8-11.

Beaird, N. L., Rhines, P. B., and Eriksen, C. C. (2013). Overflow waters at the Iceland-Faroe Ridge observed in multiyear seaglider surveys. Journal of Physical Oceanography, 43(11):2334-2351.

Boers, N. (2021). Observation-based early-warning signals for a collapse of the Atlantic Meridional Overturning Circulation. Nature Climate Change, 11(8):680-688. 
Böning, C. W., Behrens, E., Biastoch, A., Getzlaff, K., and Bamber, J. L. (2016). Emerging impact of Greenland meltwater on deepwater formation in the North Atlantic Ocean. Nature Geoscience, 9(7):523-527.

Bosse, A., Testor, P., Houpert, L., Damien, P., Prieur, L., Hayes, D., Traillandier, de Madron, X. D., D'Ortenzio, F., Coppola, L., Karstensen, J., and Mortier, L. (2016). Scales and dynamics of Submesoscale Coherent Vortices formed by deep convection in the northwestern Mediterranean Sea. Journal of Geophysical Research: Oceans, 121:7716-7742.

Bower, A. S., Lozier, M. S., Gary, S. F., and Böning, C. W. (2009). Interior pathways of the North Atlantic meridional overturning circulation. Nature, 459(May):243248.

Bracco, A. and Pedlosky, J. (2003). Vortex generation by topography in locally unstable baroclinic flows. Journal of Physical Oceanography, 33(1):207-219.

Bracco, A., Pedlosky, J., and Pickart, R. S. (2008). Eddy formation near the west coast of Greenland. Journal of Physical Oceanography, 38(9):1992-2002.

Brambilla, E., Talley, L. D., and Robbins, P. E. (2008). Subpolar mode water in the northeastern Atlantic: 2. Origin and transformation. Journal of Geophysical Research: Oceans, 113(4):1-16.

Brandt, P., Schott, F. A., Funk, A., and Martins, C. S. (2004). Seasonal to interannual variability of the eddy field in the Labrador Sea from satellite altimetry. Journal of Geophysical Research: Oceans, 109(2):1-11.

Brearley, J. A., Pickart, R. S., Valdimarsson, H., Jonsson, S., Schmitt, R. W., and Haine, T. W. (2012). The East Greenland boundary current system south of Denmark Strait. Deep-Sea Research Part I: Oceanographic Research Papers, 63:1-19.

Brink, K. (1982). A Comparison of Long Coastal Trapped Wave Theory with Observations off Peru. Journal of Physical Oceanography, 12:897-913.

Brink, K. H. (2006). Coastal-trapped waves with finite bottom friction. Dynamics of Atmospheres and Oceans, 41:172-190.

Brown, O. B. and Minnett, P. J. (1999). MODIS Infrared Sea Surface Temperature Algorithm: Algorithm Theoretical Basis Document, Version 2.0.

Bruce, G. (1995). Eddies southwest of the Denmark Strait. Deep Sea Research I, 42(1):13-29.

Buch, E., Pedersen, S. A., and Ribergaard, M. H. (2004). Ecosystem variability in West Greenland Waters. Journal of Northwest Atlantic Fishery Science, 34(September):13-28. 
Buckley, M. W. and Marshall, J. (2016). Observations, inferences, and mechanisms of the Atlantic Meridional Overturning Circulation: A review. Reviews of Geophysics, $54(1): 5-63$.

Caesar, L., McCarthy, G. D., Thornalley, D. J., Cahill, N., and Rahmstorf, S. (2021). Current Atlantic Meridional Overturning Circulation weakest in last millennium. Nature Geoscience, 14(3):118-120.

Caesar, L., Rahmstorf, S., Robinson, A., Feulner, G., and Saba, V. (2018). Observed fingerprint of a weakening Atlantic Ocean overturning circulation. Nature, 556(7700):191-196.

Castelao, R. M., Luo, H., Oliver, H., Rennermalm, A. K., Tedesco, M., Bracco, A., Yager, P. L., Mote, T. L., and Medeiros, P. M. (2019). Controls on the Transport of Meltwater From the Southern Greenland Ice Sheet in the Labrador Sea. Journal of Geophysical Research: Oceans, 124(6):3551-3560.

Cessi, P. and Wolfe, C. L. (2013). Adiabatic eastern boundary currents. Journal of Physical Oceanography, 43(6):1127-1149.

Chafik, L. and Rossby, T. (2019). Volume, Heat, and Freshwater Divergences in the Subpolar North Atlantic Suggest the Nordic Seas as Key to the State of the Meridional Overturning Circulation. Geophysical Research Letters, 46(9):47994808.

Chanut, J., Barńier, B., Large, W., Debreu, L., Penduff, T., Molines, J. M., and Mathiot, P. (2008). Mesoscale eddies in the Labrador Sea and their contribution to convection and restratification. Journal of Physical Oceanography, 38(8):16171643.

Cimoli, L., Stegner, A., and Roullet, G. (2017). Meanders and eddy formation by a buoyant coastal current flowing over a sloping topography. Ocean Science, 13(6):905-923.

Clarke, R. A. and Gascard, J.-C. (1983). The Formation of Labrador Sea Water. Part I: Large-Scale Processes. Journal of Physical Oceanography, 13:1764-1778.

Colbourne, E. B., Narayanan, S., and Prinsenberg, S. (1994). Climatic changes and environmental conditions in the Northwest Atlantic, 1970-1993. ICES Marine Science Symposia, 198:311-322.

Cunningham, S. A., Kanzow, T., Rayner, D., Baringer, M. O., Johns, W. E., Marotzke, J., Longworth, H. R., Grant, E. M., Hirschi, J. J., Beal, L. M., Meinen, C. S., and Bryden, H. L. (2007). Temporal variability of the Atlantic Meridional Overturning Circulation at 26.5 N. Science, 317(5840):935-938.

Cuny, J., Rhines, P. B., and Kwok, R. (2005). Davis Strait volume, freshwater and heat fluxes. Deep-Sea Research Part I: Oceanographic Research Papers, 52(3):519542. 
Cuny, J., Rhines, P. B., Niiler, P. P., and Bacon, S. (2002). Labrador Sea boundary currents and the fate of the Irminger Sea Water. Journal of Physical Oceanography, $32(2): 627-647$.

Curry, B., Lee, C. M., and Petrie, B. (2011). Volume, freshwater, and heat fluxes through Davis Strait, 2004-05. Journal of Physical Oceanography, 41(3):429-436.

Curry, B., Lee, C. M., Petrie, B., Moritz, R. E., and Kwok, R. (2014). Multiyear volume, liquid freshwater, and sea ice transports through Davis Strait, 2004-10. Journal of Physical Oceanography, 44(4):1244-1266.

Danabasoglu, G., Yeager, S. G., Kim, W. M., Behrens, E., Bentsen, M., Bi, D., Biastoch, A., Bleck, R., Böning, C., Bozec, A., Canuto, V. M., Cassou, C., Chassignet, E., Coward, A. C., Danilov, S., Diansky, N., Drange, H., Farneti, R., Fernandez, E., Fogli, P. G., Forget, G., Fujii, Y., Griffies, S. M., Gusev, A., Heimbach, P., Howard, A., Ilicak, M., Jung, T., Karspeck, A. R., Kelley, M., Large, W. G., Leboissetier, A., Lu, J., Madec, G., Marsland, S. J., Masina, S., Navarra, A., Nurser, A. J., Pirani, A., Romanou, A., y.Mélia David, S., Samuels, B. L., Scheinert, M., Sidorenko, D., Sun, S., Treguier, A. M., Tsujino, H., Uotila, P., Valcke, S., Voldoire, A., Wang, Q., and Yashayaev, I. (2016). North Atlantic simulations in Coordinated Oceanice Reference Experiments phase II (CORE-II). Part II: Inter-annual to decadal variability. Ocean Modelling, 97:65-90.

Daniault, N., Lherminier, P., and Mercier, H. (2011). Circulation and transport at the southeast tip of Greenland. Journal of Physical Oceanography, 41(3):437-457.

de Jong, M. F., Bower, A. S., and Furey, H. H. (2014). Two years of observations of warm-core anticyclones in the labrador sea and their seasonal cycle in heat and salt stratification. Journal of Physical Oceanography, 44(2):427-444.

de Jong, M. F., Bower, A. S., and Furey, H. H. (2016). Seasonal and interannual variations of irminger ring formation and boundary-interior heat exchange in FLAME. Journal of Physical Oceanography, 46(6):1717-1734.

de Jong, M. F. and de Steur, L. (2016). Strong winter cooling over the Irminger Sea in winter 2014-2015, exceptional deep convection, and the emergence of anomalously low SST. Geophysical Research Letters, 43(13):7106-7113.

de Jong, M. F., van Aken, H. M., Våge, K., and Pickart, R. S. (2012). Convective mixing in the central Irminger Sea: 2002-2010. Deep-Sea Research Part I: Oceanographic Research Papers, 63:36-51.

Delworth, T. L., Zhang, R., and Mann, M. E. (2007). Decadal to centennial variability of the Atlantic from observations and models. In Schmittner, A., Chiang, J. C. H., and Hemming, S. R., editors, Ocean Circulation: Mechanisms and Impacts-Past and Future Changes of Meridional Overturning, Geophys. Monogr., pages 131-148. American Geophysical Union. 
Dickson, R. and Brown, J. (1994). The production of North Atlantic Deep Water: Sources, rates, and pathways. Journal of Geophysical Research, 99(C6):1231912341.

Dickson, R., Lazier, J., Meincke, J., Rhines, P., and Swift, J. (1996). Long-term coordinated changes in the convective activity of the North Atlantic. Progress in Oceanography, 38(3):241-295.

Dickson, R. R., Meincke, J., Malmberg, S. A., and Lee, A. J. (1988). The "great salinity anomaly" in the Northern North Atlantic 1968-1982. Progress in Oceanography, 20(2):103-151.

Doyle, J. D. and Shapiro, M. A. (1999). Flow response to large-scale topography: The Greenland tip jet. Tellus, Series A: Dynamic Meteorology and Oceanography, $51(5): 728-748$.

Duyck, E. and De Jong, M. F. (2021). Circulation Over the South-East Greenland Shelf and Potential for Liquid Freshwater Export: A Drifter Study. Geophysical Research Letters, 48(5):1-9.

Eady, E. T. (1949). Long Waves and Cyclone Waves. Tellus, 1(3):33-52.

Eden, C. and Böning, C. (2002). Sources of eddy kinetic energy in the Labrador Sea. Journal of Physical Oceanography, 32(12):3346-3363.

Elipot, S. and Beal, L. M. (2015). Characteristics, energetics, and origins of agulhas current meanders and their limited influence on ring shedding. Journal of Physical Oceanography, 45(9):2294-2314.

Fichefet, T., Poncin, C., Goosse, H., Huybrechts, P., Janssens, I., and Le Treut, H. (2003). Implications of changes in freshwater flux from the Greenland ice sheet for the climate of the 21st century. Geophysical Research Letters, 30(17):8-11.

Fischer, J., Schott, F. A., and Dengler, M. (2004). Boundary circulation at the exit of the Labrador Sea. Journal of Physical Oceanography, 34(7):1548-1570.

Fischer, J., Visbeck, M., Zantopp, R., and Nunes, N. (2010). Interannual to decadal variability of outflow from the Labrador Sea. Geophysical Research Letters, $37(24): 1-5$.

Flierl, G. R. (1981). Particle Motions in Large-Amplitude Wave Fields. Geophysical and Astrophysical Fluid Dynamics, 18(1-2):39-74.

Florindo-López, C., Bacon, S., Aksenov, Y., Chafik, L., Colbourne, E., and Penny Holliday, N. (2020). Arctic Ocean and Hudson Bay freshwater exports: New estimates from seven decades of hydrographic surveys on the Labrador Shelf. Journal of Climate, 33(20):8849-8868. 
Foukal, N. P. and Lozier, M. S. (2017). Assessing variability in the size and strength of the North Atlantic subpolar gyre. Journal of Geophysical Research: Oceans, $122(8): 6295-6308$.

Foukal, N. P., Pickart, R. S., Moore, G. W., and Lin, P. (2019). Shelfbreak Downwelling in the Alaskan Beaufort Sea. Journal of Geophysical Research: Oceans, 124(10):7201-7225.

Frajka-Williams, E., Rhines, P. B., and Eriksen, C. C. (2009). Physical controls and mesoscale variability in the Labrador Sea spring phytoplankton bloom observed by Seaglider. Deep-Sea Research Part I: Oceanographic Research Papers, 56(12):21442161.

Fratantoni, P. S. and Pickart, R. S. (2007). The western North Atlantic shelfbreak current system in summer. Journal of Physical Oceanography, 37(10):2509-2533.

Fröb, F., Olsen, A., Våge, K., Moore, G. W., Yashayaev, I., Jeansson, E., and Rajasakaren, B. (2016). Irminger Sea deep convection injects oxygen and anthropogenic carbon to the ocean interior. Nature Communications, 7.

Gascard, J.-C. and Clarke, R. A. (1983). The Formation of Labrador Sea Water. Part II: Mesoscale and Smaller-Scale Processes. Journal of Physical Oceanography, 13:1779-1797.

Gelderloos, R., Haine, T. W. N., and Almansi, M. (2020). Coastal Trapped Waves and Other Subinertial Variability along the Southeast Greenland Coast in a Realistic Numerical Simulation. Journal of Physical Oceanography, 51(3):861-877.

Gelderloos, R., Katsman, C. A., and Drijfhout, S. S. (2011). Assessing the roles of three eddy types in restratifying the Labrador Sea after deep convection. Journal of Physical Oceanography, 41(11):2102-2119.

Gelderloos, R., Straneo, F., and Katsman, C. A. (2012). Mechanisms behind the temporary shutdown of deep convection in the labrador sea: Lessons from the great salinity anomaly years 1968-71. Journal of Climate, 25(19):6743-6755.

Gerdes, R., Hurlin, W., and Griffies, S. M. (2006). Sensitivity of a global ocean model to increased run-off from Greenland. Ocean Modelling, 12(3-4):416-435.

Grist, J. P., Josey, S. A., Boehme, L., Meredith, M. P., Laidre, K. L., Heide-Jørgensen, M. P., Kovacs, K. M., Lydersen, C., Davidson, F. J., Stenson, G. B., Hammill, M. O., Marsh, R., and Coward, A. C. (2014). Seasonal variability of the warm Atlantic water layer in the vicinity of the Greenland shelf break. Geophysical Research Letters, 40:8530-8537.

Hall, M. M., Torres, D. J., and Yashayaev, I. (2013). Absolute velocity along the AR7W section in the Labrador Sea. Deep-Sea Research Part I: Oceanographic Research Papers, 72:72-87. 
Halloran, P. R., Booth, B. B. B., Jones, C. D., Lambert, F. H., McNeall, D. J., Totterdell, I., and Völker, C. (2014). The mechanisms of North Atlantic CO2 uptake in a large Earth System Model ensemble. Biogeosciences, 12:4497-4508.

Harden, B., Straneo, F., and Sutherland, D. (2014a). Moored observations of synoptic and seasonal variability in the East Greenland Coastal Current. Journal of Geophysical Research: Oceans: Oceans, 119:8838-8857.

Harden, B. E., Pickart, R. S., Valdimarsson, H., Våge, K., de Steur, L., Richards, C., Bahr, F., Torres, D., Børve, E., Jónsson, S., Macrander, A., Østerhus, S., Håvik, L., and Hattermann, T. (2016). Upstream sources of the Denmark Strait Overflow: Observations from a high-resolution mooring array. Deep-Sea Research Part I: Oceanographic Research Papers, 112:94-112.

Harden, B. E., Renfrew, I. A., and Pickart, R. S. (2014b). Offshore transport of dense water from the East Greenland shelf. Journal of Physical Oceanography, 44(1):229-245.

Hátún, H., Eriksen, C. C., and Rhines, P. B. (2007). Buoyant eddies entering the Labrador Sea observed with gliders and altimetry. Journal of Physical Oceanography, 37(12):2838-2854.

Håvik, L., Våge, K., Pickart, R. S., Harden, B., Von Appen, W. J., Jónsson, S., and Østerhus, S. (2017). Structure and variability of the shelfbreak East Greenland current North of Denmark Strait. Journal of Physical Oceanography, 47(10):26312646.

Hersbach, H. and Dee, D. (2016). ERA5 reanalysis is in production, ECMWF Newsletter 147, ECMWF. ECMWF Newsletter, 147(Spring 2016):7.

Heywood, K. J., Mcdonagh, E. L., and White, M. A. (1994). Eddy kinetic energy of the North Atlantic subpolar gyre from satellite altimetry. Journal of Geophysical Research, 99(Cll):22525-22539.

Hodson, D. L. and Sutton, R. T. (2012). The impact of resolution on the adjustment and decadal variability of the Atlantic meridional overturning circulation in a coupled climate model. Climate Dynamics, 39(12):3057-3073.

Hogg, N. G. (1991). Mooring Motion Corrections Revisited. Journal of Atmospheric and Oceanic Technology, 8:289- 295.

Hogg, N. G. (1992). On the transport of the gulf stream between cape hatteras and the grand banks. Deep Sea Research Part A, Oceanographic Research Papers, 39(7-8):1231-1246.

Holland, D. M., Thomas, R. H., De Young, B., Ribergaard, M. H., and Lyberth, B. (2008). Acceleration of Jakobshavn Isbr triggered by warm subsurface ocean waters. Nature Geoscience, 1(10):659-664. 
Holliday, N. P., Bacon, S., Allen, J., and McDonagh, E. L. (2009). Circulation and transport in the western boundary currents at Cape Farewell, Greenland. Journal of Physical Oceanography, 39(8):1854-1870.

Holliday, N. P., Meyer, A., Bacon, S., Alderson, S. G., and de Cuevas, B. (2007). Retroflection of part of the east Greenland current at Cape Farewell. Geophysical Research Letters, 34(7):1-5.

Hopkins, J. E., Holliday, N. P., Rayner, D., Houpert, L., Le Bras, I., Straneo, F., Wilson, C., and Bacon, S. (2019). Transport Variability of the Irminger Sea Deep Western Boundary Current From a Mooring Array. Journal of Geophysical Research: Oceans, 124:3246-3278.

Hu, A., Meehl, G. A., Han, W., and Yin, J. (2011). Effect of the potential melting of the Greenland Ice Sheet on the Meridional Overturning Circulation and global climate in the future. Deep-Sea Research Part II: Topical Studies in Oceanography, 58(17-18):1914-1926.

Huang, J., Pickart, R. S., Huang, R. X., Lin, P., Brakstad, A., and Xu, F. (2020). Sources and upstream pathways of the densest overflow water in the Nordic Seas. Nature Communications, 11(1):1-9.

Huang, J., Pickart, R. S., Valdimarsson, H., Lin, P., Spall, M. A., and Xu, F. (2019). Structure and Variability of the North Icelandic Jet From Two Years of Mooring Data. Journal of Geophysical Research: Oceans, 124(6):3987-4002.

Hurrell, J. (1995). Decadal trends in the North Atlantic oscillation: Regional temperatures and precipitation. Science, 269:676-697.

Huybrechts, P., Janssens, I., Poncin, C., and Fichefet, T. (2002). The response of the Greenland ice sheet to climate changes in the 21st century by interactive coupling of an AOGCM with a thermomechanical ice-sheet model. Annals of Glaciology, 35:409-415.

Huyer, A., Sobey, E. J. C., and Smith, R. L. (1979). The spring transition in currents over the Oregon Continental Shelf. Journal of Geophysical Research, 84(C11):69957011.

IMBIE, T. T. (2020). Mass balance of the Greenland Ice Sheet from 1992 to 2018. Nature, 579(7798):233-239.

IPCC (2013). Climate Change 2013: The Physical Science Basis. Contribution of Working Group I to the Fifth Assessment Report of the Intergovernmental Panel on Climate Change. Technical report, Cambridge University Press, Cambridge, United Kingdom and New York, NY, USA.

IPCC (2021). Climate Change 2021: The Physical Science Basis. Contribution of Working Group I to the Sixth Assessment Report of the Intergovernmental Panel on Climate Change. Technical report, Cambridge University Press. 
Jackson, L. C., Peterson, K. A., Roberts, C. D., and Wood, R. A. (2016). Recent slowing of Atlantic overturning circulation as a recovery from earlier strengthening. Nature Geoscience, 9(7):518-522.

Jahn, A. and Holland, M. M. (2013). Implications of Arctic sea ice changes for North Atlantic deep convection and the meridional overturning circulation in CCSM4CMIP5 simulations. Geophysical Research Letters, 40(6):1206-1211.

Johnson, H. L., Cessi, P., Marshall, D. P., Schloesser, F., and Spall, M. A. (2019). Recent Contributions of Theory to Our Understanding of the Atlantic Meridional Overturning Circulation. Journal of Geophysical Research: Oceans, 124(8):53765399.

Jones, H. and Marshall, J. (1997). Restratification after deep convection. Journal of Physical Oceanography, 27(10):2276-2287.

Josey, S. A., de Jong, M. F., Oltmanns, M., Moore, G. K., and Weller, R. A. (2019). Extreme Variability in Irminger Sea Winter Heat Loss Revealed by Ocean Observatories Initiative Mooring and the ERA5 Reanalysis. Geophysical Research Letters, 46(1):293-302.

Jungclaus, J. H., Haak, H., Esch, M., Roeckner, E., and Marotzke, J. (2006). Will Greenland melting halt the thermohaline circulation? Geophysical Research Letters, 33(17):1-5.

Kanzow, T., Cunningham, S. A., Rayner, D., Hirschi, J. J., Johns, W. E., Baringer, M. O., Bryden, H. L., Beal, L. M., Meinen, C. S., and Marotzke, J. (2007). Observed flow compensation associated with the MOC at $26.5^{\circ} \mathrm{N}$ in the Atlantic. Science, 317(5840):938-941.

Kanzow, T., Send, U., Zenk, W., Chave, A. D., and Rhein, M. (2006). Monitoring the integrated deep meridional flow in the tropical North Atlantic: Long-term performance of a geostrophic array. Deep-Sea Research Part I: Oceanographic Research Papers, 53(3):528-546.

Katsman, C. A., Spall, M. A., and Pickart, R. S. (2004). Boundary current eddies and their role in the restratification of the Labrador Sea. Journal of Physical Oceanography, 34(9):1967-1983.

Kawasaki, T. and Hasumi, H. (2014). Effect of freshwater from the West Greenland Current on the winter deep convection in the Labrador Sea. Ocean Modelling, 75:51-64.

Khatiwala, S., Tanhua, T., Mikaloff Fletcher, S., Gerber, M., Doney, S. C., Graven, H. D., Gruber, N., McKinley, G. A., Murata, A., Ríos, A. F., and Sabine, C. L. (2013). Global ocean storage of anthropogenic carbon. Biogeosciences, 10(4):21692191. 
Killworth, P. (1983). Deep convection in the world ocean. Rev. Geophys. Space Phys., $21: 1-26$.

Knight, J. R., Allan, R. J., Folland, C. K., Vellinga, M., and Mann, M. E. (2005). A signature of persistent natural thermohaline circulation cycles in observed climate. Geophysical Research Letters, 32(20):1-4.

Knight, J. R., Folland, C. K., and Scaife, A. A. (2006). Climate impacts of the Atlantic multidecadal oscillation. Geophysical Research Letters, 33(17):2-5.

Krauss, W. (1995). Currents and mixing in the Irminger Sea and in the Iceland Basin. Journal of Geophysical Research, 100(C6):10851-10871.

Kuhlbrodt, T., Griesel, A., Montoya, M., Levermann, A., Hofmann, M., and Rahmstorf, S. (2007). On the driving processes of the Atlantic meridional overturning circulation. Reviews of Geophysics, 45(2).

Lab Sea Group (1998). The Labrador Sea Deep Convection Experiment. Bulletin of the American Meteorological Society, 79(10):2033-2058.

Lavender, K. L., Davis, R. E., and Owens, W. B. (2000). Mid-depth recirculation observed in the interior Labrador and Irminger seas by direct velocity measurements. Nature, 407(September 2000):66-69.

Lavender, K. L., Davis, R. E., and Owens, W. B. (2002). Observations of open-ocean deep convection in the Labrador Sea from subsurface floats. Journal of Physical Oceanography, 32(2):511-526.

Lazier, J., Hendry, R., Clarke, A., Yashayaev, I., and Rhines, P. (2002). Convection and restratification in the Labrador Sea, 1990-2000. Deep-Sea Research Part I: Oceanographic Research Papers, 49(10):1819-1835.

Lazier, J. R. (1980). Oceanographic conditions at ocean weather ship bravo, 1964-1974. Atmosphere - Ocean, 18(3):227-238.

Lazier, J. R. N. and Wright, D. (1993). Annual Velocity Variations in the Labrador Current. Journal of Physical Oceanography, 34:659-678.

Le Bras, I. A., Straneo, F., Holte, J., de Jong, M. F., and Holliday, N. P. (2020). Rapid Export of Waters Formed by Convection Near the Irminger Sea's Western Boundary. Geophysical Research Letters, 47:1-10.

Le Bras, I. A., Yashayaev, I., and Toole, J. M. (2017). Tracking Labrador Sea Water property signals along the Deep Western Boundary Current. Journal of Geophysical Research: Oceans, 122:5348-5366.

Le Bras, I. A. A., Straneo, F., Holte, J., and Holliday, N. P. (2018). Seasonality of Freshwater in the East Greenland Current System From 2014 to 2016. Journal of Geophysical Research: Oceans, 123(12):8828-8848. 
Lee, A. and Ellett, D. (1965). On the contribution of overflow water from the Norwegian Sea to the hydrographic structure of the North Atlantic Ocean. Deep-Sea Research, 12(2):129-142.

Lentz, S. J. and Chapman, D. C. (2004). The importance of nonlinear cross-shelf momentum flux during wind-driven coastal upwelling. Journal of Physical Oceanography, 34(11):2444-2457.

Li, F., Lozier, M. S., Bacon, S., Bower, A. S., Cunningham, S. A., de Jong, M. F., DeYoung, B., Fraser, N., Fried, N., Han, G., Holliday, N. P., Holte, J., Houpert, L., Inall, M. E., Johns, W. E., Jones, S., Johnson, C., Karstensen, J., Le Bras, I. A., Lherminier, P., Lin, X., Mercier, H., Oltmanns, M., Pacini, A., Petit, T., Pickart, R. S., Rayner, D., Straneo, F., Thierry, V., Visbeck, M., Yashayaev, I., and Zhou, C. (2021). Subpolar North Atlantic western boundary density anomalies and the Meridional Overturning Circulation. Nature Communications, 12(1):1-9.

Li, F., Lozier, M. S., Danabasoglu, G., Holliday, N. P., Kwon, Y. O., Romanou, A., Yeager, S. G., and Zhang, R. (2019). Local and downstream relationships between Labrador Sea water volume and North Atlantic meridional overturning circulation variability. Journal of Climate, 32(13):3883-3898.

Li, H., Ilyina, T., Müller, W. A., and Sienz, F. (2016). Decadal predictions of the North Atlantic $\mathrm{CO}_{2}$ uptake. Nature Communications, 7(May 2015):1-7.

Lilly, J. M. and Rhines, P. B. (2002). Coherent eddies in the Labrador Sea observed from a mooring. Journal of Physical Oceanography, 32(2):585-598.

Lilly, J. M., Rhines, P. B., Schott, F., Lavender, K., Lazier, J., Send, U., and Asaro, E. D. (2003). Observations of the Labrador Sea eddy field. Progress in Oceanography, 59:75-176.

Lilly, J. M., Rhines, P. B., Visbeck, M., Davis, R., Lazier, J. R., Schott, F., and Farmer, D. (1999). Observing deep convection in the Labrador Sea during winter 1994/95. Journal of Physical Oceanography, 29(8 PART 2):2065-2098.

Lin, P., Pickart, R. S., Moore, G. W., Spall, M. A., and Hu, J. (2019). Characteristics and dynamics of wind-driven upwelling in the Alaskan Beaufort Sea based on six years of mooring data. Deep-Sea Research Part II: Topical Studies in Oceanography, 162(January 2018):79-92.

Lin, P., Pickart, R. S., Stafford, K. M., Moore, G., Torres, D. J., Bahr, F., and $\mathrm{Hu}$, J. (2016). Journal of Geophysical Research : Oceans. Journal of Geophysical Research: Oceans, 121:8434-8454.

Lin, P., Pickart, R. S., Torres, D. J., and Pacini, A. (2018). Evolution of the freshwater coastal current at the Southern Tip of Greenland. Journal of Physical Oceanography, 48(9):2127-2140. 
Lozier, M. S., Bacon, S., Bower, A. S., Cunningham, S. A., De Jong, M. F., De Steur, L., De Young, B., Fischer, J., Gary, S. F., Greenan, B. J., Heimbmbach, P., Holliday, N. P., Houpert, L., Inall, M. E., Johns, W. E., Johnson, H. L., Karstensen, J., Li, F., Lin, X., Mackay, N., Marshall, D. P., Mercier, H., Myers, P. G., Pickart, R. S., Pillar, H. R., Straneo, F., Thierry, V., Weller, R. A., Williams, R. G., Wilson, C., Yang, J., Zhao, J., and Zika, J. D. (2017). Overturning in the Subpolar North Atlantic Program: A new international ocean observing system. Bulletin of the American Meteorological Society, 98(4):737-752.

Lozier, M. S., Li, F., Bacon, S., Bahr, F., Bower, A. S., Cunningham, S. A., De Jong, M. F., De Steur, L., DeYoung, B., Fischer, J., Gary, S. F., Greenan, B. J., Holliday, N. P., Houk, A., Houpert, L., Inall, M. E., Johns, W. E., Johnson, H. L., Johnson, C., Karstensen, J., Koman, G., Le Bras, I. A., Lin, X., Mackay, N., Marshall, D. P., Mercier, H., Oltmanns, M., Pickart, R. S., Ramsey, A. L., Rayner, D., Straneo, F., Thierry, V., Torres, D. J., Williams, R. G., Wilson, C., Yang, J., Yashayaev, I., and Zhao, J. (2019). A sea change in our view of overturning in the subpolar North Atlantic. Science, 363(6426):516-521.

Luo, H., Castelao, R. M., Rennermalm, A. K., Tedesco, M., Bracco, A., Yager, P. L., and Mote, T. L. (2016). Oceanic transport of surface meltwater from the southern Greenland ice sheet. Nature Geoscience, 9(7):528-532.

Maier-Reimer, E. and Mikolajewicz, U. (1989). Experiments with an OGCM on the cause of the Younger Dryas. Proc. Joint Oceanogr. Assem., pages 87-99.

Majumder, S., Castelao, R. M., and Amos, C. M. (2021). Freshwater Variability and Transport in the Labrador Sea From In Situ and Satellite Observations. Journal of Geophysical Research: Oceans, 126(4):1-17.

Malmberg, S. A. and Jónsson, S. (1997). Timing of deep convection in the Greenland and Iceland Seas. ICES Journal of Marine Science, 54(3):300-309.

Manabe, S. and Stouffer, R. (1988). Two stable equilibria of a coupled oceanatmosphere model. Journal of Climate, 1(9):841-866.

Marshall, J. and Schott, F. (1999). Open-Ocean Convection: Observations, Theory, and Models. Reviews of Geophysics, 37(98):1-64.

Martin, A. P. and Richards, K. J. (2001). Mechanisms for vertical nutrient transport within a North Atlantic mesoscale eddy. Deep-Sea Research Part II: Topical Studies in Oceanography, 48(4-5):757-773.

Martin, R. and Moore, G. W. (2007). Air-sea interaction associated with a Greenland reverse tip jet. Geophysical Research Letters, 34(24):1-5.

Mastropole, D., Pickart, R. S., Valdimarsson, H., Våge, K., Jochumsen, K., and Girton, J. (2017). On the hydrography of Denmark Strait. Journal of Geophysical Research: Oceans, 175(4449):238. 
McCarthy, G. D., Smeed, D. A., Johns, W. E., Frajka-Williams, E., Moat, B. I., Rayner, D., Baringer, M. O., Meinen, C. S., Collins, J., and Bryden, H. L. (2015). Measuring the Atlantic Meridional Overturning Circulation at $26^{\circ} \mathrm{N}$. Progress in Oceanography, 130:91-111.

McCartney, M. S. (1992). Recirculating components to the deep boundary current of the northern North Atlantic. Progress in Oceanography, 29:283-383.

McCartney, M. S. and Talley, L. D. (1982). The Subpolar Mode Water of the North Atlantic Ocean. Journal of Physical Oceanography, 12:1169-1188.

McCartney, M. S. and Talley, L. D. (1984). Warm-to-cold Water Conversion in the Northern North Atlantic Ocean. Journal of Physical Oceanography, 14:922-935.

McWilliams, J. C. (1985). Submesoscale, Coherent Vortices in the Ocean. Reviews of Geophysics, 23(2):165-182.

Moore, G. W. (2003). Gale force winds over the Irminger Sea to the east of Cape Farewell, Greenland. Geophysical Research Letters, 30(17):1-4.

Moore, G. W., Pickart, R. S., and Renfrew, I. A. (2008). Buoy observations from the windiest location in the world ocean, Cape Farewell, Greenland. Geophysical Research Letters, 35(18):3-7.

Moore, G. W. and Renfrew, I. A. (2005). Tip jets and barrier winds: A QuikSCAT climatology of high wind speed events around Greenland. Journal of Climate, 18(18):3713-3725.

Myers, P. G., Donnelly, C., and Ribergaard, M. H. (2009). Structure and variability of the West Greenland Current in Summer derived from 6 repeat standard sections. Progress in Oceanography, 80(1-2):93-112.

Myers, P. G., Kulan, N., and Ribergaard, M. H. (2007). Irminger water variability in the West Greenland Current. Geophysical Research Letters, 34(17):2-7.

NGDC (2006). ETOPO2v2 Global gridded 2-minute database.

Nof, D. (1983). The translation of isolated cold eddies on a sloping bottom. Deep Sea Research Part A, Oceanographic Research Papers, 30(2):171-182.

Ohigashi, T. and Moore, G. (2009). Fine structure of a Greenland reverse tip jet: A numerical simulation. Tellus, Series A: Dynamic Meteorology and Oceanography, $61(4): 512-526$.

Ovall, B., Pickart, R. S., Lin, P., Stabeno, P., Weingartner, T., Itoh, M., Kikuchi, T., Dobbins, E., and Bell, S. (2021). Ice, wind, and water: Synoptic-scale controls of circulation in the Chukchi Sea. Progress in Oceanography, 199:102707. 
Pacini, A. and Pickart, R. S. (2022). Meanders of the West Greenland Current near Cape Farewell. Deep-Sea Research Part I: Oceanographic Research Papers, 179:103664.

Pacini, A., Pickart, R. S., Bahr, F., Torres, D. J., Ramsey, A. L., Holte, J., Karstensen, J., Oltmanns, M., Straneo, F., Le Bras, I. A., Moore, G. W., and Femke de Jong, M. (2020). Mean conditions and seasonality of the west Greenland boundary current system near Cape Farewell. Journal of Physical Oceanography, 50(10):2849-2871.

Pacini, A., Pickart, R. S., Le Bras, I. A., Straneo, F., Holliday, N., and Spall, M. (2021). Cyclonic eddies in the West Greenland Boundary Current System. Journal of Physical Oceanography, pages 1-45.

Palter, J. B. and Lozier, M. S. (2008). On the source of Gulf Stream nutrients. Journal of Geophysical Research: Oceans, 113(6).

Pawlowicz, R., Beardsley, B., and Lentz, S. (2002). Classical tidal harmonic analysis including error estimates in MATLAB using TDE. Computers and Geosciences, 28(8):929-937.

Pedlosky, J. (2003). Waves in the Ocean and Atmosphere: Introduction to Wave Dynamics. Springer.

Penduff, T., Barnier, B., Dewar, W. K., and O'Brien, J. J. (2004). Dynamical response of the oceanic eddy field to the North Atlantic Oscillation: A model-data comparison. Journal of Physical Oceanography, 34(12):2615-2629.

Pennelly, C. and Myers, P. G. (2020). Introducing LAB60: A 1/60 NEMO 3.6 numerical simulation of the Labrador Sea. Geoscientific Model Development, 13(10):49594975 .

Pennelly, C. and Myers, P. G. (2021). Impact of Different Atmospheric Forcing Sets on Modeling Labrador Sea Water Production. Journal of Geophysical Research: Oceans, 126(2).

Pérez, F. F., Mercier, H., Vázquez-Rodríguez, M., Lherminier, P., Velo, A., Pardo, P. C., Rosón, G., and Ríos, A. F. (2013). Atlantic Ocean $\mathrm{CO}_{2}$ uptake reduced by weakening of the meridional overturning circulation. Nature Geoscience, 6(2):146152.

Pickart, R. S. (1992). Water mass components of the North Atlantic deep western boundary current. Deep Sea Res. Part I: Oceanogr. Res. P., 39(9):1553-1572.

Pickart, R. S., Smethie, W. M., Lazier, J. R., Jones, E. P., and Jenkins, W. J. (1996). Eddies of newly formed upper Labrador Sea water. Journal of Geophysical Research C: Oceans, 101(C9):20711-20726. 
Pickart, R. S. and Spall, M. A. (2007). Impact of Labrador Sea convection on the North Atlantic meridional overturning circulation. Journal of Physical Oceanography, 37(9):2207-2227.

Pickart, R. S., Spall, M. A., and Lazier, J. R. N. (1997). Mid-depth ventilation in the western boundary current system of the sub-polar gyre. Deep-Sea Research Part I, 44(6):1025-1054.

Pickart, R. S., Spall, M. A., and Mathis, J. T. (2013). Dynamics of upwelling in the Alaskan Beaufort Sea and associated shelf-basin fluxes. Deep-Sea Research Part I: Oceanographic Research Papers, 76:35-51.

Pickart, R. S., Spall, M. A., Moore, G. W., Weingartner, T. J., Woodgate, R. A., Aagaard, K., and Shimada, K. (2011). Upwelling in the Alaskan Beaufort Sea: Atmospheric forcing and local versus non-local response. Progress in Oceanography, 88(1-4):78-100.

Pickart, R. S., Spall, M. A., Ribergaard, M. H., Moore, G. W., and Milliff, R. F. (2003a). Deep convection in the Irminger sea forced by the Greenland tip jet. Nature, 424(6945):152-156.

Pickart, R. S., Straneo, F., and Moore, G. W. (2003b). Is Labrador Sea Water formed in the Irminger basin? Deep-Sea Research Part I: Oceanographic Research Papers, $50(1): 23-52$.

Pickart, R. S., Torres, D. J., and Clarke, R. A. (2002). Hydrography of the Labrador Sea during active convection. Journal of Physical Oceanography, 32(2):428-457.

Pickart, R. S., Torres, D. J., and Fratantoni, P. S. (2005). The East Greenland Spill Jet. Journal of Physical Oceanography, 35(6):1037-1053.

Piron, A., Thierry, V., Mercier, H., and Caniaux, G. (2017). Gyre-scale deep convection in the subpolar North Atlantic Ocean during winter 2014-2015. Geophysical Research Letters, 44(3):1439-1447.

Prater, M. D. (2002). Eddies in the Labrador Sea as observed by profiling RAFOS floats and remote sensing. Journal of Physical Oceanography, 32(2):411-427.

Price, J. F., Weller, R. A., and Pinkel, R. (1986). Diurnal Cycling: Observations and Models of the Upper Ocean Response to Diurnal Heating, Cooling, and Wind Mixing. Journal of Geophysical Research, 91:8411-8427.

Pujol, M. I., Faugére, Y., Taburet, G., Dupuy, S., Pelloquin, C., Ablain, M., and Picot, N. (2016). DUACS DT2014: the new multi-mission altimeter data set reprocessed over 20 years. Ocean Science, 12(5):1067-1090.

Rahmstorf, S. (1995). Bifurcations of the Atlantic thermohaline circulation in response to changes in the hydrological cycle. Nature, 378(6553):145-149. 
Rahmstorf, S. (2002). Ocean circulation and climate during the past 120,000 years. Nature, 419(6903):207-214.

Rahmstorf, S. (2006). Thermohaline Circulation. Encyclopedia of Quaternary Science: Second Edition, pages 737-747.

Rahmstorf, S., Box, J. E., Feulner, G., Mann, M. E., Robinson, A., Rutherford, S., and Schaffernicht, E. J. (2015). Exceptional twentieth-century slowdown in Atlantic Ocean overturning circulation. Nature Climate Change, 5(5):475-480.

Renfrew, I. A., Moore, G. W., Guest, P. S., and Bumke, K. (2002). A comparison of surface layer and surface turbulent flux observations over the Labrador Sea with ECMWF analyses and NCEP reanalyses. Journal of Physical Oceanography, $32(2): 383-400$.

Renfrew, I. A., Peterson, G., Sproson, D., Moore, G., Adiwidjaja, H., Zhang, S., and North, R. (2009). A comparison of aircraft-based surface-layer observations over Denmark Strait and the Irminger Sea with meteorological analyses and QuikSCAT winds. Quarterly Journal of the Royal Meteorological Society, 135(July):2046-2066.

Rhein, M., Fischer, J., Smethie, W. M., Smythe-Wright, D., Weiss, R. F., Mertens, C., Min, D. H., Fleischmann, U., and Putzka, A. (2002). Labrador Sea Water: Pathways, CFC inventory, and formation rates. Journal of Physical Oceanography, $32(2): 648-665$.

Rhein, M., Stramma, L., and Send, U. (1995). The Atlantic Deep Western Boundary Current: Water masses and transports near the equator. Journal of Geophysical Research, 100:2441-2457.

Rhines, P., Häkkinen, S., and Josey, S. A. (2008). Is Oceanic Heat Transport Significant in the Climate System? Arctic-Subarctic Ocean Fluxes: Defining the Role of the Northern Seas in Climate, pages 87-109.

Ribergaard, M. H. (2014). Oceanographic Investigations off West Greenland 2013. Technical Report May 2013, Danish Meteorological Institute Centre for Ocean and Ice, Copenhagen, Denmark.

Ridley, J. K., Huybrechts, P., Gregory, J. M., and Lowe, J. A. (2005). Elimination of the greenland ice sheet in a high CO2 climate. Journal of Climate, 18(17):34093427.

Rieck, J. K., Böning, C. W., and Getzlaff, K. (2019). The nature of eddy kinetic energy in the labrador sea: Different types of mesoscale eddies, their temporal variability, and impact on deep convection. Journal of Physical Oceanography, 49(8):2075-2094.

Rieck, J. K., Böning, C. W., Greatbatch, R. J., and Scheinert, M. (2015). Seasonal variability of eddy kinetic energy in a global high-resolution ocean model. Geophysical Research Letters, 42(21):9379-9386. 
Rignot, E. and Kanagaratnam, P. (2006). Changes in the velocity structure of the Greenland Ice Sheet. Science, 311(5763):986-990.

Robson, J., Hodson, D., Hawkins, E., and Sutton, R. (2014). Atlantic overturning in decline? Nature Geoscience, 7(1):2-3.

Robson, J., Lohmann, K., Smith, D., and Palmer, M. D. (2012). Causes of the rapid warming of the North Atlantic Ocean in the mid-1990s. Journal of Climate, 25(12):4116-4134.

Rogers, J. C. (1990). Patterns of Low-Requency Monthly Sea Level Pressure Variability (1899-1986) and Associated Wave Cyclone Frequencies. Journal of Climate, 3(12):1364-1379.

Rooth, C. (1982). Hydrology and ocean circulation. Progress in Oceanography, $11(2): 131-149$.

Rosón, G., Ríos, A., Pérez, F., Lavín, A., and Bryden, H. (2003). Carbon distribution, fluxes, and budgets in the subtropical North Atlantic Ocean $\left(24.5^{\circ} \mathrm{N}\right)$. Journal of Geophysical Research, 108(C5).

Rudels, B., Fahrbach, E., Meincke, J., Budéus, G., and Ericksson, P. (2002). The East Greenland Current and its contribution to the Denmark Strait overflow. ICES Journal of Marine Science, 59(6):101006/jmsc20021284.

Rühs, S., Oliver, E. C., Biastoch, A., Böning, C. W., Dowd, M., Getzlaff, K., Martin, T., and Myers, P. G. (2021). Changing Spatial Patterns of Deep Convection in the Subpolar North Atlantic. Journal of Geophysical Research: Oceans, 126(7):1-24.

Rykova, T., Straneo, F., and Bower, A. S. (2015). Seasonal and interannual variability of the West Greenland Current System in the Labrador Sea in 1993-2008. Journal of Geophysical Research: Oceans, 120:1318-1332.

Rykova, T., Straneo, F., Lilly, J. M., and Yashayaev, I. (2009). Irminger current anticyclones in the Labrador Sea observed in the hydrographic record, 1990-2004. Journal of Marine Research, 67(3):361-384.

Sabine, C. L., Feely, R. A., Gruber, N., Key, R. M., Lee, K., and Coauthors (2004). The oceanic sink for anthropogenic $\mathrm{CO}_{2}$. Science, 305:367-371.

Sampe, T. and Xie, S. P. (2007). Mapping high sea winds from space: A global climatology. Bulletin of the American Meteorological Society, 88(12):1965-1978.

Sandø, A. B., Nilsen, J. E., Gao, Y., and Lohmann, K. (2010). Importance of heat transport and local air-sea heat fluxes for Barents Sea climate variability. Journal of Geophysical Research: Oceans, 115(7).

Schulze, L. M. and Pickart, R. S. (2012). Seasonal variation of upwelling in the Alaskan Beaufort Sea: Impact of sea ice cover. Journal of Geophysical Research: Oceans, 117(6):1-19. 
Schulze, L. M., Pickart, R. S., and Moore, G. (2016). Atmospheric forcing during active convection in the Labrador Sea and its impact on mixed-layer depth. Journal of Geophysical Research: Oceans, 121:6978-6992.

Schulze Chretien, L. M. and Frajka-Williams, E. (2018). Wind-driven transport of fresh shelf water into the upper $30 \mathrm{~m}$ of the Labrador Sea. Ocean Science, 14(5):1247-1264.

Send, U. and Marshall, J. (1995). Integral Effects of Deep Convection. Journal of Physical Oceanography, 25:855-872.

Serreze, M. C., Carse, F., Barry, R. G., and Rogers, J. C. (1997). Icelandic low cyclone activity: Climatological features, linkages with the NAO, and relationships with recent changes in the Northern Hemisphere circulation. Journal of Climate, 10(3):453-464.

Serreze, M. C., Holland, M. M., and Stoeve, J. (2007). Perspectives on the Arctic's Shrinking Sea-Ice Cover. Science of Mental Health, 315:1533-1536.

Smith, D. M., Eade, R., Dunstone, N. J., Fereday, D., Murphy, J. M., Pohlmann, H., and Scaife, A. A. (2010). Skilful multi-year predictions of Atlantic hurricane a frequency. Nature Geoscience, 3(12):846-849.

Smith, W. H. F. and Wessel, P. (1990). Gridding with continuous curvature splines in tension. Geophysics, 55(3):293-305.

Spall, M. A. (2004). Boundary currents and watermass transformation in marginal seas. Journal of Physical Oceanography, 34(5):1197-1213.

Spall, M. A. (2010). Dynamics of down welling in an eddy-resolving convective basin. Journal of Physical Oceanography, 40(10):2341-2347.

Spall, M. A. and Pedlosky, J. (2008). Lateral coupling in baroclinically unstable flows. Journal of Physical Oceanography, 38(6):1267-1277.

Spall, M. A. and Pickart, R. S. (2001). Where does dense water sink? a subpolar gyre example. Journal of Physical Oceanography, 31(3):810-826.

Spall, M. A., Pickart, R. S., Fratantoni, P. S., and Plueddemann, A. J. (2008). Western Arctic Shelfbreak Eddies: Formation and Transport. Journal of Physical Oceanography, 38(8):1644-1668.

Spall, M. A., Pickart, R. S., Lin, P., von Appen, W. J., Mastropole, D., Valdimarsson, H., Haine, T. W., and Almansi, M. (2019). Frontogenesis and variability in Denmark strait and its influence on overflow water. Journal of Physical Oceanography, 49(7):1889-1904.

Spall, M. A. and Price, J. F. (1998). Mesoscale Variability in Denmark Strait: The PV Outflow Hypothesis. Journal of Physical Oceanography, 28:1598-1623. 
Srokosz, M. A. and Bryden, H. L. (2015). Observing the Atlantic Meridional Overturning Circulation yields a decade of inevitable surprises. Science, 348(6241).

Steinfeldt, R., Rhein, M., Bullister, J. L., and Tanhua, T. (2009). Inventory changes in anthropogenic carbon from 1997-2003 in the Atlantic Ocean between 20S and 65N. Global Biogeochemical Cycles, 23(3):1-11.

Stommel, H. (1961). Thermohahe Convection with Two Stable Regimes. Tellus, $13(2): 224-230$.

Stone, P. H. (1970). On Non-Geostrophic Baroclinic Stability: Part II. Journal of the Atmospheric Sciences, 27:721-726.

Stouffer, R. J., Yin, J., Gregory, J. M., Dixon, K. W., Spelman, M. J., Hurlin, W., Weaver, A. J., Eby, M., Flato, G. M., Hasumi, H., Hu, A., Jungclaus, J. H., Kamenkovich, I. V., Levermann, A., Montoya, M., Murakami, S., Nawrath, S., Oka, A., Peltier, W. R., Robitaille, D. Y., Sokolov, A., Vettoretti, G., and Weber, S. L. (2006). Investigating the causes of the response of the thermohaline circulation to past and future climate changes. Journal of Climate, 19(8):1365-1387.

Straneo, F. (2006). Heat and freshwater transport through the central Labrador Sea. Journal of Physical Oceanography, 36(4):606-628.

Straneo, F., Hamilton, G. S., Sutherland, D. A., Stearns, L. A., Davidson, F., Hammill, M. O., Stenson, G. B., and Rosing-Asvid, A. (2010). Rapid circulation of warm subtropical waters in a major glacial fjord in East Greenland. Nature Geoscience, $3(3): 182-186$.

Stroeve, J. and Notz, D. (2018). Changing state of Arctic sea ice across all seasons. Environmental Research Letters, 13(10).

Sutherland, D. A. and Pickart, R. S. (2008). The East Greenland Coastal Current: Structure, variability, and forcing. Progress in Oceanography, 78(1):58-77.

Sutherland, D. A., Pickart, R. S., Peter Jones, E., Azetsu-Scott, K., Jane Eert, A., and Olafsson, J. (2009). Freshwater composition of the waters off southeast Greenland and their link to the Arctic Ocean. Journal of Geophysical Research: Oceans, 114(5):1-17.

Sutherland, D. A., Straneo, F., Stenson, G. B., Davidson, F. J., Hammill, M. O., and Rosing-Asvid, A. (2013). Atlantic water variability on the SE Greenland continental shelf and its relationship to SST and bathymetry. Journal of Geophysical Research: Oceans, 118(2):847-855.

Sutton, R. T. and Hodson, D. L. (2005). Ocean science: Atlantic Ocean forcing of North American and European summer climate. Science, 309(5731):115-118. 
Swingedouw, D., Braconnot, P., and Marti, O. (2006). Sensitivity of the Atlantic Meridional Overturning Circulation to the melting from northern glaciers in climate change experiments. Geophysical Research Letters, 33(7):1-4.

Swingedouw, D., Rodehacke, C. B., Olsen, S. M., Menary, M., Gao, Y., Mikolajewicz, U., and Mignot, J. (2015). On the reduced sensitivity of the Atlantic overturning to Greenland ice sheet melting in projections: a multi-model assessment. Climate Dynamics, 44(11-12):3261-3279.

Sy, A., Rheint, M., Lazier, J. R., Koltermann, K. P., Meincke, J., Putzka, A., and Bersch, M. (1997). Surprisingly rapid spreading of newly formed intermediate waters across the North Atlantic Ocean. Nature, 386(6626):675-679.

Tagklis, F., Bracco, A., Ito, T., and Castelao, R. M. (2020). Submesoscale modulation of deep water formation in the Labrador Sea. Scientific Reports, 10(1):1-13.

Takahashi, T., Sutherland, S. C., Wanninkhof, R., Sweeney, C., Feely, R. A., Chipman, D. W., Hales, B., Friederich, G., Chavez, F., Sabine, C., Watson, A., Bakker, D. C. E., Schuster, U., Metzl, N., Yoshikawa-Inoue, H., Ishii, M., Midorikawa, T., Nojiri, Y., Körtzinger, A., Steinhoff, T., Hoppema, M., Olafsson, J., Arnarson, T. S., Tilbrook, B., Johannessen, T., Olsen, A., Bellerby, R., Wong, C. S., Delille, B., Bates, N. R., and de Baar, H. J. W. (2009). Climatological mean and decadal change in surface ocean pCO2, and net sea-air CO2flux over the global oceans. Deep-Sea Research Part II: Topical Studies in Oceanography, 56(8-10):554-577.

Talley, L. and McCartney, M. (1982). Distribution and Circulation of Labrador Sea Water. Journal of Physical Oceanography, 12:1189-1205.

Tanhua, T., Bulsiewicz, K., and Rhein, M. (2005). Spreading of overflow water from the Greenland to the Labrador Sea. Geophysical Research Letters, 32:10-13.

Thomsen, S., Carsten, E., and Czeschel, L. (2014). Stability analysis of the Labrador current. Journal of Physical Oceanography, 44(2):445-463.

Thornalley, D. J., Oppo, D. W., Ortega, P., Robson, J. I., Brierley, C. M., Davis, R., Hall, I. R., Moffa-Sanchez, P., Rose, N. L., Spooner, P. T., Yashayaev, I., and Keigwin, L. D. (2018). Anomalously weak Labrador Sea convection and Atlantic overturning during the past 150 years. Nature, 556(7700):227-230.

Våge, K., Pickart, R. S., Moore, G. W., and Ribergaard, M. H. (2008). Winter mixed layer development in the central Irminger Sea: The effect of strong, intermittent wind events. Journal of Physical Oceanography, 38(3):541-565.

Våge, K., Pickart, R. S., Sarafanov, A., Knutsen, Ø., Mercier, H., Lherminier, P., van Aken, H. M., Meincke, J., Quadfasel, D., and Bacon, S. (2011). The Irminger Gyre: Circulation, convection, and interannual variability. Deep-Sea Research Part I: Oceanographic Research Papers, 58(5):590-614. 
Våge, K., Pickart, R. S., Thierry, V., Reverdin, G., Lee, C. M., Petrie, B., Agnew, T. A., Wong, A., and Ribergaard, M. H. (2009a). Surprising return of deep convection to the subpolar North Atlantic Ocean in winter 2007-2008. Nature Geoscience, $2(1): 67-72$.

Våge, K., Spengler, T., Davies, H. C., and Pickart, R. S. (2009b). Multi-event analysis of the westerly Greenland tip jet based upon 45 winters in ERA-40. Quarterly Journal of the Royal Meteorological Society, 135(October):1999-2011.

Vallis, G. K. . (2006). Atmospheric and Oceanic Fluid Dynamics: Fundamentals and Large-Scale Circulation. Cambridge University Press.

Vizcaíno, M., Gröger, M., and Schurgers, G. (2008). Long-term ice sheet-climate interactions under anthropogenic greenhouse forcign simulated with a complex Earth System Model. Climate Dynamics, 31:665-690.

von Appen, W. J., Koszalka, I. M., Pickart, R. S., Haine, T. W., Mastropole, D., Magaldi, M. G., Valdimarsson, H., Girton, J., Jochumsen, K., and Krahmann, G. (2014a). The East Greenland Spill Jet as an important component of the Atlantic Meridional Overturning Circulation. Deep-Sea Research Part I: Oceanographic Research Papers, 92:75-84.

von Appen, W.-J., Mastropole, D., Pickart, R. S., Valdimarsson, H., Jónsson, S., and Girton, J. B. (2017). On the Nature of the Mesoscale Variability in Denmark Strait. Journal of Physical Oceanography, 47(3):567-582.

von Appen, W. J. and Pickart, R. S. (2012). Two configurations of the Western Arctic Shelfbreak current in summer. Journal of Physical Oceanography, 42(3):329-351.

von Appen, W. J., Pickart, R. S., Brink, K. H., and Haine, T. W. (2014b). Water column structure and statistics of Denmark Strait Overflow Water cyclones. DeepSea Research Part I: Oceanographic Research Papers, 84:110-126.

von Appen, W. J., Schauer, U., Hattermann, T., and Beszczynska-Möller, A. (2016). Seasonal cycle of mesoscale instability of the West Spitsbergen Current. Journal of Physical Oceanography, 46(4):1231-1254.

Weijer, W., Cheng, W., Drijfhout, S. S., Fedorov, A. V., Hu, A., Jackson, L. C., Liu, W., McDonagh, E. L., Mecking, J. V., and Zhang, J. (2019). Stability of the Atlantic Meridional Overturning Circulation: A Review and Synthesis. Journal of Geophysical Research: Oceans, 124(8):5336-5375.

Wolfe, C. L. and Cenedese, C. (2006). Laboratory experiments on eddy generation by a buoyant coastal current flowing over variable bathymetry. Journal of Physical Oceanography, 36(3):395-411.

Yashayaev, I. and Clarke, A. (2008). Evolution of North Atlantic Water masses inferred from Labrador Sea salinity series. Oceanography, 21(SPL.ISS. 1):30-45. 
Yashayaev, I. and Dickson, R. (2008). Transformation and fate of overflows in the northern North Atlantic. In Dickson, R., Meincke, J., and Rhines, P., editors, Arctic-Subarctic Ocean Fluxes: Defining the Rose of the Northern Seas in Cliamte, pages 505-526. Springer, New York.

Yashayaev, I. and Loder, J. W. (2016). Recurrent replenishment of Labrador Sea Water and associated decadal-scale variability. Journal of Geophysical Research: Oceans, 121(8):8095-8114.

Yashayaev, I. and Loder, J. W. (2017). Further intensification of deep convection in the Labrador Sea in 2016. Geophysical Research Letters, 44(3):1429-1438.

Yeager, S., Karspeck, A., Danabasoglu, G., Tribbia, J., and Teng, H. (2012). A decadal prediction case study: Late twentieth-century north Atlantic Ocean heat content. Journal of Climate, 25(15):5173-5189.

Zantopp, R., Fischer, J., Visbeck, M., and Karstensen, J. (2017). Journal of Geophysical Research : Oceans transports at the exit of the Labrador Sea. Journal of Geophysical Research: Oceans, 122:1724-1748.

Zhang, R. and Delworth, T. L. (2006). Impact of Atlantic multidecadal oscillations on India/Sahel rainfall and Atlantic hurricanes. Geophysical Research Letters, $33(17): 1-5$.

Zou, S., Bower, A. S., Furey, H., Pickart, R. S., Houpert, L., and Holliday, N. P. (2021). Observed Deep Cyclonic Eddies around Southern Greenland. Journal of Physical Oceanography, 51(10):3235-3252.

Zou, S., Lozier, M. S., Li, F., Abernathey, R., and Jackson, L. (2020). Densitycompensated overturning in the Labrador Sea. Nature Geoscience, 13(2):121-126.

Zunino, P., Mercier, H., and Thierry, V. (2020). Why did deep convection persist over four consecutive winters (2015-2018) southeast of Cape Farewell? Ocean Science, 16(1):99-113. 